


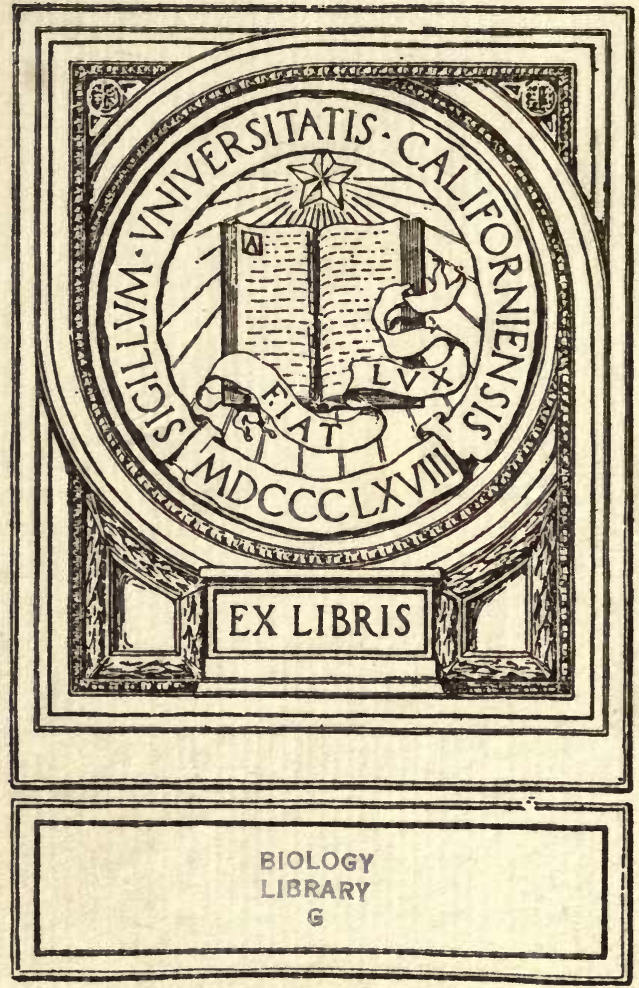




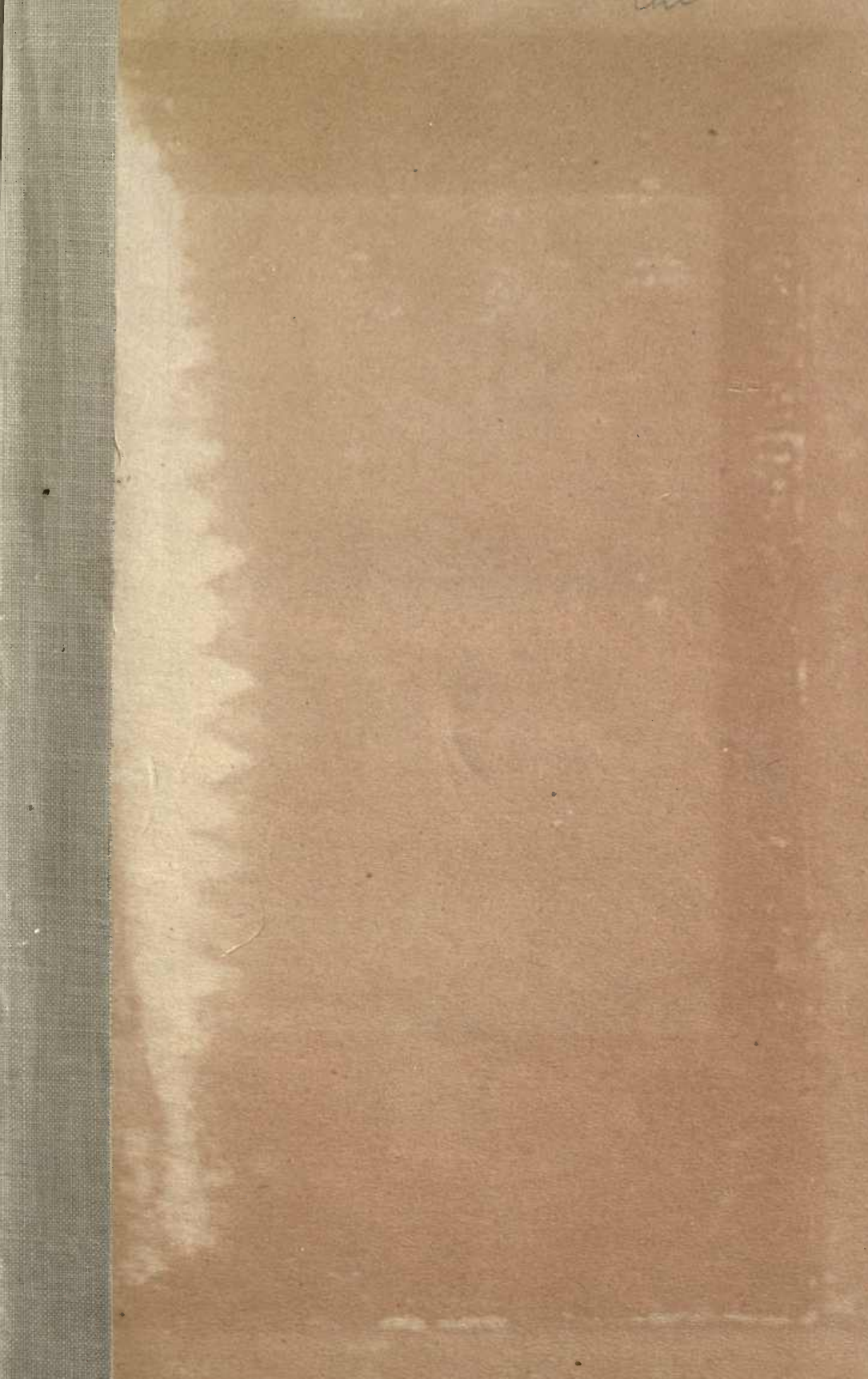



APPLIED PHYSIOLOGY 



\section{APPLIED PHYSIOLOGY}

A HANDBOOK FOR STUDENTS

OF MEDICINE

BY

\section{ROBERT HUTCHISON, M.D., F.R.C.P.}

PHYSICIAN TO THE LONDON HOSPITAL; ASSISTANT-PHYSICIAN TO THE HOSPITAL

FOR SICK CHILDREN, GREAT ORMOND STREET; LATE CHEMICAL ASSISTANT

TO THE PROFESSOR OF PHYSIOLOGY, UNIVERSITY OF EDINBURGH, AND

DEMONSTRATOR OF PHYSIOLOGY, LONDON HOSPITAL MEDICAL COLLEGE

AUTHOR OF

'FOOD AND THE PRINCIPLES OF DIETETICS,' 'LECTURES ON DISEASES OF CHILDREN'; JOINT AUTHOR OF 'CLINICAL METHODS,' AND JOINT EDITOR OF 'AN INDEX OF TREATMENT'

'Knowledge should be subservient to action'

BACON

SECOND IMPRESSION

LONDON

EDWARD ARNOLD

1909

[All rights rcserved] 

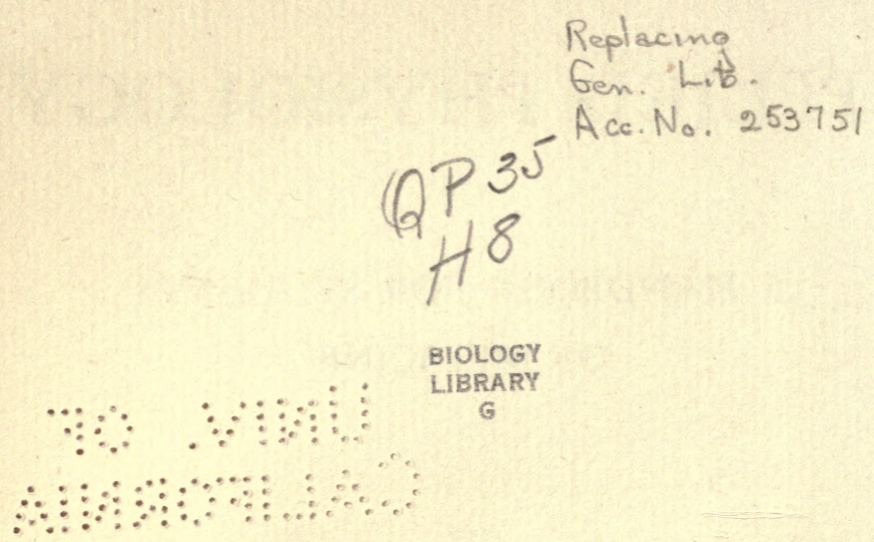


\section{PREFACE}

WrтH the increasing complexity of the medical curriculum, and the growing inclination to specialism amongst teachers, there is a tendency for the student to keep his knowledge in water-tight compartments. Physiology, for instance, is studied in the laboratory, and clinical medicine in the wards, and too often one finds that the student is incapable of applying his scientific knowledge to his clinical work. This is to be regretted, not only because it tends to lessen the interest of the practical study of disease, but because it leads to unsound and unscientific practice. For, beyond all question, the medicine of the future will be based more and more upon a sound knowledge of the normal working of the human body; or, in other words, upon Applied Physiology, and the best physician will be he who combines such knowledge in fullest measure with a wide practical experience at the bedside.

Inability to apply the teachings of physiology leads also to this curious anomaly, that a man may have been taught, and presumably still believe, certain facts as true physiologically, and yet continue to act in his clinical work upon an apparently quite opposite creed. Such an attitude of mind, it need hardly be said, is 
destructive of all sound medical thought, and makes for purely empirical practice.

In the present book-the first, so far as the writer knows, of its kind - an attempt has been made to apply physiology to medicine in the same way as anatomy has long been applied to surgery. Seeing that it is not intended to be a substitute for physiological text-books, but merely a companion to them, all descriptions of methods have been omitted, and only the facts of physiology dealt with, chief emphasis being laid upon those which have a direct bearing upon clinical work; incidentally these bearings are pointed out.

The reader may be surprised at the small size of the book, but when one deals only with the facts of physiology, it is astonishing to find how little space they occupy, and how few of them have as yet any direct practical implications. It will be observed, too, that there is no chapter on the muscular or nervous systems, or on the special senses. These omissions are intentional, for the writer is convinced that most of 'nervemuscle' physiology, as ordinarily taught to students, is perfectly useless to the physician; and, as regards the nervous system and special senses, the time is not yet ripe for writing their applied physiology-clinically, one can as yet hardly make use of more than their applied anatomy.

As the book is designed only for students, and not for specialists, few references to original sources have been given; but the writer feels that it is due to himself to say that these have always been consulted, and that the book really represents a very large amount of 
research in physiological literature, which has occupied a fair amount of time for some years. $\mathrm{He}$ is indebted to Dr. Leonard Hill and Mr. W. Rainey for kindly revising the proofs.

R. H.

1908. 



\section{CONTENTS}

CHAFtr
I. THE APPLIED PHYSIOLOGY OF METABOLISM
II. THE APPLIED PHYSIOLOGY OF BODY HEAT
III. THE APPLIED PHYSIOLOGY OF THE BLOOD AND
HAMOPOIETIC ORGANS
IV. THE APPLIED PHYSIOLOGY OF THE HEART




\section{LIST OF DIAGRAMS}

\section{IN COLOUR}

PL.1 TK

FACING PAGE

I. THE INNERVATION OF THE HEART (AFTER POWELL) 122

II. DIAGRAM OF A LOBULE OF THE LUNG (AFTER STÖHR) 183 III. THE RESPIRATORY CENTRE AND ITS CONNECTIONS 204

FIG.

PAGK

1. ABSOLUTE NUMBER OF LEUCOCYTES PER CUBIC MILLIMETRE AT DIFFERENT AGES - * - 88

2. DifFERENTIAL PERCENTAGE COUNTS THROUGHOUT

LIFE (AFTER CARSTANJEN) -

3. SERIES OF VENTRICULAR SYSTOLES (AFTER WENCKE-

BACH)

4. HEART SOUNDS

5. PULSE TRACING, SHOWING VENTRICULAR INTER-

MISSION (AFTER CUSHNY) $\quad$ - $\quad$ - $\quad 138$

6. PULSE TRACING, SHOWING AURICULAR INTERMISSION

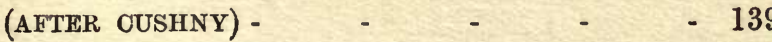

7. CHANGE IN SHAPE OF AN ARTERY DURING PASSAGE

OF THE PULSE WAVE -

8. SPHYGMOGRAM OF RADIAL PULSE (MACKENZIE) - 148

9. INFUNDIBULUM AT THE END OF COMPLETE INSPIRA-

TION AND EXPIRATION (HARRY OAMPBELL) - 184 
FIG.

10. 'PULL' EXERTED BY THE LUNGS BY MEANS OF THEIR CONTRACTIBIIITY -

11. CROSS SECTION OF THE RIGHT LUNG, SHOWING DIRECTIONS OF EXPANSION (KEITH) - - 196

12. RIGHT LUNG FROM THE SIDE, SHOWING DIRECTIONS

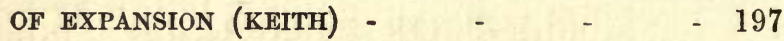

13. VERTICAL SECTION OF THE RIGHT LUNG TO SHOW

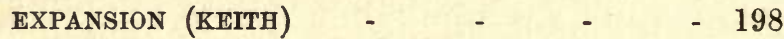

14. VITAL CAPACITY (AFTER HUTCHINSON) - - 200

15. POSITION OF SHADOW DURING THE SWALLOWING OF A MOUTHFUL OF MILK CONTAINING BISMUTH CARBONATE (HERTZ) - $\quad$ - $\quad$ - $\quad$ - $\quad 230$

16. FUNCTIONAL DIVISIONS OF THE STOMACH - -243

17. SEGMENTATION IN HUMAN SMALL INTESTINES OCCURRING SIMULTANEOUSLY WITH PERISTALSIS

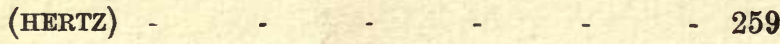

18. AVERAGE TIME AT WHICH VARIOUS POINTS OF THE COLON ARE REACHKD AFTER A BISMUTH BREAKFAST (HERTZ) 


\section{APPLIED PHYSIOLOGY}

CHAPTER I

\section{THE APPLIED PHYSIOLOGY OF METABOLISM}

The future of medicine undoubtedly depends upon the chemical physiologist. The scalpel, the microscope, and the simpler application of physical and experimental methods have, so far as we can perceive, nearly finished their work, but the investigation of the chemical processes of the body is just begun. The term 'metabolism' is used to embrace the sum of these chemical processes, and as most diseases are, in the last resort, the expression of a perverted metabolism, it can easily be understood how important a complete knowledge of the subject would be to the physician. Unfortunately, however, we are constantly hampered by our ignorance in this respect. Most of the intimate chemical changes which go on in the organs and tissues are still utterly beyond our ken. Some we guess at or catch glimpses of from afar; it is only a few that we fully understand. In the present chapter I propose to give a general sketch of metabolism so far as our present knowledge permits, and shall point out as one goes along the application of 
the facts which have been ascertained to the problems of clinical medicine - so far, at least, as such application is at present possible.

Metabolism has two great purposes to fulfil: (1) the maintenance unimpaired of the substance of the tissues ; (2) the conservation of bodily energy. The former consists in the replacement of the waste of tissue substance which the stress and strain of vital activity entails; it is: thérefore esseritially anabolic in nature. The conser$\therefore$ vation of bedily energy; on the other hand, is achieved $\therefore$ by the breaking down of food compounds and the liberation of their potential energy in the form of heat and work, and is therefore preponderatingly katabolic.

We may regard these two aspects of metabolism either from the point of view of the total amount of chemical change which takes place (quantitative metabolism), or from that of the intimate nature of the chemical processes which they involve (qualitative metabolism). As the former point of view is the simpler, it will be best to consider it first.

\section{Quantitative Metabolism.*}

\section{The Conservation of Tissue Substance.}

As protein is the only constituent of the food which is able to repair tissue waste, it is obvious that this aspect of metabolism when looked at quantitatively resolves

* In order to appreciate the relative mass of the various tissues which compose the 'vital machine' and take part in metabolism, it should be remembered that, of the total body-weight, about 40 per cent. is made up of muscle, 5 per cent. of blood, 2 per cent. of brain, whilst the other internal organs and the skeleton make up the remainder. 
itself into the question, How much protein is required to make good the daily destruction of tissue? This question is one of such enormous practical importance to the physician that a little space must be devoted to a statement of the prevailing physiological views upon it.

How much Protein is required?-If one attempts to solve this problem by the simple method of estimating the amount of nitrogen excreted daily, one is at once met by the difficulty that 'nitrogenous equilibrium' can be maintained on very varying quantities of protein. The more protein the food contains, the more nitrogen is excreted, and this goes on until the limits of the digestive capacity are reached. If, again, one takes the amount of nitrogen excreted during fasting as the basis for constructing the diet sheet, it is found that if this amount alone be supplied it is insufficient to maintain equilibrium, and nitrogen is lost from the body. At what point above this, then, is one to fix the proper quantity? Despairing of any experimental solution of this problem, the older school of physiologists fell back on purely empirical observation. They estimated the amount of protein actually consumed by groups of individuals on freely chosen dietaries, and took this as the answer to the question. It was in this way that Voit arrived at the standard of 118 grammes, which was long accepted as the proper amount of protein for the diet to contain, and it was upon this estimate that the prevailing 'standard dietaries' were constructed. Within the last few years, however, physiologists have begun to question the correctness of the Voit standard. Investigation of the diets of many 
individual vegetarians, and of vegetarian races, for example, revealed the fact that health and activity could apparently be maintained on much smaller allowances of protein than the Voit standard postulated. Finally there came the well-known experiments of Chittenden, which showed for the first time on a suffciently large scale that, beyond all apparent doubt, health and efficiency could be maintained for indefinite periods upon a much smaller protein intake than 118 grammes. Chittenden fixes the protein optimum, indeed, or the best amount for habitual consumption, at about 60 grammes per day, which is not far above the minimum upon which nitrogenous equilibrium can be maintained. Any intake above this he would regard as a luxus consumption.*

* It might seem that in human milk we would find a standard which would furnish a guide to the proper proportion of protein which the diet ought to contain.

An infant of six months, weighing 6.7 kilogrammes, and consuming an average quantity of breast milk ( 950 grammes), consumes about 14 grammes of protein, and has a total energy intake of 594 Calories per day. This is about 2 grammes of protein per kilogramme, and if an adult of average weight (70 kilogrammes) consumed the same proportion of protein, he would require 140 grammes in his diet, which is much above even the Voit standard.

There is, however, another way of looking at the question: Of the total Calories taken in by the infant, fifty-seven are derived from protein ; and assuming the adult to require an intake of 3,000 Calories per day, and that the same proportion of these is derived from protein as in the child, then the amount of protein the adult should consume would only be about 70 grammes per diem, which is approximately Chittenden's standard. Which is the correct way of looking at the question it is difficult to say. If the adult is to take as much protein per unit of his body-weight as the child, then 
If Chittenden be right, there can be no doubt of the far-reaching effect of his views; our dietary standards would have to be revised, and vegetarianism would become, not only uninjurious, but a system highly to be commended on grounds alike of humanity, hygiene, and economy. To consume a superfluous quantity of such an expensive food constituent as protein is certainly not only wasteful, but, from the great amount of work required for its digestion and the excretion of its endproducts, physiologically injurious as well. Chittenden, indeed, is of opinion that many of the degenerative diseases of later life, as well as many of the paroxysmal neuroses, such as migraine, met with in younger patients, are directly due to a luxus consumption of protein.

Notwithstanding the apparently convincing nature of Chittenden's experiments, it will be well for the physician to be cautious in applying their results in practice. It is all very well for the physiologist to dismiss contemptuously the universal practice of mankind as having been arrived at purely empirically, and as affording no basis on which to establish rational rules of diet; but the practical physician, whose art has taught him the safety of a wise empiricism, cannot so lightly discard a rule which has been adopted semper et ubique et ab omnibus.

even the Voit standard is too low. If, on the other hand, he is to take only the same amount of protein in proportion to the total energy value of his diet as the child, then Chittenden's standard is correct. It is true that the child is constantly laying up protein in the body in the form of new tissue, but against this has to be set the fact that the destruction of tissue in the adult is greater, owing to the performance of muscular work. 
It may be possible to live in apparent health on a low protein intake for a long time, but can one do so with impunity always? It may be true that a luxus consumption of protein tends to produce disease, but may an habitually low intake not predispose to diseases of another sort? To take only two examples, our experience of the treatment of tuberculosis has shown the value of a liberal meat diet in effecting a cure, and it has been found in the Japanese Navy that a liberal protein ration is a prophylactic against the ravages of beri-beri. It may well be, in short, that the supply of a liberal proportion of protein is necessary for the proper production of these chemical compounds, which are one of the means by which the body defends itself against invasion by bacteria. Again, it may prove, when the reserve of protein in the body is low-as it must be on an habitually low intake - that any attack of acute fever will result in too great inroads on the proteins of the fixed tissues, with all the dangers which that entails. These are only some of the considerations which must give us pause in at once applying to practice the results of physiological experiment. Time alone can show whether such objections deserve any weight. Meanwhile every practising physician, by observing how patients who habitually consume little protein resist the attacks of disease and withstand it when attacked, can help to furnish the data which are necessary for a final judgment in the matter.

Storage of Surplus Building Material.-In any discussion of the conservation of matter in the body, two influences must be considered: (1) the effect of growth, 
and (2) the influence of muscular labour. As regards growth, physiology teaches that it can only take place when protein is supplied in excess of the actual needs of the body as measured by the output of nitrogen. In the earlier period of life, therefore, a luxus consumption of protein is actually necessary, a point which must be borne in mind in constructing dietaries for the young. On the other hand, experiment has also shown that, once growth is completed, it is exceedingly difficult to bring about a storage of protein in the body, except when the muscles are being much exercised.* So soon, moreover, as the period of exercise ceases the protein gained is rapidly lost again. One cannot hope, therefore, to make an individual muscularly strong merely by supplying him with protein; exercise must always bo taken at the same time. Convalescence from acute disease is another event which permits of protein being stored up, for in such circumstances the waste of tissue which has taken place is rapidly made good by retaining protein in the body, even although the amount supplied in the diet be not very great. During pregnancy, too, protein is retained in order to take part both in the formation of the fotus and in the hypertrophy of the uterus and mammæ.

As regards the influence of muscular labour, experiment has clearly shown that the waste of tissue which it causes is not really great, and there is therefore $x_{0}$ physiological reason for the consumption of an excessive

* The gain of protein in a fully-grown animal is attained by an hypertrophy of cells already existing, not by the development of now cells. 
quantity of protein food during training merely to make good wear and tear.

We may now pass on to consider the other great function of metabolism

\section{The Conservation of Bodily Energy.}

1. Expenditure of Energy.-By means of experiments with the respiration calorimeter the daily expenditure of energy in the body can be calculated without much difficulty. The chief items of expenditure are these: (i.) internal work (heart, respiration, heat production, secretion, excretion, etc.); (ii.) digestive work; (iii.) external or muscular work.

The expenditure of energy in the performance of mental work cannot be calculated, and, indeed, external work is the only item which can be estimated with any accuracy.

(i.) By internal work is meant all the work which is required for carrying on the chief vital processes of the body, without which life would be impossible. The work of the heart alone amounts to about $20,000 \mathrm{kgm}$. (133 Calories),* or about 64 foot-tons, per day. In diseased conditions, in which the work of the circulation is carried on with difficulty, this amount may be very largely increased (see Chapter IV.), and may become so great, indeed, that no margin of available energy is left for any form of external work. A patient in such a condition is thus inevitably condemned to a life of complete inactivity. The work performed by the muscles of respiration in elevating the chest amounts to about

$$
\text { * Allowing for heat produced as well. }
$$


6,500 kgm., or 21 foot-tons, daily. Here, again, in pathological conditions this necessary work may be greatly increased in amount, and the daily output of energy of the body proportionately raised.

Of all the items which fall under the heading of internal work, heat production is, however, by far the greatest. The mere performance of work by the heart and the muscles of respiration involves the liberation as a by-product of more than twice as much energy in the form of heat as is actually required for the performance of the mechanical work of respiration and circulation. Whether besides this waste heat an additional quantity is produced as a result of the mere vital activity of the cells (apart from any work done) is a matter on which physiologists are not all agreed, and we shall return to its discussion later on (Chapter II.). The question is an important one; for if heat results from the mere 'living' of the cells-if it be a by-product or excretion of life as such-then it is conceivable that cells of a low degree of vitality may produce less heat, and therefore expend less energy, than those which are more 'alive,' and an explanation would be found for the apparently greater degree of economy in metabolism which some individuals exhibit when compared with others. Some such explanation, as we shall see, is almost necessary to account for individual differences in nutrition.

(ii.) The item digestive work covers the expenditure of energy required for the digestion and absorption of the food. It is an item of no small importance, amounting as it does in the case of an ordinary mixed diet to about 150 or 200 Calories-i.e., about 6 to 8 per cent. of 
the total intake of energy. It varies, of course, with the bulk of the diet, for the manipulation of large masses of food materially increases the amount of muscular work to be done by the stomach and intestine. This has to be taken into consideration in appraising the value of some forms of purely vegetable diet which are apt to be very bulky. Thus, it has been calculated that in the case of a horse fed entirely upon hay 48 per cent. of the energy of the food is expended in its digestion and absorption. It varies, too, with the chemical constitution of the food. The digestion of proteins seems to demand most work, then that of carbohydrates, whilst that of fats requires least of all. Of common articles of food, milk is that which entails the least digestive work. Anything which increases the frequency or force of peristalsis also raises expenditure under this head, and part at least of the wasting effect of purgation or diarrhoea is thus to be explained.

(iii.) By external (as distinguished from internal) work is meant the work expended by the muscles in performing not only the day's task of labour, but that required for locomotion and all the thousand ways in which the skeletal as opposed to the visceral muscles are brought into play. It is inevitably, therefore, a heavy item.

It must be remembered, too, that all expenditure on actual external work is unavoidably accompanied by an increase of the work done by the heart and lungs as well as by an increased production of heat. Physiologists differ as to exactly how much of the increased expenditure of energy that muscular labour entails goes 
in the production of the outward task and how much in increased internal work, but one may say approximately that only about one-fifth should be put down to the work itself, and four-fifths to internal expenditure. The human body is therefore rather more economical than the best steam-engine, which gives about 15 per cent. of its total discharge of energy as work, and the rest as heat.

Practice, however, is of great importance in this connection, for a man who is skilled in the performance of any special piece of work certainly does it more economically and with relatively less increase of internal work than one who is unskilled. One illustration will make this clear. It was found by Hueppe, in comparing the expenditure of energy by an untrained town-dweller and an Alpine carrier in climbing, that in the course of a six hours' ascent the former expended 449 Calories in work and 1,000 Calories in heat, whereas the latter expended 884 Calories in work, and only 565 in heat.

Fatigue, pain, overheating of the body, and being in bad health or 'out of condition,' are also all of them factors which increase the 'expense' of work. A man, for instance, who is tired, footsore, and very hot, will expend more energy in walking a given distance than is really necessary to carry his body over the same space under better conditions.

It must not be assumed from all this that human labour is necessarily cheaper than that of a steamengine. Quite the contrary, of course, is the case. If, for instance, a labourer works five days a week and earns 20 s., of which he spends $5 \mathrm{~s}$. upon food, and has a total daily intake of energy of 3,000 Calories, of which 500 
are expended upon actual mechanical labour (exclusive of increased internal work), then only one-sixth of the sum expended on food is returned in work-i.e., $10 \mathrm{~d}$. worth a week represents the external work done, or $4 \mathrm{~s} .2 \mathrm{~d}$. worth, if one assumes that four-fifths have to be added to this to allow for increased heat production. In other words, only one-fifth of a man's wages really go to produce work if one regards him as a 'hired machine.' One pound of coal a day consumed in a steam-engine would have produced more than as much work, assuming that the combustion of the coal yields 3,000 Calories of energy, and that the engine converts 15 per cent. of this into work.

It will be obvious from this that the larger part of a man's earnings must always be spent simply in keeping the machine ' alive,' apart from whether it does any work or not. If, on the other hand, one regards the machine as merely a 'peripatetic residence for the soul,' which has to be kept both alive and warm, then the only waste in it is the heat given off from the surface, and its efficiency from this point of view is advanced to about 50 per cent. of the energy consumed, which is better than that of any human invention.*

2. Income of Energy.-To balance its expenditure, the body is dependent for its income of energy upon the chemical constituents of the food. $t$ Of these, the pro-

* Thurston, 'The Animal as a Prime Mover' (Smithsonian Report for 1896).

+ It is possible that the body may derive some energy from sources other than food. Radiant heat-e.g., from the sun-may certainly be regarded as such a source, and there may conceivably Le others of which as yet we know nothing. 
teins, carbohydrates, and fats are alone of importance. It is true that small amounts of energy are contained in other ingredients of the diet, such as gelatin, but for practical purposes only the three first named need be considered. The energy yielded by a unit ( 1 gramme) of each of these constituents in the body, expressed in Calories, is as follows:

$\begin{array}{lrllll}\text { Protein } \ldots & \ldots & \ldots & 4 \cdot 1 & \text { Calories. } \\ \text { Carbohydrate } & \ldots & \ldots & 4 \cdot 1 & , \\ \text { Fat } \quad \ldots & \ldots & \ldots & 9 \cdot 3 & \end{array}$

Now, the total amount of energy expended by a man of average weight doing a moderate amount of muscular work is something between 2,500 and 3,000 Calories, or the amount which would be produced by the consumption of 1 pound of good coal; and it follows that, if equilibrium is to be maintained, the total intake in the form of food must equal this sum, and if it does not do so chronic malnutrition and inanition result.

What proportion of the total energy required should be supplied by each food constituent is an important question in practical dietetics.

We have already seen that protein should be regarded as only accidentally a source of energy, its chief use being to replace the loss of nitrogenous material in the tissues, and that by far the largest proportion of the body's energy must be derived from carbohydrates and fats.

Amount of Carbohydrate and Fat required.-As to the proportion of the total intake of energy which should be supplied by carbohydrates and fats respec- 
tively, we have no clear physiological data to guide us. So far as the tissues are concerned, indeed, the physiological teaching appears to be that it is largely a matter of indifference, but that, for the sake of the digestive organs, it is best to derive our energy, not from one or other exclusively, but in some measure from both. From a medical point of view, however, it is not so certain that fats and carbohydrates can replace each other in the diet with indifference. Rickets, for example, is a condition which seems to result from the consumption of a disproportionate amount of carbohydrate and too little fat. There is reason to believe, too, that a diet which contains an excess of carbohydrates may predispose to diabetes by straining the sugar-assimilating functions. On the other hand, when diabetes is once developed, we are compelled to supply the greater part of the patient's energy in the form of fat.

Meanwhile it may be assumed that 50 grammes of fat and 500 grammes of carbohydrate represent the accepted standard for each ingredient; but it must be borne in mind that these are capable of replacing each other to a large extent, in accordance with the digestive peculiarities of the individual and the opportunities he has of obtaining a supply of each ingredient.

The following balance-sheet, the expenditure side of which is derived from observation of an actual case by Von Noorden, whilst the income is approximately that of the Chittenden standard, will serve to show in a concise form the practical application of the study of metabolism from its quantitative side. It exhibits a surplus of income over expenditure, and it is assumed 
that the balance is stored up in the tissues in the form of fat. This is a point, however, which requires a little further discussion.

\section{Balance-sheet of Energy (in Calories).}

\section{Man of 56 kilogrammes.}

EXPENDITURE.

1. Internal work (heart, respiration, heat production) $\quad \ldots \quad 1,550$

2. Digestive work... ... 240

3. External muscular work-

(a) Actual work done $\quad \ldots 250$

(b) Increase under (1) 590

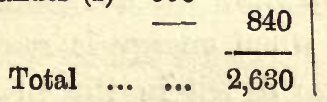
Total $\quad \ldots \quad \ldots \quad \overline{2,802}$

Balance, 172 Calories $=17$ grammes of fat, or about $\frac{7}{8}$ ounce of adipose tissue.

Storage of Surplus Energy.-It is taught by physiologists that any surplus of income over expenditure of energy is inevitably stored up in the form of fat. If, for example, an individual consumed a diet which contains just as much energy as he is expending daily, and we add to this 1 pint of cow's milk, we shall increase the intake of energy by about 425 Calories. If this be stored, it will form 45 grammes of fat, or 2 ounces of adipose tissue, and the individual's weight will go up by this amount every day. From the practical point of view, however, the matter would seem not to be so simple as this. One cannot ensure, by merely supplying 
an excess of income over expenditure of energy, that a patient will put on fat. Experience at the bedside seems to show that there are persons whom it is almost impossible to fatten. What happens to any excess of food supplied in such circumstances it is difficult to say, but in many cases, at least, it appears to fail of elaboration in the liver, and to induce a 'bilicus attack,' by which in some way it is got rid of. We shall return to the discussion of this subject, however, again.

The three chief depots in which the surplus energy of the body is stored in the form of fat are, in order of size and importance, as follows: (i.) subcutaneous tissue; (ii.) abdominal cavity; (iii.) intermuscular connective tissue. When a man fattens, the subcutaneous and intermuscular depots fill up first, the abdominal cavity more slowly. Conversely, when energy is required by the body to meet a chronic deficit in the intake, the abdominal fat is drawn upon first, * then the fat below the skin, and after that the intermuscular fat, whilst fat in the organs is only made use of in extreme emergencies.

A deficiency in the total amount of food consumed is more serious than a deficiency of protein alone; for in the former case both protein and fat are lost by the body, in the latter protein alone. Nor would it seem that the loss of protein, when the total amount of energy in the diet is defective, can be altogether prevented even by consuming large quantities of protein food-e.g., meat.

* The apparent persistence of a large abdomen, in spite of a large reduction in the diet, which may seem to contradict this statement, is really due to the large amount of subcutaneous fat in the abdominal wall, that being a favourite site for its deposition. 
A patient on the Banting diet, therefore, must inevitably suffer some loss of muscle besides his loss of fat.

The metabolic balance-sheet above described may be regarded as a standard or average one for a man of medium weight and doing a moderate amount of muscular work. We have now to discuss how it is affected by various external and internal influences.

1. Influence of Age and Sex.-The child, as someone has remarked, 'is not merely a young city, but a city of young inhabitants.' In other words, owing to their greater youth, the vital activity of the cells is greater in childhood, and metabolism more intense. The demand for food, therefore, apart from the necessity for meeting the requirements of growth, is greater than in the adult. Doubtless, too, the greater metabolic activity of the child explains the immunity of childhood from certain diseases-e.g., gout-which are common in later life. In old age, on the other hand, respiratory exchange and heat production are found to fall, so that life may be maintained at this period on a very small amount of food.

Sex appears to exert but little influence upon metabolism if allowance be made for differences of weight and build.

2. The 'build' of the body exercises considerable influence upon metabolism. Tall people have a larger surface in proportion to their bulk than short; their heat loss is therefore greater, and a larger sum of energy in the form of food must be taken in to balance it. This may explain why it is that tall persons are apt 
to remain thin, for they need to produce so much heat that there is no margin left for storage as fat.

Again, a man of large muscular development has a more active metabolism than one whose weight is to a great extent made up of fat; for muscle is a "vital tissue, whereas fat is, comparatively speaking, 'dead.' On the other hand, the mere carrying about of a stone or two of fat increases considerably the mechanical task of the muscles of locomotion in a stout man. There is thus a sort of automatic check upon indefinite increase of stoutness, for beyond a certain point the greater expenditure of energy required for locomotion will use up all the surplus intake in the form of food.

3. Influence of Work and Rest.-The large share of the daily expenditure of energy in the body which is due to external or muscular work has already been pointed out, and it will readily be understood that variations in the amount of work performed have more influence upon the total turnover of energy than any other single factor. It has been calculated that the following amounts of energy must be supplied to meet the requirements of varying degrees of muscular work in the case of a man of about 10 stone weight (MagnusLevy):

Calories.
At rest in bed

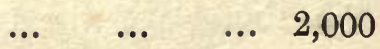
Resting indoors ...
$\begin{array}{llll}\ldots & \ldots & \ldots & \ldots\end{array}$
With light industrial work $\quad \ldots \quad \ldots \quad 2,600$
With moderate muscular labour $\quad \ldots \quad 3,100$
With severe muscular labour ... .. $\quad \mathbf{8 , 5 0 0}$

The greatest economy of energy is attained by keeping 
an individual at complete rest in bed, for not only is external work reduced to a minimum thereby, but heat loss is also greatly curtailed. In these circumstances the total turnover of energy is probably not more than 1,600 Calories per day in the case of an average patient, an amount which could be supplied by 4 pints of milk. If, on the other hand, a patient is allowed merely to be up and moving about in the ward without doing any real work, his turnover of energy is at once increased about 10 per cent. It will readily be understood from this how great an aid complete rest in bed is in cases in which it is important to reduce a patient's expenditure of energy to its lowest terms.*

* Some practical examples of the amount of energy expended in different forms of exertion may be of interest. E.g., an hour's saunter consumes 137 Calories, or about $\frac{1}{2}$ ounce of fat; an hour's quick walk consumes 260 Calories, or 1 ounce of fat (Müller). A walk of four miles increases the expenditure of the body by about 275 Calories, which could be covered by the consumption of 1 ounce of fat (Zuntz). A bicycle ride of nine and one-third miles expends 313 Calories of energy, or $1 \frac{1}{5}$ ounces of fat (Zuntz). If a man of 70 kilogrammes weight takes to living up a stair 15 metres high, and goes up four times a day, he does 4,200 kilogrammes of work daily; but, as only 30 per cent. of the energy he expends actually goes in doing the work, the increase in his metabolic turnover really amounts to 14,000 kilogrammes, or $32 \cdot 9$ Calories daily. This equals 3.54 grammes of fat per day, or about 4 pounds of adipose tissue per year (von Noorden).

Climbing expends twenty times more energy than walking on the level ; i.e., to lift one's weight one mile in a day is equivalent to a walk of twenty miles.

A man walking against a strong wind for a mile expends an amount of energy which would have raised him 8,202 feet, at a cost of 1,200 Calories (about $4 \frac{1}{2}$ ounces of fat).

Twelve per cent. more energy is expended when standing at attention than when standing at ease (Müller). 
From a therapeutic point of view, it is interesting to note that massage has no appreciable influence upon metabolism, and is therefore in no real sense a substitute for exercise.

As regards the best source from which to obtain the increased amount of energy that hard work entails, physiologists are now almost unanimous in recommending the carbohydrates and fats, for protein is only used by the body when these are not available. Whether fat or carbohydrate should be selected is chiefly a matter of the digestion, but it is possible that when a rapid output of energy is desired carbohydrate is preferable, whereas for a more gradual expenditure over a long time fat may have some advantages. Whatever the empirical results yielded by a large meat diet in training may be, therefore, there is certainly no scientific grounds for its adoption.

Of the influence of mental work upon metabolism we know very little, but there is some reason to believe that it is accompanied by a diminution of general, and an increase of cerebral metabolism, as manifested especially by an increased elimination of phosphoric acid.* There is thus some justification for the old belief that phosphoric acid is a useful 'brain-food.'

4. Of the influence of such external conditions as season, period of the day, and weather upon metabolism we know but little. It would seem, however, as if, contrary to general opinion, the metabolic processes

* See Mairet and Florence, 'Le Travail Intellectuel et les Fonctions de l'Organisme,' Montpellier, 1907 (rev. in Brit. Med. Journ., 1907, ii. 539). 
in the body are but little affected by them. It used to be believed that metabolism was most active in early spring, and that at this period every function was at its highest degree of efficiency, a decline taking place as summer advanced, with a gradual rise again in the autumn. Later observations have shown, however, that the demand for food, and presumably, therefore, the activity of metabolism, is not less in summer than in winter. The daily variations in metabolism, also, would appear to be very slight if the influence of muscular exertion and the taking of food be eliminated, but there remains a certain amount of evidence to show that metabolism is more active in the later part of the day than in the earlier, the maximum being reached about 5 p.m., and the minimum about five o'clock in the morning.* Medical experience would certainly seem to show that 'vitality' is less in the early hours of the morning than at other times, and the need for stimulants in asthenic conditions is then greater.

The influence of 'weather' upon metabolism is a subject of great interest to the practical physician, but, unfortunately, we have no accurate information about it from the physiologist. Such observations as have been made relate to the part played by such ingredients of weather as heat and moisture, and will be referred to in another chapter.

5. Of the influence of the nervous system on meta-

* For a comprehensive study of the whole subject, see H. D. Marsh, 'The Diurnal Course of Efficiency,'Archiv. of Phil. Psychol. and Scientific Methods, No. 7, July, 1906; New York, Science Press (abst. in Brit. Med. Journ., 1907, ii. 1541) 
bolism the physiologist has also little to tell us, although from the clinical point of view there is evidence that such an influence must be exerted in no small measure. How else is one to explain the chronic malnutrition so often met with in neurasthenic subjects, and which may exist quite apart from any disturbance of digestion? In the acute forms of neurasthenia, indeed, a patient may emaciate rapidly even although he be taking a fair amount of food. There is one way in which it is obvious that nervous control can influence the amount of general metabolism. The maintenance of 'tone' in the muscles is one of the functions of the nervous system, but 'tone' involves chemical transformations in the muscle akin to those which take place in contraction, though doubtless less in degree. The greater the degree of tone in the muscles, then, the greater their consumption of energy, and it is noteworthy that in many neurotic subjects there is evidence, from an exaggeration of the tendon reflexes, of the presence of an abnormal degree of 'tone.' On the other hand, flaccid paralysis of any large number of muscles must lessen metabolism, just as it has been found experimentally that poisoning with curare does. These nervous influences upon metabolism are apparently exerted through the medium of the ordinary nerve fibres which are concerned in calling into play the functional activity of the tissue concerned (e.g., in the case of the muscles, the motor nerves, in the case of glands the secretory), and not through any special trophic fibres, for the existence of these-though often assumed clinically-has never yet been proved physiologically. 
It would almost seem as if the nerves which subserve the physiological function of any organ or tissue exert either a promoting influence on its anabolism or a restraining influence on its katabolism, with the consequence that when the nervous influence is withdrawn or perverted rapid tissue destruction or alteration ensues. It is perhaps in some such way as this that the influence of emotional and mental states on local and general nutrition is exerted, an influence which is shown locally in the blanching of the hair from fear, and generally in the promotion of fatness by cheerfulness ('laugh and grow fat'), and of leanness by anxiety. Again, 'constitutional' as opposed to muscular strength may perhaps be due, in part at least, to a firm grip of the nervous system upon metabolism. Medical experience, at all events, would seem to show that a strong will and a cultured mind make for strength and long life, whilst a weak brain and will are often accompanied by a feeble general vitality.

6. Influence of Internal Secretions. - The term 'internal secretion' has come to be used in rather a loose way, and in clinical medicine, at least, it is often employed like the terms 'reflex action,' 'trophic influence,' and 'toxin,' as a sort of deus ex machina to explain pathological phenomena which would be otherwise difficult of comprehension. It is, of course, in a sense true that every tissue and organ produces an 'internal secretion,' inasmuch as the waste products of its metabolism are turned into the blood-stream, and, being diffused throughout the body, may conceivably influence chemical processes in remote parts. It would 
be more correct, however, to speak of such waste products as internal excretions, and to reserve the term internal secretion for the products of glandular organs which are not provided with ducts opening on to a free surface. In any case, the fact that removal of an organ is followed by certain derangements of metabolism is no proof that the organ in question produces even an internal excretion, for the changes observed might quite as well be due to the blood being no longer deprived of some of those constituents which should be taken out of it by the organ removed. There is, therefore, a great deal of loose thinking on the whole subject, and in considering the influence of internal secretions on metabolism it will be well to restrict ourselves to the more exact connotation of the term indicated above.

Now, of internal secretions in the strict sense we know for a certainty of one only-namely, the secretion of the thyroid gland, the active constituent of which is the iodine-containing compound known as 'iodothyrin.' This is not the place in which to speak of the exact chemical nature of this compound, and, indeed, but little is known about it, but that it exerts a profound influence upon metabolism there can be no question. That influence may be described as one of stimulation resulting in a great increase in the rate of oxidation in the tissues. The increased elimination not only of carbonic acid gas, but also of urea, which follows thyroid feeding shows that both the fatty and nitrogenous tissues are involved in the increase of katabolism which it brings about. The pronounced effect upon the nitrogenous tissues-presumably the muscles-is important 
clinically; for were fat alone affected we would possess in the thyroid an ideal remedy for obesity, but the simultaneous destruction of fixed nitrogenous tissues renders it a dangerous drug to employ for that purpose. Considering the extremely minute quantity of iodothyrin which is required to produce a profound metabolic effect, one must regard it as one of the most potent of all the agents at our command for influencing chemical changes in the body, and the close resemblance of its action in this respect to that of the poisons of many infective processes renders it of the greatest interest to the physician.

Further, the influence which the thyroid secretion exerts upon metabolism explains fully the results observed in disease of the gland. Myxœedema, for example, is pre-eminently a condition in which metabolic change has undergone a partial arrest, resulting in the accumulation of an immature connective tissue beneath the skin, the cells of which have not undergone the normal process of division and maturation. In the scalp, again, the development of young hairs is at a standstill, and when the effete hairs fall out there are no fresh ones to take their place, and the patient becomes bald. Fat also accumulates in the body, and from the lessened production of heat the patient has a subnormal temperature and a constant feeling of chilliness. In this way one could run through all the well-known symptoms and signs of myxœdema, and show that they are all the result of a partial arrest of metabolism brought about by the failure of the stimulus which the thyroid secretion should normally supply. 
Conversely, Graves' disease is a condition characterized by an increased rate of tissue metabolism, and many pathologists believe that the essential fact in its etiology is an over-activity of the thyroid gland. It is interesting in the light of these facts to speculate on the question whether variations in the metabolism of individuals may not be due to a varying degree of activity of their thyroids. Is the sluggish and obese person one whose thyroid is functionally rather inactive, and the alert spare man one whose metabolism is constantly being stimulated by an exceptionally abundant outpouring of iodothyrin? Again, is the tendency to accumulate fat after the middle period of life to be ascribed to a natural decline of thyroid activity about that time? It would take us too far afield to consider these questions in detail, but they are full of interesting suggestion to the clinician.

Of the influence, if any, of the suprarenals on general metabolism we know nothing. Even assuming that adrenalin is a true secretion, its action is exerted upon the vascular system, and not upon the tissues at large, and upon the phenomena of Addison's disease experimental physiology has not yet thrown any clear light.

It is commonly assumed that the reproductive glands exert a marked influence upon general metabolism. Physiological experiments upon this subject have yielded rather discordant results, but there is a considerable amount of evidence to show that castration in either sex results in a diminution of oxidation, and a tendency to the accumulation of fat. This tendency is well shown in many women after the menopause. Whether this is 
due to the direct withdrawal of an 'internal secretion' (in the wider sense), however, or whether it is the result of the change in disposition which the operation is apt to bring about, is not yet determined. In favour of the former hypothesis are some experiments which seem to show that the administration of ovarian extract is able to counteract the effects of ovariotomy in animals, and to raise the oxygen consumption again to its normal level. Evidence is also accumulating that the development of the secondary sexual characters, the changes in the uterus which determine menstruation, and the enlargement of the mammary glands during pregnancy, are all the result of chemical influences.

More and more, then, is it becoming evident that no organ lives to itself alone, but that the chemical changes which take place in each may be of the greatest importance to metabolism as a whole, and to the normal interchanges in others.

7. Influence of Personal Peculiarity.-A factor in metabolism which is not often considered by the physiologist, but which is of the first importance to the physician, is the question of personal peculiarity. Putting aside such agents as differences of age and build, and variations in the amount of body fat, by which differences in the metabolic balance-sheet of individuals can be explained, is there any reason to suppose that the activity of metabolism is greater in some persons than in others? As regards the qualitative side of metabolism, we shall see that individual peculiarities are not only possible, but can actually be proved to occur; but even as regards the total turn- 
aver of energy in the body, there is a strong presumption that such differences exist. It is tempting to suppose, for instance, that the vital activity of the cells is greater in some persons than in others. A feeble vitality of the cells might explain the undoubtedly greater tendency to obesity in some persons and families than in others. From a physiological point of view such persons might be regarded as very economical machines, their economy being effected by a diminished output of heat. That a lowering of general metabolism is attended by diminished heat production is shown in the case of such diseases as myxœdema and diabetes, in which the body temperature is habitually subnormal; and it is conceivable that in some individuals an unusually large fraction of the energy set free by oxidation of the food is converted to work, and an unusually small fraction to heat. It must be admitted, however, that investigations into the metabolism of obese individuals have not clearly established the occurrence of such physiological economy, though some distinguished physiologists, such as Cohnheim and Bouchard, have been believers in its possibility. Meanwhile the question must be regarded as still sub judice.

Individual variations in muscular tone must also, as already described, affect the total amount of metabolism. A 'highly strung' person is one whose muscles are always in a high state of 'tone,' and are therefore always consuming energy; such a one has brisk kneejerks, and is characterized by 'energy' which leads him to perform muscular movements very quickly (and therefore uneconomically), and also to be constantly 
executing superfluous movements (note how he is constantly twisting and untwisting his fingers, clasping and unclasping his hands, or walking up and down the room instead of sitting in an easy-chair). In all these ways energy is expended, and the balance for 'savings' in the form of adipose tissue is reduced. It is in this way that 'temperament' affects 'physiological personality'; or one might reverse the order of cause and effect, and say, perhaps with equal truth, that it is the possession of a protoplasm of unusual vital activity which expresses itself inwardly by an active metabolism, and outwardly by all the marks of the energetic temperament. To the physician, at all events, the metabolic peculiarities or physiological personality of his patient is a factor of the greatest importance in practice.

\section{Qualitative Metabolism.}

\section{Proteins.}

Physiologists are as yet only beginning the investigation of the chemical changes which proteins undergo in the body, and of the facts already ascertained but few are capable of application in medicine. This line of research, however, is now being actively prosecuted, and there is every reason to hope that the results which it will yield will soon throw a flood of light on many of the obscure disorders of metabolism met with in disease. In the following paragraphs an attempt will be made to trace the life-history of the proteins in the body so far as present knowledge permits.

The protein of the food is first brought into solution 
in the stomach, and its molecules are then split up in the intestine into finer fragments, nearly all of which are amido-acids. It is in this form that proteins are absorbed, and out of these fragments the specific body proteins are again built up. It is not yet determined where this reconstitution takes place. There is much reason to believe, however, that the epithelial cells of the intestine are mainly responsible for the rebuilding, and that the proteins of the blood are the material that they produce. On this view all the proteins of the food are ultimately converted into serum proteins, which are in turn taken to pieces by the cells of the tissues, and from the products of their disintegration the special protein peculiar to any particular tissue is finally formed. On the other hand, there are some who believe that the amido-acids derived from the original food-proteins are conveyed to the tissues direct, and that it is from them that the specific tissue-proteins are reconstituted. Whichever view be correct, it is easy to understand how the initial picking to pieces of the protein molecule can enable the body out of the manifold forms of food-protein to produce for itself any kind of tissue-protein required. It must be remembered, however, that there are many different kinds of protein contained in the food, and that the nature of the amido-acids or ultimate fragments of which these are composed is very variable; indeed, at least twenty different kinds of amido-acids are already known. One ought not, therefore, to speak of the food containing so much 'protein,' as if the latter were always one definite chemical compound. It may well prove to be the case that it is not a matter of indifference to a patient 
what the kind of protein on which he is fed may be, but that certain varieties, yielding particular forms of amidoacids, may be peculiarly suitable or specially harmful in particular pathological states.

Having once traversed the intestinal wall, it would appear that protein is subjected to different treatment according to the particular use which it is to serve. That portion which is destined to serve as a source of energy (or 'energy-protein,' as we may call it) appears rapidly to undergo a process of 'denitrification' (possibly in the liver), by which the nitrogen-containing part of the molecule is split off, leaving the carbonaceous moiety, which may contain 90 per cent. of the energy of the original molecule, to be utilized, like fat and carbohydrate, as a source of work and heat. The remainder, or 'repair-protein,' is conveyed to the tissues, and there enters into the actual living substance of the cells, ultimately replacing the molecules which are worn out in the vital processes. The nitrogen-containing part of the 'energyprotein' is speedily broken down by oxidation, and eliminated chiefly in the form of urea and inorganic sulphates; the repair-protein, on the other hand, is broken down slowly, not by oxidation, but by a process which seems more to resemble ferment action, and eliminated largely in the form of kreatinin, uric acid, and neutral sulphur compounds.

There are thus two main lines along which protein metabolism proceeds, each with its own objects and resulting in the formation of its own end-products.

The proportion of the total intake of protein which is destined to follow each of these two possible lines depends 
upon various circumstances. If the intake be greatly in excess of the minimum required for the maintenance of nitrogenous equilibrium, the larger part is devoted to early denitrification and utilized for energy production. Much heat may be liberated in consequence of this, which may, indeed, be harmful in cases in which heat regulation is defective. Hence the importance of avoiding large protein meals in fever. If, on the other hand, but little protein is consumed, a large proportion finds its way to the tissues. The amount and nature of the other food constituents also exert a determining influence in the matter. The gelatin, carbohydrates, and fats of the food exert a shielding influence on the protein, preventing it from undergoing the 'denitrification' process, and enabling a larger proportion to take part in tissue metabolism than would otherwise be the case. This shielding process is known to physiologists as the doctrine of the 'protein-sparers.' The exact mechanism of the sparing process is unknown to us, but some idea of its possible modus operandi may be arrived at by the use of a somewhat anthropomorphic simile. Let us assume that into the neighbourhood of a cell there is brought in solution an equal number of molecules of protein, carbohydrate, and fat respectively. It would appear that the cell has least difficulty in 'tackling' (to use an expressive colloquialism) the molecules of protein, possibly because they are most like itself, and therefore least foreign to it, and in consequence more molecules of protein are broken up than of either carbohydrate or fat. If, however, instead of an equal number of molecules of each kind reaching the neighbourhood of 
the cell. there is a great preponderance of those of carbohydrate and fat, the 'mass influence' of these asserts itself, the attention of the cell is, as it were, distracted from the protein, and some of the latter safely runs the gauntlet and escapes denitrification.

Whether or not this represents with any accuracy an approximation to what actually takes place, there can be no doubt of the importance of the influence of the proteinsparers, and the way to ensure the least degree of degradation of protein to the purposes of energy production is to take care that carbohydrates and fats reach the cells along with it. Now, in vegetable foods proteins and carbohydrates are so intimately mixed that this result is achieved without difficulty, and hence it is that nitrogenous equilibrium can be more easily attained on a vegetarian diet than on any other. Similarly, if one wishes to maintain life on as low an intake of protein as possible, care should be taken that the protein food is not mainly consumed at one meal, but that it is spread over the day and mixed with non-protein ingredients. In this way much more of it is likely to escape denitrification, and be available for purposes of tissue repair.

It will be evident, then, that part of the protein which is utilized for the production of energy is, so far as its nitrogenous moiety is concerned, wasted, for carbohydrate and fat would have served the purpose just as well. This, in point of fact, is the contention of those who say that the ordinary protein-food standard is too high. Indeed, they go further, and say that such protein is not only wasted, but is injurious, in so far as the elimination of the urea and other products of its dis- 
integration entails work upon the excretory organs. In other words, the ideal they would have us aim at is the utilization of protein-if that be possible-for repair purposes alone.

Of the stages in the breaking-down of the repairprotein we know very little, but there is reason to believe that, like the preparation of food-protein for assimilation, it consists in resolution by successive stages into amido-acids. In normal circumstances these undergo further destruction, and mere traces of them appear in the urine, but in pathological states they may be excreted in large amounts. The appearance of leucin and tyrosin in acute yellow atrophy of the liver, and the anomalies of metabolism which result in cystinuria and alkaptonuria, are examples of such imperfect destruction.

\section{Fats.}

The assimilation of fat appears to be a much simpler process than that of protein. The fat molecules of the food, having been split up by digestion into fatty acids and glycerine, are absorbed in that form by the cells of the intestine, and apparently immediately reconstituted into fat; they then reach the general circulation by means of the lymphatics. By the cells fat appears to be received much more as a foreign body than protein is, and there is not the same attempt to recast it into a substance of uniform chemical composition. Hence it is that the fat stored up may partake very largely of the chemical characters of the fat absorbed. If, for instance, a fat of low melting-point be given in large quantities, the fat stored up is apt to be soft. This is, no doubt, the physio- 
logical explanation of the remark of an old nurse, quoted by Lauder Brunton, that 'some fats are hard and some soft, but cod-liver-oil fat is soon wasted.' It is probable, however, that after its storage in the tissues fat is gradually worked up into a chemical form peculiar to the human body.

The functions of stored fat are stated to be two: (1) to serve as a reserve of energy-forming material, and (2) to diminish heat loss. Of the reality of the first of these alleged functions there can be no question, but it may be asked, How large a fat reserve is it advisable to harbour in the body? There can be no doubt that in . the conditions of civilized life, with its regular three meals a day, there is little advantage in the possession of a large reserve of energy-forming material, although in the case of a prolonged wasting disease such a reserve must tend to lengthen the period during which a patient can hold out. On the other hand, the presence in the body of a large amount of fat has the obvious disadvantage that it increases the weight of the mass which the muscles have to transport in locomotion, and in this way must increase metabolic expenditure and restrict activity. What the optimum amount of fat in the body is we have no means of determining precisely.* It probably corresponds to what is popularly known as the 'fighting-weight'-that is to say, the weight at which an individual is at his highest point of bodily strength and endurance, and this appears to vary very much in different persons.

* In a well-nourished man fat makes up about 18 per cent. of the body-weight. 
Whether fat really restricts heat loss is not so certain. Seeing that it is a highly vascular tissue, it is not quite easy to see why it should, although it seems certainly to be true that lean individuals stand cold badly. We shall return to this point in another chapter.

In addition to its formation from the fat of the food, body-fat is undoubtedly derived from carbohydrates-a fact which is turned to account every day in the treatment of obesity. The fat so derived appears to be richer in palmitin and stearin and poorer in olein than fat derived from fats in the food. Whether protein can be used to form fat is a question which is still not definitely settled. Certainly, the amount of fat so derived must be very small. Were it otherwise, the results of the Banting system of treating obesity would not be so satisfactory.

Of the stages in the destruction of fat in the body we know but little, but they are probably-in their initial steps, at least-very similar to the cleavage into fatty acids and glycerine which takes place in digestion. The possibility of the production of $\beta$-oxybutyric acid in the course of cleavage is of great interest in connection with the pathology of diabetes. The stages in the production can be seen from the following formulæ:

$$
\begin{aligned}
& \mathrm{CH}_{3}-\mathrm{CH}_{2}-\mathrm{CH}_{2}-\mathrm{CO}_{2}=\text { Butyric acid. } \\
& \mathrm{C}_{3} \mathrm{H}_{5}\left(\mathrm{CH}_{3}-\mathrm{CH}_{2}-\mathrm{CH}_{2}-\mathrm{CO}_{2}\right)_{3}=\text { Glyceryl tributyrate, a } \text { typical fat. } \\
& \mathrm{H}\left(\mathrm{CH}_{3}-\mathrm{CH}-\mathrm{OH}-\mathrm{CH}_{2}-\mathrm{CO}_{2}\right)=\beta \text {-oxybutyric acid. }
\end{aligned}
$$

That fats undergo such a transformation as this in diabetes a study of the chemical pathology of that disease seems to show, and it is possible that the change 
is always going on to a less extent even in normal metabolism.

\section{Carbohydrates.}

From the comparative simplicity of the chemistry of the carbohydrates and the ease with which sugar can be recognized, even in small amounts, it might have been supposed that by this time we would have been well informed as to the details of carbohydrate metabolism. In spite, however, of the immense amount of work which has been devoted to the subject, and the stimulus to research which has been supplied by the ever-present riddle of diabetes, we are still profoundly ignorant even of the main outlines of the process. We know that carbohydrates are all converted into glucoses by the processes of digestion, but so soon as these disappear into the wall of the intestine our uncertainties begin. That sugar reaches the liver by the portal blood and is there converted into glycogen* is well established, but in what form it leaves the liver is still open to dispute. According to the classical view, glycogen is reconverted into sugar by the action of a ferment, and in that form is transported to the cells. Opposed to this is the view of Pavy, who strenuously denies that carbohydrates leave the liver in the form of sugar, and maintains that they are worked up into combination with nitrogenous material to form proteins, and in that form are carried to the cells. It might be thought that the dispute could be settled by the experimentum crucis of estimating the amount of sugar in the blood of the portal vein during * The liver contains about 10 ounces of glycogen, and the muscles rather less. 
fasting, and comparing it with that in the blood of the hepatic vein. Needless to say, this experiment has been tried many times, but observers are not agreed as to the result. The fact appears to be that a degree of difference which would be quite sufficient to establish the truth of the classical view once and for all is yet within the limits of experimental error in the estimation of sugar. Apart from this, however, it would seem unlikely that all the sugar entering the body could be transported in a protein form; for, after all, though most proteins do contain a carbohydrate radicle, yet the amount of this in the ordiñary blood-proteins is but small. At present, however, the dispute is still unsettled, though the vast mass of physiological opinion is in favour of the classical view. The point is of importance to the clinician in the pathology of diabetes, for, according to Pavy, one factor in the production of that disease is a failure of the liver to perform its normal function of converting sugar into other forms, with the result that it passes unchanged into the blood and leaks out through the kidneys.* According to the prevailing view, on the other hand, diabetes is due to a failure on the part of the cells to utilize sugar, which failure, in its turn, is consequent upon defective power of glycogen formation; for it is only as glycogen that carbohydrates can be utilized, or, as von Noorden puts it, glycogen is the natural fuel of the cells, not glucose. In the reason for this failure of glycogen formation the riddle of diabetes resides.

* It should be remembered that in health the whole volume of the blood contains less than $\frac{1}{2}$ ounce of sugar in solution. 
It is interesting to note that it is only those sugars which are directly fermentable by yeast which are capable of conversion into glycogen, and of subsequent utilization in the body. Unfermentable sugars, such as cane-sugar and lactose, if they reach the blood-stream as such, are excreted by the kidney. It is for this reason that these sugars are unsuitable for administration hypodermically in artificial feeding, and the same fact explains the tendency for nursing women to suffer from lactosuria ; for if lactose is reabsorbed from the mammary glands, it cannot be burnt up in the body, but is excreted in the urine.

It is further noteworthy that it is only those sugars which contain three carbon atoms, or a multiple of that number, which are capable of direct fermentation, and therefore of conversion into glycogen. Those which contain five, seven, or any other number of carbon atoms cannot be so converted, and should they gain access to the blood, are only with difficulty destroyed, and are apt to be excreted in the urine. Now, sugars with five carbon atoms (pentoses) commonly occur in certain fruits, and hence pentosuria, as it is termed, is a not infrequent consequence of the free consumption of such foods.

It must be remembered that there is a limit to the capability of the liver to convert soluble carbohydrates into glycogen. If the amount of carbohydrates consumed be excessive, the liver may not be able to keep pace with the supply, with the result that some escapes conversion, and passing into the general circulation is excreted by the kidney. To this the term alimentary 
glycosuria is applied. The limit of assimilating power varies in different individuals and in the case of different forms of carbohydrate. For starch, owing to its very gradual digestion, no limit is known. For some of the chief sugars the limit is as follows :

For glucose ... 150 to 200 grammes in one dose.

" lævulose ... 140 to 160

" cane-sugar 150 to 200

" milk-sugar 80 to 120

$\begin{array}{ll}\text { " } & \text { " } \\ \text { " } & \end{array}$

It will be observed that the assimilation limit is less for lactose than for any other form of sugar. This may perhaps be due to some of it escaping the action of the ferment in the intestine, which should convert lactose into glucose and galactose, with the result that it reaches the blood as lactose, in which form, as we have seen, it cannot be utilized. It is a curious fact that even in advanced cases of cirrhosis of the liver it is by no means easy to produce alimentary glycosuria, except in the case of lævulose, and such 'alimentary lævulosuria' may be regarded as a sign of 'hepatic insufficiency.' The reason for this is unknown.

That some of the sugar which enters the body is converted into fat we are quite sure, but we do not even know for certain where this transformation takes place. The liver is generally regarded as the most probable site, but it is not unlikely that the cells of the connective tissue possess the power of fat formation also. There is some reason to believe, on clinical grounds, that this power of converting carbohydrate into fat is not well developed in certain individuals, and that from the 
consequent imperfect assimilation of carbohydrates various diseased states may arise. Some cases of glycosuria in elderly subjects, for example, may be due to sugar running off through the kidneys instead of going to form fat. Such persons are only 'glycosurics' because they are not obese.

That sugar can be formed in the body from sources other than glycogen a study of the chemical phenomena of diabetes has made quite clear, and it was at first supposed that proteins were the source from which sugar could be so derived. This view received confirmation when it became known that most proteins contain a carbohydrate moiety - usually glucosamin -in their molecule. Subsequent investigation, however, has suggested doubts as to whether proteins can be an important source of sugar, and whether their glucosidal constitution is an adequate explanation of it-for, in the first place, the commonest and most usual proteins are those which contain least of the carbohydrate element; and in the second place, diabetics may continue to produce large quantities of sugar even when fed on proteins, such as casein, which contain no carbohydrate radicle at all. It has therefore recently been suggested that the amidoacid alanin-and possibly also glycocoll and leucinmay be the source of the carbohydrate derived from protein. At all events, there can be no question that sugar can be formed in the body from proteins, and that in severe cases of diabetes it may be as necessary to limit the consumption of protein as it is to restrict that of carbohydrates themselves.

Opinion has now veered round towards regarding even 
fats as a possible source of sugar, though this view as yet lacks actual confirmation. How important a solution of the problem would be to the physician in affording him guidance in the dietetic treatment of diabetes need not be pointed out.

Relation of the Pancreas to Carbohydrate Metabolism. - When first it was discovered that complete removal of the pancreas resulted in permanent glycosuria, and when subsequent histological investigation showed the almost invariable presence of lesions of the islands of Langerhans in patients who had died of diabetes, a great step forward in our knowledge of carbohydrate metabolism had certainly been made. Up to the present, however, the therapeutic results of this increase of knowledge have been disappointing. Experience showed that the administration of pancreatic extracts in all forms and in all ways, or even transplantation of the gland, failed to exert any influence on the course of diabetes. It would appear, then, that it is not by the mere elaboration of an internal secretion that the pancreas promotes the utilization of sugar. Nor, apparently, is it by neutralizing some 'toxin,' for the injection of the blood of depancreatized animals into those of others does not induce the disease. The view that the pancreas produces some secretion which activates a ferment in the muscles, which ferment is the active agent in glycolysis or the katabolism of sugar, has also fallen into disrepute, and the two most probable solutions of the puzzle are that the pancreas produces a ferment which (1) either promotes the polymerization of sugar into glycogen, or (2) restrains the disintegration of 
glycogen into sugar. Which of these will prove to le the correct explanation time will doubtless show.

Puncture Glycosuria. - Since the time of Claude Bernard it has been known that puncture of a point in the floor of the fourth ventricle results in the appearance of sugar in the urine. The glycosuria so produced disappears when the liver has been emptied of glycogen, and is apparently the result of a disturbance of the bloodsupply of the liver through its vasomotor nerves. A similar result is sometimes observed in man in consequence of injury to the central nervous system, but the glycosuria which results is transient, and in that way differs from true diabetes.

Phloridzin Diabetes.-In addition to its production by removal of the pancreas and by puncture of the floor of the fourth ventricle, glycosuria may also be produced in animals by the administration of phloridzin, a glucoside derived from the thorn-apple. The glycosuria so brought about resembles very closely that of true diabetes, and is accompanied also by an acid intoxication identical with that found in the later stages of the disease in the human subject. It has generally been supposed, however, that phloridzin diabetes is brought about by an action of the drug on the 'renal filter,' which it renders more permeable to sugar, and that it has therefore nothing in common with true diabetes. Opposed to this explanation is the fact that much more sugar may be excreted in the urine after the administration of phloridzin than the amount present in the blood will account for, and it would seem that the drug must 
actually lead in some way to an increased formation of sugar. Certain facts seem to suggest that fat may be the source of the increased sugar formation, but this is not yet clearly established.

If the kidneys be diseased, the excretion of sugar under the influence of phloridzin is much less than normally occurs, or may even be absent altogether. Advantage has been taken of this as a test of the glandular activity of the kidney in cases of suspected renal inadequacy.

Metabolism of Uric Acid.-A knowledge of the metabolism of uric acid is of special importance to the physician because of its bearings upon gout. It must be confessed, however, that, in spite of an enormous amount of work which has been done upon the subject, we are still very far from a complete understanding of it. Some facts, however, have been made out beyond dispute, and these, with their clinical applications, must now be briefly set forth.

The first point to grasp clearly is that uric acid metabolism goes on quite independently of general protein metabolism, and pursues special lines of its own. The amount of protein in the food has therefore no necessary connection with the metabolism of uric acid, and in considering the pathology of gout this must be constantly borne in mind. The disentanglement of uric acid metabolism from general protein metabolism, indeed, must be regarded as one of the most important advances in chemical physiology, and when it has once been thoroughly grasped by physicians will do much to dissipate the rather confused thinking about gout and 
'goutiness' which has hitherto prevailed in clinical medicine.

Uric acid belongs chemically to the group of bodies called 'purins,' which possess a common nucleus, the purin nucleus, or ring, having the following formula:

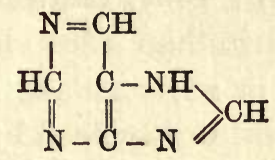

Uric acid is trioxypurin :<smiles>O=CNc1cc2ccc1NC(=O)N2</smiles>

It is not very long since it was believed that uric acid resulted from the breaking down of any protein in the body, and as a corollary of this it was taught that in gout, in which there is an excess of uric acid in the body, any protein food is bad for the patient, and he should consume as little of it as possible. It is now known that the breaking down of proteins as such does not give rise to uric acid, but that the latter is derived from three possible sources.

1. From Purin Bodies contained in the Food.-This is called 'exogenous' uric acid. The foods which contain most purin are flesh foods and the internal organs of animals (e.g., liver and sweetbreads), peas, beans and lentils, oatmeal, asparagus, tea and coffee.

Of the purins taken in with the food part are destroyed in the body-probably in the liver-with the production 
of glycin and possibly of oxalic acid and allantoin, and only a fraction appears in the urine. Of oxypurins (hypoxanthin), about one-half ; of amino-purins (e.g., those derived from nuclein), three-fourths; and of methyl purins (caffeine), two-thirds, are destroyed in this way. Whether gouty individuals have less capacity for destroying purin than others has not been definitely determined, but in any case the attempt to lessen the amount of uric acid in the blood by feeding an individual on a purin-free diet is undoubtedly rational therapeutics. A diet of milk and vegetables was recommended to the gouty so long ago as 1729 by Dr. George Cheyne, and has since, under the title of a purin-free diet, been widely advocated in this country by Dr. Haig.

2. Uric acid is also produced by the breaking down of body tissues which contain amino-purins (e.g., adenin and guanin) and oxypurins (e.g., xanthin and hypoxanthin). The two former are most abundant in nuclein, the two latter in muscle. The uric acid so derived is spoken of as 'endogenous' uric acid. It was at first supposed that the destruction of leucocytes supplied the nuclein from which most of the endogenous uric acid arose, and this opinion gained confirmation from the large excretion of uric acid in cases of leukæmia. It is now known, however, that there is no constant relation between the number of leucocytes and the excretion of uric acid, and present physiological opinion is more in favour of regarding the muscles as the chief source of endogenous uric acid.

The amount of endogenous uric acid varies considerably in different individuals, but is singularly constant 
for the same individual under the same conditions as regards exercise, etc. It might be supposed that the gouty person is one who produces an unduly large amount of uric acid, but this is apparently not the case. It is probable, also, that a mere fraction of the uric acid produced endogenously ever reaches the urine, but that, as happens with urates taken in with the food, a considerable part is destroyed in the liver; but this is a matter very difficult to investigate at all accurately. In any case, the amount of uric acid produced endogenously is almost beyond our control, and so our knowledge of its production in this way cannot be turned to account in treatment.

3. A third way in which uric acid may, perhaps, be produced in the human body is by synthesis from other substances which do not contain the purin-ring at all. We know that it is so produced in birds and reptiles from ammonium lactate, but there is no reason to suppose that any large production of it takes place by this method in man. Still, a small percentage may be derived from lactic, tartronic, and $\beta$-oxybutyric acids, and it may be that persons of the so-called 'uric acid diathesis ' have a special aptitude for forming it in this way. The supposed synthesis from glycin and urea, which at one time was so prominent in physiological teaching, is now discredited; for glycin and urea, when administered to mammals, cause no change in uric acid excretion, and glycin is probably rather a decomposition product than a precursor of uric acid. The same may be true of urea.

Quite as important in the pathology of gout as the 
source of uric acid in the body is the form in which it circulates in the blood. Now, it is a curious fact that, although the administration of purins is followed by an increase in their excretion, yet mere traces of purins can be discovered in the blood in health. It has therefore been suggested that they circulate in a combinationpossibly with proteins - which prevents them from giving the usual reactions (just as iron is masked by its combination in hæmoglobin); and another thinkable hypothesis to explain gout is that in the gouty individual this combination is for some reason not formed, and that uric acid circulates as urates, a form in which it is with difficulty excreted.

Finally, it has been ascertained that in health the subcutaneous injection of uric acid, or its excessive ingestion in the form of purins, is accompanied by an increased excretion in the urine; but prolonged examination of the urine in gout shows that the excretion of uric acid is not greater than normal. It seems to follow from this that the excess of urates in the blood in gout must be due to diminished excretion, and not to increased ingestion of exogenous, or increased production of endogenous, uric acid. 


\section{CHAPTER II}

\section{THE APPLIED PHYSIOLOGY OF BODY HEAT}

Heat is to be regarded as a by-product of the metabolic processes described in the last chapter. It is not a thing which the living body manufactures, as it does a secretion, for its own sake; on the contrary, life and heat are inseparable, and so long as life exists in the body, so long will heat continue to be produced. It is important to make this clear, for there is still a tendency to regard heat as something which is produced, as it were, by an effort, simply in order to keep the body warm. So far from this being the case, the ordinary processes of metabolism result in normal conditions in the production of considerably more heat than is really required to maintain the body temperature at its usual level. It has been calculated, indeed, that were it not for the fact that heat is constantly being lost from the body, a man of 10 stones in weight, with the usual metabolic turn. over of 3,000 Calories, would reach boiling-point in thirty-five hours! The greater the degree of 'vitality,' the larger, naturally, is the amount of heat produced. Hence, any agent which tends to paralyze the protoplasm of the body cells brings about a diminished production of heat. Alcohol and anæsthetics are amongst such agents, and it is a well-known fact that cold is 
highly prejudicial to a person who is intoxicated. Seeing that life always manifests itself by developing heat, we need not be surprised to be told that there is really no such thing as a 'cold-blooded' animal in the literal sense, and that the creatures commonly so described usually have a body temperature appreciably above that of their surroundings. The real distinction, in fact, is not between warm-and cold-blooded animals, but between those whose temperature is constant and those in whom it is not.

Now, the question naturally presents itself, What are the advantages of having a constant temperature, or, in other words, of being what is commonly called 'warmblooded'? The reply to this is, that constancy of temperature makes an animal more independent of its surroundings. Extremes of heat and cold both tend to paralyze living cells, and if the temperature of a man's body fell with that of his surroundings, all his vital processes would become sluggish in cold weather. On the other hand, when exposed to heat, it would be necessary for him to adopt a voluntary sluggishness, as otherwise his temperature might rise to a point at which the vitality of his cells would become impaired. In the process of evolution, therefore, when animals ceased to be aquatic, and came to live in a medium of varying temperature, it became necessary to develop a mechanism for maintaining the temperature of the body at a constant level, and the animals which succeeded in doing this in greatest perfection survived. Even yet we can see in the Monotremata an example of creatures in which the development of a heat-regulating mechanism has 
been arrested at an early stage, with the consequence that they can only to a small degree maintain their activity, regardless of what the surrounding temperature may happen to be, and in some cases at least, such as Echidna, are compelled to resort to the device of hibernation and a suspension of all attempts at bodily activity when exposed to great cold. Even in some of the higher mammals the heat-regulating mechanism is not in proper working order at the time of birth, and such animals perish from cold if separated from their mothers. In the case of puppies, for instance, which of course are born blind, the power of maintaining the temperature of the body does not arise until sight is attained. Babies who are born prematurely, also, are unable to control their temperature, and would perish were it not for the aid of an incubator or some other device for keeping them warm. Even in normal infants the power of regulating heat production and loss is very imperfect during the first week; hence the importance of warmth to the newly-born baby.

Now, although all the higher animals have developed the power of maintaining their bodies at a constant temperature, it is an interesting fact that the exact point at which evolution has fixed it to be maintained is by no means the same in all. In man it may be taken as a temperature of $98.6^{\circ} \mathrm{F}$., the range of internal temperature in health being from $96.8^{\circ} \mathrm{F}$. to $100^{\circ} \mathrm{F}$.; but in most other mammals it is more nearly $102^{\circ} \mathrm{F}$., whilst in birds it is as high as $107^{\circ} \mathrm{F}$. Why these differences exist it is difficult to explain. All one can say is that a temperature of $98.6^{\circ} \mathrm{F}$. is the tune to which the 
molecules of human cells ' dance' most actively. If the temperature of the body falls below this point, their movements become more sluggish; whilst if it rises much above this point, they may dance more violently indeed, but it tends to be a dance of death. Of the two extremes, a low temperature would appear to be the less dangerous, for whilst clinical observation shows that recovery may ensue even when the temperature of the body has fallen as low as $75^{\circ} \mathrm{F}$., a rise of even $132^{\circ} \mathrm{F}$. above the normal is but rarely survived unless it be of short duration.

Although the heat-regulating mechanism succeeds in keeping the mean temperature of the body very uniform, slight daily variations do occur, the maximum being reached about five o'clock in the evening, and the minimum in the small hours of the morning. In cases of fever these normal variations are sometimes exaggerated, and a 'two-hourly' chart may therefore exhibit a rise of temperature which would be missed if the thermometer is used only twice a day. The cause of these daily variations is obscure, but it is certain that they occur during both starvation and complete rest, and it is probable that they result from the normal daily fluctuations in metabolism to which reference has already been made (p. 20). In people who pursue nocturnal vocations the daily rhythm of temperature may be inverted, the maximum being attained in the early morning, and the minimum in the evening. So stereotyped, however, has the normal type of metabolism become through long habit that such inversions of it are but rarely met with. 
Even if one transposes day and night by a journey to the other side of the world, the temperature rhythm adjusts itself to the new conditions, so as still to show the normal daily curve.*

There is a considerable amount of evidence, also, to show that the temperature of the body is not quite uniform all over the globe, but that it tends to be somewhat higher in the tropics than it is in temperate regions. This is probably owing to interference with heat loss. The eentral temperature, however, is much less affected by climate than that of the periphery of the body.

\section{Temperature-Regulating Mechanism.}

The constancy of temperature of the body is attained-

1. By varying the heat loss (physical regulation).

2. By varying the heat production (chemical regulation).

\section{Physical Regulation.}

In man the heat loss is regulated (a) naturally, (b) artificially (i.e., by clothes and artificial heating of rooms).

(a) The Natural Channels of Heat Loss are-

Percentage of Total Heat Loss.
(i.) The skin ...
(ii.) The lungs ...
... $87 \cdot 5$
(iii.) The excreta
... $10 \cdot 7$
... $1 \cdot 8$

* Gibson, "The Effects of Transposition of the Daily Routine on the Rhythm of Temperature Variation' (Amer. Journ. Med. Sci., 1905, cxxix., 1048). 
Of these, the skin alone is utilized for purposes of regulating the temperature in man.

Heat is lost from the skin-

1. By radiation.

2. By conduction.

3. By convection.

4. By evaporation.

1. Radiation is by far the most important of these, for 73 per cent. of the total loss from the skin, or 1,700 Calories, may be accounted for in this way. Radiation is most active in cold, dry air, and the greater the surface of the body relative to its mass, the greater is the loss by radiation. Small animals, therefore, tend to lose heat more rapidly than large, which is the chief reason why children should be warmly clothed. It would appear that the amount of heat lost by radiation cannot be varied much by natural means, for even such a degree of dilatation of the surface capillaries as will produce visible redness only serves to raise the surface temperature of the skin $1 \cdot 75^{\circ} \mathrm{C}$. (Hale White).

2. Conduction.-Seeing that water is twenty-eight times better as a conductor of heat than air, it will be obvious that the greater the degree of moisture in the atmosphere, the greater is the loss by this means; hence the chilling effect of cold, damp air. Fortunately, however, the human body is a bad conductor of heat. Indeed, it may be compared to a mass of but moderate conducting power containing a warm substance-the blood - of almost constant temperature, and the temperature of any point in the body depends upon its 
nearness to the large bloodvessels and on the conducting power of the intermediate tissues. Were it not for this low conducting power of the body it would be impossible to make use of the local effects of the cautery or of freezing as we do. Fat is the tissue which is the worst conductor of heat,* so that there is some reason in the common belief that a thick layer of subcutaneous fat serves as a blanket, which lessens heat loss.

Against loss of heat by conduction it is impossible for the body to protect itself by natural means at all, but clothes are of some avail against it (see p. 57).

3. Convection only comes into play when the body is exposed to the influence of air in motion. Draughts, for instance, produce their local chilling effects by this means, and winds are even more potent, the combined effect of conduction and convection produced by a cold, damp wind being one of the most chilling influences to which the body can be exposed.

4. Evaporation stands next to radiation in importance as a mode of heat loss from the skin, 14.5 per cent. of the total surface loss being accounted for in this way. It has been calculated by Erasmus Wilson that the skin contains twenty-one miles of sweat glands, from which about 600 c.c. of sweat are evaporated daily, which will produce a loss of about 350 Calories. During hard exertion this loss is, of course, greatly increased. It has been found, for instance, that stokers may lose 3 pounds

* For experiments on the conducting power of the different tissues of the body, see Bordier, Archives de Physiol., 1898, xxx. 17; also Charrin and Guillemonat (ibid., p. 455). 
of sweat by evaporation in less than an hour. That complete cessation of evaporation can induce a rise of temperature there can be little doubt. In belladonnapoisoning, for example, in which sweat secretion is entirely arrested, the temperature may rise to $104^{\circ} \mathrm{F}$.

These various modes of heat loss present a different degree of activity in different individuals. In tall thin persons, for example, who have a large body surface, radiation and conduction are very active, and evaporation plays but a minor part. In short stout individuals, on the other hand, who have a relatively small surface and a bad power of conduction, the loss of heat by the evaporation of sweat is much more often called for.

(b) Artificial Regulation of Heat Loss.

By the invention of clothes man has enormously increased his power of withstanding cold. Thanks to them, we live and move in a nearly constant atmosphere of $91^{\circ} \mathrm{F}$. , $^{*}$ whilst a naked man would have great difficulty in maintaining his temperature at the normal level if that of the surrounding air were even as high as $80^{\circ} \mathrm{F}$.

Locket quotes with approval the answer given by the Scythian philosopher to the Athenian who wondered how he could go naked in frost and snow. 'How,' said the Scythian, 'can you endure your face exposed to the sharp winter air?' 'My face is used to it,' said the Athenian. 'Think me all face,' replied the Scythian.

* Rubner, working with a thermopile, has shown that, if the radiation of heat from the naked skin be taken as 100 , with a vest on it is 73 ; shirt and vest, 60 ; waistcoat, shirt, and vest, 46 ; and coat, waistcoat, shirt, and vest, 33.

†' Some Thoughts concerning Education.' 
The answer is really not a good one at all, for we can only afford to expose the face because the rest of the body is warmly clothed. Clothes regulate heat loss by diminishing it, whereas the natural regulation of heat loss by the skin is chiefly in the direction of increasing it. Civilized man trusts to the former method to enable him to resist cold, and to the latter to help him to withstand heat.

Clothes should be so constructed as to lessen radiation and conduction without interfering any more than can be helped with evaporation. They will thus be of the maximum utility in cold, and of the least inconvenience in heat. The material of the clothes should therefore be a bad conductor of heat. Count Rumford made some interesting experiments* on the conducting power of different materials, which are instructive from this point of view. He placed a thermometer with its bulb in a glass globe, the space between the thermometer and the globe being filled with the material to be tested. The instrument was heated to the temperature of boiling water, and then plunged into a freezing mixture, and the time taken for it to cool down to $35^{\circ} \mathrm{F}$. noted. The results were as follows:

When surrounded with-

Seconds.

Twisted silk ...

Fine lint

Cotton-wool

Sheep's wool ...

Eider-down $\quad$...

Hare's fur

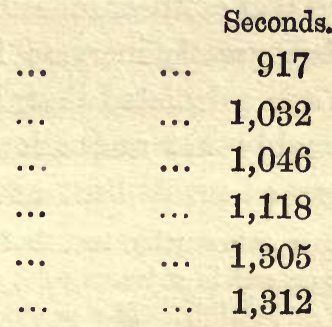

* Phil. Trans., Roy. Soc., 1792, lxxxii. 48. 
Wool is therefore a better non-conductor than either vegetable fibre or silk.

Equally important, however, to the material employed is the mode in which it is woven; for the air enclosed between the different layers of clothing, and entangled in its meshes, forms a warm envelope which is a worse conductor of heat than any material of which clothes are made, and which greatly interferes with heat loss, besides being not readily removed even by convection. Thus, too, garments which enclose a layer of air between them are much more efficient in checking loss than one garment, even though it be equal in thickness to two. Clothes should therefore fit loosely. They should also be loosely woven, so as to enclose as much air as possible in the interstices of the material. Here again the superiority of woollen garments is pronounced, for 1,000 volumes of soft flannel contain 923 volumes of air, as against 723 contained in linen. It is in accordance with this principle that 'cellular' clothing is made.*

The utility of clothes is greatly interfered with by damp, for the moist air penetrates into the interstices of the cloth and removes heat from the body by evaporation. Wet clothes, indeed, are almost worse than none, for they greatly increase loss by evaporation. Thus, it has been calculated that, if the boots and stockings are thoroughly wet and allowed to dry on the feet, they remove as much heat as would have been required to

* It is noteworthy, too, that even in the lower animals the hair stands on end in extreme cold, so as to enclose as large an amount of air as possible. The production of 'goose-flesh' in the human subject is apparently a survival of the same device 
melt half a pound of ice or raise an equal weight of water to boiling-point. This is a striking proof of the danger of 'wet feet.'

Even in respect of damp, wool is the best clothing material, for, being far more hygroscopic than vegetable fibre, it can absorb much more water without feeling wet. Again, when thoroughly wet, only 26 per cent. of the pores in wool are closed and their air displaced, whereas in the case of silk the percentage is 39 , and in linen as high as 56. Wool is also difficult to wet both on account of the natural oil which it contains and because of the horny covering of its fibres. These advantages are well illustrated in the case of Harris tweed.

As regards the amount of clothing which should be worn, all that can be said is that it should be sufficient to prevent ' an abiding feeling of cold.' As a rule, the weight of the necessary clothes is from 6 to 12 pounds, which may be easily doubled by the addition of an overcoat and other outdoor apparel. Thus, in winter a man may easily carry 18 per cent. of his weight on his back. The lower animals are much more favourably situated in this respect, for the weight of hair carried by a dog weighing 9 pounds is only about 3 ounces.

Small animals should, for reasons already given, be more warmly clothed than large. Infants, therefore, require abundance of clothing, and the 'hardening' plan so foolishly advocated even by such a profound thinker as Locke* is opposed to all the teaching of physiology.

* 'Give me leave, therefore, to advise you not to fence too carefully against the cold of this our climate. ... Be sure let not his [the 


\section{Chemical Regulation.}

In addition to the method of varying its heat loss, the temperature of the body can be regulated by increasing or lessening the amount of heat produced. As this method, however, implies the production of variations in the amount of metabolism, it is not used except in emergencies, and for all ordinary contingencies variation of loss is what is relied upon.

Metabolism in man is at its lowest point when the surrounding temperature is somewhere between $60^{\circ}$ and $98^{\circ} \mathrm{F}$. If it falls below this, metabolism is quickened, and more heat produced to meet the demand. If, on the other hand, the temperature rises above this, it is difficult-indeed, almost impossible, except by curtailing bodily activity - for the body to produce less heat, as it is already producing as little as is compatible with the full exercise of the vital powers, and it is accordingly forced to keep its temperature down by increasing the amount of heat lost.

Muscle is the tissue which is chiefly called upon when greater heat production is demanded. Even in a state of repose, 75 per cent. of the total heat production of the body is derived from the muscles, and when the body is in a condition of activity their share in the production rises to 90 per cent. In normal conditions, therefore, the effect of muscular exercise in raising the temperature

child's] winter clothing be too warm. ... I I would also advise his feet to be washed every day in cold water, and to have his shoes so thin that they might leak and let in water whenever he comes near it' ('Thoughts concerning Education,' 1690, p. 404). 
of the body is quite marked. Jurgensen, for instance, found that the work involved in sawing wood for six hours raises the temperature of a healthy man $1.2^{\circ} \mathrm{C}$. above normal. Davy showed that walking for two or three hours raised the temperature of the urine $0.8^{\circ} \mathrm{C}$. Clifford Allbutt found that Alpine climbing raised the temperature of the mouth half a degree. Hobday has taken the rectal temperature of omnibus horses, and found that it is raised about $2^{\circ} \mathrm{C}$. by hard work.* These effects, however, are quite temporary, and in about a quarter of an hour after the exercise has terminated the temperature has again fallen to normal, but they will serve to show what a valuable source of heat muscular metabolism is.

When the body is exposed to cold, this source of heat supply is drawn upon by throwing the muscles into activity partly voluntarily (e.g., by moving about, stamping the feet, swinging the arms, etc.), and partly in a semi-involuntary way by the act of shivering. The nerve mechanism which is made use of in throwing the heat-generating apparatus into action will be described immediately.

The amount of heat which can be produced in this way is very well seen in the table on page 62 , which shows the results which Rubner obtained from individuals immersed in a cold bath.

The bath lasted one hour. For half an hour one must halve the increased heat production.

Roughly it may be said that every fall of $1^{\circ} \mathrm{C}$. in

* These esamples are taken from Hale White's Croonian Lectures for 1897. 
the surrounding temperature increases metabolism by 2 to 3 per cent. It will be seen from this how expensive a method of regulating temperature increased heat production is. So expensive is it, indeed, that feeble individuals are sometimes unable to produce enough heat, and suffer a lowering of their body temperature in consequence; and whenever in cases of disease one finds a permanently subnormal temperature, one may conclude that heat production is insufficient. Good examples of such diseases are found in the case of diabetes and myxoedema.

\begin{tabular}{|c|c|c|c|c|}
\hline $\begin{array}{c}\text { Temperature } \\
\text { of Bath. }\end{array}$ & $\begin{array}{l}\text { Incronsed Heat } \\
\text { Productlon } \\
\text { Caused. }\end{array}$ & $\begin{array}{l}\text { Increamed } \\
\text { Demtruction } \\
\text { of Fat. }\end{array}$ & $\begin{array}{c}\text { After-joffoot } \\
\text { on Fat. }\end{array}$ & $\begin{array}{l}\text { Combinod } \\
\text { Effocta, before } \\
\text { and after. }\end{array}$ \\
\hline $60^{\circ} \mathrm{I}$ & 107 Calories & 48 grammes & 9 grammes & 52 grammos \\
\hline $77^{\circ} \mathrm{F}$ & 167 & 18 & 4 & 22 \\
\hline $95^{\circ} \mathrm{w}$ & 7 & 0.7 & 0 & 0.7 \\
\hline
\end{tabular}

The hent produced in the muscles in response to an incrensed demand is distributed throughout the body by the blood, and much of the glow felt after hard exercise is really due not so much to increased heat production as to better heat distribution. If the movement of the blood is languid and the surface bloodvessels contracted, as is the case with persons who suffer from what is called a 'bad circulation,' the heat produced is not well distributed, and consequently such persons have difficulty in maintaining their body temperature when exposed to cold.

'Wo are not all blessed,' says Lewes," 'with the same

* The Physiology of Common Lifo,' i. 436. 
capacity for rapidly developing heat; wo are not all blessed with the same activity of the circulation. Yet each is apt to make himself the standard. B. shivers, and complains of the cold; thinks he must have the fire lighted though it be June. C. is amazed that anyone can possibly be cold on such a day; C. is quite warm.... . The difference may arise from two causes: the heatproducing capacity may be less, or the circulation feobler. The stimulus of the external cold increases the activity of the organio processes in one man, and depresses it in another. That this is the real cause will appear on examining the influence of cold on the various elasses of warm-blooded animals. One class-the hybernaters -is so incapable of resisting cold by an adequate increase of its own temperature, that it falls into a torpor; other classes are forced to seek external warmth in nests and holes, as we seek it in warm elothing and heated rooms; others, again, neod nothing but their own temperature. In spite of the active respiration of a mouse, it needs a warm nest, and unless in active exercise will perish if exposed to a temperature which we should consider moderate; we, again, should perish in a temperature which the eat or dog could endure without uneasiness.

'Among men there are some who resemble the mouse, and others who resemble the eat. The slightest fall of tomperature causes the first to put on warmer elothing or to light the fire, at which their robuster friends are liberal in sarcastio allusions, spoken or thought, and aro somewhat impatient of this "coddling." These sarcastio friends are the cats. 
'It is important to bear in mind, however, that this inadequate production of heat does not always translate itself by the expression of "chilliness"; the effect of cold is often totally unlike that of a chilly sensation. It produces a vague uneasiness, a feeling of depression, resulting from the lowering of the organic activity, and many periodic forms of disease are probably connected therewith. Without positively "feeling cold," the person so affected need only enter a well-warmed apartment to be at once aware of a reinvigorated condition.'

The immediate effect of a warm meal in raising the temperature of the body is more apparent than real, being due to stimulation of the circulation, with consequent better distribution of the blood in the periphery. Apart from this effect, however, food is undoubtedly an important source of heat after it has had time to be digested and absorbed. Of the chemical constituents of the food, protein is the most rapid developer of heat, probably owing to its speedy cleavage and the partial oxidation of the nitrogenous part of its molecule already referred to. Next to it in potency is carbohydrate, whilst fat comes lowest in heating power.* These facts have important bearings on the dietary suitable for hot weather and warm climates.

\section{The Nerve Mechanism of Temperature Regulation.}

Variations in heat loss from the surface of the body are brought about through the medium of the vasomotor and sweat-secreting nerves. The mechanism involved

* If the heat-generating power of protein be taken as 20 , that of carbohydrate is 10 , and that of fat 7 . 
is a true reflex. When the skin is exposed to cold the cutaneous vessels are reflexly contracted, and radiation is lessened. When exposed to heat the vessels are dilated, and sweat secretion begins. Thus both radia-tion and evaporation are rendered more active. It is important for adequate and instantaneous temperature regulation that the nervous apparatus concerned should be kept in good working order, and part of the good effect of a morning cold bath is no doubt to be attributed to its putting the vasomotor nerves 'through their drill.' It should be noted in this connection that the cutaneous nerves are not tuned to appreciate actual degrees of temperature, but merely a gain or loss of heat from the skin. This explains why it is, for instance, that when we go down into a 'tube' railway in winter it feels warm, but in the summer it feels cool, although the temperature of the tunnel is really almost constant all the year round. Mere sensation, therefore, is a most fallacious guide to temperature, for which reason we cannot trust to the hand in gauging the presence or absence of fever in a patient, but have to fall back upon the reading recorded by a thermometer.

The chemical regulation of temperature by increasing heat production is also a function of the nervous system. It used not to be believed that this was so. It was thought that cold stimulated the activity of the cells directly. That, of course, was an error. Cold is really a depressant of vitality, and paralyzes the cells just as a narcotic does. The clinical effects of cold, indeed, if it be sufficiently severe actually to lower the temperature of the blood, are wonderfully like those of an anæsthetic 
or of toxic doses of alcohol, and, as Watson says, 'there is too much reason to believe that poor wretches who have been picked up by the constables in the streets at night during periods of hard frost have been supposed to be drunk, when in truth they were only stupefied by cold.'

The nervous mechanism which calls out an increased production of heat by the muscles, however, is not thrown into action in a purely reflex way. In part it is a voluntary process, active movements being performed instinctively in order ' to keep one's self warm.' In part also it is a subconscious 'psychical reflex,' comparable to that which leads to blinking of the eye on any sudden menace to the cornea, and which leads to more or less involuntary shivering-i.e., slight but rapid muscular contractions-and which can be more or less completely inhibited by the will. Short of actual shivering, cold seems, through nervous action, to raise the 'tone' of the muscles, and therefore to increase the volume of heat they produce (see p. 22). Everyone feels more 'strung up' on a cold day, and this is what is really meant when a cold climate is spoken of as ' bracing.' It has, in fact, a tonic effect very like that of strychnine.

Whether or not there is a special centre in the brain which presides over the function of heat production is a point on which physiologists are not yet agreed, though the bulk of opinion is opposed to such a conclusion, in spite of the experimental and clinical evidence which points to the existence of such a centre in the corpus striatum. On the whole, it seems more probable that the control is exerted through the medium of the ordinary motor and vasomotor centres. There can be 
little doubt that, in spite of the regulating mechanism, the body becomes habituated to a certain level or balance of heat production and loss, and takes a little time to readjust matters when external conditions suddenly change. Captain Parry, the Arctic explorer, tells us, for instance, that when he and his men had been exposed to a temperature of $13^{\circ} \mathrm{F}$. for some time, they complained of the heat when the thermometer rose to $26^{\circ} \mathrm{F}$., and everyone knows how much more trying a cold day is in the middle of summer than a day of the same temperature in mid-winter, even although the clothing be the same.

Similarly, persons who inhabit warm latitudes become accustomed to losing much heat from the surface by evaporation, and are out of practice, as it were, in producing more heat to meet emergencies, and are therefore prone to succumb to chills when they remove to colder regions.

Alcohol in excessive doses and prolonged anæsthesia both paralyze the heat-regulating mechanism. A man who is 'dead drunk' resembles a cold-blooded animal; exposure to cold produces not an increase but a decrease in combustion, and his temperature steadily falls (Pembrey). It is not surprising, therefore, that 'death from exposure' chiefly occurs in the case of intoxicated persons.

An anæsthetized patient also cannot regulate his temperature, and the importance of warm surroundings in promoting recovery from prolonged operations and in obviating 'shock' is generally recognized.

'Heat stroke' and 'heat exhaustion' are probably also due to a disturbance of the mechanism for regulating 
temperature brought about by muscular exerciseespecially when unsuitably clothed-in a hot and damp atmosphere.

\section{Internal Heat-Regulating Mechanism.}

In addition to the mechanism already described for regulating the heat production and loss of the body in accordance with variations in the temperature of its surroundings, there must also be a means of regulation in correspondence with variations in the temperature of the blood which arise from within. The increased heat production induced by hard exercise, for example, must be met by some means of increasing heat loss, and we know that this takes place by sweating. The mechanism involved here is apparently not a reflex one, but is a direct action of the temperature of the blood on the heatregulating centres. There is reason to believe that this mechanism is less delicate and active than the reflex one, and it is probable that disorders of it play a part in the production of fever. Into the subject of fever, however, we can hardly enter, as it is purely a matter of pathology, although one or two statements about it which can be directly deduced from the teaching of physiology may now be pointed out.

Fever. - In the first place, a permanent rise of temperature in the body cannot be due simply to increased heat production, for, as we have seen, even hard exercise, in which heat production is enormously increased, only raises the temperature but a little, and for a short time. Nor can diminished loss alone be the cause of 
fever, for in that case the rise of temperature of the body would be steady and progressive. It is probable, however, that diminished loss plays a large part in the production of hyperpyrexia in which the rise of temperature is marked by those very characters. We may conclude, then, on physiological grounds alone, apart from the evidence of pathology, that in most cases fever is due to a disturbance of the normal balance between manufacture and loss of heat, or, in other words, to a disorder of the internal heat-regulating mechanism. What the nature of this disorder may be is uncertain, but it has been suggested that the poisons which produce fever lower the sensitiveness of the internal heat-regulating mechanism, so that (to compare it with a thermostat) it is 'set' for a higher temperature than in bealth.

It is further of importance, in considering fever, to distinguish between the mere temperature of the body and the total amount of heat which it contains. The 'specific heat' of the human body is high; i.e., it takes a considerable amount of heat to raise its temperature, and the larger the mass of the body, the greater is the amount of heat required. Other things being equal, therefore, a given rise of temperature signifies a greater amount of heat production in a large body than in a small one. There is also every reason to believe that the specific heat of the body rises with an increase of its temperature, or, in other words, the hotter the body becomes, the greater is the amount of heat required to heat it still more. It follows from this that a rise of temperature from $104^{\circ}$ to $105^{\circ} \mathrm{F}$. is of relatively graver significance than a rise from $99^{\circ}$ to $100^{\circ} \mathrm{F}$. 
Seeing that the direct effect of heat upon the cells is to stimulate and accelerate their katabolism-much as the growth of plants is stimulated in a hothouse-it would seem to be inevitable that, when the temperature of the blood rises, tissue waste must be increased. A good example of this is seen in the case of the heart, the rate of contraction of which is increased by eight beats per minute for every rise above the normal temperature of $1^{\circ} \mathrm{F}$. Fever per se has therefore a destructive effect on the cells of the body, whether it be primarily due chiefly to an increased production of heat, to a diminution in heat loss, or to a disturbance of the normal balance between the two.

If it be desired to lower the temperature in fever, the easiest means of doing so is to increase the amount of heat loss, for this is more under our control than heat production. Cold baths, for instance, act by removing heat from the surface by conduction; sudorifics, by increasing evaporation. On the other hand, we know of but few drugs which diminish the amount of heat produced in the body. Alcohol in large doses appears to do so, probably from its paralyzing effect upon the cells, and quinine seems to have a similar action. Antipyrine and other antipyretics of the same class appear to raise heat loss by dilating the surface bloodvessels, and so increasing the amount of radiation from the body, whilst at the same time they seem to have some action on the heat-regulating centres whereby they overcome the disorganization of those centres which play a leading part in the production of fever. 


\section{CHAPTER III}

THE APPLIED PHYSIOLOGY OF THE BLOOD AND HAMOPOIETIC ORGANS

General Functions of the Blood.

From the earliest times of medical science the blood has attracted to itself the most earnest attention of the investigators of the secrets of life. Whole systems of pathology have been built up upon supposed alterations in its properties, and have subsequently fallen into disregard, and yet in these latter days there is still no field of research which is cultivated with more enthusiasm. Nor is the reason for this far to seek. Blood is the one constituent common to all the organs and tissues alike. It is the currency or medium of exchange in the body, giving to every cell the substances necessary for its life, and receiving back from it again the products of its activity or waste. In this respect the blood, as it flows ceaselessly along the bloodvessels, has been aptly compared to the water in the canals of such a city as Venice or Amsterdam, which brings to the doors of the inhabitants the provisions necessary for their life, and carries away the products of their handicraft, but which is at the same time the recipient of their refuse and 
sewage Blood is thus an epitome of the results of the metabolic exchange between the organs and tissues. It contains within itself representatives of all the soluble constituents which play a part in the drama of cell life. If any substance is being produced in excess it will be found in the blood; if anything is in defect it is the blood which will show it.

Not only is the blood the great medium of exchange : it is also in a sense an organ which has had entrusted to it one of the most important of all functions in the community of cells which we call the body-that, namely, of defence. As pathologists penetrate more deeply into an understanding of the means by which we are protected from disease, these defensive functions of the blood assume an ever-increasing importance, and the most promising, though the most complicated, chapter in modern bacteriology is that which deals with the antitoxic and bactericidal properties of the blood.

Add to all this the comparative accessibility of the blood and the ease with which many of its changes can be studied, even in the living subject, and one does not wonder that 'hæmatology' has assumed such a large place in latter-day medicine.

We have spoken of the blood as a fluid medium of exchange, but that is only one aspect of it. In virtue of the fact that it contains living cells, the blood is also to be regarded as a tissue. Even here it is unique, for the blood is a peripatetic tissue free from nervous control. If in its capacity as a fluid it is to be regarded as a mirror of metabolism, so in its quality as a tissue the blood may be considered as a reflection of the mature 
red bone marrow. Is the marrow in defect? Then the cells of the blood are also in defect. Is the marrow diseased? Do its cellular constituents no longer preserve their due relative proportion to one another? Then the microscopic picture of the blood faithfully mirrors such disease and such alterations. It is becoming probable, indeed, that the blood is never itself the seat of a primary pathological process, but simply exhibits the consequences of disease in the marrow or elsewhere.

We must now turn to a closer study of the properties of the blood as outlined above, and we shall begin by looking at it as a tissue containing living cells.

Celulular Constituents of the Blood.

The cells which constitute the population of the bloodstream are of three kinds : the red cells, the white cells, and the blood platelets. We shall endeavour to trace the origin, life-history, and fate of these separately.

The red cells in the adult-with their origin in the foetus we are not concerned-arise in the red marrow of the bones. They are produced from mother cells which are at first colourless, but in which hæmoglobin gets deposited, and at first, like all cells, they contain a nucleus. How the nucleus is got rid of - whether by extrusion (as is most probable) or by absorption-has been much discussed, but is a subject of little practical interest. At any rate, by the time they reach the general circulation they are non-nucleated, and for that reason are by some denied the title of 'cells' at all. Everything in them, indeed, seems to have been 
sacrificed to facilitate their function-that of taking up and giving off oxygen. Their shape, for instance-that of a biconcave disc-is such as to present the largest possible surface compatible with their free movement in the blood-stream. Collectively, therefore, they offer in the lungs and in the tissues a large area over which gaseous exchange can take place-an area which has been not inaptly termed the 'internal respiratory surface.'* Further, they are enclosed in a smooth membrane of great elasticity, which enables them easily to wriggle their way through the most tortuous capillary channels. This remarkable elasticity is a sign of health in the corpuscle, and is lost in many diseases of the blood in which the disc form gives place to various irregularities of shape (poikilocytosis). Each corpuscle is stuffed full of hæmoglobin, but the exact mode in which this is disposed-whether it is partly in solution in the corpuscle or loosely united in an amorphous form to a stroma of nucleo-protein-is still disputed. In addition, the red corpuscles contain a considerable amount of lecithin and cholesterin, which probably form a sort of waterproof coating to their walls. So long as this impermeable membrane is in a living condition it prevents the diffusion out of the contents of the corpuscles, but if it be killed, diffusion begins, because the plasma and the contents of the corpuscles are not iso-tonic. Chilling seems to kill the membrane and

* Assuming that the body contains $3 \frac{1}{2}$ litres of blood, with $5,000,000$ red cells in each cubic millimetre, then the 'internal respiratory surface' will amount to 2,500 square metres, or more than 1,000 times the external body surface (Buckmaster). 
allow the passage outwards of hæmoglobin, and this is probably how blood pigment gets into the plasma in cases of Raynaud's disease. Hæmolysins also affect in some way the permeability of the envelope without necessarily dissolving the corpuscle.

The red cells are also fairly rich in salts of potash, a recognition of which fact, indeed, has led some people to recommend the treatment of pernicious anæmia by the administration of potassium compounds.*

Practically, then, one may regard a red corpuscle as an elastic bag designed for the transportation of hæmoglobin, and whether it be really 'alive' or not is an academic question still open to discussion.

The red cells make up by far the larger proportion of the population of the blood-stream, amounting on an average to $5,000,000$ per cubic millimetre of blood. In women, and in the earlier years of life in both sexes, the number is somewhat below this. On the other hand, in some 'full-blooded' individuals higher counts may be obtained. The actual number of red cells and the amount of hæmoglobin in the blood apparently depend, to a great extent, on the degree of muscular activity of the body. In other words, the number of oxygen-carriers is in proportion to the amount of oxygen needed. The chief physiological condition which influences the number of the corpuscles, however, is altitude, for numerous observations have shown that with increasing elevation above the sea-level the number of the red cells is augmented, every 330 feet ascended causing an increase of about 100,000 per cubic millimetre. The cause of * Rumpf, Berlin. Klin.Woch., 1901, xxxviii. 477. 
this increase, attempts to arrive at an explanation of which have led to much controversy, cannot be discussed here, * but it may be said in brief that, whilst in part the increase is apparent only, and due to an altered distribution of the blood which is driven out of the abdominal organs by the deeper respiration which life at high altitudes entails, and also, perhaps, to a concentration of it from increased cutaneous evaporation, yet most observers admit that in part the increase is real and due to a greater formation of red cells. The natural teleological explanation of such increased formation is, of course, that it is an attempt to compensate for the greater difficulty of oxygenating the blood experienced at high elevations, more corpuscles being exposed to the air to make up for less oxygen being taken up by each individually. At all events, whatever the real explanation is, many of the valuable therapeutic effects of residence at high altitudes have been attributed to this increased formation of blood. Unfortunately, however, the number is soon reduced on return to lower levels.

A pathological increase in the number of red cells is not common, and may be apparent only-the result of stagnation of blood in the capillaries and its consequent inspissation. On the other hand, all cases are not to be so explained, and in the form of polycythæmia associated with splenic enlargement the evidence points rather to an increased formation of red cells. It is interesting to note that there would seem to be a limit to the extent

* For a full discussion of the subject, see Pacht, 'Ueber die Veranderungen des Blutes im Hochgebirge,' St. Petersburg Med. Woch., 1901, xxvi. 543. 
to which the red cells can be augmented. Normally the corpuscles make up about half the volume of the blood; if, then, their number were doubled, the blood would become practically solid. For this reason it is difficult to see how clinical estimations of $10,000,000 \mathrm{red}$ cells per cubic millimetre and upwards, such as are sometimes recorded, can be really correct.

Ample provision has been made, in adult life at any rate, to meet the demand for an increased supply of red corpuscles which any abnormal destruction of them in the blood-stream entails; for the red marrow of the long bones, which under normal conditions is confined to their extremities, can, if necessary, encroach upon and displace the marrow fat until the whole interior of the bone becomes a manufactory of red corpuscles. The best example of such an extension of the blood-forming territory is seen in pernicious anæmia, in which the whole of the marrow of the long bones becomes red. In young children such an extension is impossible, for the whole of their marrow is red already. Perhaps that is why young children stand loss of blood badly. On the other hand, it would seem that sometimes the red marrow is congenitally deficient or may disappear, in which case a great diminution of red cells in the blood results.*

The function of the red cells, as we have seen, is essentially a respiratory one. They carry oxygen from the lungs to the tissues, and help in conveying back carbonic acid from the tissues to the lungs. This they are able to do in virtue of the fact that they contain

* For a report of such a case, see Muir, Brit. Med. Journ., 1900, ii. 911. 
hæmoglobin, to a consideration of which remarkable substance we must now turn.

Hæmoglobin is in many ways a unique compound. It has the honour of possessing the largest molecule in the body, and of being the only body protein which can be easily obtained in a crystalline form. It consists of an iron-containing pigment (hæmatin) united to a histon termed 'globin.' It is to the fact that it contains iron that it owes its power of taking up oxygen; the protein part of the compound merely serves the humble function of acting as a sort of lifebuoy to the heavy iron-containing part of the molecule, and floating it along in the bloodstream. Oxygen is, unfortunately, not the only gas with which hæmoglobin is ready to enter into partnership. It has an inconvenient affinity for carbonic oxide, nitric oxide, and other gases, and when it is united to them its proper respiratory function is at an end. Hence a patient poisoned by carbonic oxide really dies from sheer inability to get oxygen conveyed from his lungs to his tissues. Oxygen inhalation, which increases the amount of oxygen dissolved in the plasma as opposed to that in the corpuscles, may tide over the difficulty until the gradual dissolution of the unnatural partnership has taken place.

That hæmoglobin is formed like the corpuscles in the red marrow is probable, but not proven. It seems to be deposited in the cells whilst they are still in their nucleated condition, but by what intricate chemical processes its complex molecule is built up is still a secret. This, however, we do know-that hæmoglobin is only built up rather slowly, and that it takes some time, after 
a hæmorrhage, for the new corpuscles to be loaded up with it, so that one finds that the percentage of hæmoglobin in the blood remains low for a considerable time after the red cells have reached their normal number. Long before hæmoglobin was known to contain iron, the power of the latter metal as a remedy in some forms of anæmia was well known to physicians; but the natural inference that such forms of anæmia are due to a deficient supply of iron in the food is not necessarily correct. It would rather seem as if iron, arsenic, and some other metals, have a direct power of stimulating the bone marrow* to increased functional activity.

Hæmoglobin is the mother of pigments in the body. Bile pigment is its direct descendant, and so also is the closely allied or iron-free pigment hæmatoidin, which is met with at the site of old hæmorrhages, such as apoplectic cysts.

Hæmatoporphyrin is another iron-free derivative of hæmoglobin, which is normally produced from the latter in the body in small quantities. In patients who have been taking sulphonal for a long time it is apt to be produced in much greater amount, and gives to the urine a deep port-wine colour, which is always a sign of danger.

Hæmin, on the other hand, is a purely artificial derivative of hæmoglobin never met with in the body, but of great interest and importance as a test for blood in medico-legal cases.

Methæmoglobin is met with in the urine in small * See Stockman, Brit. Med. Journ., 1893, i. 881. 
amounts in the rare and interesting disease methæmoglobinuria. It probably owes its production to the action of the acids of the urine on hæmoglobin. It is also produced from hæmoglobin in poisoning with chlorate of potash and antifebrin.

The duration of life of a red corpuscle is a point upon which, unfortunately, we have no information, for one cannot earmark one and trace its development, as naturalists have done for fish, by passing a dated metal plate through a fin. Transfusion experiments indicate -though rather doubtfully - that the average length of life is about three to four weeks. At all events, although all the corpuscles in any given drop of blood appear exactly alike, they must really be of different ages, and presumably therefore of different degrees of vitality. In accordance with this, one finds a great variation in the resistance offered by different corpuscles to disintegrating agencies, such as may be active in disease.

The ultimate fate of the red corpuscle is to be broken down in the portal system, and got rid of in the form of bile.* The spleen also seems to take a share in removing the corpuscular débris from the blood (vide infra). Whether a corpuscle is only destroyed when it is old and effete, or whether some 'massacre of the innocents' also goes on, it is impossible to say with any assurance.

It would seem that the liver, spleen, and marrow can retain the broken-down pigments of about 87 c.c. (3 ounces) of blood, but not more; and should the destruction of blood in the portal area be greatly increased,

* See Hunter, 'Pernicious Anæmia,' and Heinz, Beitr. z. Path. Anat. u. Allgem. Path., 1901, хxix. 299. 
as it may be when various pathological agents are at work, so much solid bile matter is formed that the resulting viscidity of the bile may block the passages, and hæmatogenous jaundice result (see p. 283).

The destruction of hæmoglobin would appear to take place to some extent independently of the red corpuscles as a whole. It has been found, for example, that the amount of it falls by about 7 per cent. during the day, as a result, presumably, of the wear and tear of life, and rises about the same amount during the night.'*

In persons who work by night this alternation is reversed, whilst exercise increases the daily fall. In these observations the number of corpuscles was not affected; the variation is in the 'worth' of each cell. This helps to explain the undoubted aid which rest in bed affords in the building-up of blood in anæmic subjects.

White Cells.-Ever since the publication of Virchow's 'Cellular Pathology,' the white cells, which make up the second great tribe in the population of the blood-stream, have been objects of the greatest interest to pathologists, and in recent years have had devoted to them a greater amount of research and a larger literature than any other single set of cells in the body. Unfortunately, however, many important points as to their origin and life-history are still shrouded in obscurity. Unlike the red corpuscles, the white cells are not all of one sort. They differ in size, in the character of their nuclei, in the staining reactions of their protoplasm, and in the presence or absence of granules in the cell body, and * Edgecombe, Brit. Med. Journ., 1898, i. 1650. 
no doubt these morphological differences must mean corresponding differences in function. As regards the mutual relations of the different varieties of white cell, investigators are at present divided into two camps. On the one hand are those who assert that they are all derived from a single type of cell, and that the nongranular can develop into the granular forms; on the other hand are those who maintain that, as regards the non-granular and the granular cells, at all events, no relationship exists, and that the one never changes into the other. Into the merits of the controversy one cannot enter here, but it is possible that, as in so many cases, truth lies in a compromise between the two views, and that whilst, if one goes far enough back, the two sets of cells will be found to have a common origin, yet once they have attained their distinctive features, and are free in the blood-stream, no further transition occurs.

The varieties of white cell in normal blood may be grouped as follows:

1. Non-granular :

(a) Lymphocytes (large and small), 23 per cent.

(b) Large mononuclears, 2 per cent.

2. Granular :

(a) Polymorphonuclear, with abundant neutrophil granulations, 70 per cent.

(b) Transitionals, with very few neutrophil granulations, 1 per cent.

(c) Eosinophils, 3 per cent.

(d) Basophils, 0.5 per cent.

The morphological details exhibited by these different 
varieties need not be described here, as they will be found in any text-book, or, better still, can be learnt from a personal study of stained films. We may deal, however, with their place of origin and their function.

White cells are the special product of two tissues in the body-(1) the red marrow of the bones, (2) the adenoid tissue.

The red marrow is confined within the narrow limits of the short bones, the ribs, and the ends of the long bones. Adenoid tissue, on the other hand, is diffused throughout the body, existing partly in substantial masses, such as the lymph glands, the thymus, the tonsils, Peyer's patches in the intestine, and the Malpighian bodies of the spleen, and partly in smaller conglomerations to be found more or less in every tissue and organ, probably including the bone marrow. It is probable that the marrow is the sole seat of origin of the granular cells, and that the adenoid tissue is the chief breeding-ground of lymphocytes. Whether or not the latter are also produced in the marrow, or, to put it otherwise, whether or not the marrow, like other tissues, also contains some adenoid tissue, is still disputed. In lymphatic leukæmia the red marrow becomes virtually converted into a mass of adenoid tissue, with the natural result that the granular cells disappear almost entirely from the blood. Whether such a replacement of the normal marrow is to be regarded as an invasion by lymphocytes or a mere hypertrophy of already existing adenoid tissue depends upon the view one takes as to whether or not lymphocytes are a natural product of the marrow. 
The mother cells of the granular leucocytes in the marrow are large clear cells with a single nucleus ('lymphoid' cells). By the deposition of granules in their protoplasm these become converted into granular myelocytes in which the nucleus is still single, and these are the cells so largely present in the blood in myelogenous leukæmia. The nucleus subsequently becomes contorted or apparently subdivided when the cell takes rank as a polynuclear leucocyte. It is believed by some that the so-called 'large lymphocytes' met with in the blood in the acuter forms of lymphatic leukæmia are identical with the original 'lymphoid' cells. Some (e.g., Wolff) go so far as to regard the lymphoid cell as the original parent from which all the cells of the blood are derived, according to the following scheme:

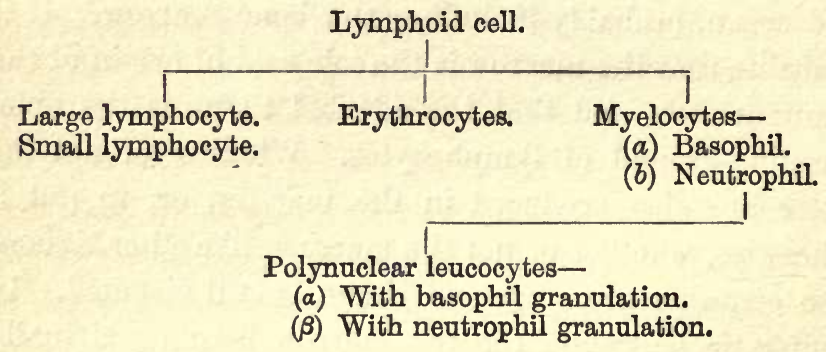

In process of development, according to this view, a gradual differentiation of function takes place on the part of the blood-forming organs, in consequence of which the lymphoid cells of the marrow confine themselves to the production of granular cells, whilst those of the adenoid tissue become exclusively concerned in the production of non-granular cells (lymphocytes). The specialization, however, is never so complete but 
that, when a demand for a greater number of cells of one type occurs, the lymphoid cells in any blood-forming organ are able to produce that type.

The place of origin of the large mononuclears and of the transitional cells derived from them is uncertain, but it is probably in the bone marrow, though in part also they may come from the lymph glands and the spleen.

Various origins have likewise been described for the eosinophils, but they, too, seem to arise from the eosinophil myelocytes of the marrow.

The mast cells or basophils are probably also derived from the bone marrow, and their number in the blood is therefore increased as a result of the proliferation of the marrow in leukæmia.

It will thus be seen that the marrow is by far the most important seat of blood formation, for not only is it the sole producer of red corpuscles, but it also gives origin to all the granular leucocytes, to the large mononuclears, and probably also to some extent to lymphocytes, whilst adenoid tissue can give rise to lymphocytes only.

The functions of the different forms of white corpuscle have been as much disputed as their genesis. Metchnikoff's discovery of phagocytosis at once raised the leucocytes to a position of great esteem as protectors of the body against disease. They were regarded at first as 'soldiers' ready to rush out and destroy any invading micro-organisms, and it became the fashion to speak of them as if almost endowed with a sentient intelligence and great discriminative powers. Further investigations tended to throw doubt on the ability of the leucocytcs 
actually to destroy living organisms, and they were degraded from the rank of 'soldiers' to that of a set of mere 'scavengers' or ' undertakers' who removed from the field of action the bodies of micro-organisms already killed by the blood or tissues. At the present time the very important part played by the leucocytes in the destruction of bacteria is generally admitted, though it is now recognized that many fixed cells of the body (e.g., endothelial cells and connective-tissue corpuscles) have a similar property. Nor are all forms of leucocytes to be regarded as phagocytic. The lymphocytes, the eosinophils, and the mast cells are not so endowed. In addition to these duties, it must be remembered that leucocytes produce ferments-e.g., fibrin ferment, and possibly fat-splitting and tryptic ferments as well. They also play an important part in the repair of the body after injuries.

The abundance of lymphocytes in the neighbourhood of the alimentary canal would lead one to suppose that they may have some part to play in nutrition, possibly in the absorption of proteins or in the carriage of fat or glycogen. The greater number of lymphocytes in the blood during the earliest years of life would also seem to indicate that they may have nutritive functions. On the other hand, they are increased like other white cells in the neighbourhood of infections, and there is reason to believe that in the lymph glands they inhibit the growth of bacteria, although incapable of 'englobing' them. It is thus possible that the lymphocytes aid in the protection of the body.

The functions of the eosinophils are even less under- 
stood. It cannot be doubted that the coarse granules which they contain must be intimately concerned in some way with the functional activity of the cell, and if we knew the nature of these granules we might be nearer to a comprehension of the work of the cell as a whole. But, unfortunately, we do not know the nature of the granules. They have been variously supposed* to consist of (1) fat, (2) protein, (3) hæmoglobin or a derivative of it, (4) nucleo-albumin, (5) defensive secretory granules. Some people have asserted that the granules are rich in phosphorus and iron; others have denied that they can find any evidence of iron in them at all. Nor is any light thrown upon their functions by the fact that their number in the blood is increased in such diverse conditions as asthma, some skin diseases, and helminthiasis. If we know little of the eosinophils, we know nothing of the basophils at all. They are so extremely scanty in normal blood that one cannot attribute to them any important function.

The total number of white cells in the adult blood varies between 10,000 and 7,000 per cubic millimetre, and is by no means the same in every one.

Assuming the total number of leucocytes in a cubic millimetre of blood to be 7,500, the proportion of this made up by the different varieties is as follows:

$\begin{array}{lrrrr}\text { Polymorphonuclears } & \ldots & \ldots & 5,000 \\ \text { Lymphocytes r.. } & \ldots & \ldots & 2,000 \\ \text { Large mononuclears } & \ldots & \ldots & 350 \\ \text { Eosinophils } & \ldots & \ldots & \ldots & 150\end{array}$

* See Howard and Perkins, Johns Hopkins Hospital Reports, 1902, x. 249. 
It has been calculated that there are about 25,000 million leucocytes in the whole blood, which if gathered together would make up a solid organ about as large as the thyroid.*

At birth the total leucocytes number 17,000 per cubic millimetre, but have fallen by the end of a year to 14,000 , and by the end of three years have reached the adult standard. The excess in the earlier years is entirely due to an increased number of lymphocytes.

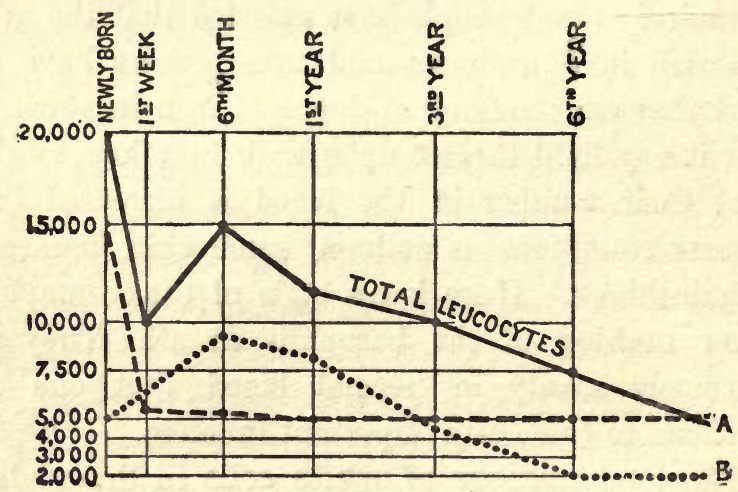

Fig. 1.-Absolute Number of Leucocytes Per Cubio Millimerere at Different Ages.

A, Polynuclears; B, Lymphocytes.

The relative numbers of the different forms present at different ages will be found in graphic form in Figs. 1 and 2.

A distinct increase in the number of leucocytes can usually be observed a few hours after a meal, which is sometimes due to an increase in the polynuclear cells, and at others to an augmentation of uninuclears. The

* Muir calculates that all the white cells in the blood put together would not suffice to form more than an ounce of pus. 
mechanism and meaning of this physiological leucocytosis is obscure, and it does not seem to be of much importance. Its occurrence must be borne in mind, however, when one is estimating the leucocytes in disease, and the time of the blood examination chosen so as to avoid it.

The average duration of life of a leucocyte is quite unknown, but it is almost certainly much less than that of a red cell, and may not amount to more than a few

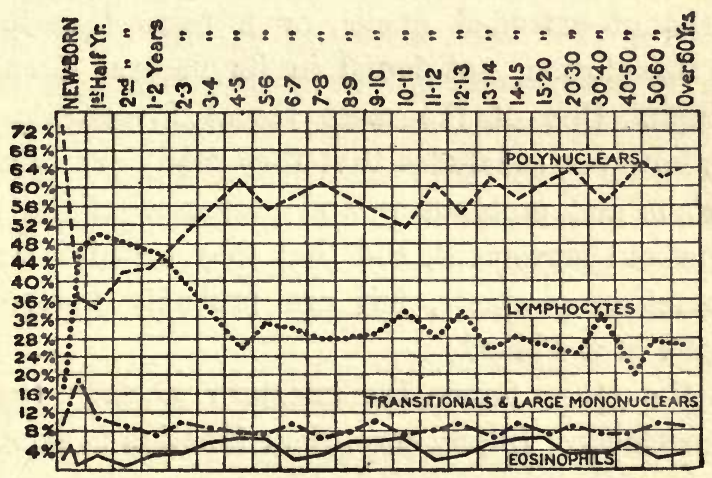

Fig. 2.-Differential Percentagn Counts throughout Life. (After Carstanjen.)

days. Hence any theory of immunity which is based upon the 'education' of individual leucocytes in dealing with bacteria must be regarded as very unlikely to be correct.

Leucocytes probably perish everywhere. We know, indeed, that many of them are destroyed under pathological conditions at the seat of infections, and subsequently are themselves 'englobed' by mononucleated phagocytes, thus falling victims to the same fate which 
they themselves inflict upon bacteria. That the spleen is largely concerned in their destruction under normal conditions, or, at all events, in the removal of their débris from the blood, there is little reason to doubt (vide infra).

The Blood Platelets.-There are some who would deny to the platelets the right to be regarded as cellular constituents of the living blood. They have been variously supposed to be simply 'chips' off leucocytes, portions of extruded nuclei, or a mere 'precipitate' from the plasma, not found in its natural circulating condition. One of the most recent investigators* of them, however, concludes that they really are cells with a nucleus and protoplasm, and possessed of the power of amoeboid movement, and that they certainly are not degeneration products, but are probably independent elements of the blood.

On the other hand, Buckmaster + regards them as pure artefacts. In any case, their function is as obscure as their origin, although it has been suggested that they are in some way concerned in the process of coagulation, and their number in the blood appears to be increased in those diseases in which there is a marked tendency to clotting. So far no one has attributed to them any definite rôle in pathology, and they cannot be considered of much interest to the clinician.

* Deetjen, Virchow's Archiv, 1901, clxiv. 239.

+ 'The Morphology of Normal and Pathological Blood' (John Murray 1906), p. 132. 


\section{The Blood Plasma.}

The plasma, or fluid in which the corpuscles float, consists essentially of certain proteins dissolved in a solution of sodium salts. It contains in all about 10 per cent. of solid matter, of which 8 per cent. is made up of proteins. These proteins belong partly to the albumin and partly to the globulin group. In the former are serum albumin, in the latter serum globulin and fibrinogen. Whilst one speaks of them in this collective fashion, there can be no doubt that there are really several albumins and several globulins present. The proportion of serum albumin to serum globulin is in man about $4 \frac{1}{2}$ to 3 , but the exact proportion varies considerably in different animals. In the cold-blooded animals, for instance, it is chiefly globulins which are present. Of the part played by the albumins and globulins respectively we know nothing, but one cannot believe that it is a matter of indifference which predominates. Bunge has suggested that globulin is the form in which protein circulates in the body for nutritive purposes, whilst the albumin is the more constant basis of the plasma; but this has not yet been proven. Nor do we know whence the proteins are derived. They can hardly be built up directly from the protein of the food, for they are apparently regenerated even during starvation. It has been suggested that they are 'secreted' by the blood corpuscles, but it is quite as likely that fixed cells in the body are able to help in their production. Modern theories of immunity compel us to believe that the blood may contain bodies, pre- 
sumably of a protein nature, thrown off by the fixed cells, which act as protectives against infection, and, reasoning from analogy, it seems not unlikely that the normal proteins of the blood may have a similar origin.

The salts of the plasma are chiefly the chloride, carbonate and phosphate of sodium, the two latter being responsible for the reaction of the blood, a matter which must now be considered more closely.

From a strictly chemical point of view the blood is really an acid fluid, for the phosphates and bicarbonates which it contains are really acid salts, inasmuch as they still contain hydrogen atoms replaceable by a base.* The blood is generally regarded as alkaline, however, because its chief salts are alkaline to litmus, and it will be convenient still to speak of it as alkaline. Quantitatively considered, the alkalinity of the whole blood is equal to 300 milligrammes of $\mathrm{NaOH}$ per 100 c.c., and this degree of alkalinity is maintained with extraordinary constancy, although a slight rise in it can be detected after meals. In disease the alkalinity is probably never increased, but it is occasionally diminished when large quantities of acid are entering the circulation-e.g., in diabetic coma, and also in anæmia. The mechanism by which this constancy of reaction is maintained is interesting. Alkaline compounds entering the blood are apparently partly excreted by the kidneys, carrying with them a certain amount of water, so that they act as diuretics, and partly turned out of the blood-stream into

* It is interesting to note that the blood is really neutral by physical methods of investigation, 
the lymph spaces of the tissues.* Free acids or acid salts are neutralized partly by the alkaline sodium phosphate $\left(\mathrm{Na}_{2} \mathrm{HPO}_{4}\right)$ of the blood, which they convert into sodium acid phosphate $\left(\mathrm{NaH}_{2} \mathrm{PO}_{4}\right)$, and which is voided in the urine, and partly by the sodium carbonate of the plasma with the liberation of $\mathrm{CO}_{2}$, which is eliminated by the lungs. If there be more acid than can be dealt with in this way, the excess appears to lay hold of ammonium carbonate (probably in the liver), diverting it from its usual fate of being turned into urea, and converting it into an ammonium compound of the corresponding acid which is excreted by the kidney. A surplus of ammonium salts in the urine is therefore an indication of the entry into the circulation of acid compounds, one of the best examples of which is to be found in diabetic coma, in which aceto-acetic acid is excreted in such combination in enormous quantities. So perfect is this mechanism that the reaction of the blood remains largely independent of the amount of acid entering the circulation. Thus, even a dose of 2 drachms of the official $\mathrm{HCl}$ has no effect on the reaction of the blood. On the other hand, an ounce of dilute lactic acid when given in one day reduced the alkalinity by one-fourth, whilst 2 drachms of tartaric acid reduced it one-sixth (Freudberg). +

The relative proportion of phosphoric and carbonic acids in the blood depends very much upon the composition of the diet. The chief mineral constituents of

* Hence it is that if bicarbonate of soda be given in large quantity for some time-e.g., in diabetes-dropsy is apt to result.

+ Virchow's Archiv, 1891, cxxv. 566. 
animal food are phosphates; those of vegetable foods, carbonates. The blood of herbivorous animals is therefore rich in the latter, that of carnivora in the former, and the acids formed in the tissues will form bicarbonates in the blood of the herbivora, and acid phosphates in that of carnivora. Now, acid phosphates hold earthy phosphates in solution, and bicarbonates dissolve earthy carbonates. Hence the urine of carnivorous animals is rich in pnosphates of lime and magnesia, that of the herbivora in calcium and magnesium carbonate.

The molecular concentration of the blood is isotonic with a 0.9 per cent. solution of common salt, and it tends to maintain this degree of concentration with great constancy. It takes a very large loss of fluid from the body to render the blood appreciably more viscid, but this does sometimes occur, as, for instance, in the case of choleraic diarrhœa.

In addition to its saline ingredients, the plasma also contains, as one would expect, traces of various soluble substances on their way to and from the cells. Chief amongst these are urea, sugar, and fat, but many other substances are represented in traces. The exact amount of these ingredients must naturally vary greatly from time to time. Sugar, for instance, normally amounts to about 1 part per 1,000 , but may rise above this after an excessive consumption of carbohydrates. Fat is usually present to the extent of 0.75 per cent., but after a meal rich in fat this amount may be greatly exceeded. Where the body fat is being utilized as food also, the amount in the blood on its way to be consumed may rise considerably. Thus, it may be very high in cases of œesophageal 
obstruction, in which no food can reach the stomach,* and in diabetic coma it may be present in such quantity that the blood serum becomes milky.

The most striking thing about the composition of the plasma is its great constancy. The blood maintains in a wonderful way a uniform standard of composition. This it does by means of two mechanisms-viz., excretion through the kidney and excretion into the lymph spaces of the tissues. Hæmorrhage, for instance, does not concentrate the blood, for fluid is instantly withdrawn from the tissues to make good the loss. Nor is the blood necessarily more watery in conditions of dropsy, for the excess of fluid is got rid of into the tissues. $t$

Injection of saline solution into a vein does not dilute it, for the excess is immediately excreted through the kidneys, and, above a certain point, into the tissues also. As a matter of fact, if $\frac{3}{4}$ litre of normal solution is injected into a vein, only a slight fall in the specific gravity of the blood is noticeable, and it only lasts for about half an hour (Schmaltz $\downarrow$ ).

In the same way it is impossible permanently to increase the proportion of any of the mineral constituents of the plasma, for the kidney immediately excretes any surplus.

The total amount of blood in the body is about onetwentieth of the body-weight, or on an average $3 \frac{1}{2}$ litres (about 6 pints). In health this amount is probably as

* Böninger, Zeit. f. Klın. Med., 1901, xlii. 65.

$\dagger$ Askanazy, Deut. Arch. f. Klin. Med., 1897, lix. 385; also Hammerschlag, Zeit. f. Klin. Med., 1892, xxi. 475.

$\ddagger$ Deut. Arch.f. Klin. Med., 1891, xlvii. 145. 
constant as the composition of the blood itself, variations depending only on variations in the capacity of the vascular system. In chlorosis the total volume of blood is increased, and the constant tension of the vessels is believed to be the cause of the vascular murmurs in that disease. In no form of anæmia is the total volume of the blood constantly diminished.*

Clotting.-The power of the blood to clot is one of its most convenient attributes. Were it not for this, we should all be liable to bleed to death from any trivial wound of a bloodvessel.

Much ingenious experiment has been expended in attempts to explain the true inwardness of clotting and what really happens when it takes place, but it cannot be said that we are even yet completely informed on all details. It is generally agreed, however, that clotting is due to the conversion of the soluble globulin called fibrinogen into insoluble fibrin, and that this change takes place under the influence of a ferment called thrombin, which, however, is not present in the living blood as such, but is liberated by the breaking down of white corpuscles, and possibly of platelets. Thrombin belongs, apparently, to the nucleo-protein class, and exists as a 'zymogen' (prothrombin) which only becomes active in the presence of soluble salts of lime.

It is difficult to say what the rate of clotting of blood outside the body is, as it varies greatly according to the method employed to determine it. It seems certain, however, that the rate is very variable, not only in

* See Lorrain Smith, Trans. of the Path. Soc. of London, 1900, li. part 311 . 
different individuals, but in the same individual at different times, and this must be borne in mind when attempts are made to estimate the coagulation time clinically.

To the question, Why does the blood not clot inside the living vessels? it may be replied that such an occurrence is apparently prevented (1) by the active movement of the blood, (2) by the absence of free fibrin ferment, (3) by an influence-not understood-exerted by the lining of the living and healthy vessel. It has recently been suggested that the absence of clotting in the living body is due to the constant neutralization of fibrin ferment (plasmase), produced by leucocyte disintegration by an antibody or thrombase.*

If these conditions are not fulfilled, clotting can and does occur. If the blood stagnates for a time, as it may do in the interior of a dilated heart, for example, clotting may occur; or if anything injures the leucocytes and causes them to break down, fibrin ferment is liberated, and clotting ensues. This has been taken advantage of in the treatment of aneurysm. By the introduction of a coil of wire into the sac, separation out of leucocytes and platelets is brought about and clotting is promoted. If, again, the wall of a vessel becomes diseased, it may lose its power of preventing clotting, and actually promote the process just as a foreign body does. Hence clotting is not infrequent in atheromatous vessels. The fact that the presence of calcium salts favours the coagulation of blood has been turned to therapeutic account. In patients who are the subject of jaundice the blood tends * Buckmaster, loc. cit., p. 217. 
to clot very slowly, and prior to operations in such cases surgeons often administer calcium chloride in full doses, with, it is stated, very satisfactory results. The same drug is also useful in preventing hæmorrhage in scurvy. Albumoses appear to have a power of inhibiting coagulation. In a fluid secreted by the mouth of the leech this is made use of to prevent clotting in the bites, for such fluid is found to contain an albumose, and it is so efficient in its action that serious hæmorrhage may take place from the bites of leeches applied medicinally. There is an impression amongst some clinical observers that the administration of ammonia salts also tends to lessen the coagulability of the blood, and such salts have been given in cases of threatened thrombosis. I am not aware, however, of any direct experimental evidence in support of such a belief. Gelatin, on the other hand, promotes coagulation, and has been largely used by subcutaneous injection to increase the clotting power of the blood in cases of aneurysm.

Clotting may be regarded as the death of the blood, for the serum which is squeezed out of the clot is, as compared with the plasma, de-vitalized. If injected into another animal, its constituents are broken down and excreted, the output of urea being raised. Thus serum can be regarded as a food. After the injection of plasma, on the other hand, no rise in nitrogenous output can be observed.

Serum contains all the sonstituents of plasma except fibrinogen, and in addition it holds in solution the products of disintegration of leucocytes; and amongst the bodies interesting to the pathologist which have been 
recognized in it are antitoxins, agglutinins, precipitins, ferments, opsonins, and cytotoxins. It would be transgressing on the domain of pure pathology to consider most of these in any detail, but a word may be said about precipitins, which are assuming some importance in legal medicine.

If some human ascitic fluid be injected into the peritoneal cavity of a rabbit, there develops in the blood serum of the latter a substance (precipitin) which causes a turbidity when added to diluted human blood, but which has no effect on the blood of other animals. The nature of the precipitin is unknown, nor do we know how it is that it causes a precipitate in human blood (possibly this is due to an agglutination of protein molecules), but it is obvious that we have here a specific test for human blood which is of great delicacy. The test has already been widely employed in forensic medicine in Germany, and has been the means of bringing about conviction in cases of suspected murder.

The Spleen.-The spleen is usually classed in textbooks of physiology amongst the ductless glands. If by a 'gland,' however, one means an organ with secretory functions, then the term is hardly applicable, for whatever its part in the economy of the body, the spleen certainly does not secrete. Indeed, physiology can tell us almost nothing definite about the spleen, except that it is not an organ which is essential to life, and that was already known more than a hundred years ago.* All other statements about this organ are more or less conjectural, and it is for this reason that the part it plays in pathology

* See the collected works of William Hewson, F.R.S. 
is so ill-understood, and that diseases of the spleen are the despair of the physician.

The spleen is often regarded as a blood-forming organ. In man, however, there is really no evidence that it can form red cells. Richly endowed as it is with adenoid tissue in the form of the Malpighian bodies, there is no doubt that it helps in the manufacture of lymphocytes, but that is the only blood-forming function which can be assigned to it. There is more reason for regarding it as playing a part in the destruction of the blood, but it is still open to question whether it does so actively or whether it merely removes from the blood-stream the débris or corpuscles which have been broken down elsewhere. It is uncertain, in other words, whether the spleen is an active agent in hæmolysis or whether it is only a blood-filter. Injection of poisons, such as chlorate of potash, which disintegrate the blood corpuscles, causes the spleen to enlarge, and the enlargement is in direct proportion to the amount of blood destruction.* Similarly, if bacteria or pigment particles be injected into the vessels they are found to accumulate in the meshes of the spleen. It would seem, therefore, as if the filter function of the organ can be definitely established, and it is believed that this explains its enlargement in such diseases as malaria and enteric fever, in which blood destruction is increased. On the other hand, there are difficulties in the way of this view. The spleen is not constantly enlarged in pernicious anæmia, and yet most pathologists are agreed that in that disease blood destruction is greatly increased. The subject is still further

* Jawein, Virchow's Archiv, 1900, clxi. 461. 


\section{BLOOD AND HAMOPOIETIC ORGANS 101}

complicated by the fact that splenic anæmia can be cured by the operation of splenectomy, which would appear to indicate that the spleen in that disease is playing an active rôle in the production of anæmia. The only conclusion which these considerations justify is that we are still much in the dark as to the part played by the spleen in hæmolysis, although the balance of evidence is in favour of the view that it serves at least as a filter in removing effete corpuscles from the bloind; whether or riot it can also give them the coup dẹ grare? In any case its duties cannot be very important, or they must te capalle of being performed vicariously by other organs, for removal of the spleen does not seem to lead to any impairment of health.* Even here, however, we want more light. What, for instance, would happen to a spleenless man if he took malaria or enteric fever?

A slight enlargement of the lymphatic glands has been noted after removal of the spleen, but neither constantly nor to any striking degree. Probably this is compensatory-an effort to replace the lost adenoid tissue. The blood shows at first an increase of lymphocytesmost likely as a consequence of the hypertrophy of the glands, and later on a considerable rise in eosinophils, the meaning of which is quite obscure. It cannot be said that these observations throw any great light on the functions of the organ.

As the spleen is practically a sponge filled with blood, its volume varies with fluctuations in the general bloodpressure. Such variations, however, are devoid of

* For the results of splenectomy in man, see Harris and Herzog, Annals of Surgery, 1901, xxxiv. 111. 
clinical significance. When the discharge of blood from the splenic vein is interfered with, the organ becomes passively overfilled. This is probably the reason for the enlargement of the spleen which occurs in cirrhosis of the liver. Oncometer tracings show that the spleen exhibits independent rhythmical contraction, apparently by means of the muscular tissue in its capsule and trabeculæ. In consequence of this it has been looked upon as encrowed with a propulsive power as regards the blogd in the portal circulation, and has even been spoken "of as the "portal heart." The thickening of the capsule and trabeculæ of the spleen, which undoubtedly occurs when the portal circulation is obstructed, has been regarded as evidence of an attempt on the part of the 'portal heart' to overcome the obstruction by hypertrophy.

The Thymus. - The only thing we know with certainty about the functions of the thymus is that, like adenoid tissue generally, it is a place where lymphocytes are born. Beard,* indeed, regards the thymus as the starting-point of all adenoid tissue in the body. In his view, lymphocytes are first formed by a transformation of the primitive epithelial cells of the embryonic thymus, and until the latter appears there are no white cells in the blood. Later on secondary depots or colonies of adenoid tissue are started in various parts of the body by lymphocytes which have emigrated from the thymus, and when these have been fairly established the thymus itself disappears. With its disappearance, however, as he justly remarks, adenoid tissue no more vanishes from * Lancet, 1899, i. 144. 
the body than the Anglo-Saxon race would disappear if the British isles became submerged. Most writers are agreed* that the thymus attains its maximum development relative to that of the body as a whole between the second and fourth years of life, and it is interesting to note that it is after this period that the lymphocytes of the blood undergo a diminution in number. It would appear as if more lymphocytes were wanted in the earlier years of life, and that the thymus existed in order to manufacture them; but why they are wanted we do not know. Excision of the gland throws little light on the matter, most experimenters having found after it a diminution of red cells and an increase of white. Nor do we even know whether the presence of the organ ir the first years of life is essential to existence or even to health. I know of only one case in which the thymus was absent in an infant, + and in that case the child lived until it was six months old, but as one kidney was absent also, this case is of little value as evidence.

Physiology and pathology are here alike at fault. Neither has succeeded in showing that the thymus is more than a mere mass of adenoid tissue.

The lymphatic glands are, like the thymus, important birthplaces of lymphocytes, and when they take on increased functional activity, as in lymphatic leukæmia, there ensues a great rise in the lymphocytic population of the blood-stream.

In addition to this they seem to help, at least, in the protection of the body against invasion by bacteria or

* Bonnet, Gaz. des Hôpitaux, 1899, lxxii. 1321.

$\uparrow$ Reported by Alfred Clark, Lancet, 1896, ii. 1077. 


\section{APPLIED PHYSIOLOGY}

their poisons. Placed, as they are, like sentinels at the points of convergence of the lymphatics, they entangle micro-organisms in their meshes and prevent their onward passage. That they are able directly to destroy these is unlikely, for the lymphocytes are not phagocytic, and it is well known to surgeons that organisms can lie latent in lymph glands for a long time and come to life and dangerous activity again if the gland be opened into. In the meantime, however, the growth of the germs has been restrained, probably by means of a chemical influence exerted by the cells of the gland.*

* See Manfredi, in Virchow's Archiv, 1899, clv. 335. 


\section{CHAPTER IV}

THE APPLIED PHYSIOLOGY OF THE HEART

\section{The Beat of the Heart.}

THE tendency of all recent physiological investigation has been to magnify the importance and independence of the heart muscle. It is now believed that the beat of the heart takes place independently of nerve influence, and as a consequence of the automatic contractility which the cardiac muscle possesses in virtue of its comparatively embryonic and undifferentiated form.* The beat or contraction starts, as might be expected, in that part of the heart wall which possesses these characteristics in the greatest degree-i.e., in the muscle at the mouths of the great veins. Thence the contraction is conducted from muscle cell to muscle cell, sweeping over the auricles and producing their systole, and is transmitted to the ventricles by means of the auriculo-ventricular bundle of fibres which crosses the auriculoventricular groove. $\dagger$

* This is sometimes spoken of as the 'myogenic' theory of the heart's action, as opposed to the 'neurogenic ' theory, which supposes the necessity of a local nerve apparatus to maintain the contractions of the heart.

$\dagger$ A full anatomical description of the auriculo-ventricular bundle in man will be found in a paper by Keith and Flack (Lancet, 
The force with which the fibres contract seems to depend largely upon the pressure in the interior of the heart, or, in other words, on the extent to which it is filled during diastole. If, for example, the heart ' misses a beat,' and in consequence of that the left ventricle becomes overfilled, the next systole is unusually powerful, and is felt as the 'thump' so often complained of by patients with palpitation.

Although, as has just been pointed out, the normal contraction starts at the venous ostia, yet it must be remembered that the whole of the heart muscle possesses the power of originating stimuli, and a contraction set up in the ventricles will pass back to the auricles. In cases of disease this abnormal mode of cardiac contraction sometimes occurs. The capacity of transmitting a wave of contraction is spoken of by physiologists as the conductivity of the heart muscle, and we shall see later on that alterations in conductivity explain many of the alterations in cardiac rhythm which can be observed in disease. The ventricles respond to the contraction wave by a simultaneous and co-ordinated shortening of all their fibres-not by a peristaltic wave-by which the ventricular systole is produced. These fibres are partly circular and partly longitudinal in arrangement. The

1906, ii. 359). The muscle fibres which make up its ramifications are of the Purkinje type, and possess a lower degree of conductivity than the more highly developed fibres of the heart wall. If the bundle is destroyed by disease, the propagation of the wave of contraction is prevented, and a condition of 'heart-block' results. In such a case the ventricles take on an independent action, and contract rhythmically at a rate of 28 to 36 beats per minute. 
contraction of the circular fibres results in considerable diminution of the diameter of the base of the heart (the clinical importance of which we shall see immediately), whilst the total length of the ventricles is not increased, owing to the fact that the transverse thickening of the circular fibres of the wall is neutralized by the contraction of the opposing longitudinal fibres.*

The result is that the walls of the heart approach nearer to the septum, and in consequence the blood is, as it were, 'wrung out' into the aorta and pulmonary artery. It must not be supposed, however, that the expulsion of the contained blood takes place the moment the ventricular wall enters into contraction. During an appreciable interval - 'the presphygmic interval'which varies in the human heart from seven to tenhundredths of a second, the muscle of the wall is engaged in compressing the contained blood in order to get up a pressure sufficient to overcome the resistance in the aorta and pulmonary artery, and it is only when a sufficient degree of pressure has been attained that the semilunar valves fly open and the blood is expelled. Thus one might divide the period of systole into (1) a compression time, during which pressure is brought to bear on the contained blood, and (2) an expression time, which is occupied by the expulsion of the blood into the aorta and pulmonary artery. $t$ It is during the

* For a very interesting description of the functional anatomy of the musculature of the heart the reader should consult a paper by Dr. Arthur Keith in the Journal of Anatomy and Physiology, 1907, vol. xlii.

† See Martius: 'Der Herzstoss des Gesunden und Kranken Menschen.' Volkmann's Samml. Klin. Vort. 1894, Inn. Med., No. 34, p. 171. 
former of these periods that the apex-beat is produced. The greater the resistance offered to the escape of blood from the ventricles, the more prolonged is the compression period required, and the longer, therefore, the systole.* Hence the slow systole of aortic stenosis and high arterial pressure. It is now generally believed that the systole never succeeds in expelling the whole of the blood contained in the ventricles; a fraction is always left behind. If the systole is feeble, this fraction is increased, and may be so great as to retard the whole current of blood through the heart, in consequence of which all the signs of back pressure may result even in the absence of any valvular defect. To this condition the term 'systole catalectic' is sometimes applied. $\dagger$

After their contraction, the walls of the ventricles rebound in diastole. Whether this is due merely to an elastic recoil of the compressed columnæ carneæ and musculi papillares, or whether there is an 'active' retraction of the muscle fibres, is disputed; but, at all events, the force of the recoil is sufficient to produce a degree of negative pressure in the ventricular cavities. It is still denied by some physiologists that this is of sufficient degree to aid in the filling of the heart, but it seems to play a larger part in some conditions of disease. One cannot explain the diastolic murmur met with in some cases of mitral stenosis, for instance, unless on the

* Even when the aortic pressure is high, the compression time does not seem to be much prolonged so long as the heart muscle is healthy. As Hill points out, this is equivalent to saying that the heart can meet great demands on its powers without any appreciable loss of time (Schäfer's 'Physiology,' ii. 20).

$\dagger$ Graham Steell. 
assumption that there is a considerable degree of suction exerted by the ventricles during diastole.*

If the ventricle is unable to empty itself completely at each systole, any negative suction which it can exert is, of course, abolished. This may be an additional reason for the laboured action of a dilated heart. The part played by the negative pressure in the mediastinum in promoting expansion of the heart during diastole is also of considerable importance, and will be considered in another chapter.

\section{The Apex-Beat.}

The apex-beat is normally felt in the fifth intercostal space at a point (in the adult) about $4 \frac{1}{2}$ inches from the mid-sternal line. The apex-beat is not felt with equal ease, however, at all periods of life. Up to the age of twenty or thereabouts it is always palpable in normal conditions, even when the subject lies on his back; but beyond that age it can only be made out at all easily in about half the individuals examined. The reason for this is that the ease with which the apex-beat can be determined depends upon the extent to which the heart and chest wall are in contact-i.e., upon the size of the heart relative to that of the thoracic cavity. Now, the ratio of the heart to the chest is greatest in young subjects, hence the ease with which the apex-beat can be made out in such cases. For this reason, too,

* Stacey Wilson, "The Diastolic Expansion Movement of the Ventricles as a Factor in Compensation for Disease of the Mitral Valve,' Brit. Med. Journ., 1900, ii. 895. 
an hypertrophied heart always displays a strong apexbeat.

The exact way in which the apex-beat is produced has been much discussed, but everyone is agreed that it does not result from the heart knocking up against the chest wall as the fingers knock on a door, for the simple reason that the heart and chest wall are always in contact. We have seen that the apex-beat is synchronous with the ' compression' period of the systole, and it is really due to the hardening and change of shape of the heart as it contracts upon its contained blood, but before the expulsion of the latter begins. Hence one finds that the apex-beat always precedes the thrill felt over the aortic orifice in aortic stenosis, for the thrill occurs as the blood escapes into the aorta from the ventricles, and thus the apex-beat really occurs before the diminution in size of the ventricle begins, and the old difficulty of explaining how the beat could be felt though the ventricle was getting smaller is seen not to exist. An hypertrophied heart produces a forcible apex-beat, but in dilatation the beat, though diffusely felt, owing to the large surface of heart in contact with the chest wall, is less forcible, because the left ventricle does not completely empty itself, and so the diminution of the volume of the heart during the 'expulsion time' is not so pronounced. There is, then, no necessary relation between the ease with which the apex-beat can be appreciated and the force of the heart; the latter can be judged from the pulse alone.

It should be noted that when the right ventricle is so much dilated as to bulge into the epigastrium the im- 
pulse which it communicates is not synchronous with the apex-beat, but is diastolic in time, and really due to the filling of the chamber and not to its contraction. During systole in such a case the epigastrium recedes.

Tracings of the apex-beat will be found in any work on physiology, but clinically they are of little interest.

\section{The Pericardium.}

The pericardium corresponds to the tunica adventitia of the arteries, and is to some extent a protection to the heart. It has been argued that it tends to prevent dilatation of the heart under sudden strain (acting like the outer case of a football or the netting round an indiarubber spray bag), but this can only be true of extreme emergencies.* Certainly a sudden paralytic dilatation of the heart sufficient to cause its arrest does not seem to be prevented by the pericardium. Nor does free movement between the surface of the heart and the inner aspect of the pericardium appear to be essential to the unhampered action of the former, for clinical observation shows that, provided the heart muscle has escaped damage in the process which leads to the pericardial adhesion, little, if any, hypertrophy of the heart ensues. As the space inside the pericardium is strictly limited, it seems not unlikely that great enlargement of one side of the heart must interfere with the action, and especially with the filling, of the other. Thus, for example, the

* See Theodore Fisher, 'Dilatation of the Heart,' Lancet, 1902, i. 1594. 
great overdistension of the right heart in asphyxia may help to explain the emptiness of the left.

There is probably but little room for lateral movement of the heart inside the pericardium. The change in position of the apex-beat when an individual moves over on to his side-a change which may amount to some inches-is believed by physiologists to be due to the heart rolling over inside the pericardium under the action of gravity, so that a different part of its wall comes into contact with the chest. It is doubtful, however, if this can be regarded as a complete explanation, for 'fixation of the apex-beat' is believed by many good clinical observers only to occur when the pericardium itself is adherent to the chest wall, but not when the heart and pericardium are alone adherent to one another,

\section{The Valvular Mechanism of the Heart.}

If the blood contained in the heart is always to be driven on in a definite direction, it is obvious that the orifices between its different chambers and at its entrances and exits must be provided with valves. The tendency amongst clinicians in the past-a tendency due partly to the introduction of the stethoscope as an instrument of observation and partly to an almost exclusive study of the naked-eye pathology of the heart-has been to attach an undue importance to the membranous valves as guardians of the orifices. At all events, this is indisputably true as regards the auriculo-ventricular valves. It is doubtful, as MacAlister has said, ${ }^{*}$ if these 
would be alone sufficient to prevent the reflux of blood into the auricles in two cases out of three were it not that, as has been already stated, the diameter of the base of the heart undergoes such a marked diminution during systole in consequence of the contraction of the circular muscle of the ventricular wall. In other words, the muscular contraction of the ventricle is quite as important in preventing a backward flow of blood as is an intact condition of the auriculo-ventricular valves. One need not wonder, then, that mitral incompetence so often results simply from disease of the muscular wall. The closure of the aortic and pulmonary orifices, on the other hand, is entirely brought about by the semilunar valves, but it is well known that even extreme cardiac dilatation does not lead to any regurgitation at these situations. Recent investigations by Keith* tend to show that the backflow of blood into the venæ cavæ is also prevented, to some extent at least, by a series of muscular arrangements in the heart which are of too intricate an anatomical nature to be described here. Enough has been said, however, to show that the valvular mechanism of the heart is as largely muscular as membranous in character, a conclusion which is quite in harmony with the results of clinical observation.

\section{Sounds of the Heart.}

It is generally agreed that the first sound of the heart is the product of at least two factors: (1) the tone produced by the contraction and vibration of the muscle

* Proc. of Anat. Soc. Gt. Brit. and Irel., 1902, Nov. p. ii. (issued with vol. xxxvii. of Journ. of Anat. and Physiol.). 
substance of the ventricles, (2) that which results from the stretching of the auriculo-ventricular valves. One says advisedly the stretching of the valves, for the sound is not due, as was once supposed, to the driving together of the membranous flaps, but to their sudden tension between the fibrous ring round the mouth of the auriculoventricular orifice on the one hand and the papillary muscles on the other. The flaps of the mitral and tricuspid valves are at no period of the cardiac cycle in anything approaching to a horizontal position. On the contrary, they are always more or less vertical, and the contraction of the musculi papillares merely serves to counteract the tendency of the cusps to float up owing to the constriction of the base of the heart during systole. Hence it is that the valves are suddenly made tense by being pulled on at both their extremities like a sheet well shaken, and the characteristic flapping sound results. Either the muscular or the membranous element of the first sound may come to predominate in conditions of disease. If the ventricular wall is hypertrophied, the sound is low and booming from an emphasis of the muscle element; if, on the other hand, the muscle is thin and atrophied, the predominance of the membranous factor imparts to the sound a high-pitched and slapping character. When the ventricular systole is feeble and inefficient, both the muscular contraction and the stretching of the valve are so much reduced that the first sound becomes very faint, or may even be inaudible.

The second sound, on the other hand, is due entirely to the tension of the semilunar valves, and its loud- 
ness depends solely upon the pressure in the aortic and pulmonary systems. Increased loudness of this sound, therefore, always indicates an increased arterial or pulmonic blood-pressure. The sound produced in the left ventricle is always louder than that of the right, and both attain their maximum intensity between the ages of twenty and forty. The pulmonary second sound is louder than the aortic up to the age of puberty ; thereafter the aortic second becomes progressively the louder.

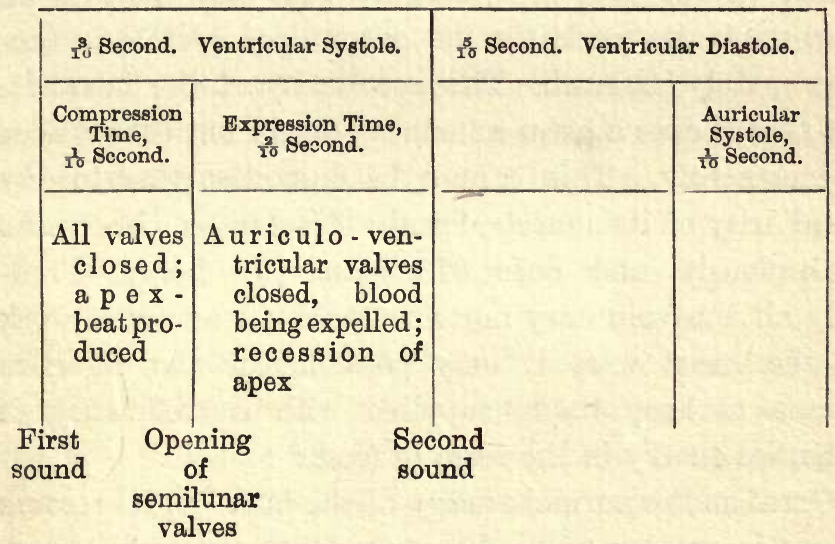

\section{The Work of the Heart.*}

The total work of the heart is the sum of that done by its different chambers. The work of the ventricles consists chiefly in overcoming the pressure in the aorta and pulmonary artery, and, to a much less extent, in imparting to the expelled blood the necessary velocity.

* Benno Lewy, 'Die Arbeit des Gesunden und des Kranken Herzens,' Zeit.f. Klin. Med., 1897, xxxi. 321. 
About 7 per cent. of the total work is also expended in overcoming resistance in the heart itself. Assuming that the volume of blood expelled from each ventricle is approximately 60 c.c., the total work of a cardiac cycle amounts to $0.2 \mathrm{kgm}$. (or $1 \frac{2}{5}$ foot-pounds). At a rate of seventy beats per minute this means 252 litres of blood distributed to the organs every hour, and implies a work of $815 \mathrm{kgm}$., or 20,000 per day (about 140,000 foot-pounds). In normal circumstances an increase in the rate of the heart does not indicate an increase in its work, for the output per systole is proportionately lessened. The peculiarity of the heart is, not that it does a great amount of work, but that it does it incessantly. This cannot be due altogether to any peculiarity of its muscle, for the diaphragm also works continuously, and does $376 \mathrm{kgm}$. per hour. Probably all the voluntary muscles could do as much work as the heart were it only possible for the digestive organs to keep them supplied with a sufficiency of potential energy in the form of food.*

Great as the normal energy of the heart is, its reserve power is greater still. Even moderate muscular work demands a fourfold output of cardiac energy, and the total reserve power has been estimated at thirteen times the normal output during rest. In conditions of disease the work of the heart is enormously augmented, largely from increased resistance in driving the blood through its own chambers (e.g., in mitral stenosis). In disease, too, all such factors as number and duration of systoles are of importance. 
In a case of aortic stenosis, for example, in which $0 \cdot 7$ of the opening is obstructed, as happens when two of the cusps are completely adherent, the heart does $1,000 \mathrm{kgm}$. of work at sixty beats per minute, but at seventy beats it does $1,150 \mathrm{kgm}$. Further, the fluid tension to which the wall of the heart is subjected increases with the radii of curvature of the cavity. Hence a dilated heart must put forth more energy in order to expel its contents than one of normal ventricular capacity, and for that reason it hypertrophies.*

In addition to this, the mere overfilling of the left ventricle must always lead to an increase of its work during systole, for although the systole is prolonged in such circumstances, yet the prolongation never extends to more than 20 or 30 per cent. of the normal time.t Hence the blood must be expelled more rapidly-i.e., more work must be done.

It has been calculated that if a lesion is so bad as to require $7 \cdot 7$ times as much energy as usual to compensate it-i.e., a heart $7 \cdot 7$ times heavier than normalthe maintenance of the circulation is impossible.

In normal circumstances the different chambers of the heart transmit equal volumes of blood in the same time. Were this not so, of course, the circulation would come to a standstill, and the usual cause of death from heart failure is inability on the part of one or more chambers of the heart to fulfil its duty in this respect. Even in health, however, the law may be temporarily

* See Hill in Schäfer's 'Physiology,' ii. 40.

† See von Frey, Deutsch. Arch. f. Klin. Med., 1890, xlvi. 398. 
disregarded, and unequal volumes of blood transmitted; but the balance is always speedily rectified by an extra effort on the part of the heart.

\section{Physiological Properties of Heart Muscle.}

The starting of the cardiac systole is due to the excitability of the heart; the propagation of the systolic wave, as we have seen, to its conductivity; the expulsion of the contained blood to its contractility; and the regularity of the contractions to its rhythmicity.

The properties of excitability and rhythmicity will be

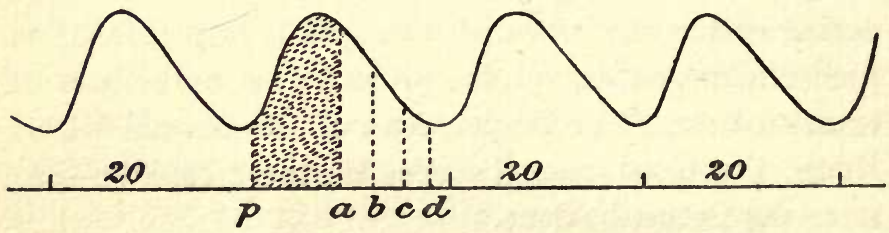

Fig 3.-Series of Ventricular Systoles (after Wenckebach.) $p$ to $a=$ Refractory period ; at $a, b, c$, and $d$ lessening degrees of stimulation will induce contraction.

further discussed when we come to consider the rhythm of the heart (p. 130).

As regards the property of contractility, two peculiarities must be emphasized. The first is that the contractions of the heart are always maximal-i.e., if a stimulus is strong enough to excite the heart to contract at all, the latter always responds with all the strength of which it is capable at the moment. The advantages of this, as pointed out by Wenckebach, are (1) that it makes the heart independent of the strength of the stimulus, and (2) that while reak stimuli produce the 
full effect, strong ones are unable to produce an excessive contraction.

The second peculiarity of the contraction of the heart is that it abolishes for a time (the refractory period) all the other properties of the heart muscle, including the power of further contraction. This ensures a period of rest to the heart, and makes it impossible for it to pass into a tetanic condition (Fig. 3).

The property of conductivity is exercised through the muscle fibres themselves, and not through nerves. The advantage of this is that, even although the heart be extensively diseased, conduction can still go on so long as the muscle cells are connected to each other, which would hardly be possible if conduction were dependent on a comparatively small number of nerve fibres.

It should be pointed out, further, that the physiological properties of the heart muscle are all independent of each other, so that one may be diminished or even abolished altogether without affecting the other.

The question must now be discussed, Does the heart wall possess, in addition to these properties, the quality of tonicity? By this one means does the volume of the heart and the capacity of its chambers tend to be kept always somewhat reduced in consequence of a slight tonic contraction of its muscle fibres, or, what comes to much the same thing, as a result of their elastic resilience? To this question physiology now furnishes an affirmative reply, and various clinical facts render the existence of tonicity undoubted. It will be obvious that tonicity must oppose dilatation of the heart from 
pressure on the inner aspect of its wall during diastole. Now, the degree of resistance offered to such dilatation appears to vary considerably in different individuals. In other words, the 'tone' of the heart seems to be by no means constant. That is probably why one man gets cardiac dilatation as the result of a degree of exertion which is borne with impunity by another. The toxins of some diseases, too, such as diphtheria and influenza, appear to lower heart tone, and predispose to dilatation; and the same is true of some poisons, such as muscarine. Considerable variations in the tone of the heart may, and probably do, occur unobserved. Thus a degree of relaxation sufficient to double the output would only mean an increase in diameter of the heart of 2 centimetres-an increase inappreciable by percussion.*

On the other hand, the most valuable property of digitalis as a drug appears to be its power of increasing the 'tone' of the heart muscle and so of opposing dilatation. The possible relation of such tone to nervous influence will be discussed later.

Tonicity resembles in a minor degree an active contraction of the heart, and we shall see later (p. 137) that contraction suspends the other functions of the heart muscle whilst it is taking place, and for some time afterwards. Similarly, when tone is increased, conductivity and excitability are diminished, and when tone is diminished these are increased. $\dagger$ Now, diminution of

* See Hensen, Deutsch. Arch.f. Klin. Med., 1900, lxvii. 436.

+ See a very suggestive paper by Gossage, Med. Chir. Trans., 1906 , vol. xc. 
tonicity is one of the commonest events in cardiac disease, and, probably in consequence of this, increased excitability and conductivity of the heart muscle are common occurrences in disease too, and are mainly responsible for some of the chief forms of irregularity of the heart's action.

\section{The Nervous Control of the Heart.}

The maintenance of the heart's action is a matter of such transcendent importance to the organism that, as we have seen, it has been made to depend upon the intrinsic qualities of the heart muscle. On the other hand, the dependence of every organ upon the heart for a due supply of blood, and the necessity for frequent variations in the rate and force of the blood-stream and the height of the general blood-pressure, make it essential that the heart should be 'connected up' with all other parts of the body by nervous communications. As a matter of fact, this is very carefully provided for, and the heart is accordingly played upon by more reflex influences than almost any other organ in the body.

These nervous influences act upon the various physiological properties of the heart muscles, either intensifying or lessening them. Thus they may:

1. Accelerate or lessen the rate of stimulus production, and so increase or lessen the rate of the beats.

2. Accelerate or lessen the rate of conduction of the contraction, and so accelerate or retard the beats.

3. Increase or diminish the excitability of the muscle, and so affect the strength of the stimulus required to produce a beat. 
4. Increase or diminish contractility, and so affect the force of the beats.

If one remembers that each of the physiological properties of the heart muscle can be affected independently by nervous influences in a positive or negative direction, and reflects upon the different permutations and combinations of disturbances of the heart's action which may be so produced, one will readily understand how complicated the control exercised by the nerves of the heart in health really is.

\section{Efferent Impulses.}

The paths by which these influences reach the heart are shown in detail in Plate $I$.

It will be observed that two sets of efferent fibres pass to the heart from the nervous system:

1. Inhibitory fibres contained in the vagus.

2. Accelerator or augmentor fibres which run in the sympathetic system.

The inhibitory fibres are inimical to the exercise of most of the physiological functions of the heart muscle. They lower its excitability, its conductivity, ${ }^{*}$ and its contractility, but not, apparently, its tonicity. $\dagger$ In other words, the influences which they convey are opposed to those molecular changes which manifest themselves in the discharge of function-i.e., they restrain katabolism. For this reason the vagus has been described

* Muskens (Amer. Journ. of Physiol., 1898, vol. i., p. 486) regards as the chief effect of the vagus.

+ Gaskell, however, believes that the vagus does lower tonicity (Schäfer's 'Physiology,' ii. 215). 


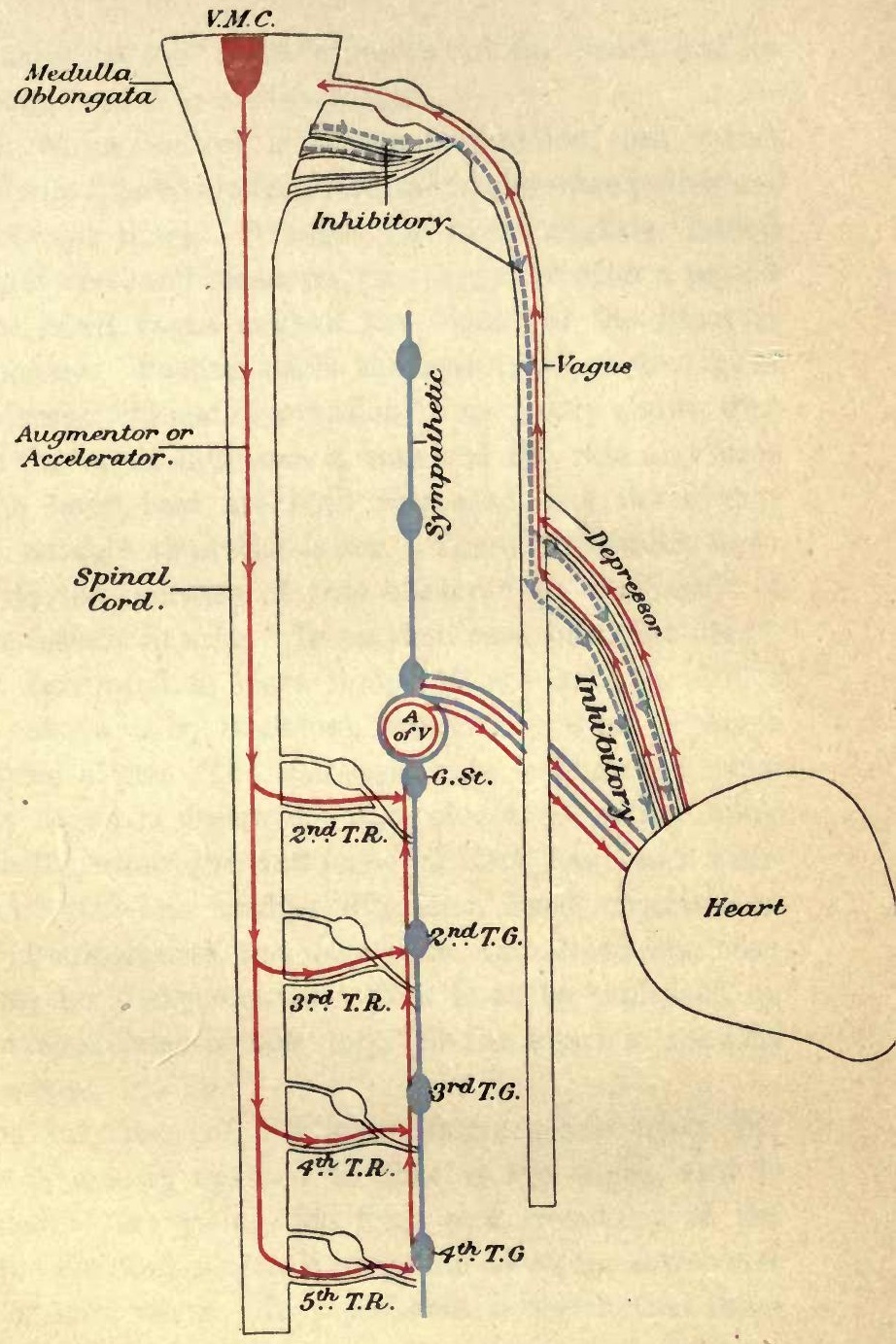

Plate I.-The Innervation of the Heart (AfTer Powell). 

by Gaskell as the 'anabolic nerve' of the heart, and he has compared it to a vaso-dilator.

The vagus control is in constant action, but varies greatly in different individuals and in the same individual at different times. It keeps the heart slightly ' reined in,' as it were, and conserves its energy, for after a period of increased vagus control the vigour of the heart is augmented. Putting aside the results of physiological experiment, clinical observation* has clearly shown that when the vagus influence is removed the rate and force of the heart-beat are both increased, but the former more notably than the latter. There are limits, however, to the increase of rate observed as the result of vagus lesions in man. In no such case have the heartbeats amounted to more than 160 per minute. Pulse rates above this, therefore, cannot be due to vagus paralysis alone. The increased rate is observed when either vagus is destroyed, but, of course, rather more markedly when the influence of both has been withdrawn. Nor has cardiac dilatation been observed in such circumstances, not even when the lesion has been present for many months. This is to be explained by the independence of the 'tone' of the heart of nervous influences.

The influence of the sympathetic nerve upon the heart is exactly opposed to that of the vagus, and is directed to increasing the force and frequency of the beats. For that reason it is spoken of as the accelerator or augmentor nerve. It is probable, however, that these

* See a collection of twenty-four cases by Martius, 'Tachycardie,' p. 37 (Stuttgart, 1895). 
two influences are separate and travel by different fibres, for on stimulating the sympathetic one sometimes produces a mere increase in rate, whilst at other times one gets an augmented output and rise of bloodpressure. Gaskell has described the effects of the sympathetic on the heart, as a whole, as a 'katabolic' one, for it tends to increase those chemical changes which lead to the beat, and he compares it to a vasoconstrictor. The right sympathetic seems to exert more influence than the left.

Curiously enough, we know much less of the action of the sympathetic, both clinically and physiologically, than of the vagus. It was even long disputed whether or not the sympathetic had a constant tonic action. It is now generally agreed, however, that it has.* Indeed, its action seems to be at least as continuous as that of the vagus. The normal heart rate, in fact, appears to be determined by the influences reaching it through the vagus and sympathetic channels, and between these there is, as it were, a constant struggle for supremacy going on. All the physiological evidence, however, points to the fact that an increase in the rate of the heart is always due to a diminution of vagus tone, and not to an increased action of the sympathetic. It might seem natural to suppose that cases of palpitation characterized by increased force and frequency of the beats were produced by an increase of the sympathetic influence; but this would appear not to be the case. The mere fact that such attacks may cease very abruptly would negative such a view, for experimental stimulation

* See Reid Hunt, Amer. Journ. of Physiol., 1899, ii. 395. 
of the sympathetic always shows that the heart continues to beat rapidly for a long time after the stimulation has ceased. Even emotional increase in the heart's rate, then, is apparently due to a temporary diminution of vagus tone, and the same is true of the acceleration observed during swallowing and as the result of inspiration. At the same time such temporary suspension of vagus control could not exert such an immediate and marked influence upon the rate of the heart were it not for the constant action of the sympathetic, which merely waits, as it were, for the opportunity afforded by the relaxed control of the vagus in order to assert its influence. Conversely, when the heart has been slowed by increased vagus action, the sympathetic limits the slowing, and enables the heart to return more quickly to its normal rate. This action is probably of importance in counteracting influences which tend to cause reflex slowing, such, for example, as injury to the abdominal viscera. It therefore minimizes shock.

The accelerator centres and nerves would appear to be very resistant to influences such as a low bloodpressure, extreme asphyxia, and certain drugs, which quickly depress other nerve centres. This is fortunate, for they are thus, in virtue of their tonic activity, in a state to aid the heart in an emergency when it most needs help.

The degree of control exercised by the nervous system over the heart probably varies at different ages. This certainly seems to be so in the case of the inhibitory fibres, at any rate. These appear to be almost inactive 
at birth,* but their tone increases up to twenty-five to thirty-five years, and from this time lessens again, and is very slight in old age. Atropine, which acts by paralyzing the ends of the inhibitory fibres, has thus very little effect on the heart at the extremes of life. This may be one reason why children stand large doses of belladonna so well.

\section{Afferent Impulses.}

The course of the afferent nerves from the heart to the nervous system is not so well known as that of the efferent. In man they appear to be both in the vagus and in the rami communicantes of the upper dorsal nerves.t The vagus fibres which constitute the depressor nerve are those with which we are best acquainted, though these probably belong, in man at least, to the root of the aorta rather than to the heart itself. The name 'depressor' is applied to these fibres because of the great lowering of general blood-pressure which stimulation of them brings about. They appear to be thrown into action when the heart is struggling against an aortic pressure which is rather too great for it to overcome, and their stimulation appears to be attended by the production of pain, which may manifest itself in some cases in the form of the disease known as angina pectoris. Normally, however, the heart, like most of the internal organs, appears to be but poorly endowed

* Cushny, 'A Textbook of Pharmacology,' first edition, 1900, p. 280.

$\uparrow$ See Ferrier's Harveian Oration on 'The Heart and Nervous System,' Brit. Med. Journ., 1902, ii. 1336. 
with sensibility, except, perhaps, to states of abnormal tension within its cavities. The insensibility of the heart was first demonstrated by Harvey in the case of the son of Viscount Montgomery, whose heart had been exposed by destructive ulceration of the overlying chest wall. Harvey related as follows* :

'I found a large open space in the chest, into which I could readily introduce three of my fingers and $m y$ thumb: which done, I straightway perceived a certain protuberant fleshy part, affected with an alternating extrusive and intrusive movement; this part I touched gently. Amazed with the novelty of such a state, I examined everything again and again, and when I had satisfied myself, I saw that it was a case of old and extensive ulcer, beyond the reach of art, but brought by a miracle to a kind of cure, the interior being invested with a membrane and the edges protected with a tough skin. But the fleshy part (which I at first sight took for a mass of granulations, and others had always regarded as a portion of the lung), from its pulsating motions and the rhythm they observed with the pulse ... I saw was no portion of the lung ... but the apex of the heart! covered over with a layer of fungous flesh by way of external defence, as commonly happens in old foul ulcers. The servant of this young man was in the habit daily of cleansing the cavity from its accumulated sordes by means of injections of tepid water, after which the plate was applied, and with this in its place the young man felt adequate to any exercise or

* William Harvey, Collected Works (Sydenham Soc., 1847), on Generation, p. 383. 
expedition, and, in short, he led a pleasant life in perfect safety. Instead of a verbal answer, therefore, I carried the young man himself to the King, that His Majesty might with his own eyes behold the wonderful case: that in a man alive and well he might, without detriment to the individual, observe the movement of the heart, and with his own hand even touch the ventricles as they contracted. And his most excellent Majesty, as well as myself, acknowledged that the heart was without the sense of touch; for the youth never knew when we touched his heart except by the sight or sensation he had through the external integument.'

Cases such as this belong, of course, to the curiosities of medicine, but the insensitiveness of the heart to punctured wounds is a well-established clinical fact.

The nervous mechanism of the heart may be brought into action in various ways.

1. Psychical and emotional influences may so stimulate the cardio-inhibitory centre as to lead to instant and fatal arrest of the heart's action. A number of classical examples of such cases are mentioned by Balfour.*

'Sophocles, at the age of ninety, died suddenly of joy on being crowned as the first tragic poet of the age. Philippides, the comic writer, died a similar death. Chilon, of Lacedæmon, died in the arms of his son, who had borne away the prize at the Olympic games. The famous Fouguet died of joy on being set free by Louis XIV. The niece of Leibritz died suddenly of joy at finding a box containing ninety thousand ducats beneath the philosopher's bed.... It seems more natural that terror and grief should be

* 'Diseases of the Heart,' third edition, 1898, p. 267. 
more hurtful than joy, and though this does not appear to be the case, yet these emotions have in their turn been fatal to many. Philip II., King of Spain, enjoys the unenviable notoriety of having frightened two of his counsellors to death. One of his Ministers of State died suddenly on being sharply rebuked for a hesitating answer. Another, the Cardinal Espinoza, died a few days after being sternly told, "Cardinal, know that I am master." . . . In the end of last century Prince George Louis of Holstein, having removed the body of his wife from one coffin to another of more costly materials, desired his valet to read him some pages from a pious book, and, kneeling at the side of the coffin, he burst into tears and died. And a few years ago there occurred in France an even more startling instance of the fatal effect of overwhelming emotion. Dr. Deleau, a celebrated aurist, only forty-four years of age, leaning over his dying daughter to receive her last farewell, himself fell dead as if struck by lightning.'

Even in the more prosaic records of clinical medicine death from a 'broken heart' is not unknown, * and it is thanks to the play of emotional influences on the inhibitory mechanism that

\section{'A merry heart goes all the day;}

Your sad tires in a mile-a.'

\section{The nervous mechanism of the heart may also} be affected reflexly by impulses arising either in the skin or in the internal organs. A good example of reflex inhibition of the heart from stimulation of the skin is seen in some cases of death from so-called 'cramp' on plunging into cold water. On the other hand, gastric irritation is one of the commonest causes of that temporary diminution of vagus control which manifests itself in 'palpitation'; and many similar instances might be multiplied.

* See Schrötter, ' Verhand. d.17th Cong. f. Inn. Med.', Weisbaden, 1899, p. 23. 
What the advantage to the organism of many of the disturbances of the heart brought about by nervous influences may be it is often hard to say, but probably we shall not be far wrong if we regard most of them as essentially protective and compensatory in their nature. In particular, they seem to be designed to mitigate the effects of sudden rises of blood-pressure, especially, perhaps, on the heart itself ; for all rises of arterial pressure seem to induce a slowing and enfeeblement of the heart's action, whilst, conversely, sudden falls of pressure are attended by a more frequent and powerful heart-beat. In this way, too, the heart itself is protected from undue strain.

3. The ability to exercise any voluntary control over the nervous mechanism of the heart is a phenomenon of the rarest occurrence. The best example of it is the classical case of Colonel Townshend, recorded by Dr. George Cheyne,* who, when on his death-bed, was able to throw himself at will into a state of suspended animation, in which the heart's action became imperceptible. There are other cases on record as well, in which the heart's rate could be voluntarily increased, and in all such instances there has been an unusual degree of control over the involuntary muscles. $\dagger$

\section{The Rhythm of the Heart.}

The maintenance of the regularity or otherwise of the rhythm of the heart depends upon two factors: (1) the * 'The Case of the Hon. Colonel Townshend,' 'The English Malady,' fourth edition, 1734.

$\dagger$ See Reid Hunt, Amer. Journ. of Physiol., 1899, ii. 395. 
condition of the muscle wall; (2) the influence of the nervous mechanism.

\section{Rhythmicity and Excitability.}

What it is in the fibres of the heart muscle which endows them with the property of regular rhythmical contraction, or rhythmicity, we do not know. In the last resort it must depend upon some peculiarity in their metabolism, possibly the building up of some 'explosive' compound; upon the disintegration of which the starting of a contraction ensues, the normal intervals between contractions representing the time required for the formation of this compound. From this point of view the heart muscle might be compared to a gun, which is always fired off as quickly as it can be loaded. To pursue this analogy, the 'rhythmicity' of the heart corresponds to the rate of loading; its 'excitability' to the ease or otherwise with which the trigger can be pulled.*

The more excitable the heart, the less the stimulus which is required to produce a contraction. A very excitable heart, therefore, is like a gun with a 'hairtrigger,' and any abnormal stimulus can readily prompt it to produce extra beats. Increased excitability-a

* In the text the myogenic origin of the rhythmical contraction of the heart has been adopted, but the reader is reminded that many physiologists believe that the production of the stimulus to rhythmical contraction resides in the intrinsic nervous mechanism (neurogenic theory). The question is one of no direct clinical interest, but the pros and cons of the two theories are well stated in a paper by Gossage on 'The Automatic Rhythm of the Heart' (Brit. Med. Journ., 1907, ii. 1818). 
condition of 'irritable weakness' - is a common occurrence in disease.

\section{Alterations in Rhythm.}

Alterations in rhythm may be induced either by abnormal conditions of the muscle substance or by the intervention of nervous influences, and clinically it may be impossible to say which of these factors is at work.

A discussion of the rhythm of the heart involves a consideration of-

1. Its rate.

2. The relative duration of systole and diastole.

3. The regularity of the beat.

4. The synchronism of the two sides of the heart.

1. The rate of the heart-beat is due primarily to the excitability of the less differentiated muscle of the sinus venosus, but it is also dependent upon the degree of control exercised by the inhibitory fibres of the vagus. The greater rate of the heart in young subjects is probably due to a feebler influence of the vagus in early lifo (see p. 125), and the same may be true of the differences in the rate of beat in different individuals. On the other hand, alterations in the heart muscle may be a cause of a more frequent beat. Fever seems to affect the excitability of the heart directly, as well, perhaps, as through the nervous centres, and the same is probably true of the chemical products produced by muscular exercise.

The initial increase in the heart-rate which exertion induces, however, must be due largely to mechanical influences. 
- The first effect of powerful general muscular action is to drive the blood along the veins towards the heart, and the right auricle and ventricle are at once distended. To pass on the blood through the lungs as fast as it arrives, the right heart must act more frequently and powerfully, and the stimulus to this exists in the increased pressure on its inner surface. For a time there is accumulation in the pulmonary circulation, and while this is the case there is dyspnoea and shortness of breath and panting; but when the individual is vigorous the circulation in the lungs and system becomes equalized, and he gets his second wind, as the term is."

All sudden alterations in the general blood-pressure immediately affect the heart through its nervous connections. Thus, on standing up the blood-pressure tends to fall, but the heart beats more rapidly to make up for it. The difference in rate between the horizontal and erect postures, indeed, may amount to 8 or 10 beats per minute, or 500 to 600 beats per hour. One can see from this how great rest is afforded to the heart by maintaining the horizontal position. In slow walking a pulse of 60 per minute goes ap to about 100 , in quick walking to 140, and on running to sbout 150 (Mackenzie). On the other hand, conditions of high bloodpressure are attended by a slowing of the heart which is partly reflex, and partly the result of prolongation of the 'compression period' of the systole from the obstacle offered to the expulsion of the ventricular contents.

Persistent acceleration of the heart from diminution of ragus inhibition seems sometimes to occur as the * Brosdbent, 'The Palse,' p. 77. 
result of nervous shock. A soldier in South Africa, for instance, was suddenly startled by the explosion near him of a $4 \cdot 7$ gun. His heart immediately began to beat very rapidly, and continued to do so for some months. Vagus acceleration, however, can never, as we have seen, lead to a rate of more than 150. Attacks of 'paroxysmal tachycardia,' in which the beat runs up temporarily to 200 per minute or more, must have another origin than that, and seem to be due to a sudden loss of tone in the heart leading to temporary dilatation, in which so little blood is expelled at each systole that the total number of beats must be greatly increased if the circulation is to go on.* The opposite condition of bradycardia, or diminution in the heart's rate, may also be due either to diminished excitability of the muscle itself or to increased vagus inhibition. The former is the cause of the very slow pulse sometimes observed during convalescence from enteric fever or pneumonia. The latter occurs, as we have already seen, when the vagus is stimulated by a high blood-pressure, and also occasionally under emotional influences. A slow beat from change in the heart muscle can easily be distinguished clinically from one due to increased vagus inhibition by the administration of a dose of atropine. In the former case the rate will not be accelerated; in the latter case it will.

* Mackenzie has suggested ('The Study of the Pulse,' p. 126) that paroxysmal tachycardia is really due to a long-continued series of premature systoles.

Martius, 'Tachycardie' (Stuttgart, 1895).

† Dehio, 'Ueber die Bradycardie der Reconvalescenten,' Deut. Arch.f. Klin. Med., 1894, lii. 74. 
Of alterations in rate due to augmentor impulses we know nothing, but it seems not unreasonable to suppose that the rapid and forcible beat of excitement may be induced in that way.* Experiment, however, has shown that stimulation of the accelerator does not raise the heart rate above 120 per minute.

2. In health, no matter how fast or how slowly the heart may be beating, the relative duration of systole and diastole remains unaltered. If the cardiac muscle is diseased, however, or if nervous influences are at work, the normal relative duration of the different phases of the cardiac cycle is often disturbed. Such disturbance can be recognized at the bedside by changes in the spacing of the heart sounds. In early life irregularity of rhythm is chiefly due to occasional prolongation of the diastole. In later life the occurrence of premature systoles is a more potent source of varying rhythm.

The following alterations may occur :

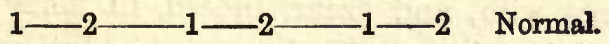

$1-2-1-2-1-2$ Prolongation of systole (pendulum rhythm).

1-2-1-2-1-2_ Shortening of systole.

1- - 2-1- - 2-1 Prolongation of diastole(brady. cardia).

1-2-1-2-1-2-1-2-1-2- Shortening of systole and diastole (tic-tac rhythm).

$1-2-1-2-1-2-1$ Shortening of diastole (tachy. cardia).

(a) The systole may be unduly prolonged from in-

* Determann, 'Ueber Herz-und Gefässneurosen,' Volkmann's Samml. Klin. Vort., 1894, Inn. Med., Nr. 30, p. 1. 
creased resistance to the outflow from the heart, as in aortic stenosis, or it may be unusually short from diminution of the resistance to be overcome, or from incomplete contraction of a dilated ventricle.

In the former condition the time between the first and second sounds will be prolonged, and the heart assumes on auscultation a pendulum rhythm. In the latter state of affairs the interval between the two sounds is unusually brief.

(b) Prolongation of the diastole occurs in bradycardia, shortening of it in palpitation with increased frequency of action, and in dilatation of the ventricle. In the latter case one gets a tic-tac or fœtal rhythm on auscultation. Shortening of the diastole is always of serious significance for the heart, as it is only during that phase of the cycle that rest and restoration of the fibres can take place.

3. Variations in the regularity of the beats are also frequently mot with, and occur, indeed, in many persons throughout life without affecting the circulation.

As we have already seen, the regular beat of the heart depends upon a proper degree of excitability in the auricle which initiates the systole, the wave of contractility so started being propagated to the ventricles by the conductivity of the muscle fibres, the ventricles in their turn then passing into systolic contraction. Now, it must not be supposed that the muscle substance of the ventricles is equally excitable and responsive to the auricular stimulus at all periods of the cardiac cycle. During their systole, and for a short period after it, the ventricles are irresponsive to stimuli, this constituting 
the 'refractory period' of the physiologists. Should the auricular stimulus happen to arrive during this period, the ventricle will fail to respond, with the result that the heart 'misses a beat.'

The arrival of the auricular stimulus at the wrong moment may be due either to (1) undue excitability of the auricles, so that they pass prematurely into contraction again before the ventricles have had time to complete their systole.* This is the chief cause. (2) To alterations in the conductivity of the heart muscle, either in the direction of increase, so that the auricular impulses reach the ventricles too soon, and whilst they are still refractory; or of diminution, so that some of them never get there at all, and the ventricles are not 'fired off.' (3) The excitability of the ventricles themselves may be raised, so that they occasionally go into contraction whilst waiting for the auricular signal, with the result that when the latter arrives they are incapable of responding.

These ventricular 'extra-systoles' are commonly inefficient, and do not expel enough blood to reach the wrist, so that we arrive at the apparent paradox that intermittence of the pulse is sometimes due to extra heart-beats. + Their occurrence, however, can be told by

* Gaskell points out that the fact that the conductivity of the heart muscle is diminished immediately after a contraction will tend to counteract the effect of extra systoles of the auricle, for the impulse so produced will be conducted slowly to the ventricles, and its effect largely neutralized, the ventricular contractions being more regular than those of the auricles (Schäfer's 'Physiology,' ii. 195).

† Wenckebach, 'Zur Analyse des Unregelmässigen Pulses,' Zeit. f. Klin. Med., 1899, xxxvi. 181. 
the appearance of a feeble first sound immediately after the second (Fig. 4). On the other hand, the excitability of the ventricles may be lowered, so that they fail to respond to all of the auricular contractions, again with the result that some beats are dropped.

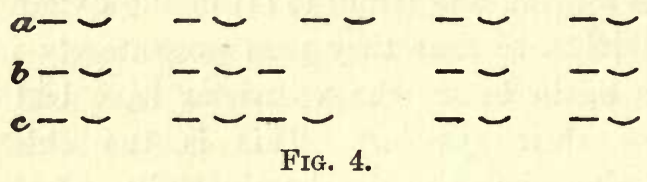

$a=$ Normal heart sounds ; $b$ and $c=$ sounds heard when extra-systoles
are occurring.

Now, inasmuch as the variations in the excitability and conductivity of the heart upon which those irregularities of rhythm depend may be brought about either through disease of the heart muscle or from nervous influences, it will readily be understood that the clinical interpretation of irregularities of the pulse is often a

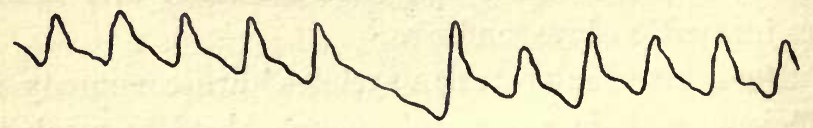

\section{$\left.\left.\left.\left.\left.\left.\left.\left.\left.\right|_{73}\right|_{76}\right|_{74}\right|_{76}\right|_{258}\right|_{77}\right|_{76}\right|_{72}\right|_{73} \mid$}

Fig. 5.-Pulse Tracing, showing Ventricolar Intermission. (Aftre Cushny.) (The Figures represext ONe-hUNDredths OF A SECOND.)

The intermission, 152, is exactly twice the length of the preceding pulse, 76.

matter of no small difficulty. We are aided, however, in arriving at an idea of the nature of the irregularity in any particular case by the fact that ventricular intermissions during which the auricle continues to beat 
regularly must always be as long as twice the ordinary pulse interval (Fig. 5). Those of auricular origin may be of this length, but are not usually so; for the irritability of the auricle increases so fast during quiescence that it is not likely to wait so long before passing again into contraction (Fig. 6). On the other hand, all intermissions less than two beats in duration are not necessarily due to disease in the auricular fibres, for some of them may be brought about by excessive vagus control, which actually stops the heart for a moment. This form of intermission, however, is abolished by atropine, and can be recognized by that peculiarity.*

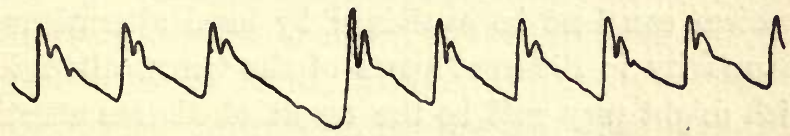

$\begin{array}{llllllllll}l_{84} & 98 & I_{188} & I_{98} & 94 & 95 & 94 & 97\end{array}$

Fig. 6.-Pulsh Tracing, showing Auriodlar Intgrmission. (After Cushny.)

The intermission, 158 , is much less than twice the length of the preceding pulso.

As a matter of clinical experience, irregularity of the heart seems specially prone to occur when the auricle is diseased. $t$ Such irregularity proceeding from the automatic contractile fibres is of more serious import than that due to alterations in conductivity or lowered ven-

* Cushny, 'On the Interpretation of Pulse Tracings,' Journ. of Exper. Med., 1899, vol. iv., p. 327, and Brit. Med. Journ., 1900 , ii. 892.

† Radasewsky, Zeit. f. Klin. Med., 1895, xxvii. 381. 
tricular excitability. The former has been likened to a man who stumbles because he is lame, the latter to one whose gait is irregular because he is on rough ground. The first may be described as 'arhythmia,' the second as 'pararhythmia' (Wenckebach).

4. The last form of irregularity of the cardiac rhythm (allorhythmia) is that due to a want of synchronism in action between the two auricles or two ventricles respectively, or between the two sides of the heart as a whole. A want of complete synchronism in the action of the ventricles is believed to be the clinical explanation of reduplication of the first sound, the tension on the mitral and tricuspid valves reaching its maximum at different moments. Such want of synchronism can best be explained by local alterations in conductivity in different parts of the heart, alterations which might very well be the result of disease affecting the muscle of one ventricle more than that of the other, or to local variations in nervous control.*

The former is the more likely cause, for the normal synchronism of the ventricles appears to be maintained, not through nervous, but through muscular connections, and to be independent of nerve cells. Further, it is apparently managed by the ventricles themselves, and not by the auricles. $†$

* Engelmann, Arch. f. d. Ges. Physiol., 1896, lxii. 543.

$\dagger$ Porter, 'The Co-ordination of the Ventricles,' Amer. Journ. of Physiol., 1899, ii. 127. 


\section{CHAPTER V}

\section{APPLIED PHYSIOLOGY OF THE CIRCULATION}

IT might seem at first sight that our knowledge of the circulation must be more precise and susceptible of more direct clinical application than that of any other department of physiology; and to some extent, indeed, this is true. It must be admitted, however, that when one comes to apply this knowledge at the bedside, many gaps are discoverable in it. This is due partly to our still imperfect comprehension of the physical laws which govern the circulation of fluids in a closed system of tubes, and partly to our ignorance of the extent to which such laws are applicable to the conditions which obtain in the living body. The problems presented by disorders of the circulation, moreover, are rendered still more difficult by the complicated nature of the checks, adjustments, and compensations which are exhibited in it under the sway of nervous influences, the precise nature and mode of action of which we are still far from fully comprehending even in health, to say nothing of disease. Much attention, however, is now being devoted to the exact study of disorders of the circulation by physical methods, which the invention of instruments of precision has rendered possible, and there can be no doubt 
that the results of such study will add much to our knowledge both of physiology and pathology. Meanwhile an attempt will be made here to indicate the applications of the chief facts about the circulation on which physiologists are generally agreed.

\section{The Arterial Circulation.}

The arteries are both propulsive and conducting tubes. Their function in the circulation is to assist the heart in driving the blood into the capillaries, to induce a continuous flow in the latter, and to maintain a 'head of pressure' sufficient to allow any part of the body to become flushed with blood when its arterioles are dilated.

The driving power of the arteries is due to their elasticity, and the elastic element in the arterial coat is most abundantly present and most widely diffused throughout the wall in the large arteries. The blood which is expelled from the heart at each systole of the left ventricle distends the aorta and stretches to some extent its elastic wall; part of the force of the ventricle is thus converted from an actual into a potential form, and is again liberated in the recoil of the arterial wall during disastole, thus maintaining a continuous 'squeeze' on the contained blood, and causing the flow of the latter to be constant instead of intermittent, whilst distributing the work of the heart over more than twice the time occupied in its contraction. If the elasticity of the arteries be impaired through disease of their walls, the work of the heart is increased, and enlargement of it follows; at the same time the flow of blood approximates 
more to an intermittent stream, and the pulse wave is propelled more rapidly throughout the body. It is for this reason that, in cases of aortic incompetence which are secondary to aortic atheroma, the 'delayed' pulse characteristic of incompetence due to rheumatic endocarditis is not observed. It should be noted, also, that the distensibility of the elastic coat of the arteries is greatest when the pressure within them is moderate. In conditions of high tension a greater degree of force is required to stretch them, and hypertrophy of the heart results, whilst any increase in the pulse volume raises the tension within the arteries far more than it would do at a lower pressure, and so tends to rupture them.

In the smaller arteries the muscular element predominates over the elastic fibres, for it is in the smaller arteries that the power of actively regulating the amount of blood-flow to any part resides. This stop-cock action of the arterioles will be more fully considered under the head of blood-pressure, and is largely controlled by the vasomotor nerves, but it may be pointed out here that the muscular wall has a certain amount of independent action. Thus, the muscular coat of the small arteries reacts to a stretching force of contraction* just like unstriped muscle elsewhere. Hence any permanent increase in the volume of the blood may be expected to lead to hypertrophy of the muscular coat, and in conditions of plethora this actually occurs. The muscular coat also contracts to cold or great degrees of heat, an action which is constantly taken advantage of in the * Bayliss, Journ. of Physiol., 1902, vol. xxviii. 220. 
arrest of hæmorrhage. Some drugs also-e.g., ergotcause a direct contraction of the muscle fibres, whilst others-e.g., the nitrites-cause them to relax.

In addition to their muscular elements, the arteries possess an outer fibrous coat which is purely protective, and an inner endothelial lining which is designed to lessen friction. Underneath this is a delicate layer of connective tissue which, although it does not bulk largely under the microscope, is of great importance in disease, for in it many of the pathological processes which affect the arteries have their starting-point.

\section{The Arterial Pulse.}

The pulse is of such extreme clinical importance that a thorough knowledge of its mode of production and physiological characters is essential to the physician. It is necessary at the outset to clear the mind of two misconceptions about the pulse, which are still very prevalent: (1) It is not due to the transference of a wave of blood along an artery, but to the transference of a wave of pressure; (2) it is not due to a change in size or distension of an artery, but to a change in its shape.

The blood discharged from the left ventricle during its systole is accommodated in the large vessels immediately beyond the heart, and merely raises the pressure throughout the smaller arteries without actually distending them, the rise of pressure being transmitted along the columns of blood contained in the arteries in the form of the wave called the 'pulse.' To suppose, 
as some do, that the actual 4 ounces or so of blood which is expelled at any given systole rushes straight along the arteries and produces a 'swelling of them,' and that this is the pulse, is erroneous, though it may be admitted that such a misconception need not make a man a worse physician. On the other hand, one can hardly feel a pulse intelligently unless it be clearly realized that it indicates merely a change in shape of an artery from an oval to a circular form-along with a certain amount of straightening out, like a slack wire suddenly put on the stretch-and not a real increase in circumference of the artery (Fig. 7). The proof of this,

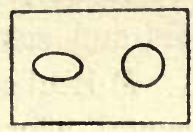

Fig. 7.-Showing the Change in Shape of an Artery from an Oval to a Circular Form during the Passage of the Pulse Wave.

as Broadbent pointed out, is readily demonstrated by placing the foot on a leather fire-hose (which of course cannot change in calibre), when a pulse will be felt at each stroke of the pump.

Of the characters of the pulse studied at the bedside, one group-its frequency, regularity, and equality-are entirely cardiac in origin, and are merely convenient indications of the way in which the systole is being performed.

Of these features the frequency need alone be referred to here, as variations in regularity and equality have been dealt with in considering the heart. 
The average frequency of the pulse varies with age as follows :

\begin{tabular}{|c|c|c|c|c|c|}
\hline \multicolumn{2}{|c|}{ Fœtus } & $\ldots$ & ... & ... & 130-140. \\
\hline \multicolumn{2}{|c|}{ 0-1 year } & $\ldots$ & ... & $\ldots$ & 130. \\
\hline \multicolumn{2}{|c|}{ 1-2 years } & $\ldots$ & ... & ... & 115-120. \\
\hline $3-4$ & , & $\ldots$ & $\ldots$ & $\ldots$ & 105-110. \\
\hline $5-9$ & , & ... & ... & $\cdots$ & $95-100$. \\
\hline $9-10$ & " & ... & ... & $\ldots$ & 90. \\
\hline $16-17$ & $"$ & ... & $\cdots$ & ... & 80. \\
\hline Adults & & ... & ... & ... & $70-80$ \\
\hline
\end{tabular}

In old age it tends to quicken again a little. As a general rule the pulse tends to be slower in tall and big men than in short and small. It is quicker in women than in men. Muscular effort quickens the pulse considerably; mental effort slightly. On slow walking it may run up to 100 per minute, and on quick walking to 150. Exposure to cold renders the pulse less, and response to warmth more frequent. A cup of hot milk or a plateful of hot soup raises the pulse five beats for half an hour; large quantities of cold water may reduce it ten beats. Cold dry meals have no influence, but warm meals result in quickening.

Every sensation of burning, pressure or nausea in the stomach or of distension in the intestine (especially the rectum) raises the rate. It is in this way that indigestion or flatulent distension of the bowels causes ' circulatory excitement' and sleeplessness.

The volume of the pulse, or the height to which it appears to rise under the finger, indicates the increase in pressure within the artery during systole, or the 
'pulse pressure.' The degree of this increase depends upon the volume of blood thrown into the aorta by the left ventricle, and the amplitude of the pulse is usually a guide to the amount of this volume. If, however, the diastolic pressure within the artery be very low, as it is, for example, when the arterioles are dilated, a comparatively small output on the part of the heart may cause a considerable relative rise in the systolic pressure, and so make the pulse appear one of large volume, and the 'pulse pressure' high. Further, if the radial artery be of small size, or if its muscular coat be contracted, the pulse volume may appear small, even although the systolic pressure within the artery rises very considerably. In such a case a sphygmometer is a useful corrective to the indications furnished by the finger.

The force with which the pulse wave is transmitted indicates the energy of contraction of the left ventricle. A forcible pulse is usually one of large volume, but an ample pulse is not necessarily forcible if it be the result of a low diastolic pressure within the arteries; nor is a small pulse necessarily a weak one, for its want of volume may be due to contraction of the arteries or to the output of the ventricle being small owing to its being imperfectly filled, as happens, for example, when the total volume of the blood is reduced by hæmorrhage.

The tension of the pulse will be considered when we come to deal with blood-pressure.

The Sphygmogram.-If one analyzes a pulse wave as depicted by the sphygmograph, it will be found to consist of an upstroke (called the 'primary' or 'percussion' wave), an apex, and a downstroke. On the downstroke 
are two secondary waves, the upper called the 'predicrotic' or tidal wave, and the lower the 'dicrotic' wave (Fig. 8).

Physiologists seem to vary in their interpretation of the meaning of the predicrotic wave, but it would appear that it indicates the true summit of the pulse wave, and that the primary wave is merely the result of instrumental error, and due to the sudden jerking upwards of the lever of the sphygmograph.*

If the tension in the artery rises very slowly, as it does in aortic stenosis, the lever is not jerked upwards

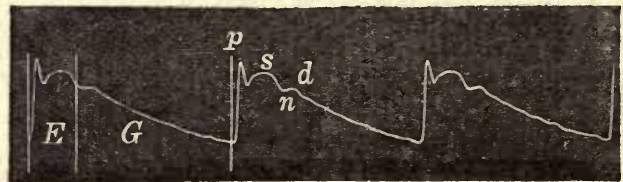

Fig. 8. - Sphygmogram of Radial Pulse. (Mackenzie.)

$E=$ Period of systole when aortic valves are open; $G=$ Ventricular diastole ; $s=$ pulse wave due to systole ; $n=$ aortic notch ; $d=$ dicrotic wave ; $p=$ wave due to instrumental defect.

so abruptly, and in that case the predicrotic wave comes to form the apex of the pulse curve, whilst the tidal wave is represented by a notch on the ascent; this is termed the 'anacrotic pulse.'

The most probable explanation of the dicrotic wave is given by Mackenzie as follows: $\dagger$ ' The semilunar valves

* This view, though supported by Mackenzie, is not universally accepted. Lewis, for instance, as a result of a recent careful study of the subject (Journ. of Anat. and Physiol., 1906-7, xli. 137), concludes that, in the great majority of cases, the primary and predicrotic waves are both genuine, and are of central origin.

†'The Pulse,' p. 20. 
are so delicately constructed that they readily respond when the pressure on one side rises above that on the other. As soon as the aortic pressure rises above the ventricular the valves close. At the moment this happens the valves are supported by the hard, contracted ventricular walls. The withdrawal of the support by the sudden relaxation of these walls will tend to produce a negative pressure wave in the arterial system. But this negative wave is stopped by the sudden stretching of the aortic valves, which, on losing their firm support, have now themselves to bear the resistance of the arterial pressure. This sudden checking of the negative wave starts a second positive wave, which is propagated through the arterial system as the dicrotic wave.'

This is not the place to describe all the modifications of the pulse curve which may occur in various states of health and disease. It must suffice to point out some of the more general clinical applications which follow from the exposition which has been given of the way in which its different parts are produced.

The ascent of the curve will obviously be abrupt in proportion as the output from the left ventricle is large, its contraction forcible, and the pressure in the arteries low. All these conditions concur in sthenic fever, and they are also present to an extreme degree in most cases of aortic incompetence, both of which conditions are therefore characterized by a sudden rise of the pulse.

On the other hand, the ascent will be gradual in proportion to the resistance which the heart experiences in expelling its contents into the aorta. Narrowing of the 
aortic orifice, therefore, and cases in which the diastolic pressure within the arteries is high are characterized by a pulse wave of gradual ascent

The apex of the curve will be well or ill sustained, and the downstroke gradual or abrupt, in accordance with the ease with which the blood can escape through the arterioles into the capillaries. When the arterioles are contracted, therefore, the apex is blunt and the pulse 'well sustained '; when they are dilated, it is pointed and the pulse 'collapsing.'

The predicrotic wave will be well marked when the artery tends to flatten itself slowly between the beats, and so allows the lever to rest upon it for a moment before collapsing. A well-marked predicrotic wave is, therefore, a sign of a high diastolic pressure in the artery. The dicrotic wave, on the other hand, is best marked when the pressure tends to fall rapidly after the pulse, so allowing the secondary rebound from the aortic cusps the opportunity to make its presence felt, which it could not do in a full vessel. A 'dicrotic' pulse is, therefore, usually met with in cases of low pressure due to rapid escape of blood into the capillaries, especially when combined with a short, sharp systole. Its presence, however, is not incompatible with high systolic pressure, provided the latter be of ventricular origin.

The pulse wave travels along the arteries at the rate of about 30 feet per second. Owing to the elasticity of the great vessels, part of the work of the heart is spent in distending them, and this causes a delay in the transmission of the wave of pressure, so that the pulse is not synchronous with the heart-beat, but follows it at an 
appreciable interval. It is for this reason that the radial pulse cannot be used in timing heart murmurs. The less elastic the arteries are, the less is the delay in the transmission of the pulse, and in cases of extensive atheroma the delay may for this reason be very slight. The actual time occupied by the pulse wave in passing any point-e.g., under the finger laid upon it-depends upon the resistance it has to overcome from in front. If the arterioles are contracted the resistance is great, and the pulse passes slowly, and in clinical language it is spoken of as a long pulse; on the other hand, if the arterioles be dilated so that blood escapes easily into the capillaries, the wave sweeps on rapidly and the pulse is short. In other words, a 'long' pulse is characteristic of high tension in the arteries, and a 'short' pulse of low tension.

We may sum up the characters of the standard or typical pulse of the adult male in the words of Broadbent,* as follow :

'It will have a frequency of seventy-two beats per minute, will be perfectly regular in time, and the beats will be of equal force.... The individual pulse waves reach the finger nearest the heart with a definite stroke, which can scarcely be described as sudden, still less as sharp; they have sufficient vehemence to be felt by all three fingers, unless decided pressure is made on the vessel, but they can be arrested without difficulty by one finger, the beat feeling then both more sudden and more vehement. The wave of expansion or distension of the artery does not instantly * 'The Pulse,' p. 46. 
drop, but subsides gently and without perceptible dicrotism.

'The sphygmogram corresponding to this description will have a nearly perpendicular rise, a moderate elevation, a rounded summit, and a gradual, almost unbroken fall.'

The great differences in the frequency, volume, force, and tension, and the character of the wave, in the pulse of different individuals are matters of common knowledge, and it is of interest to ask whether differences of pulse are indicative of differences in physical or mental constitution. It is instructive, on this point, to learn the opinion of such an experienced observer as Broadbent. 'Speaking generally,' he says,* 'I have found physical strength, energy, and endurance impartially associated with small, low-tension pulse, and with large arteries and high tension, and the reverse. I can say the same of intellect, perseverance, courage, and force of character generally; they appear to be absolutely independent of circulatory conditions. It is, indeed, clear that the circulation is not the determining influence in the production of the differences which are found to exist in respect of bodily or mental energy. The circulation is the servant, and not the master; and, physiologically, it is tissue activity which conditions the blood-supply, and not the blood-supply which conditions the tissue change. In disease, again, the modifications of the circulation which are observed are more frequently effects than causes, and the pulse is an index not so much of a more or less rapid movement of the blood, to be taken

$$
\text { * 'The Pulse,' p. } 48 .
$$


into account as a factor in the morbid processes, as of the state of the nervous system and of the body generally which has determined its rate and character.'

\section{The Capillary Circulation.}

As the whole aim and end of the circulation is to convey material to and from the tissues, the passage of blood through the capillaries is, in a sense, the most important part of the circulatory process. Unfortunately, however, the attention of physiologists has been until lately so much concentrated upon the arteries that we are still very far from being conversant with all the facts relating to the capillary circulation.

In what follows an attempt will be made to indicate briefly the present state of our knowledge on the subject, and its application to clinical medicine.

The capillaries are only about $\frac{1}{2}$ to 1 millimetre in length, but they form a network so dense that it would hardly be possible to stick a pin into any part of the body without injuring one of them. Notwithstanding this, the capillaries are by no means always full of blood, as is shown, for instance, by the great increase in redness of the skin when one applies a blister to it. They consist, anatomically, of a single layer of endothelial cells, which, although they appear to be of the simplest structure, are possibly endowed with important selective and other properties. In health this layer is so thin that it forms a mere hair line, but in disease it may become considerably thickened.

The appearance presented by the blood as it circulates through the capillaries must be so vividly present to the 
mental eye of anyone who has ever looked at the web of a frog's foot through a microscope that it calls for no description, but some of the conditions on which the character of the flow depends must now be considered.

The velocity of the capillary flow varies greatly0.5 to 25 millimetres per second being given as the extremes by some observers-and is constantly changing from time to time. It depends upon several factors, amongst which the energy of contraction of the heart and the pressure in the veins are of great importance. If the heart be contracting feebly, or if the back pressure in the veins be increased (and in most cases of circulatory failure these two factors co-operate), the blood flows so slowly through the capillaries that it becomes surcharged with carbonic acid, and the patient is cyanosed. Dilatation of the arterioles, which supply any part of the body, quickens the flow through the corresponding capillary area. This happens at the outset of inflammation. On the other hand, there is no constant relation between general blood-pressure and the rate of the flow. The viscosity of the blood is another factor of great importance, but of which little is yet known. In the tarry blood of cholera the viscosity is often so great that it will not flow through the capillaries at all. In polycythæmia, again, which raises the viscosity considerably, the capillary flow is so much impeded that the extremities of the patients are usually cold or dusky. Whether changes in the capillary wall may retard the flow is not certainly known, but retardation from such a cause has been postulated to explain the high bloodpressures sometimes met with in pathology. 
The pressure of the blood in the capillaries is only second in importance to the rate of flow, and upon it in large measure the amount of lymph transudation depends. The pressure in the capillaries is surprisingly high, being often, according to Hill, above 100 millimetres of $\mathrm{Hg}$. The capillary wall is so slender that it would be unable to withstand such a pressure were it not supported from without by the 'tension' of the tissues. The degree of this tension varies greatly in different localities, being greatest in the lower limbs and where it is low increased transudation from the capillaries, or even rupture of them from the strain of internal pressure, is apt to occur. This is the reason for subconjunctival dropsy and occasional ecchymosis as the result of the high tension of chronic renal disease for the tension' of the subconjunctival tissue is very low.

The pressure in the capillaries depends more upon the venous than upon the general arterial pressure. When the small arterioles are contracted the capillaries are thereby shielded to some extent from the high arterial pressure, and if the contraction be extreme the capillary pressure may fall to zero. On the other hand, if the pressure in the veins be raised it tells directly back upon the capillaries, and the transudation in them is increased. This is often a factor in the production of dropsy, and it is taken advantage of to increase local transudation in Bier's method of treatment. Dilatation of the arterioles raises the capillary pressure, and if the dilatation be local and the general blood-pressure high, the capillary blood-pressure in the area concerned may rise very greatly. This is the reason why hæmorrhage 
from the capillaries of the brain so often occurs in cases of high arterial pressure, for the cerebral arteries being unprovided with vasomotor nerves, there is no method of shielding the intracranial capillaries from the effects of the general rise.

The action of gravity may increase the capillary pressure very markedly. Thus the pressure in the finger is more than twice as high when the hand is hanging by the side than when it is raised to the level of the top of the head. It is for this reason that raising the hand relieves the pain and throbbing in an inflamed finger so noticeably.

The most important function of the capillaries is to permit of an interchange between the blood and the tissues, and two opposing views have long been held by physiologists as to how this takes place. The upholders of the mechanical theory, first propounded by Ludwig, maintain that the physical processes of diffusion, osmosis, and dialysis (which may be spoken of collectively as 'transfusion') are sufficient to explain all the facts; on the other hand, Heidenhain and the 'vital' school invoke a special secretory power on the part of the cells forming the capillary wall, and look upon lymph as a secretion of the capillaries, just as milk is a secretion of the mammæ or urine of the kidneys. The problem is one which is, perhaps, more of abstract physiological interest than of direct concern to the physician, but it may fairly be said that at present the views of the mechanical school tend to hold the field.

On neither hypothesis has a complete explanation yet been given of the chief anomaly of lymph production- 
dropsy. We know, indeed, that this must be due to an over-production of lymph, and not to a diminished absorption of it from the tissues, for ligature of the chief vein of a limb does not lead to its becoming codematous, but the parts played in the increased production by alterations in (1) capillary pressure, (2) permeability of the wall, (3) tissue-tension, and (4) composition of the blood respectively, have not been unravelled, and it is possible that in different cases each of these is responsible in different degree. We know still less of the opposite condition of diminished lymph formation, or whether, indeed, that ever occurs at all, although more knowledge on this head might explain some anomalies of nutrition which at present puzzle us. There appears to be no doubt that the permeability of the capillary wall varies in different localities. It is least in the limbs and greatest in the liver. This may explain how it is that ascites may be present in mitral stenosis without there being any evidence of dropsy elsewhere. It is possible, too, that the permeability of the wall is increased as the result of the action upon its cells of certain poisons which fail to be excreted in disease of the kidneys, and this may play a part in the production of renal dropsy.

\section{The Venous Circulation.}

The veins resemble the arteries in their essential structure, but contain relatively less muscular and elastic tissue, and a stronger external fibrous coat, which enables them to withstand the influence of gravity. They attain their maximum distension at a much lower 
internal pressure than the arteries, and when the pressure within them is much increased they easily become overdistended, and lose their elasticity. Hence it is that when the arterial pressure is brought to bear upon a vein by the establishment of a communication between it and an artery the vein becomes varicose (aneurysmal varix).

The flow of blood in the veins is determined br the following factors: (1) the vis a tergo of the arterial pressure; (2) the vis a fronte of the 'thoracic pump'; (3) the 'squeeze' exerted by the contraction of the muscles, and by the 'tissue-tension,' which, thanks to the veins being provided with valves, drive the blood always towards the heart. Gravity would exert a very great retarding effect on the flow were it not for the valves with which every vein subjected to its action is provided, but if these fail to act the flow is greatly impeded, as happens in cases of varicosity.

The influence of the vis a tergo will depend upon the degree to which the potential energy exerted by the force of the arterial pressure is obliterated by the peripheral resistance in the capillaries. If, owing to high viscosity of the blood or great contraction of the arterioles, the potential energy of the arterial system be greatly reduced, the velocity of the flow in the veins will be proportionately diminished, and in cases of heart. failure these factors help to bring the circulation to a standstill.

The influence of the vis a fronte exerted by the thoracic pump is almost as important as that of the arterial pressure, but will be fully dealt with when 
we come to consider the relation of respiration to the circulation.

The squeezing of the veins by contraction of the skeletal muscles is also a factor of great importance in promoting the venous flow, and is one of the chief reasons why muscular exercise so powerfully promotes the circulation. Whilst one is standing this factor is in abeyance, and the venous flow in the legs is sluggish; whereas during walking the veins are constantly being massaged by the contractions of the muscles of the legs, and the return of blood from them is brisk. It is for this reason that much standing tends to produce varicose veins, whilst walking does not. The military plan of 'marking time' when standing tends to counteract the tendency to stagnation of blood in the veins of the legs.

The pressure exerted by the 'tone' of the skin and tissues is only second in importance to the more active squeeze effected by the muscles. Where this tone is low, as in the scrotum, overdistension and varicosity of the veins easily occurs, and it used to be a recognized method of treating varicose veins in the leg to excise a large area of skin on the back of the calf, in order to increase the pressure on the veins by forming a natural 'elastic stocking.'

\section{Blood-pressure.}

Blood-pressure signifies the degree of fluid-pressure present within the vessels, putting their walls on the stretch. As commonly used, the expression refers only to the arterial blood-pressure, and as this is the sense in 
which it is always employed in clinical work, it will be used with that meaning in what follows.

The advantages of having a certain amount of fluidpressure within the arteries are these :

1. It ensures a 'head' of pressure by which any sudden demand for an increased supply of blood on the part of an organ or tissue can be immediately met.

2. It ensures an adequate degree of transudation of lymph for the nourishment of the cells.

3. It accommodates the amount of their contents to the size of the arteries, so that a considerable loss of blood can take place without the pressure falling to a dangerously low level.

It is obvious that the arterial pressure must always be at least high enough to overcome the resistance of the arterioles, and so ensure a steady flow of blood through the capillaries. The fraction of the total arterial pressure which is necessary for this purpose may be spoken of as the 'essential' element in blood-pressure, whilst the margin above this, which maintains a 'head of pressure' sufficient to meet the varying demands of the tissues, is the 'functional' element (Janeway). About 50 millimetres of mercury is the amount of the 'essential' pressure; the remainder (70 millimetres or more) is functional and variable.

In considering arterial pressure, one has always to distinguish between the pressure during the pulse wave or systolic pressure, and the pressure between the waves or diastolic pressure. Most clinical sphygmometers record the former, and it is systolic pressure that is ordinarily referred to when one speaks clinically of a 
patient's 'blood-pressure.' This distinction between the systolic and diastolic pressure has already been pointed out when the pulse was described, and it was then seen that the systolic pressure depends mainly upon the left ventricle and the diastolic pressure upon the degree of contraction of the peripheral arterioles. An estimation of the former, therefore, gives us most information about the heart; an estimation of the diastolic pressure about the tone of the arterioles. Information on both of these points is of great use clinically, but whereas we have many other means of ascertaining the efficiency of the heart, we have none of estimating the degree of peripheral constriction; it is, therefore, to be regretted that our clinical methods of measuring diastolic pressure are not more perfect.

The factors concerned in maintaining blood-pressure are :

\section{The Force and Output of the Left Ventricle.-} If the force fails or the output per beat diminishes, blood-pressure falls.

2. The peripheral resistance, which is made up of the opposition offered to the passage of the blood by the tonic contraction of the small arteries, by the friction produced in the capillaries by the viscosity of the blood, and by the 'tissue-tension.' Variations in the degree of

* Under the term 'tissue-tension' may be included not only the elastic pressure exercised on the vessels from without, but the atmospheric pressure, and all casual mechanical pressures the result of posture, etc. That these, collectively, are a considerable factor in making up the sum total of the 'peripheral resistance' there can be no doubt. The influence of external pressure, for 
the peripheral resistance are the most potent cause of individual and pathological variations in blood-pressure, especially of diastolic pressure.

3. The Elasticity of the Arterial Wall.-Without this there would be no diastolic pressure at all, and the flow would correspond to that through rigid tubes i.e., the pressure would be alternately very high and reduced to nil. In the rigid arteries of advanced atheroma an approximation to this state of things actually obtains.

4. The Volume of Blood in Circulation. - This factor is not of so much importance as might be expected, owing to the action of compensating mechanisms. If the total volume of the blood is lessened-e.g., by hæmorrhage - blood-pressure is temporarily lowered; but it is quickly restored again by the power of the bloodvessels to contract down and accommodate them. selves to the amount of blood they contain, whilst at the same time fluid tends to be withdrawn from the tissues. It follows from this that venesection is but of temporary use as a means of lowering tension. Conversely, if the amount of the circulating blood be increased-e.g., by transfusion-the blood-pressure is only raised for a short time, and to a comparatively slight degree; for the excess

example, has been shown by Crile, who found that, by enclosing a patient in a pneumatic rubber suit into which air can be pumped, the blood-pressure could be controlled to the extent of 25 to 60 millimetres of Hg. He makes use of the pneumatic suit in order to produce an artificial peripheral resistance in cases of shock, in which the general vasomotor centre is completely paralyzed (see 'Blood-pressure in Surgery'). 
of fluid is quickly drained off into the lymph spaces or accommodated in the large veins of the abdomen. Transfusion, therefore, may raise a depressed bloodpressure to the normal level, but it cannot do much more than this, and, like venesection, its effect tends to be very transient.

There is but very little difference between the pressure in the large arteries near the heart and that in the smaller peripheral arteries. It is only when the arterioles themselves are reached that a rapid and notable fall of pressure occurs. Hence it is immaterial which artery is selected for the clinical estimation of the blood-pressure, and the brachial, which is the artery usually chosen, will afford quite a trustworthy indication of the aortic pressure.

\section{Variations in Blood-pressure.}

The general arterial blood-pressure tends, like the body temperature, to be maintained at an extraordinarily constant level, and such variations as do occur are more in an upward direction than a downward-i.e., abnormally high pressures are much commoner than abnormally low ones. It would appear, indeed, that the normal degree of pressure is pretty near the minimum at which life can be constantly sustained, and every effort is made to uphold it.

The normal systolic pressure in a healthy young adult male is about 120 millimetres $\mathrm{Hg}$, and the diastolic pressure about 100 . In women they are about 10 per cent. less, and in children the systolic pressure may be 
as low as 90 millimetres $\mathrm{Hg}$, with a diastolic pressure of about 80 . As age advances pressure tends to rise, on account of lessened elasticity of the vessels.

It must be noted, however, that the blood-pressure differs from the body temperature, and resembles the pulse rate in that it is not necessarily the same for all healthy individuals of the same age. In some persons and families the pressure tends to be habitually low; in others it is always above the normal, and, just as in the case of the pulse, there is no constant mental or physical peculiarity which one can associate with these differences. Seeing, however, that a high arterial pressure must tend to determine a relatively large amount of blood to the brain, owing to the uncontracted cerebral arteries offering the path of least resistance (see p. 175), one might expect an habitually high arterial pressure to be favourable to the performance of mental work. Families in whom such habitually high tension is discernible are often 'gouty,' and it is interesting in this connection to remember that gout has been described as the 'disease of the intellectual'-the dominus morborum, et morbus dominorum.

There appears to be a slight diurnal variation of pressure in health in the direction of a rise in the morning and a fall at night, corresponding to the morning fall and the evening rise in temperature and pulse rate.

Rest tends to lower pressure, whilst exercise increases it at first, but ultimately lowers it. Thus, a man may start out for a walk with a systolic pressure of 125 , which during the first half-hour may rise to 140 or 150 ; 
but as he continues his walk, and the peripheral arteries dilate, it drops to 100 or less. Sudden or violent effort raises the pressure abruptly (though briefly), and is a fertile cause of apoplexy in persons whose tension is abnormally high. Mental work also raises the pres sure considerably, and those who use their brains much are often the subjects of high tension. Excitement is an even more potent elevator of blood-pressure, and explains the frequency with which cerebral hæmorrhage is associated with anger; hence the expression 'apoplectic with rage.' The possible disturbing influence of excitement should always be borne in mind when making blood-pressure observations on patients. Posture is also of considerable influence, the pressure being about 10 millimetres less when lying down than when standing up. This will be referred to again when we come to speak of the effect of gravity on the circulation.

Cold contracts the peripheral arteries, and raises the pressure, so that the first onset of cold weather in winter is apt to be attended by a crop of apoplexies. Warmth has the opposite effect. Hence during a spell of hot weather an arterial pressure may appear quite normal which in ordinary conditions would exceed the upper physiological limit (Oliver).

A meal has much the same effect on pressure as exercise, raising it at first, and causing a fall later. Sleep has the reverse effect, the pressure falling during the first few hours and then rising gradually up to the time of waking.

The effect of all these influences is a transient one, for, as has been already pointed out, the mean blood- 
pressure tends to be maintained at a very constant level; but they are of sufficient importance to make it necessary to exclude them when making blood-pressure estimations in patients.

\section{Regulation of Blood-pressure.}

The constancy of the arterial blood-pressure is attained by the control exercised over it by the general vasomotor centre, which exerts a continuous tonic influence upon the muscular coat of the arterioles. By the agency of this centre and its nervous connections the general blood-pressure is kept fairly constant, whilst at the same time the varying local needs of the organs or tissues for an increased blood-supply are provided for, as will be described more fully when we come to speak of the distribution of blood in the body.

When the pressure in the arteries tends to rise very high, the heart is slowed through the influence of the vagus, the reflex being probably started by the pressure of the blood in the left ventricle; and at the same time its output is lessened, and thus the high pressure tends to be counteracted. The diminution of output may in these circumstances become so great that the ventricle does not completely empty itself at each systole, with the result that blood is dammed back into the lungs, and thence into the veins, and all the symptoms of back pressure result. Hence in conditions of high tension one may get all the clinical signs of heart failure without there being any defect of the mitral valve.

If the rise of arterial pressure be very abrupt-as, 
for example, during sudden muscular effort-and if the heart tends to be overwhelmed by it, the depressor fibres of the vagus come into action, and the vasomotor centre is reflexly inhibited, with the result that the blood-pressure suddenly falls and the heart is relieved.

Seeing that such efficient arrangements exist for counteracting abnormally high blood-pressure, it is difficult to understand how a continuously abnormal degree of tension can exist unless there be some derangement of the compensating mechanism. Abnormal lowering of the blood-pressure is not so easily compensated for, but it is noteworthy that anæmia of the medulla stimulates the general vasomotor centre, and in this way a fall of blood-pressure from hæmorrhage is counteracted. When the pressure is low, too, the action of the heart is more rapid, and the total output of blood from it in a given time greater, and this also tends to raise the pressure again towards the normal level.

\section{Distribution of Blood in the Body.}

Intimately associated with blood-pressure is the question of the distribution of the blood in the body. We have seen that the existence of blood-pressure is in part the result of the necessity for accommodating the vascular 'bed' to the volume of the circulating blood. The capacity of the vascular system is so great that it could accommodate one-half or one-third as much blood as it already contains, and the volume of the blood can be increased by this amount without the pressure in the aorta being affected, for the vessels simply relax in order 
to make room for the increased quantity. In conditions of true plethora, and in chlorosis, the total volume of the blood may be increased to this amount, and the vasomotor centre accommodates the vascular area to it without affecting the pressure.

On the other hand, if. the vasomotor centre be paralyzed the vascular bed is so much widened that the blood simply accumulates passively in the most dependent part of it, or in the large splanchnic area. In these circumstances the return of blood to the heart becomes less and less, and finally the circulation may come to a standstill, even although the heart is still quite fit to maintain it were it only supplied with blood. This is what happens in surgical shock and in the 'collapse' which often comes on in acute disease; and the indication in such cases is not to stimulate the heart, but artificially to increase the peripheral resistance (see footnote, p. 162).

In the distribution of the blood as a whole there is a reciprocal action between the splanchnic system and the more peripheral parts of the circulation. When blood is wanted at the periphery the splanchnic vessels are contracted by the vasomotor centre and the normal level of the blood-pressure maintained. This happens, for instance, when the cutaneous vessels are dilated by heat, and if the compensating mechanism be not in good working order, the blood-pressure may fall so low that the individual faints. Many cases of 'collapse' in hot weather are brought about in this way. On the other hand, when more blood is wanted in the splanchnic system, the peripheral vessels contract to make up for it; hence 
the occurrence of cold feet in many persons or a general feeling of coldness during the early stages of digestion.

The splanchnic system may be described as the 'resistance-box' of the circulation (Hill), by means of which variations in the systemic blood-pressure are regulated, and examples of its operation have already been given. In addition to this, the circulation possesses two regulating 'reservoirs' in the liver and lungs. As Stolnikow has pointed out, the liver acts as a blood reservoir on the systemic circulation, so that the right heart may take a greater or less volume of blood from the great veins without materially modifying the systemic pressure. The lungs play a similar part to the left heart, acting as a reservoir in which blood may be stored if the left heart for some reason diminishes its output, and, conversely, contains a reserve of blood upon which the left heart draws when its output increases (Brodie). Overfilling of the pulmonary and hepatic reservoirs are prominent features among the 'backpressure' signs of a failing heart.

Local variations in blood distribution are controlled by the tissues or organ concerned themselves. By means of afferent impulses the tonic constriction normally exerted on the arterioles of the part by the vasomotor centre is cut off, the arterioles dilate like stop-cocks which have been suddenly turned on, and the general arterial pressure drives more blood into the dilated area In the case of org $n s$ in which a sudden and very copious blood-supply is often demanded vasodilator nerves are present as well, by means of which an active dilatation of the arterioles is brought about. 
This local control of the blood-supply is apt, as might be expected, to become deranged with resulting disease. Sometimes, for example, as in the syncopal stage of Raynaud's disease, the arterioles pass into a state of spasm, and the blood-supply to the part is entirely cut off, so that it goes white and cold. A similar state of things on a larger scale occurs in the condition known as ' intermittent limp.' On the other hand, a permanent dilatation of the arterioles is the cause of the local capillary congestion known as erythromelalgia. In neurasthenic subjects the local control of the circulation by the vasomotor system seems to be peculiarly feeble, and many of the symptoms of which they complain, such as throbbings and flushings, and probably many more obscure symptoms as well, are the result.

That the veins of a part as well as its arteries are subject to nervous control there can be little doubt. In no other way could one explain, for example, the spasm of veins which seems to be the cause of the asphyxial stage of Raynaud's disease. Both the inflow and outflow of blood, therefore, can be regulated through the nervous system.

\section{The Influence of Gravity upon the Circulation.}

The pressure effects exerted by the influence of gravity on the contents of the bloodvessels may be spoken of as the hamostatic pressure, as opposed to the hamodynamic pressure which results from the action of the heart. The actual pressure at any point of the vascular system is equal to the sum of these two (see Scheme). In a man of 6 feet the hydrostatic pressure of a column of blood, 


\section{THE CIRCULATION}

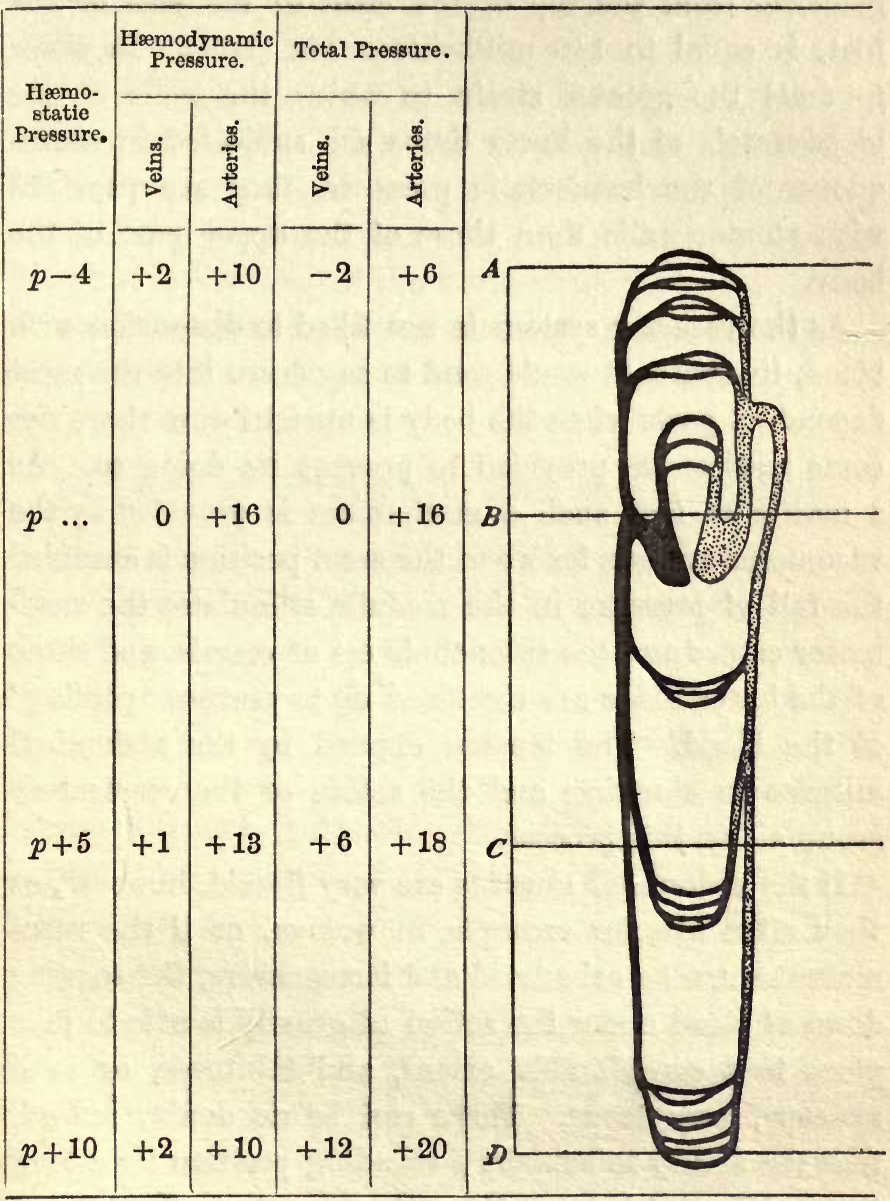

Scheme of Blood-Pressure Relations in the Systemic Circulation in the Vertical Position. (Thoma.)

$A=$ level of top of head ; $B=$ level of venous orifices ; $C=$ level of umbilicus ; $D=$ level of feet ; $p=$ pressure at venous orifices in $\mathrm{cm}$. of mercury. 
reaching from the top of the head to the sole of the foot, is equal to 140 millimetres $\mathrm{Hg}$ (Hill). In order to meet the greater strain to which the walls of the bloodvessels of the lower limbs are subjected in consequence of the hæmostatic pressure, they are provided with stouter walls than those of the upper part of the body.

As the vascular system is not filled to distension with blood, its contents would tend to sag down into the most dependent parts when the body is upright were there not some mechanism provided to prevent its doing so. As a matter of fact, such a mechanism is provided by the vasomotor system, for when the erect position is assumed the fall of pressure in the medulla stimulates the vasomotor centre and the splanchnic set of vessels, and those of the lower limbs are tightened up to prevent 'pooling' of the blood. The tension exerted by the abdominal muscles in standing and the action of the respiratory group aid in this process.

If the abdominal muscles are very flaccid, however, as they often are, for example, in women, or if the vasomotor centre be exhausted and irresponsive, the sagging down of blood under the action of gravity is able to take place to a considerable extent, and faintness, or even syncope, may ensue. There can be no doubt, indeed, that the ability to support a standing position for a long time without faintness depends upon the efficiency of the counteracting mechanism. In feeble subjects, in conditions of great fatigue, and after long confinement to bed, the efficiency and promptitude of the mechanism are impaired, and in such circumstances if an individual 
be suddenly set up in the erect position the blood may settle down into the most dependent parts by hypostasis, and the heart stop owing to its being no longer kept filled with blood. This has already been referred to when the mechanism of shock was described (p. 168).

The less the hæmodynamic pressure, the more pronounced is the effect of the hæmostatic pressure. Hence sudden changes of position are most dangerous in those whose arterial blood-pressure is low.

\section{Influence of Respiration upon the Circulation.}

Owing to the negative pressure within the thorax (p. 190), the heart and part of the large veins are really placed in a partial vacuum, which has the effect of helping to fill the heart during diastole. By the act of inspiration this suction effect is greatly increased, whilst at the same time blood is squeezed out of the large abdominal veins into the inferior vena cava. As a result the current of blood in the large veins is accelerated, and the right heart more rapidly filled. At the same time the pathway for the blood through the lungs is opened up, and the escape of blood from the right side round to the left is greatly facilitated. It can readily be understood from this what a great aid the action of the respiratory pump is to the proper carrying on of the circulation. If, however, the action of the respiratory pump be interfered with, as it is, for example, in emphysema, the circulation is apt to become laboured, and the large veins engorged with blood. One consequence of the orthopnœa of cardiac disease is to facilitate 
the action of the pump as an auxiliary in maintaining the circulation. In cases of pericardial effusion the heart, instead of being placed in a vacuum, is subjected to a constant positive pressure which interferes greatly with its proper filling; hence the large veins become overdistended, whilst the output of the left ventricle falls.

Owing to the aspiration of blood into the chest at each inspiration, a certain degree of 'pooling' of it takes place in the lungs at the commencement of the act, and in consequence the output from the left heart is diminished at first, and the arterial blood-pressure falls. So soon, however, as the blood has had time to find its way round to the left ventricle the output rises again above the average, and the blood-pressure rises in proportion. If there be any obstruction to the free entry of air into the lungs, the amount of blood which can be accommodated in the thorax is all the greater, and in such circumstances the output from the left ventricle may fall so low that the pulse disappears for a time. This result is all the more likely to ensue if the peripheral arterioles be dilated, so that blood can readily pass out of the arteries into the veins-i.e., in conditions of low arterial pressure. Such a temporary disappearance of the pulse during inspiration is spoken of clinically as the pulsus paradoxus.

\section{The Cerebral Circulation.}

The circulation in the brain is so peculiar, and at the same time its disturbances are of such clinical importance, that it demands a special description. The peculiarity 
consists in two points : (1) the cerebral arteries alone of all systemic arteries in the body are not under the direct control of the vasomotor centre; (2) the circulation takes place in a rigid, enclosed space. Seeing that the cerebral arteries are not endowed with vasomotor nerves, they do not participate in any general constriction of the arteries brought about by the vasomotor centre. On the contrary, as the blood-pressure throughout the body tends to rise as the result of such constriction the blood, choosing the path of least resistance, passes through the intracranial cavity in increased amount.

General vasoconstriction, therefore, increases the amount of arterial blood which the brain receives, and cerebral hyperæmia is a necessary concomitant of high blood-pressure, and may explain some of the symptoms of the latter.

Seeing, again, that the skull forms a rigid box, and that its contents are incompressible, this increased amount of arterial blood can only be accommodated by the squeezing out of a certain amount of cerebro-spinal fluid or of venous blood.

If a foreign body - such, for example, as a blood-clotbe introduced into the intracranial cavity, room can only be found for it at the expense of a certain amount of blood-i.e., the brain becomes to a greater or lesser degree anæmic. If the anæmia increases to such a degree as to affect the arterial flow through the medulla, the vasomotor centre experiences its effects, and responds by constricting the arterioles throughout the body, with the result that the general blood-pressure rises and more arterial blood is squeezed through the brain to make 
good the deficit. Hence it is that clinically cerebral compression is marked by increased blood-pressure, and this increase of pressure must be regarded as essentially conservative in its action, and designed to compensate for the cerebral anæmia which compression causes. It is therefore not lightly to be interfered with-e.g., by venesection.

The intracranial tension or pressure of the brain against the skull wall is, as Hill has pointed out, purely circulatory in origin, and is the same as the cerebral capillary or venous pressure, and varies with every change of pressure in the aorta or superior vena cava; but, like capillary pressure generally, it is more sensitive to an increase of tension in the veins than in the arteries (see p. 155). It is for this reason that an abrupt rise of venous pressure - such, for example, as occurs when any effort is made with the glottis closed-may easily rupture a weakened cerebral capillary. This is the explanation of the frequent occurrence of apoplexy during straining at stool. 


\section{CHAPTER VI}

\section{THE APPLIED PHYSIOLOGY OF RESPIRATION}

\section{The Air Passages.}

The nose is an organ whose function it is to protect the lungs in the same way as the mouth protects the stomach. It 'cooks' the raw external air, if one may use the expression, and renders it fit to enter the lungs. It is enabled to do this - by the tortuous course of its airway, and by its succulent mucous membrane so richly supplied with nerves, vessels, and glands. As the air enters the nostrils, any large particles of foreign matter which it contains are entangled by the vibrissæ, which like sentinels guard the entrance to the nasal cavities. The current of air then sweeps upwards and backwards in a curved direction to pass over the superior and middle turbinated bodies. In its course it is further purified from foreign particles by the layer of viscid mucus which covers the lining membrane, and which catches particles of dust and bacteria as a fly-paper catches flies. At the same time the air is moistened and warmed. It is moistened by the evaporation of the watery secretion produced by the glands embedded in the mucous membrane, and it has been calculated that the nose yields up to the inspired air in 
this way as much as $\mathbf{2}$ quarts of water in the twentyfour hours. It is warmed by passing over the highly vascular mucous membrane, the surface of which is increased by the projection of the turbinates, just as the surface of a radiator by which one warms a room is multiplied by its projecting metal bars. How efficiently the warming is carried out may be judged from the result of experiments, which show that air entering the nose at the freezing-point is warmed to a temperature of $81^{\circ} \mathrm{F}$. by its passage through the nose alone.

But the nerves of the nose have also a protecting part to play. The sense of smell is no doubt primarily protective rather than æsthetic. It warns us of the presence of gases which might be injurious to the lungs. Nor is the common sensibility of the nose without its uses. Stimulation of the branches of the fifth nerve in the nasal mucous membrane has been found to induce a reflex contraction of the bronchial muscles,* and so prevent the entrance of air into the lungs. It can easily be understood that in many circumstances-as, for example, when irritating fumes have been inadvertently inhaled-this may be a real source of protection to the lungs.t Sometimes, on the other hand, this reflex mechanism becomes unduly sensitive, and brings about spasm of the bronchial muscles on quite inadequate provocation, and it is in this way that some cases of asthma are caused.

* See Dixon and Brodie, Journ. of Physiol., 1903, zxix. 97, and Trans. of the Path. Soc. of London 1903, liv. 17.

T See Mackenzie, Amer. Journ. of Med. Sciences, 1883, lxxxvi., 106; also Riegel and Edinger, Zeit. f. Klin. Med., 1882, v. 413. 
As the air leaves the posterior nares, its course turns sharply downward, and the stream impinges on the posterior wall of the pharynx; and it is here, perhaps, more than anywhere else that particles of dust are most likely to get entangled. It is not to be wondered at, then, that the inhalation of dust is apt to produce a pharyngitis.

The functions of the nose in respiration, then, are (1) to free the air to a large extent of suspended particles and micro-organisms; (2) to warm it ; (3) to saturate it with moisture; (4) to advertise us of the presence of noxious gases, and, by a reflex mechanism, to prevent the entrance of irritating fumes into the lungs.

The disadvantages of mouth-breathing will now be apparent, for the buccal cavity is not primarily designed to fulfil the above requirements for the modification of the air before its entry into the lungs. It is true that the warming process is almost as efficiently carried out by the mouth as by the nose,* but the absence of a sufficient apparatus of secreting glands renders it almost impossible for the mouth to moisten the air sufficiently without its mucous membrane becoming dry and irritated in the process; hence the parched, cracked tongue produced by the stertorous breathing of apoplexy and the dry morning throat of the nocturnal mouth-breather. Dust and micro-organisms, too, are less perfectly removed by the mouth, and, reaching the bronchi, set up irritation there. This probably explains the frequent association of bronchitis with adenoids and other causes of nasal obstruction.

* Kayser, Pflïger's Archiv, 1887, xli. 127. 
The Trachea and Bronchi.-The trachea and large bronchi are wide tubes kept permanently patent by hoops of cartilage. Scattered through their wall are numberous bands of elastic fibres, chiefly longitudinal in direction, which permit of a certain amount of stretching as the lungs move up and down in respiration, or when the head is thrown back. The free ends of the hoops of cartilage are connected by unstriped muscle - fibres, the function of which it is difficult to understand. Embedded in the wall of these tubes are numerous mucous glands, the secretion of which moistens the surface of the mucous membrane, and entangles such particles of dust as have escaped capture in the nose. Lining the tube is a layer of stratified ciliated epithelium, the cilia of which are constantly engaged in maintaining an upward current in the mucus poured out on the surface, so that particles of foreign matter are floated away from the direction of the lungs. The removal of such particles is also facilitated by the existence in the submucous coat of masses of adenoid tissue, the cells from which wander into the tube and lay hold of intruding bodies, and carry them off to be dealt with in the lymphatic glands. As the bronchi break up after entering the lungs, the hoops of cartilage become replaced by smaller plates, which allow of partial collapse of the tubes during expiration; and as the breathing surface is approached these disappear altogether, neither cartilage nor glands being found in the walls of the bronchioles, which measure only half a millimetre in diameter. As the cartilage disappears, however, the muscular layer in the wall becomes more pronounced, 
and can be seen to consist of two layers-one circular, the other longitudinal. The function of the circular layer in controlling the entrance of gases into the air cells, and the inconvenience it may give rise to in the shape of asthma, have already been pointed out. The longitudinal layer probably aids in producing the contractility of the lung (vide p. 188). It is believed, too, by some that the asthmatic attacks which sometimes supervene in the course of chronic bronchitis are due to the inflammatory products which infiltrate the bronchial wall, affecting the delicate longitudinal fibres more than the circular, with the result that the action of the latter is unopposed and spasm supervenes.*

Each bronchiole terminates in a 'lobule,' which may be regarded as the ultimate pulmonary unit, $\dagger$ or a lung in miniature, shut off by a fibrous covering and endowed with its own vessels, nerves, and lymphatics, and capable of becoming the seat of disease independently of the other lobules by which it is surrounded. In the interior of the lobule the bronchiole subdivides into still smaller divisions (intralobular bronchioles), the terminal branches of which end in the narrow alveolar ducts, which expand in turn into the comparatively wide infundibula lined by their air cells. This sudden widening out of the air passage is believed to aid in the production of the ' inspiratory sound' heard in ausculting the lungs, eddies being set up in the passage of the air from the narrower to the wider cavity.

When the lungs expand during inspiration the infun-

* Aufrecht, Deut. Arch.f. Klin. Med., 1900, lxvii. 586.

† See Ewart, 'The Bronchi,' etc. (Lond.), 1889. 
dibula are enlarged, whilst the alveoli lining them are widened and flattened out. Keith's observations* show that the infundibula in the anterior and superficial parts of the lungs are larger and more easily distended than those which occupy the deeper and posterior parts, and it is to this, perhaps, that their greater liability to suffer from the overdistension of emphysema is to be attributed.

The alveoli, or air cells, are the respiratory units. Their walls contain a large quantity of elastic tissue, to which the contractility of the lungs is due. They also contain a dense network of capillaries, the meshes of which are no larger than the diameter of the individual twigs. In these the blood is spread out and separated from the air in the alveoli only by the walls of the capillaries and by a single layer of endothelial plates, not even provided with nuclei, and through which interchange between the blood and the lungs can readily take place. In the meshes of the capillary network, however, where interchange does not occur, one finds smaller and nucleated cells, from which the larger plates appear to be continually renewed. It has been calculated that the total area of the alveolar surface of the lung amounts to no less than 90 square metres, or 100 times the body surface, from which one can realize how perfect the arrangements for bringing the blood and the air into proximity are. Here, however, as in all the organs of the body, ample provision has been made for accidental contingencies, and the fact that life can be maintained

* 'Why Does Phthisis Attack the Apex of the Lung?' (London Hosp. Gaz., 1904, х. 99). 



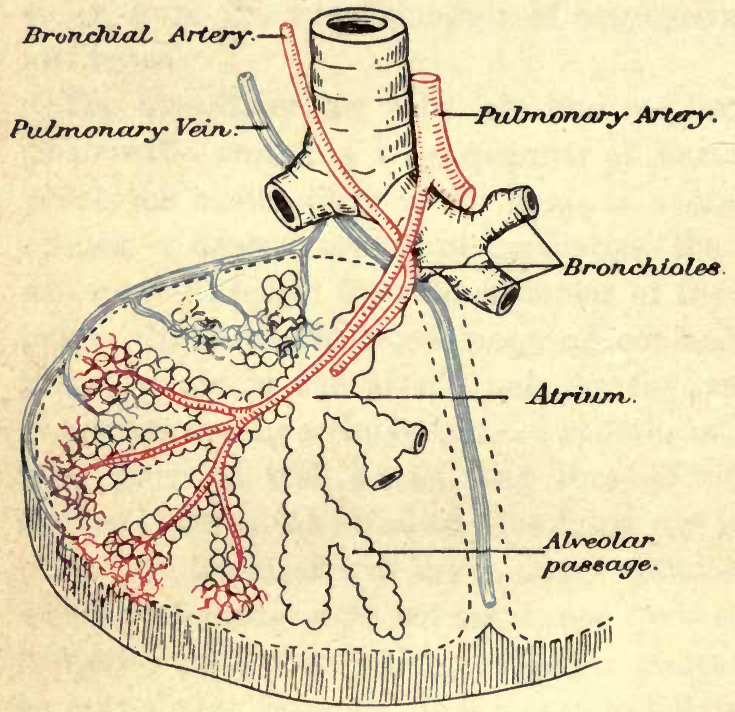

Plate II.-Diagram of a Lobule of the Lung (AFTER Stöhr). 
even when one lung has been completely destroyed, or rendered temporarily useless by disease, shows that a much smaller alveolar area than this is sufficient to allow of efficient oxidation of the blood.

\section{Bloodvessels, Nerves, and Lymphaties of the Lung.}

Each lobule is supplied by a branch of the pulmonary artery, which accompanies the bronchiole and divides with it, ending by pouring its blood into the capillary network in the walls of the alveoli. From the margin of that network the purified blood is taken up by a branch of the pulmonary vein, and ultimately returned to the left auricle. The lobular branches of the pulmonary artery are therefore 'end arteries,' and so liable to become the seat of embolic infarction-a process often met with in cardiac disease.

The balance of evidence is opposed to the view that the pulmonary bloodvessels are possessed of vasomotor nerves.* Hence, perhaps, the ease with which they become the seat of passive engorgement when there is any obstacle to the onflow of blood into the left heart, and enable the lungs to act as a reservoir for the pulmonary circulation in much the same way as the liver serves the systemic. There can be no doubt, also, that such passive congestions play a large part in the diseases of the lungs. By the expansion of the lungs during inspiration the alveolar capillaries are opened out and

* See Brodie, 'The Pulmonary Circulation,' Lancet, 1902, i. 803. 
the circulation through the lung facilitated; during expiration, on the other hand, the pulmonary circulation is much more difficult (Fig. 9). This is one reason why a patient whose circulation is embarrassed tends

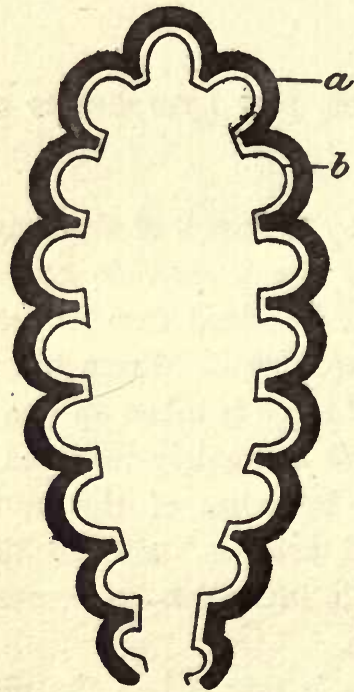

$\boldsymbol{A}$

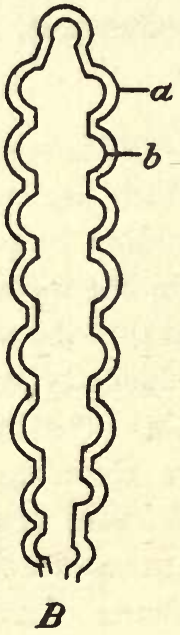

Fig. 9.

These diagrams represent an infundibulum, $A$ at the end of a complete inspiration, and $B$, at the end of a complete expiration. $b=$ alveolar wall ; $a=$ bloodvessels of the same. It will be seen that the amount of blood in the lungs varies directly with the amount of air, and that the pulmonary bloodvessels are most dilated and the resistance to the right heart least at the end of a full inspiration; while, contrariwise, the vessels are most contracted and the resistance to the right heart greatest at the end of a complete expiration. (Harry Campbell.)

instinctively to keep his chest as much as possible in the position of inspiration.

The absence of a vasoconstrictor supply to the pulmonary arteries also implies that suprarenal extract 
(which acts only on the terminals of such nerves) can be of no use in checking hæmorrhage from the lungs.

In addition to the pulmonary set of vessels, each lobule is provided with a branch of the bronchial artery for the nourishment of its own tissues. Free anastomosis between the pulmonary and bronchial sets occurs at the edges of the alveoli, which render the latter liable to become the seat of congestion, both in obstruction to the return of blood through the pulmonary veins, as, for example, in mitral regurgitation, and when there is a damming back of blood in the venæ cavæ, as occurs when the lungs themselves are the seat of the obstruction-e.g., in emphysema. In both events bronchitis will be apt to ensue.

The pulmonary pleura is supplied by the bronchial arteries, and the parietal pleura by the internal mammary and intercostals, whilst the venous blood is carried away by the azygos veins. The latter are very imperfectly provided with valves, and hence when the pressure in the right heart is raised the venous radicles in the pleura readily become congested, and effusion (hydrothorax) results.

Unlike the pulmonary vessels, those of the pleura are supplied with vasoconstrictor nerves, which renders them susceptible to the action of adrenalin. Advantage has been taken of this fact by Barr in the treatment of pleural effusion.

There are two sets of lymphatics in each pulmonary lobule. First, a central set which accompany the branch of the pulmonary artery and pass direct to the bronchial glands at the root of the lung; the flow of lymph in 
these is promoted by the pulsation of the adjoining artery. Secondly, a peripheral set which run in the fibrous tissue between the lobules, and often into the lymphatic plexus of the pleura. The flow in these is kept up by the respiratory movements of the lung. It will therefore be most active where these movements are freest-e.g., in the lower and anterior parts of the lung, and most sluggish where expansion is least-e.g., at the apices. This helps to determine the greater liability of the apices to become the seat of tuberculosis. Both of these are in communication with the air cavities by means of stomata, and are provided with valves, so that any foreign particles which have successfully run the gauntlet of the arresting mechanisms of the nose and air passages are finally conveyed either to the bronchial glands or pleura.

It is in this way that disease of these parts is so often set up. Tubercle bacilli, for instance, get lodged in the bronchial glands, and set up there a local tuberculosis, which may become the starting-point of a general infection; or particles of dust pass from the alveoli to the pleural cavity, and are thence taken up into the costal pleura, and may thus excite a pleurisy by purely mechanical means.* A consideration of these facts still further emphasizes the importance of keeping the nose and other protective mechanisms of respiration in a healthy condition.

The respiratory movements favour absorption from the pleural cavity, acting like a 'pleural pump' through the stomata, and as these movements are more extensive

* Grawitz, Berlin. Klin. Woch., 1897, xxxiv. 621. 
in the erect position, the absorption of a pleural exudate may be favoured by allowing a patient to get up and move about. A very large effusion, however, may stop the action of the 'pump,' and in such a case removal of part of it by aspiration may restart the mechanism, and be followed by spontaneous absorption of the remainder.

Compared with that of most other organs, the lymphatic supply of the lungs is peculiarly abundant, a circumstance which, whilst it undoubtedly predisposes to rapid toxic absorption from the pulmonary surface, also facilitates the speedy absorption of fluid or inflammatory exudates which have been poured out into the alveoli. As the lung expands during inspiration the stomata in the alveoli open up, and absorption is made much easier. In accordance with this, one finds that the clearing up of a pneumonic exudate often goes on much more quickly if the patient is allowed to get up and move about a little, for that ensures deeper breaths than when he is lying in bed. It has been pointed out* that there is much less variation in respiratory pressure at the apices of the lungs than elsewhere. The blood and lymph flow are thus not so well promoted in these regions, with the result that they are apt to be less well nourished than the rest of the lungs. The bearing of this upon the special liability of the apices to become the seat of tuberculosis has already been pointed out.

The nerves of the lobule are derived from branches of the vagus, which supply motor twigs to the muscle of the bronchioles and sensory fibres to the alveoli. The broncho-constrictor fibres of the vagus are of great

* Hofbauer, Zeit. f. Klin. Med., 1906, lix. 38. 
interest, for there is no doubt that reflex stimulation of them is the cause of asthma. As has been already mentioned, reflex constriction of the bronchioles can be best obtained by exciting the nasal mucous membrane, but it can also be induced by impulses from other organs-e.g., the stomach. Certain drugs have a marked effect on the apparatus. Muscarin, for example, stimulates the nerve endings, and may induce an artificial asthma, whilst the inhalation of chloroform or ether, or the injection of atropin, abolishes the effect of the vagus and leads to bronchial relaxation.

\section{The Mechanies of Respiration.}

The lungs may be compared to two elastic bags partially distended with air and enclosed in a closed box, the thorax. They are only prevented from collapsing altogether by the pressure of the atmosphere (amounting to 15 pounds to the square inch), which can reach their interior through the air passages, but is prevented from pressing on their outer surfaces by the resisting chest wall. When the chest wall is perforated, the lung on that side at once falls in to about one-fifth of its original bulk.*

This tendency of the lungs to collapse-their 'contractility,' as it may best be called-is the result mainly of the large quantity of elastic tissue in the lung substance, but in part also, perhaps, of the tonicity of the muscular fibres in the walls of the bronchi, and has been described by some writers as 'pulmonary tone.' $\dagger$

* See Salter, Lecture on Dyspncea, Lancet, 1865, ii. 111.

† Samuel West, Med. Chir. Soc. Trans., 1898, Ixxxi. 273. 
It is easily overcome by too great an inflating strain, as happens in some forms of emphysema, and for this reason artificial inflation of the lungs by bellows is dangerous; and it is also diminished when the lung is floated up by fluid in the pleura or when it is the seat of acute congestion. The normal 'lung note' obtained on percussing the healthy chest depends on a proper 'tone' in the lungs, and when that is diminished, as happens, for example, in the upper part of the lung when there is an effusion into the pleural cavity or where the lung is the seat of acute congestion or miliary tuberculosis, a more resonant and even tympanitic percussion note is obtained (Skodaic resonance).

The surface of the lung is bound to the chest wall by an 'atmospheric ligament,' which acts in the same way as a rubber sucker (Keith). This permits of the lung gliding freely over the interior of the thoracic wall without the bond being broken. The weight required to separate the visceral from the parietal pleura over both lungs amounts to about a ton, which is far greater than any force the inspiratory muscles can bring to bear. Hence by no muscular effort can the pleural bond be broken.

The contractility of the lungs causes them to exert a certain 'pull' on the chest wall and on the mediastinum (Fig. 10). A sort of 'tug-of-war,' indeed, goes on between the two lungs, with the mediastinum and its contents as the rope, so that if one lung becomes collapsed-e.g., in pneumothorax - the other, being no longer opposed, pulls over the heart and other mediastinal organs to its own side. It is mainly in this way that displacement of the 
heart is produced in cases of pneumothorax and pleural effusion.

The 'pull' of the lungs on the chest wall entails a slightly negative pressure (amounting to about 6 milli-

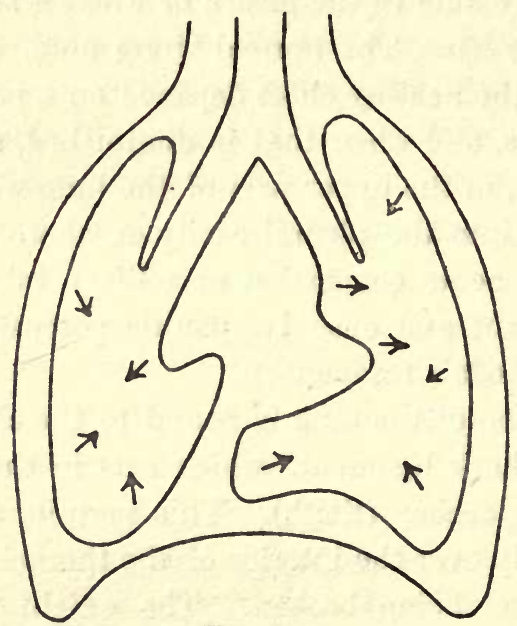

FIg. 10.

The arrows represent the direction of the 'pull ' exerted by the lungs by means of their contractility.

metres $\mathrm{Hg}$ ) in the pleural cavity and on the heart.* This favours the effusion of fluid (hydrothorax) when

* The following table exhibits approximately the variations in the intrathoracic pressure under different conditions:

Milligrammes Hg.

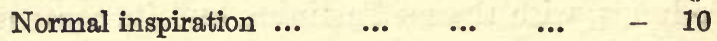

$\begin{array}{llllllll}\text { Normal expiration } & \ldots & \ldots & \ldots & \ldots & \ldots & - & -7\end{array}$

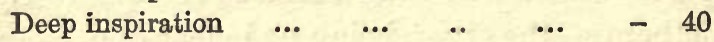

Deep expiration $\quad \ldots \quad$... $\quad \ldots \quad$... $\quad$ - 0

Deep inspiration with air passages closed $\quad-100$

Deep expiration with air passages closed $\quad+100$ 
the pleural bloodvessels are passively congested. As fluid is poured out, the contractility of the lung is gradually able to assert itself, and the organ continues to recede pari passu with the encroachment of the fluid. As it does so the negative pressure gradually diminishes, but it requires a large effusion to produce a really positive pleural pressure. Hence the necessity for aspiration in removing small effusions. If one lung collapses, the other, being no longer pulled on from its mediastinal side, contracts up to a considerable extent, and the healthier it is-i.e., the greater its 'tone'-the more does it do so. Hence if a healthy man becomes suddenly the subject of a pneumothorax, he loses not only the lung of the affected side, but a large part of the other as well, and his dyspnoea is proportionately great.

During forcible expiration the intrathoracic pressure becomes positive, with the result that the two layers of the pleura are squeezed tightly together, and even although the lung be penetrated by a punctured wound, pneumothorax may not result. This point has been graphically put by Sir James Barr:* 'I do not know if any of you have encountered a man who was making indiscriminate use of a knife. I have, and for a short time I got the worst of the conflict. If you should meet such an individual, you can deal with him as you think best, but if you find him making a lunge for your chest, I would strongly advise you to let your breath out before he does it for you. In this way the knife or dagger has another inch to travel before it reaches your chest, and you establish a positive pressure within your thorax * The Bradshaw Lecture, 1907. 
which prevents the two pleural surfaces from separating. After the injury keep the wounded side as much as possible in a state of expiration, and do not on any account take a deep inspiration.'

Respiration is a process in which the whole body wall participates. In textbooks of physiology it is usually stated that inspiration alone is a muscular act, that expiration takes place as the result of elastic recoil ; but, as Keith has shown, all the muscles of respiration are involved in both phases. During inspiration the inspiratory muscles overcome those of expiration; during expiration the reverse takes place. This view is in conformity with the well-recognized principle that in performing any movement active relaxation of one set of muscles has as much to do with it as the active contraction of their opponents. Inspiration, however, is an opposed act, the opposing forces being the contractility of the lungs, the elasticity of the chest wall, and, to some extent, the force of gravity. Expiration is an unopposed act. Hence the thorax is in a position of expiration after fainting or death, and in great weakness it is inspirations alone which are delayed. Expiration follows inspiration at the usual interval. The opposition to be overcome during inspiration is considerable, and involves, it has been calculated, a muscular strain equivalent to raising a weight of 100 pounds, not counting the contractility of the lungs. This has to be raised eighteen to twenty times per minute. Where inspiration has to be repeated very frequently, as in many conditions of disease, the expenditure of muscular energy may become very great. It is inadvisable, therefore, to add to 
it in any way, as, for example, by placing a heavy poultice on the front of the chest.

The elevation of the ribs is effected partly by the scaleni and intercostals, partly by the diaphragm. The normal condition of the latter is one of 'arched tension,' it being held up partly by its attachment to the pericardium, partly by the pull exercised on it by the elasticity of the lungs. It is the tension of the diaphragm, indeed, which retains in the lungs their supplemental air. As long as the ribs are fixed the diaphragm cannot be pushed upwards, but if the abdominal muscles pull the lower ribs inwards, then the tension of the diaphragm is relaxed, and the abdominal viscera, under the pressure of the abdominal muscles, can drive it upwards and expel the supplemental air.

The mode of action of the diaphragm is peculiar, and has important bearings in disease.* The diaphragm is to be regarded as a digastric muscle which takes origin from the vertebræ behind, and is inserted into the lower six ribs. Its central tendon rests upon the liver, which acts as a sort of fulcrum, over which the muscle passes. As the diaphragm contracts, the liver tends to be pushed forwards and downwards; but its movement in this direction is frustrated by the anterior abdominal wall, with the consequence that it forms a fixed point, over which the ribs are pulled up. If the abdominal muscles are badly developed, however, or if they have become partially atrophied from practical disuse, as happens,

* Keith, 'The Anatomy of Glénard's Disease,' London Hosp Gaz., 1902, ix. 55. 
for instance, in women in whom the normal function of the abdominal muscles has been largely usurped by the support given by corsets, then the descent of the liver and the organs lying beneath it is unopposed, and a dislocation downwards of the abdominal viscera takes place, a condition known in clinical medicine as Glénard's disease. It might be supposed, from a study of the anatomical relations of the diaphragm, that it would tend to pull the ribs inwards quite as much as to elevate them; * but such an action is prevented partly by the resistance offered by the comparatively solid mass of the liver, partly by a fixation of the ribs by the intercostal muscles. As a matter of fact, when the latter are paralyzed, as happens, for example, when there is a transverse lesion of the cervical cord or when the ribs are already much raised, as in emphysema, a recession of the ribs along the line of attachment of the diaphragm can be observed to take place.

The slight descent of the central tendon of the diaphragm, which takes place during inspiration, pulls down the heart with it, and so provides a still larger space into which the lungs can expand. This descent of the diaphragm is aided in the vertical position by the action of gravity, but in the case of a patient lying on his back the liver has got to be pushed upwards instead of downwards, and so the easy descent of the diaphragm is impeded. It is for this reason, in part, that patients in whom the respiration is embarrassed prefer to sit up in bed. An accumulation of fluid or gas in the * Gerhardt, 'Ueber Inspiratorische Einziehungen am Thorax,' Zeit.f. Klin. Med., 1896, xxx. 37. 
abdomen will also offer a mechanical obstacle to the descent.

The degree to which the ribs and the diaphragm respectively take part in elevating the chest determines whether the respiration will be mainly 'costal' or 'abdominal' in type.* The better developed the abdominal muscles are, the more easily can the diaphragm elevate the ribs, and the more 'thoracic' the type of respiration. Abdominal respiration is the type in men. In women, on the other hand, the elevation of the upper ribs takes place more freely. In part this is only apparent - the mass of the mammæ magnify the apparent movement, as a writing style exaggerates the movements of a lever-but in part also it is genuine. It is now generally admitted that the occurrence of this type of breathing in women is due to the wearing of corsets.

Under diseased conditions it would seem as if the different parts of the chest wall attained a certain independence of action, so that one side, or even part of the chest, may move more than the rest, the air seeming to be sucked into some parts of the lung and prevented from reaching others. Thus rest is ensured to diseased parts of these organs.

The result of the combined action of the muscles of inspiration is that the chest is enlarged downwards, forwards, and outwards, and a vacuum formed within

* Whether respiration is costal or abdominal in type depends also upon the order in which the different parts of the body wall come into action. If the wave begins in the abdomen and passes upwards, the type is abdominal; if it begins above and passes down, the type is costal. 
it. In normal circumstances this vacuum is filled partly by blood which enters the large venous trunks and right heart, but mainly by air which rushes into and inflates the lungs. Should there be any obstacle to the entrance of air, the vacuum in the alveoli tends to be filled by the transudation of fluid. It is in this way that œedema of the lungs is produced in laryngeal or tracheal obstruction. If the chest wall is very soft, it may be unable to

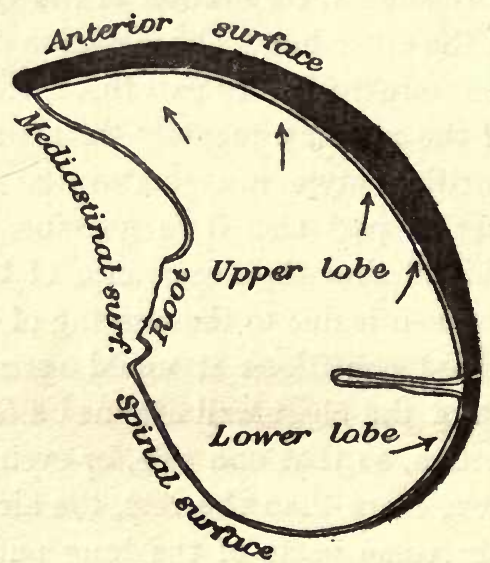

Fig. 11.-Cross Section of the Right Lung, Showing Directions of Expansion. (Keith.)

withstand the atmospheric pressure on its outer surface when the internal pressure is lessened by inspiration, and it will then sink in at its softest parts. It is in this manner that the chest deformity of rickets is produced. As the greatest increase in the capacity of the thorax during inspiration occurs in its lower part, it will readily be understood that the expansion of the lungs is freest in their lower and lateral portions; indeed, they cannot 
expand either upwards, inwards, or backwards. It is probably for this reason that the friction sound of pleurisy is usually best heard over the antero-lateral aspect of the chest wall. The expansion of the apices, on the other hand, is relatively feeble, and can only

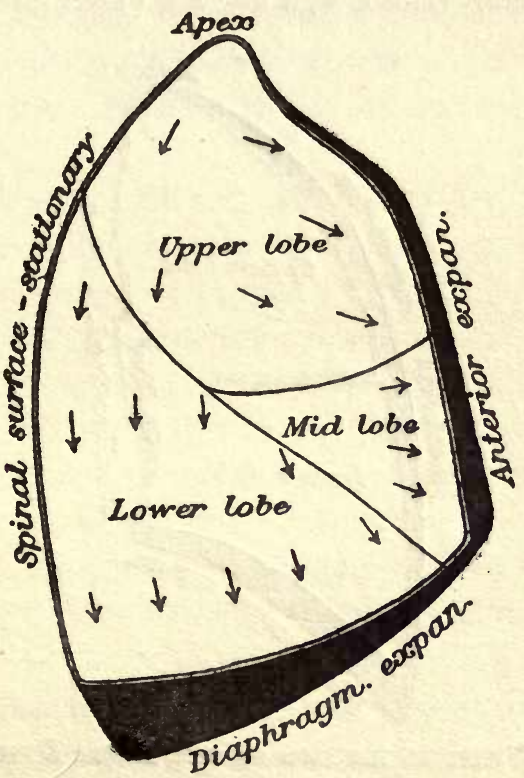

Fig. 12.-Right Lung from the Side, showing Directions of Expansion. (Kuith.)

take place indirectly and chiefly through the diaphragm allowing descent of the lung as a whole, and some writers have ascribed to this fact the liability of the apices to become the seat of tuberculous deposits (Figs. 11, 12, and 13).

In forced inspiration all the muscles which can in any 
way help in raising the chest wall are called into play, and the expenditure of muscular energy becomes very great, equivalent, it has been calculated, to raising a weight of 300 pounds. In forced expiration the abdominal muscles are largely made use of to press up the liver and other viscera against the under surface of the

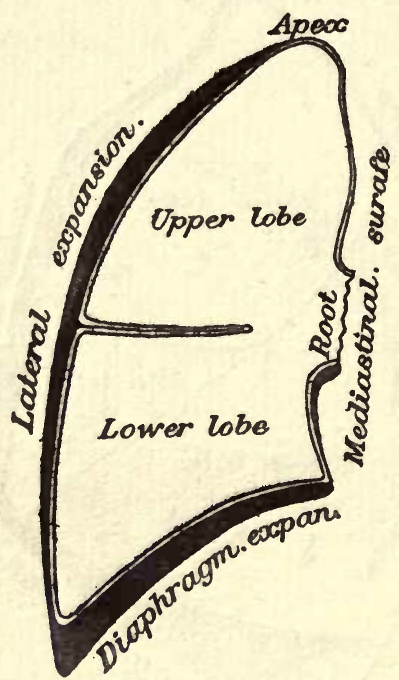

Fig. 13.-Vertical Section of the Right Lung to show EXPANSION. (KeITH.)

diaphragm, which has been relaxed by the pulling down of the lower ribs. Hence the capacity of the chest is lessened both laterally and vertically.

The air which is still left in the lungs after the fullest expiration, and which is only displaced when the chest wall is opened, is termed 'residual.' It amounts to about 100 cubic inches for the two lungs. When the 
lungs are overdistended, however, as in emphysema, it is greatly increased. The volume of air which we ordinarily use for breathing, and which passes out and in at each breath, is about 20 cubic inches. This is called the 'tidal air.' For the most part, however, it does not go straight into the alveoli, but only into the upper air passages, the renewal of the air in the lungs themselves taking place by a process of diffusion, whilst the composition of the alveolar air remains fairly constant.

The tidal air is sufficient for the ordinary purposes of life, but, when an emergency arises, we are able to get an increased supply of oxygen by taking into the lungs by a full breath another 100 cubic inches of air which is termed complemental. By a forced expiration an equal quantity can be expelled in the wake of the tidal air, and this is termed supplemental. Were it not for these reserves of capacity every extraordinary effort would entail great dyspncea and the risk of premature death. 'Every man,' says Sibson, 'has much more lung than he requires in the quiet pursuits of life; he requires less when he lies down, sleeps, or is depressed; but more when he walks, runs, wrestles, or is roused by passion. The lung that is used is an ever-varying quantity. . . . The more the lungs are used, the more is their capacity nursed. The man that under one training is the feeble, narrow-chested, sickly mechanic, is under another the active, full-chested, and healthy sailor.'

The tidal air supplies only enough oxygen to last us a few seconds; if the breath is suddenly held, discomfort begins to be experienced after the lapse of that time. 
Even the supplemental air only gives another two minutes' supply, for the most expert pearl-divers cannot stay longer under water than that.

The complemental capacity of the lungs is made use of by a man who fills his chest preparatory to swimming under water; the supplemental by a singer in sustaining a prolonged note.

If the chest be filled as completely as possible, and

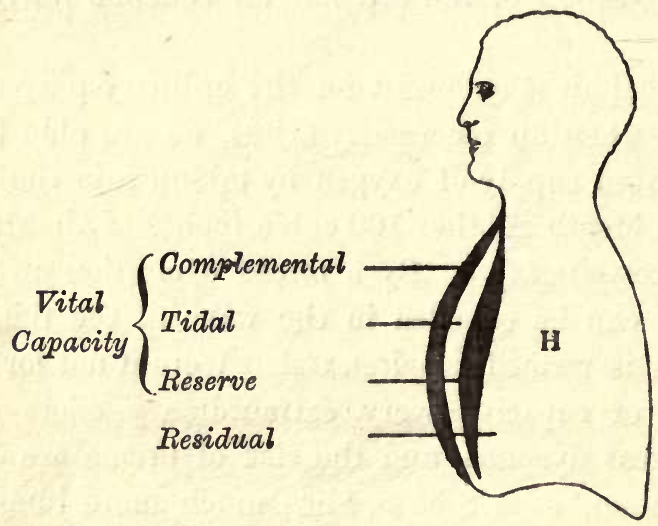

Fig. 14.-Diagram of Vital Capacity. (After Hutchinson.)

then squeezed as empty as the expiratory muscles can squeeze it, the volume of air expelled is the measure of the vital capacity. The vital capacity is thus a gauge of the efficiency of respiration or of the vital activity of the lungs. In health it amounts to about 225 cubic inches, but varies greatly with age, size of chest, etc. Tall people have a greater vital capacity than short,* and,

* For every inch of stature between 5 and 6 feet, 8 additional eubic inches of air are given out by a forced expiration. 
curiously enough, broad-chested persons are not necessarily well endowed in this respect. Disease affects it very markedly, especially phthisis. Thus a man below fifty-five whose capacity is only 193 cubic inches is probably the subject of disease of the lungs. Curiously enough, both pleuræ may be entirely adherent all over without in any way limiting the respiratory capacity.

The vital capacity also varies greatly with posture. Thus in the same man it was:

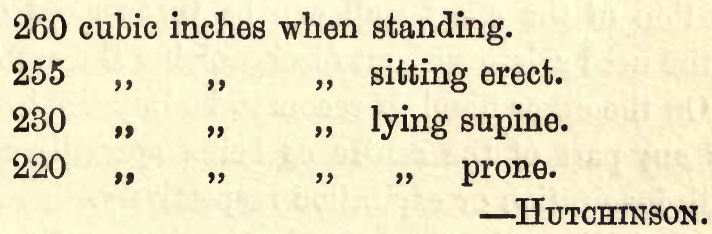

This shows how it is that patients with dyspnœa cannot breathe when lying down. The diminution of vital capacity as age advances is due to an increasing difficulty in completely emptying the lungs on account of thoracic rigidity.

\section{The Nervous Mechanism of Respiration.}

The mechanical part of the respiratory process is controlled by an elaborate nervous apparatus, the headquarters of which are situated in the respiratory centre in the medulla. This centre consists of two lateral halves either of which is apparently able to act independently of the other, for it is quite common for a patient with disease of the lungs-e.g., pleurisy-to breathe on one side only. There would also appear to be independence of action as regards those parts of 
the centre which control the diaphragm and the ribs respectively, so that one or other of these can be thrown out of action without interfering with the other. Thus it is possible for a patient with localized peritonitis to breathe with his ribs only, part or the whole of the diaphragm being kept motionless. It is probable that a like independence is possessed by the different groups of cells in the centre which innervate the muscles which act upon the individual ribs, so that even a limited portion of the chest wall can be thrown out of action if the need arises without disorganizing the rest.

On the other hand, it seems to be impossible to mark off any part of the centre as being specially connected with inspiration or expiration respectively.

Much discussion has raged over the question whether the centre can act spontaneously or whether it must always be prompted by influences coming to it from without. The truth would appear to be that whilst the centre is possessed of power of spontaneous action, such power is very rarely put into exercise; probably, indeed, never at all even in conditions of disease, unless, perhaps, the last gasping breaths of life are to be regarded as evidence of such activity.

The respiratory centre can be powerfully influenced by two distinct agencies: (1) nervous stimuli, (2) th composition of the blood. We shall consider these separately.

1. The chief afferent nerves which act upon the centre are the vagi. As regards these, matters seem to be so arranged that each phase of respiration prepares the way for its successor. Collapse of the 
lungs excites in the vagi impulses which lead to an inspiration; distension of the lungs arouses nerve currents which prompt the centre to an act of expiration. Divide the vagi, and the respiration becomes slower and deeper; apply a powerful stimulus to the upper end, and the inspiratory movements are greatly increased. This controlling action of the vagus is no doubt often disturbed in disease. Irritation of the fibres of the vagus, for example, appears to be the cause of the rapid respiration which comes on in pneumothorax, for it disappears when the nerve is divided (Traube). If, again, the air passages are in any way obstructed, as may happen, for example, in stenosis of the larynx, the respirations - though the need for air is urgent-are very slow, the reason being that the lung can only be slowly expanded with air, which takes a long while to get past the obstruction, and during all that time the reflex inhibitory action of the vagus in inspiration is steadily in action.

The vagi, though the most constantly active, are by no means the only afferent nerves which can influence the respiratory centre. Stimulation of the nasal branches of the fifth nerve produces expiratory efforts (sneezing), and stimulation of the superior laryngeal has a similar but even more powerful effect (coughing). Both of these reflex effects upon the centre are protective in nature, and lead to the expulsion of irritating foreign bodies from the nose and larynx respectively. The temporary arrest of respiration which is necessary during the act of swallowing is secured by the action of the glossc. pharyngeal, which, when stimulated in the throat, 
induces a temporary cessation of the breathing movements.

Irritation of the splanchnic also seems to induce an arrest of respiration, as is familiar to anyone who has been 'winded' by a blow on the upper part of the abdomen. This mechanism seems to be brought into play in lessening the diaphragmatic movements in painful affections of the viscera in the upper part of the abdomen. Further, all sensory nerves appear to be able to influence the centre. This reflex action, indeed, is perhaps the first we make use of on entering the world, for our first breath is, in part at least, brought about by the action of cold air on the skin of the trunk, and if it is at all delayed the accoucheur puts the reflex into more powerful action by dashing cold water on the chest and abdomen.

Similar methods of reflexly stimulating the respiratory centre through sensory nerves are constantly used in disease. In collapse of the lung in young children, for instance, frequent and vigorous 'spanking' is constantly resorted to in order to induce re-expansion of the alveoli by the deep breaths which crying necessitates. In cases of narcotic poisoning, too, the respiratory centre is kept awake by flicking the patient with wet towels or applying a strong faradic current to the skin.

None of the vital centres, in fact, is more intimately in touch with the whole body than that which presides over respiration. Nor need this cause surprise when one remembers how important it is that our breathing should be able to respond at once to the most varying demands for oxygen which the emergencies of life call 


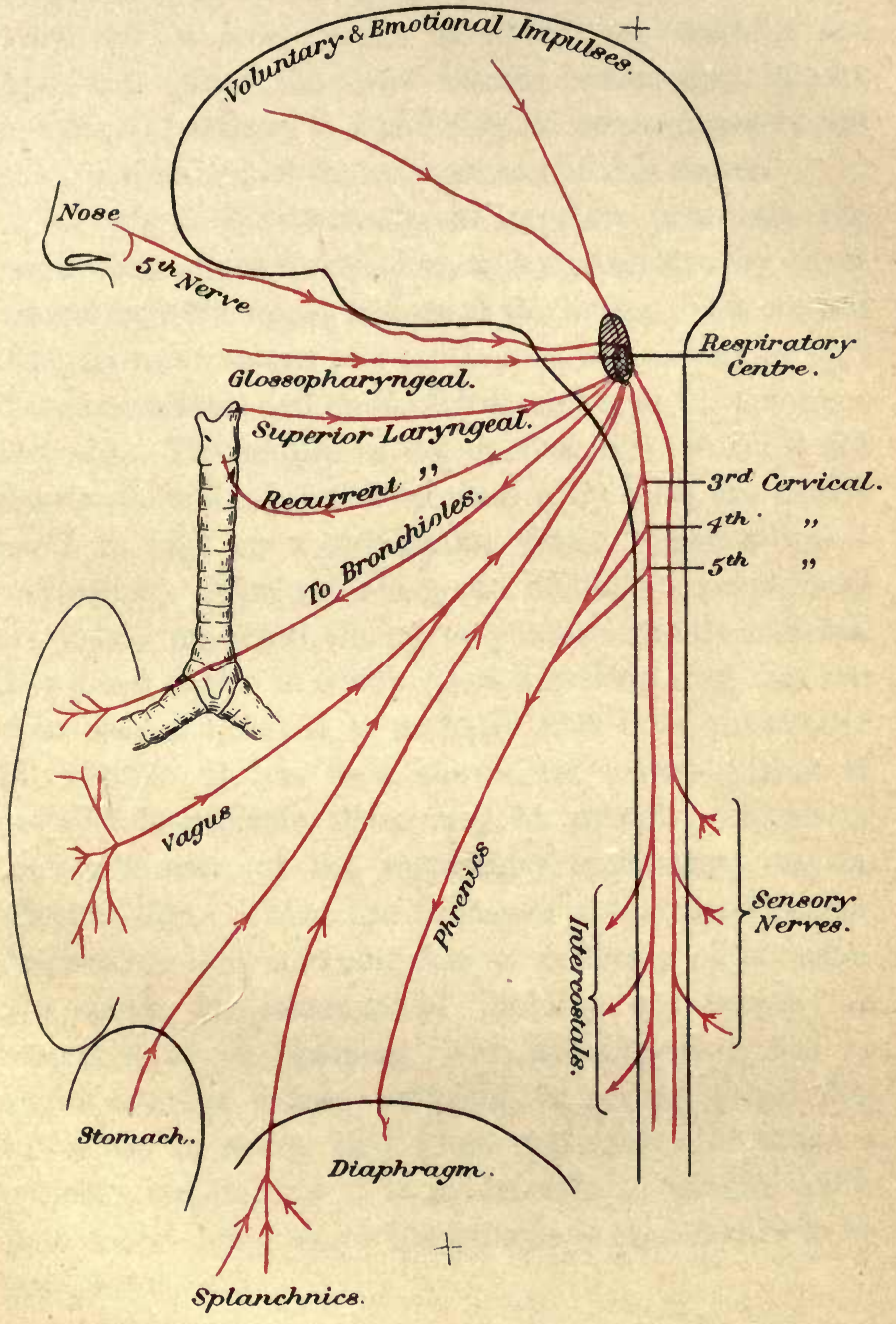

Plate III.-The Respiratory Centre and its Connections. 

forth; whilst at the same time it controls the voice, which is one of the chief means by which the emotions are expressed. That the most diverse causes may induce an attack of asthma is a pathological consequence of the wide ramification of the connections of this centre.

Not only do constant afferent impulses pour into the respiratory centre from below, it is also under very direct control from the upper regions of the brain. This control is partly unconscious and continuous in nature; in part it is intermittent and under the dominion of the emotions and will. The nature of the unconscious control is not clearly understood, but when it is withdrawn the centre tends to take on a rhythmical action (Cheyne-Stokes respiration). The voluntary and emotional promptings are no less important, though only intermittently asserted. The exact centre in which such impulses arise has not been localized, but it is probable that it is situated in the cortex. It has been shown, for example, that in cases of hemiplegia there may be partial paralysis or inco-ordination of the respiratory movements on the affected side, ${ }^{*}$ whilst the influence of the emotions on respiration is a commonplace of ordinary observation. We speak, for instance, of 'holding our breath' in suspense, or of 'gasping' with astonishment, and so slight are the causes sufficient to set emotional disturbances in action that when one wishes to count a patient's respirations it is inadvisable to let him know that one is doing so, or the process is almost sure to be quickened.

* Grawitz, Zeit. f. Klin. Med., No. 26, and Stirling, ibid., 1896, No. 30, p. 1. 
It is an interesting fact that whilst voluntary or forcible breathing soon produces a feeling of fatigue, he equally powerful breathing of hard exercise does not. The physiological explanation of this apparent anomaly may, perhaps, be that voluntary breathing involves the use of the brain cortex, whereas the involuntary breathing of exercise does not, and it is well known that the sense of fatigue, though referred to the muscles, is really experienced in the brain.

The efferent impulses from the respiratory centre travel along the vagi, the phrenics, and the intercostal nerves. Those which proceed by the vagi innervate the posterior crico-arytenoid muscles, and so cause the glottis to open more widely during respiration. Interference with these fibres is the cause of the 'abductor paralysis' so common in cases in which there is pressure upon the recurrent laryngeal nerve. The separate route pursued by the fibres for the diaphragm and the intercostals respectively enables one or other of those portions of the breathing apparatus to be paralyzed without the other. Thus a patient who has sustained a crush of the cord below the level of the fifth cervical roots can breathe for a time by his diaphragm alone.

If, again, the phrenic nerve be in any way injured or degenerated, the patient can breathe-in a sort of way, at least-with the intercostals, although the imperfect expansion of the lower parts of his lungs is very apt to lead to troublesome complications.

Division of one vagus in man does not appear to lead to bad results. On the other hand, a case is on record in which the left vagus was included by mistake in a 
ligature of the common carotid. In this case the respiration stopped from stimulation of the inhibitory fibres in the superior laryngeal, and death resulted.

2. In addition to its susceptibility to nervous influences, the respiratory centre responds with marvellous delicacy to variations in the composition of the blood which circulates through it. Should an excess of venosity in the blood indicate the necessity for a fuller and freer interchange between the blood and the air, the respiratory movements are at once increased in frequency and depth. This is the prime cause of the exaggerated breathing of dyspncea. Experiments tend to show that even the chemical products of muscular fatigue can exercise this effect, and that it is by this means that deeper breathing and a fuller supply of oxygen are ensured during exercise. If, too, the blood which reaches the centre is unduly warm, the activity of the latter is increased. This may explain in part the rapid respiration of fever. Certain drugs have a similar influence, and strychnine is constantly used in clinical medicine in order to produce such effects. On the other hand, some agents, such as alcohol and opium, ultimately depress the centre, and may end by paralyzing it, and so lead to death.

Whether the nervous or chemical method of stimulation plays the greater part in determining the normal quiet rhythmic action of the respiratory centre is not yet determined, but the trend of recent physiological opinion is in favour of attaching more importance to the effect of the condition of the blood and less to nervous influences than was the case a few years ago; 
and it is significant that the mode of starting of the first breath after birth, which was so long a fruitful source of discussion, is now pretty generally attributed to the effect upon the respiratory centre of the accumulation of carbonic acid in the blood rather than to the action on the centre of stimuli from the surface of the body. That the latter can be powerful aids in stimulating the centre to action, however, the good effect of 'spanking' a newly-born infant which is disinclined to breathe effectually proves.

We have spoken hitherto as if there was only one respiratory centre, and that wholly given over to the superintendence of inspiration. It is probable, however, that there is an expiratory centre as well, and that it comes into play in the performance of forced expiration. It may be excited reflexly, as in the act of coughing, or by voluntary effort when it is desired to increase the intrathoracic pressure, as in straining; and it would seem also to react to peripheral sensory stimuli, and to excessive venosity of the blood. Unlike the inspiratory centre, however, it is not rhythmically active, for it must always be remembered that the act of respiration consists in a series of inspirations only, the expiratory part of the process being, in normal conditions, purely physical.

The inverted type of breathing observed in young children suffering from pneumonia is perhaps due to stimulation of the expiratory centre. 


\section{The Chemistry of Respiration.}

\section{Pulmonary Respiration.}

The general principles of the chemical side of respiration are easily understood, though the details are in many points still involved in obscurity. The essence of the process consists in the conveyance of oxygen to the tissues and the removal of carbonic acid from them. The lungs thus play a double part. They absorb oxygen from the air just as the stomach and intestine absorb nutritive constituents from the food, and they excrete carbonic acid just as the kidneys excrete urea. Disease may result from a disorganization of either of these functions : on the one hand from failure of the lungs to absorb sufficient oxygen, and on the other hand from an inability on their part to excrete carbonic acid.

We may now look at some of the practical bearings of this interchange between the lungs and the air in greater detail.

If one compares the composition of the air as it enters and leaves the lungs, one gets such a result as the following:

Inspired Air.

Oxygen $\quad . .20 .96$ per cent.

Nitrogen ...

$\mathrm{CO}_{2}$
79 per cent.

0.04 per cent.
Expired Air.

16.03 per cent.

79 per cent.

$4 \cdot 4$ per cent.*

In addition, the expired air is saturated with water

* Variations in 'respiratory exchange'-i.e., the total consumption of oxygen and excretion of $\mathrm{CO}_{2}$-usually discussed under 'Respiration,' are really the expression of variations in metabolism, and are considered under that subject. 
vapour; but so, probably, is the inspired air before it reaches the alveoli, thanks to the moistening influence of the upper air passages already described.

A comparison of the composition of inspired and expired air does not, however, give us an accurate idea of the actual composition of the air when it comes into relation with the blood in the alveoli, for the following reason: The air in the passages from the nose to the alveoli is not really changed during respiration, but comes out again the same in composition as it went in. The air which has actually been in the alveoli, therefore, is, as it were, diluted by this purer air when the total output of a breath is collected, and the latter does not, therefore, really represent the composition of the air as it actually left the alveoli themselves. Seeing that the volume of air in the air passages is about 140 c.c., and the total air taken in and sent out again at one breath is about 500 c.c., it will easily be seen that a considerable fallacy is introduced if the composition of the expired air be taken as representing that of the alveoli. As a matter of fact, if the alveolar air be collected separately, as it can be, it is found to contain much more $\mathrm{CO}_{2}$ and less oxygen than ordinary expired air, the oxygen amounting to only 13 or 14 per cent., and the $\mathrm{CO}_{2}$ to 5 or 6 per cent. Further, this method of analysis has shown that the partial pressure of $\mathrm{CO}_{2}$ in the alveoli is constant.

It will be seen from this that the essential fact of respiration is that the blood gives up carbonic acid to the air in the lung and receives back oxygen from it.

When one comes, however, to ask how this exchange is effected, one finds oneself involved in a maze of con- 
troversy. Is the process a purely physical one, in which the epithelium of the alveoli which separates the air from the lung acts merely as a permeable membrane, or have the epithelial cells themselves something to say in the process? Are they able actively to pick up oxygen out of the air, and to excrete $\mathrm{CO}_{2}$ from the blood, irrespective of such considerations as the tension of these gases? In other words, is the process a purely physical one, or is it-to use the only available word-in part at least vital? This question is one, it need hardly be said, of great theoretical importance; it is one of the fundamental problems of physiology which goes to the root of our conceptions of living function. But it has also practical bearings. For if the epithelial cells of the alveoli really do play an active part in the process of exchange in the lungs, it is conceivable that the disorder of this exchange and the imperfect purification of the blood which results from it, as seen in acute disease of the lungs, may be due, in part at least, to disorganization of the alveolar epithelium. Asphyxia would then be the result of an inability of the epithelium of the air cells to excrete $\mathrm{CO}_{2}$, just as uræmia is the result of a failure of the renal epithelium to excrete the constituents of the urine. That such interference with function does occur in acute disease there is some experimental evidence to prove. Lorrain Smith,* for example, concludes that an interference with active absorption through the lung epithelium is an integral part of many conditions of disease directly or indirectly associated with the lungs.

Meanwhile it is interesting to note that most physiolo* Journ. of Physiol., 1897-98, xxii. 307. 
gists are coming round to the view that the part played by the epithelium of the lungs is an active and not merely a passive one, and cannot yet be explained by the ordinary physical laws as we see them in operation in non-living matter. As G. H. Lewes said nearly fifty years ago:* 'Physical laws reveal only one part of the mystery. Respiration is not a simple physical act. It is the function of a living organism, and as such receives a specific character from that organism. No sooner do we cease to regard the exclusively physical aspect of this function-no sooner do we fix our attention on the organism and its influence, than the theory raised on the simple laws of gaseous interchange suddenly totters and falls.'

One hundred volumes of arterial blood yield sixty volumes of gas of the following composition:

$\begin{array}{llllc}\text { Oxjgen } & \ldots & \ldots & \ldots & 20 \text { parts. } \\ \text { Nitrogen } & \ldots & \ldots & \ldots & 1-2, \\ \text { Carbonic acid } & \ldots & \ldots & \ldots & 40\end{array}$

Of the oxygen less than one volume is in solution in the plasma. The rest is combined with hæmoglobin in the red cells. Arterial blood is, however, not saturated with oxygen. It is only about nine-tenths saturated, and under ordinary conditions not more than one-third of the combined oxygen is used. There is, therefore, a considerable margin of oxygen to draw upon in emergencies. Thanks to this, a very considerable proportion of the hæmoglobin in the blood can be

* 'The Physiology of Common Life,' 1859, i., 878. 
saturated by a foreign gas, such as carbonic oxide, without any symptoms of want of oxygen arising. On the other hand, where the amount of hæmoglobin in the blood is greatly reduced, as, for example, in anæmia, there is no margin of oxygen-carrying power to draw upon when oxidation in the tissues is increased, and dyspnœe results upon slight exertion; and if 70 per cent. of the total blood be removed the deficiency of oxygen is enough to cause death.

If the tension of oxygen in the inspired air is increased, the proportion of dissolved oxygen in the blood is also increased. This is specially true when, owing to disease of the lungs, the normal oxygenation of the blood is interfered with. Physiologists who studied the subject on perfectly healthy animals came to the conclusion that oxygen inhalation would be of little use in disease, for they found that even when the amount of oxygen in the atmosphere was doubled the uptake of it was only slightly affected.*

We have here, however, an example of the danger of the premature application of the results of physiological experiment directly to the problems of disease. As a matter of fact, an increase in the oxygen tension in the air breathed does result in a considerable increase in the amount of oxygen which enters the blood in conditions of partial asphyxia, and the treatment of such conditions by oxygen inhalation has justified itself by its

* Thus, when air is breathed, arterial blood contains $18 \frac{1}{2}$ per cent. combined $\mathrm{O}_{2}$ by vol., and 0.6 per cent. dissolved $\mathrm{O}_{2}$ by vol.

When pure oxygen is breathed, arterial blood contains $18 \cdot 7$ per cent. combined $\mathrm{O}_{2}$ by vol., and 3 per cent. dissolved $\mathrm{O}_{2}$ by vol.- TiALDANz. 
results.* The matter has been put very clearly by Pembrey :

- The normal animal does not increase its respiratory exchange when it breathes oxygen instead of air, for its metabolism is regulated by the needs of its tissues and not directly by the amount of oxygen absorbed in the lungs. In the case of some diseases, during which the blood, owing to diminished absorption of oxygen in the lungs, is abnormally venous, the breathing of pure oxygen would increase the percentage of oxygen in the alveolar air, and thus enable the blood in the lungs to take up more oxygen. In these cases breathing oxygen under pressure greater than that of oxygen in the air would, for a similar reason, be effective, and would also increase the amount of oxygen simply dissolved in the plasma. It would appear, therefore, that there is strictly no contradiction in most of the experimental and clinical results, for in the normal animal breathing ordinary air the arterial blood is almost saturated with oxygen, and without doubt contains as much or more oxygen than the tissues need. This is certainly not the case in some diseases, during which the patients have derived benefit from breathing oxygen.' $\dagger$

At the same time it must be remembered that the phenomena of asphyxia are, to some extent, due to the presence in the blood and tissues of an excess of $\mathrm{CO}_{2}$, and this, of course, oxygen inhalation can do nothing to remedy. Nor can it be expected to be of use where the

* See Michaelis, 'Ueber Sauerstoff Therapie,' Zeit. f. diät. u. phys. Therapie, 1900, iv. 122.

† Schäfer's 'Physiology,' i. 736. 
difficulty in respiration is due to a breakdown in the circulation and a failure of the regular transportation of oxygen between the lungs and the tissues.

The carbonic acid in the blood is distributed equally through the corpuscles and plasma. It is to a small extent in solution, but for the most part combined with alkali in the plasma and corpuscles, and perhaps also to some extent united in some fashion to the hæmoglobin. It is the alkalinity of the blood which gives it its chief power as a $\mathrm{CO}_{2}$ carrier, for sodium carbonate $\left(\mathrm{Na}_{2} \mathrm{CO}_{3}\right)$ is able to take up one molecule of the gas, forming sodium bicarbonate $\left(\mathrm{NaHCO}_{3}\right)$. There seems to be a constant struggle going on between the proteins of the blood and $\mathrm{CO}_{2}$ for the possession of the sodium carbonate of the plasma, and it depends upon the relative mass of each present which prevails. Should any stronger acid get access to the circulation and lay hold of the existing alkali, the carriage of $\mathrm{CO}_{2}$ is greatly interfered with. Until recently it was believed that this took place in diabetic coma owing to the presence in the blood of large quantities of oxybutyric acid; but the observations of Pembrey have rendered it doubtful whether the sodium carbonate is sufficiently neutralized in that condition to interfere seriously with the transport of $\mathrm{CO}_{2}$ from the tissues.

On the subject of ventilation a study of the chemistry of respiration throws disappointingly little light. We do not even know, to begin with, what the effects of 'fresh ' air are due to, or wherein the evils of 'vitiated' air consist. Analysis has failed to tell us to what ingredients the different effects on health and vitality 
produced by the air of different localities is to be attributed; yet upon such effects the undoubted benefits of ' change of air' largely depend. Dalton even held the view that chemical experiment could not distinguish the air of Manchester from that of Helvellyn. This opinion, though shared by other chemists, cannot any longer, however, be regarded as accurate. Francis Jones, * for example, found that on the same days, when the air in the centre of Manchester contained on an average 4.526 parts of $\mathrm{CO}_{2}$ in 10,000 , that of Alexandra Park, three miles distant, contained $3 \cdot 1186$ parts, and when the air of Manchester contained on an average 4.255 parts $\mathrm{CO}_{2}$, that of Arnside, near the Lake District, contained only $3 \cdot 237$. Still, such comparatively small differences as these can scarcely explain the difference between town and country air.

All that physiology clearly teaches on this subject,

* 'The Air of Rooms' (Manchester: Taylor, Garnett, Evans and Co.), 1900. Some of the results of Dr. Jones's experiments may be summarized here: The air of a room always contains more $\mathrm{CO}_{2}$ than the external air, even when it is well ventilated. The writer concludes that a certain amount of $\mathrm{CO}_{2}$ is in some way retained by the walls, and is constantly passing back into the room.

The amount of $\mathrm{CO}_{2}$ is always high during fogs and in snowy weather, and is greater in winter than in summer, The air of a room is always purest at the floor, less pure 3 feet above, and most impure at the ceiling.

When a coal fire is in use for heating and the electric light for lighting an inhabited room, the air is purer than by any other method of heating and lighting, and this is the only combination which will keep the $\mathrm{CO}_{2}$ in the air of the room below 10 parts per 10,000 .

A room heated by a gas fire contains more $\mathrm{CO}_{2}$ than one heated by a coal fire. 
indeed, is that either an excess of $\mathrm{CO}_{2}$ or a deficiency of oxygen is injurious. The former acts as a narcotic poison, but it does not begin to exert its effects until 3 per cent. is present, an amount which is never reached even in a very 'stuffy' room. It is to deficiency of oxygen that the effects of breathing a limited quantity of air and the phenomena of asphyxia are due, but here, again, it is not until the proportion of oxygen is reduced to about 10 per cent. that any bad symptoms manifest themselves. Reviewing the whole subject, even such a careful and experienced worker in this department as Professor Haldane is able to come to no more satisfactory conclusion than that the headache, lassitude, etc., which are experienced in a badly ventilated room are not due either to want of oxygen or to the presence of an excess of $\mathrm{CO}_{2}$, but that they are partly the result of heat and moisture, and partly, perhaps, produced reflexly through the olfactory nerves.*

An interesting point in connection with this subject is that much-breathed air is more injurious to healthy, vigorous animals than to those which are feeble and exhausted. If, for example, a sparrow is confined in a bell jar for a matter of two hours it will still be alive and fairly vigorous. A second sparrow now introduced, however, dies at once. It would thus appear as if an animal can accommodate itself to oxygen starvation, probably by a general lowering of its metabolism, but in part also, perhaps, by an increased power of absorbing

* Hale White's 'System of Pharmacology.' The proportion of $\mathrm{CO}_{2}$ in an inhabited room should not exceed 12 parts per 10,000 during daylight, and 20 parts per 10,000 when gaslight is used. 
oxygen.* This may possibly be the reason why the East-End Jew who is accustomed to overcrowding from infancy appears to suffer so little in health from it.

The limit of height at which respiration can still be carried on is another practical question to which no definite reply is fortheoming. We know that Whymper on Chimborazo reached a height of 20,517 feet, and Sir Martin Conway in the Himalayas got as high as 22,600 feet, but it is probable that even higher altitudes than these could be reached if time were given for the subject to become accustomed to them. It is an interesting fact that the higher one goes the more easily oxygen appears to enter the blood, perhaps because of the greater mobility of its molecules at reduced pressures. No doubt some of the benefits derived from residence in the high altitude health resorts are to be thus explained.

An impetus has recently been given to the study of the effects of increased atmospheric pressure on the body by the use of caissons in engineering operations, and by the observance of cases of 'caisson disease.' The result of breathing compressed air is naturally to cause the blood to take up a much larger proportion of dissolved gas, especially of nitrogen. When the pressure is relieved nitrogen is liberated in the blood-stream in the form of bubbles which may block some of the smaller capillaries. It is to such blockage that the symptoms of caisson disease are now believed to be due. As two * See Haldane and Lorrain Smith, Journ. of Physiol., 1897-98, xxii. 231. 
French writers on the subject have put it, 'Payment is only made on coming out.'

The effect on the lungs of breathing compressed air is to cause them to expand downwards, the liver and diaphragm being depressed so as to occupy the space obtained by the compression of the gases in the stomach and intestine. At the same time, the circumference of the chest is increased and the number of respirations lessened. By frequent repetition of exposure to compressed air these effects may become permanent.

In medicine, compressed-air baths have been used in the treatment of emphysema. Favourable results have been reported in many cases, results which, when one considers the state of the lungs in emphysema, it is very difficult to explain. One would have expected, indeed, that their effect would have been to aggravate the condition, for what is emphysema but overdistension of the lung? In the subjects of this disease, however, the physical effects of compressed air on the lung seem to be exactly the reverse of those produced in health, the diaphragm being raised instead of lowered, and the circumference of the chest diminished, not increased. The explanation of this apparent paradox is not forthcoming.

\section{Tissue Respiration.}

In the days of Priestley (1772) it was held that respiration and combustion were identical processes, that compounds carried to the lungs were burnt up there by oxygen, and carbonic acid formed from them, just as happens in the combustion of a candle. When this 
simple view was disproved, physiologists shifted their ground, and declared that the combustion process took place, not in the lungs, but in the blood. Finally, and in comparatively recent years, the correct notion was arrived at, as the result of indisputable experiments, that the utilization of oxygen and the production of $\mathrm{CO}_{2}$ take place in the tissues themselves. In other words, the tissues control their own respiration. Supply a man with more oxygen, and you do not necessarily 'burn up' his tissues one whit, though a candle under similar circumstances will be consumed faster. The cells simply ignore the excess of oxygen, even if it does not actually 'lessen their vitality, as the experiments of Paul Bert would seem to indicate. The acceptance of this view has modified profoundly some of our fundamental pathological notions. In consequence of it we no longer believe that the high temperature of fever is the result of an increased 'combustion' in the lungs, and that a free supply of food must necessarily be injurious under such conditions. It implies, too, that the regular practice of 'deep breathing,' which is so much vaunted by some professors of personal hygiene, is no substitute for exercise. The latter alone can really increase the oxidation processes in the body.

In the lymph which actually bathes the cells there is almost no free oxygen. Indeed, its presence in even small amount seems to exercise a depressing influence on cell activity. It is for this reason that, at pressures of even 5 atmospheres of air, oxygen, instead of being a stimulant, is actually poisonous to the tissues after long exposures. 
Some Special Respiratory Acts.

The mechanism of sneezing and of coughing have already been described. Of the latter it need only be said further, that although primarily protective in its nature, and designed to bring about the expulsion of irritating bodies from the upper air passages, it may also be excited by peripheral stimuli in various parts of the body. Thus, irritation of the gastric branches of the vagus is said to produce a 'stomach' cough, and of its auricular branch an 'ear' cough. In persons who are unduly sensitive to cold, a hard dry cough may be excited by getting into bed between cold sheets, or when exposed to a draught.

Curiously enough, irritation of the interior of the trachea does not seem to excite cough. Perhaps that is why a tracheotomy-tube can be worn so comfortably. The bronchi appear to be less sensitive than the larynx, but more so than the trachea. Foreign bodies in them sometimes excite cough, sometimes not. The same is true of the lung substance. Disease of it does not necessarily lead to coughing. Coughing may also be excited by irritation of the pleura; hence the cough of pleurisy and the paroxysm of coughing which often comes on in aspirating the chest. Even a 'uterine' cough has been described, although its real existence is somewhat doubtful. When such peripheral irritations exist, the cough which they excite is useless, and its suppression by opium justifiable.

Sighing is a deep inspiration intended to make up for a temporary depression or a cessation of breathing. 
When the mind is much preoccupied, the breathing becomes feeble, and this has to be compensated by a few deep inspirations, which take the form of 'sighs.' It is the result, therefore, of a spell of 'breathless attention.'

'The philosopher brooding over his problem,' says Lewes,* "will be heard sighing from time to time, almost as deeply as the maiden brooding over her forlorn condition. All men sigh over their work when their work deeply engages them; but they do not remark it, because the work, and not their feelings, engages their attention, whereas during grief it is their feelings which occupy them.'

A similar sighing respiration has been noted as the result of the depression of the respiratory centre from the excessive use of tobacco.

Hiccough is the result of a spasm of the diaphragm, which produces a sudden inspiration, the inrush of air being as suddenly checked by closure of the glottis, which produces the characteristic sound. It is often the result of gastric irritation, and is a common phenomenon in many conditions of disease.

Sobbing is another alteration of respiration, consisting in an inco-ordination in the different parts of the process. It consists in sudden inspirations, in which the glottis opens a little too late, the inrush of air producing the familiar sound. It is comparable to the crowing sound produced in laryngismus stridulus.

* 'The Physiology of Common Life,' i. 3999. 
Yawning consists of a slow deep inspiration performed with the mouth widely open, and succeeded by a slow expiration accomplished with a gaping mouth and contracted glottis, which produces the well-known sound. It is apparently the result of a fatigue of attention, and therefore appears most readily when the brain is easily exhausted, as in the subjects of anæmia. The stretching of the limbs which accompanies it is believed to be an attempt to overcome the stasis of blood in the muscles, and to drive it to the brain.

Laughing and crying are, like sobbing, results of disordered action of the respiratory centre brought about by emotional influences.

The peculiar rhythmical form of breathing which goes by the name of Cheyne-Stokes respiration is probably due to periodic variation in the automatism of the respiratory centre. This periodic variation shows itself when the influence of higher regulating centres is removed, as may happen, for example, in uræmic poisoning, and perhaps also simply as a result of a lowering of the activity of the respiratory centre itself. When the sensitiveness of the respiratory centre is lowered, it does not respond to the stimulus normally given by an excess of carbonic acid in the blood until this has reached an unusual degree. A series of deep inspirations is then initiated, which result in very perfect ventilation of the lungs, and the carbonic acid is so thoroughly removed that a period of apnoea sets in until enough of it has accumulated to stimulate the centre once again. That this explanation is correct seems to be proved by the fact that Pembrey has been 
able to abolish the apnœic period by causing a patient exhibiting Cheyne-Stokes respiration to inhale carbonic acid.

Rhythmical respiration is often accompanied by similar periodic variations in the control exercised over the bloodvessels by the general vasomotor centre and over the pupil by the pupil centre, and even by rhythmical increase and diminution of the activity of the brain cortex as manifested in consciousness.

It is noteworthy that in sleep, when the higher centres are presumably less active, the respirations readily take on a rhythmical character, particularly in childhood, when the control of the lower centres is presumably not well developed. 


\section{CHAPTER VII}

\section{THE APPLIED PHYSIOLOGY OF DIGESTION}

\section{Digestion in the Mouth.}

THE object of digestion in the mouth is to convert the food into a mechanical form in which it can be easily swallowed. By means of the teeth the solid part of the food is broken up and reduced to a state of fine division, in which form it is easily attacked by the gastric juice. It can therefore be readily understood how imperfect chewing, brought about either by bolting the food or by a defective dental apparatus, impedes gastric digestion, and by allowing the entrance of lumps of food into the stomach which irritate its walls is a frequent cause of gastritis.

By means of the saliva dry food is moistened, and the bolus which results from chewing is lubricated with mucus and rendered fit for swallowing. That the mere moistening of the food is one of the chief objects of salivary secretion is shown by the experiments of Pawlow, which have demonstrated that a much larger secretion of saliva is called out by the introduction into the mouth of dry substances than by those that are moist. 
The ingredients of mixed human saliva are water, mucin, ptyalin, a trace of globulin, and certain salts, of which the chief are sodium chloride, sodium phosphate $\left(\mathrm{Na}_{2} \mathrm{HPO}_{4}\right)$, along with earthy carbonates and phosphates, and a trace of sulphocyanide of potassium. Its alkalinity is due to sodium phosphate, but there is not a trace of sodium carbonate present.* The production of gastric flatulence can therefore hardly be due, as has been suggested by some, to the liberation of $\mathrm{CO}_{2}$ from a highly alkaline saliva by the gastric juice. The alkalinity is greatest before breakfast. Salivary calculi result from the separation out of the lime-salts in the gland ducts. The meaning of the presence of sulphocyanide of potassium-of all salts! -in the saliva has given rise to much speculation, and attempts have been made-without much successto show that variations in its amount are of diagnostic value in disease. It has also been suggested that it may play the part of an antiseptic, but this is apparently not the case, + and we are still really quite in the dark as to its significance.

The ptyalin of the saliva plays a considerable part in the conversion of the starch of the food into dextrins, but its powers in this direction are chiefly exerted in the stomach, where it remains active for a much longer time than used to be supposed. It is most active in a neutral medium, any degree of acidity being specially inimical to

* See Chittenden and Richards, Amer. Journ. of Physiol., 1898, i. 461 .

+ See Nicolas and Dubief, Journ. de Phys. et Pathol. Gen. 1899 , i. 979. 
it. Hence the taking of acid fluids-e.g., wines-along with starchy food is apt to interfere with the digestion of the latter, although to some extent this is counteracted by the more profuse flow of saliva which acids call out. Tannin is also a powerful inhibitor of ptyalin, which explains part, at least, of the unfavourable effect of strong tea upon digestion. It is interesting to note that the activity of the ptyalin of the saliva is diminished in most cases of dyspepsia, and in dilatation of the stomach it may be entirely absent. On the other hand, in cases of diabetes it is unusually powerful.*

The secretion of saliva is called out reflexly through the medium of cranial and sympathetic fibres, which are the nerves of secretion. Not all stimuli are capable of exciting secretion-in other words, it needs a 'specific' stimulus to do so, but the range of these is very wide. Psychical impressions-such as the mere sight or smell of food-are powerful stimuli, and may literally 'make the mouth water.' Very dry substances, again, as has already been pointed out, call out a profuse secretion, in order to moisten them and wash them out of the mouth. Acid and acrid substances, too, which, if not neutralized or diluted, would be injurious to the mouth and stomach, strongly excite the glands. In the action of all of these the essentially purposive nature of the salivary reflex is clearly shown forth. Of the two sets of secretory nerves, the cranial fibres produce a more watery flow, and the sympathetic one which is richer in mucin. The latter comes specially into play under

* "The Activity of the Saliva in Diseased Conditions of the Body,' Aitchison Robertson, Journ. of Pathol., 1900, vii. 118. 
the influence of emotion, with the result that the saliva then becomes sticky, and the tongue may 'cleave to the roof of the mouth.' On the other hand, if the chorda tympani be paralyzed, as it is in some cases of facial nerve palsy, the saliva is more scanty. Division of the secretory nerves leads after a time to the appearance of a steady flow of saliva, spoken of by physiologists as a 'paralytic secretion,' which may last for some days. It has been suggested that the ptyalism met with in cases of bulbar paralysis is of this nature, but against such an explanation is its long persistence.

The secretory nerves of the salivary glands are susceptible to the influence of certain drugs. Atropine, for instance, paralyzes the terminals of the cranial fibres, and diminishes the flow; whilst pilocarpine, by stimulating them, exerts an opposite effect. Hence dryness of the mouth is one of the unpleasant consequences of the exhibition of atropine, whilst pilocarpine is used as a remedy in cases of diminished salivary secretion (xerostomia).

The salivary glands also possess a degree of excretory power for some substances. We know that certain drugs, for instance, are so excreted. Chlorate of potash is a case in point: when swallowed in solution it is partly excreted by the saliva, and may thus exert a local effect upon the mouth. It is useful in this way in cases of stomatitis. Again, 'a bad taste in the mouth' is probably due, in some cases at least, to the excretion of abnormal substances by the salivary glands. 


\section{Deglutition.}

The bolus which is formed by mastication and insalivation is pushed by the tongue to the back of the throat. The cavity of the mouth is then closed by the spproximation of the dorsum of the tongue to the palate by the palato-glossal muscles, whilst the nose is shut off by the elevation of the soft palate by the levator palati and palato-pharyngeal muscles. This stage of deglutition may be interfered with by paralysis of the tongue-e.g., in bulbar paralysis-or of the soft palate, when fluids tend to regurgitate into the nose-e.g., in post-diphtheritic paralysis. Food is prevented from entering the larynx during deglutition by the larynx being drawn up towards the base of the tongue, and by its posterior wall being pulled forwards away from the back of the pharynx. The bolus of food therefore glides over the posterior wall of the epiglottis, which explains how it is that destruction of the epiglottis by disease has no effect on deglutition-a fact which was inexplicable on the old theory that the epiglottis shut down on the top of the larynx like a lid. Normally, respiration is reflexly inhibited whilst the food is passing over the top of the larynx, but if a breath be involuntarily taken during the process, food enters the larynx, and coughing and 'choking' result.

In the case of fluids, the contraction of the pharyngeal muscles is sufficient to force them rapidly through the œsophagus until the cardiac orifice is reached, after which their progress becomes much slower, and they merely trickle into the stomach (Fig. 15). Hence, when corrosive liquids are swallowed, it is found that the 
œsophagus may escape injury except at the cardiac orifice, which is much longer in contact with them.

The process of deglutition in the case of well-chewed and thoroughly insalivated solids is very much the same as that of fluids, but if lumps of dry food are swallowed, they traverse the œsophagus very slowly, and may,
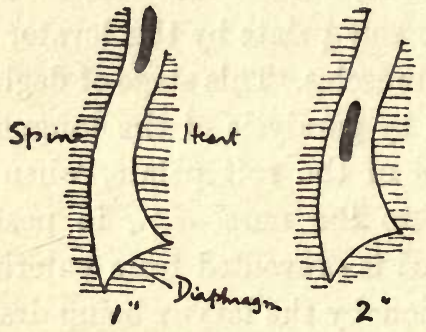

$2^{*}$
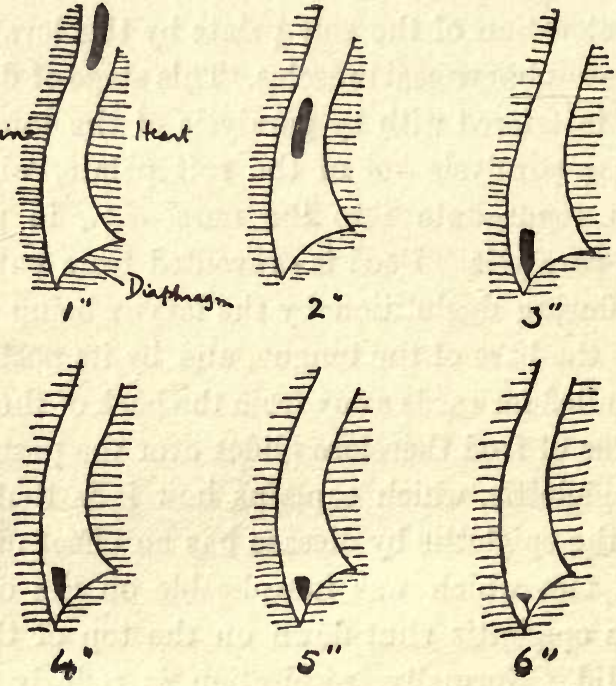

Fig. 15.-To show Position of Shadow at Intervals of One Second during the Swallowing of a Mouthful of Mirk containing Bismuth Carbonate. (Hertz.)

indeed, stick there for some minutes. It has been suggested (Hertz) that the feeling of pressure in the chest experienced after a hurried meal may be due to distension of the cesophagus caused by the presence of solid lumps of food, which only pass very slowly downwards. 
The swallowing reflex is started by the contact of food with the back of the tongue, the superior laryngeal being the afferent and the recurrent laryngeal the efferent nerve concerned. Loss of the swallowing reflex always indicates a bilateral lesion, as destruction of either both superior or both inferior laryngeals is necessary to bring it about. The unstriped muscle of the lower part of the œsophagus is to a large extent automatic in its action, and independent of the nervous system. Thanks to this it is still possible to introduce food into the stomach even when voluntary swallowing is impossible and the deglutition reflex abolished; for if a tube be passed into the upper thoracic region of the cesophagus, any food introduced through it will be passed on by the unstriped muscle. Advantage is taken of this in 'nasal' feeding. If the vagus nerves be divided, a condition of paralytic dilatation of the csophagus ensues, and it is probable that this may also occur as the result of disease affecting the nerves. That a reverse peristalsis in the csophagus is possible seems to be proved by the occurrence of rumination in some subjects.

\section{Digestion in the Stomach.}

Experiments on animals, as well as the results of gastrectomy on patients, have shown that the stomach is not actually essential to life. On the other hand, there can be no doubt that it is not really a superfluous organ, but is of great use in so preparing the food as to protect the intestine from possible injury.

The uses of the stomach are apparently these: (1) To 
act as a reservoir, from which the intestine may be gradually supplied; (2) to sterilize the food to some extent; (3) to regulate its temperature; (4) to help to reduce the food to a fluid form; (5) to aid in the stimulation of pancreatic secretion.

These may now be briefly considered.

1. By acting as a reservoir the stomach enables us to take food in considerable quantities at a time-i.e., it renders meals possible. The practical convenience of this does not need to be pointed out. The capacity of the stomach varies considerably in different individuals and in the same individual at different periods of life. Roughly it may be put down in the case of liquids at 2 to 4 pints, and in the case of solids at about 2 pounds. If it be remembered that the total amount of solid food required daily amounts to about 3 pounds, it will be evident that it is hardly possible to take all our food at one meal without seriously overburdening the stomach. Again, were it not for the reservoir action of the stomach, there would tend to be a waste of food by putrefaction, owing to the intestine being supplied with it more rapidly than it could be digested and absorbed.

2. Another function which the stomach fulfils is that of partially sterilizing the food by the antiseptic action of the hydrochloric acid of the gastric juice. This action, however, is not a powerful one, and some organisms, such as those that form acids, seem to escape it altogether, and there is reason to believe that the same is true of some, at least, of the commoner pathogenic 
organisms, notably the tubercle bacillus. Hence the possibility of acquiring tuberculosis by drinking milk. The sterilizing power of the stomach varies greatly, according to the stage of digestion and the nature of the food. It reaches its maximum towards the end of digestion, when hydrochloric acid is present in the free state, whilst it is much less, or even in abeyance altogether, in the earlier stages, when only combined acid is present. Foods rich in protein, by combining with much of the acid, lessen the germicidal power of the gastric juice. Over the growth of organisms in the intestine the stomach seems to exert but little control. Even when the secretion of gastric juice is entirely arrested, or the stomach is excised, no increase in the amount of intestinal putrefaction occurs.* Increased decomposition in the bowel can therefore hardly be regarded as the cause of the diarrhoea which is apt to occur in cases of achylia.

3. The regulation of the temperature of the food is one of the minor, but none the less important, functions of the stomach. In this respect it acts as a protector of the intestine, which appears to be more sensitive to extremes of temperature than the stomach itself. As ordinarily taken, the temperature of food may be considered to vary between $5^{\circ} \mathrm{C}$. and 50 to $60^{\circ} \mathrm{C}$. It requires only about ten minutes for a pint of liquid at $50^{\circ} \mathrm{C}$. $\left(122^{\circ} \mathrm{F}\right.$.) to be brought down to the body temperature after it has been swallowed, but considerably longer for a similar quantity at $5^{\circ} \mathrm{C} .\left(41^{\circ} \mathrm{F}\right.$.) to be raised to the

* Schlatter, Lancet, 1898, i. 146, and Filippi, Deutsch. Med. Woch., 1894, zx., No. 40. 
same point.* Hence cold fluids are more apt to escape over into the intestine imperfectly warmed, and may thus excite diarrhœa. The best temperature for food is that of the body, for it then stays the shortest time in the stomach. This should be remembered in cases such as those of atonic dyspepsia, in which it is important that the food-and especially its fluid constituents-should be passed on out of the stomach as quickly as possible.

4. By reducing the protein constituents of the food to a soluble form, the stomach helps to prepare them for more complete digestion in the intestine. In studying this process one has to do with the three physiological properties of the stomach: (a) sensibility, (b) secretion, (c) motility; and for the sake of clearness it will be well to take these up separately, especially as the disorders of gastric digestion can be traced in every instance to a disturbance of one or more of these functions.

\section{Sensibility.}

Normally the stomach does not appear to be sensitive in the ordinary sense, or, at all events, any sensations which proceed from it fail to reach the seat of consciousness. It would appear, however, that the degree of anæsthesia of the stomach varies in different persons, for some, at least, are able to discriminate between hot and cold liquids when introduced by the stomach tube.t It is noteworthy that in such cases the sensation is referred,

* See Mueller, Zeit.f. Diät. und Phys. Therapie, 1905, Bd. viii., Heft 11.

+ Neumann, Archiv f. Verdauungskrankh., 1907, xiii. 81. 
not to the stomach itself, but to the skin of the epigastrium, just as pain is in cases of gastric hyperæsthesia and gastralgia. There can be little doubt, too, that in everyone centripetal impulses reach the lower centres from the stomach, which are concerned in producing the 'sensation' which we call appetite, and it is possible that anorexia is due to a subnormal state of gastric sensibility. On the other hand, it is also possible that in certain states of the nervous system the centripetal impulses from the stomach actually penetrate as far as the seat of consciousness, and are 'felt' as pain, or, at least, as vague discomfort. It would appear, too, that pain can be produced even in an otherwise normal stomach by any excessive or irregular contraction of its muscular coat, just as it may be so produced in any other hollow viscus, and many cases of dyspeptic pain are probably thus brought about. Again, traction on the cardiac or pyloric ends of the stomach affects the nerves of the subserous connective tissue, and is extremely painful. It is probably to this that the pain which may result from the presence of gastric adhesions owes its origin.

\section{Secretion.}

The secretion of gastric juice is not the result of mechanical stimulation of the mucous membrane of the stomach by the contact of food, as was once supposed, but of the action of nervous impulses reaching the stomach through the vagus. Mechanical stimulation is merely followed by a flow of alkaline mucus, which is designed to protect the delicate lining membrane, and 
it is in consequence of such direct stimulation that irritating and unsuitable foods may set up gastric catarrh.

The stimuli which can excite a flow of juice are either (1) psychical or (2) chemical. The mere sight or smell of food, or the agreeable taste of it in the mouth, given the presence of appetite, is sufficient to start an active flow of juice whilst the stomach is still empty. It is not the mere mechanical act of chewing, but the relish of the food which originates the reflex. Hornborg, ${ }^{*}$ for instance, has observed in the case of a boy with a gastric fistula and occlusion of the cesophagus that the chewing of indifferent substances, such as indiarubber, failed to cause gastric secretion.

The juice thus poured out-to which Pawlow has given the name of 'appetite juice'-is of great value in starting the process of digestion, and it has been suggested that the favourable results in some cases of dyspepsia of giving frequent small meals rather than a larger quantity of food at longer intervals are to be attributed to the greater quantity of 'appetite juice' which is thus obtained. Be this as it may, the realization of the value of the 'appetite juice' is of the first importance to the physician, and should encourage him to make every effort to promote the appetite of patients with feeble digestion by attention to the rsthetic qualities and flavour of their food, as well as by the administration of exciters of appetite such as bitters. $\dagger$

* Skandinav. Archiv f. Physiol., 1904, xv. 248.

+ Seeing that bitters promote a flow of gastric juice by acting upon the nerves of taste, they should always be administered in solution if their full effect is to be obtained, and not swallowed in the form of a tabloid, capsule, or pill. 
'It appears to me,' says Pawlow,* 'that . . . instinct has often made out a brilliant case when brought before the tribunal of physiology. Perhaps the old and empirical requirement that food should be eaten with interest and enjoyment is the most imperatively emphasized and strengthened of all. In every land the act of eating is connected with certain customs designed to distract from the business of daily life. A suitable time of day is chosen; a company of relatives, acquaintances, or comrades assemble. Certain preparations are carried out (in England a change of raiment is usually effected, and often a blessing is asked upon the meal by the oldest of the family). In the case of the well-to-do a special room for meals is set apart; musical and other guests are invited to while away the time at meals-in a word, everything is directed to take away the thoughts from the cares of daily life, and to concentrate them on the repast. From this point of view, it is also plain why heated discussions and serious readings are held to be unsuitable during meal-times.'

The above quotation shows the importance attached to the 'appetite juice' by the distinguished Russian physiologist even in a state of health, and in abnormal conditions it is of still greater importance to bear it in mind. In cases, for instance, in which it is necessary to introduce food directly into the stomach through an œsophageal tube or a gastrostomy wound, care should be taken, whenever possible, to call out a flow of 'appetite

* 'The Work of the Digestive Glands,' English translation, 1902, p. 133 (Griffin and Co., Limited). 
juice' by introducing substances into the mouth before the meal is given.

In this connection it is of interest to ask, What is appetite, and can the physiologist give any explanation of it? The reply is that the nature of the state of feeling we call 'appetite' is still very obscure. One thing is certain-namely, that it is not the same as hunger. Hunger is the cry of the tissues for food, or, as it has been put, 'the expression of the caloric requirements of the tissues,' and may be experienced even when the stomach is quite full, as happens, for example, in the case of a patient who has a fistula high up in the $i_{\text {ntestine. }}$

Appetite, on the other hand, is apparently more dependent on sensations derived from the stomach itself, and may be quite absent in cases of gastric disorder, even although the patient be in a state of hunger. It has been suggested, as already pointed out, that the sensations from the stomach on which appetite depends are of a subconscious nature, and that a depression of them may give rise to abolition of appetite (anorexia), whilst their exaltation may produce an excessive desire for food (bulimia).

How long the flow of 'appetite juice' lasts in normal feeding it is impossible to say, but very soon the second or chemical method of excitation comes into play. This is brought about by the action of certain chemical constituents of the food on the nerves of the stomach. Not all nutritive substances are able to excite the gastric nerves. The most powerful are the extractives of flesh, dextrins, milk, and water. 
A consideration of these facts shows that the longestablished custom of beginning dinner with soup is justified, and should also be a guide to us in selecting suitable foods for administration by forced feeding.

On the other hand, some foods, such as bread, starch, and white of egg, do not excite a flow of juice at all, whilst fat tends actively to restrain the secretory activity. The former foods are therefore indicated where one wishes to excite gastric secretion as little as possible, whilst the administration of fatty substances is justified in cases in which secretion is already excessive. Some drugs, such as bicarbonate of soda and bismuth, appear also to have the power of inhibiting the secretion.

The proof which physiology has now furnished that gastric secretion is entirely dependent upon nervous influences, and is not the result of mechanical stimulation by the food, is of great interest to practical medicine, for it makes it easier to understand the large part which disturbances of the nervous system play in the production of functional dyspepsia.

The gastric juice, then, which is required for the digestion of an ordinary meal is the result of the combined action of these two sorts of stimulus, and the flow of it begins even before food has actually entered the stomach, and continues actively during the first hour or so of digestion, and then undergoes a gradual decline. The composition of the juice appears to be fairly constant in the same individual, but varies in different persons, even although the food be the same. In other words, when more hydrochloric acid is required it is obtained by increasing the total quantity of juice 
secreted, and not by the outpouring of a more acid juice. The time at which free $\mathrm{HCl}$ appears varies with the composition of the food; the richer the latter is in protein, the longer is the appearance of uncombined acid delayed, for protein has a high acid-binding power. It is for this reason that foods rich in protein are recommended in cases in which the production of $\mathrm{HCl}$ tends to be excessive. If free $\mathrm{HCl}$ appears early it disappears soon, and the later it appears the longer it lasts, but the average duration of its presence is probably about one and a quarter to one and a half hours. It is of interest clinically to know that after an ordinary Ewald's test-breakfast, free $\mathrm{HCl}$ is always quite evident in an hour (Penzoldt). The stomach is always and at all times acid to litmus, although at the beginning and end of digestion the reaction is very feeble.

The total acidity of the stomach contents an hour after a test-breakfast (Ewald's) varies from 0.11 to 0.26 per cent. in different individuals, and the proportion of free $\mathrm{HCl}$ from 0.07 to 0.2 per cent. These differences are apparently due to individual peculiarities. The production of acid seems to be greater in young and healthy subjects than it is in the old, and in 40 per cent. of persons above the age of fifty free $\mathrm{HCl}$ is absent altogether (Seidelin),* a fact which should be borne in mind a propos of the diagnostic value of the absence of free $\mathrm{HCl}$ in cases of carcinoma.

It will be obvious from the above description that abnormalities of gastric secretion may arise in several ways: (1) The total amount of juice produced may be * Abst. in Archiv f. Verdauungskrankh., 1904, x. 426 - 
too great (hypersecretion); (2) the total amount of juice may be normal, but the percentage of $\mathrm{HCl}$ which it contains too high (hyperchlorhydria); (3) there may be errors in the time-rate of the secretion-e.g., it may be poured out too fast if the glands are irritable or overexcited, or it may be produced too slowly.

The experiments of Pawlow appear to show that in the dog, at least, there is a certain adaptation of the composition and strength of the gastric juice to the kind of food which has to be digested. For example, for bread-protein five times more pepsin is poured out than for protein in milk, and for flesh-protein 25 per cent. more than on that of milk. It is doubtful, however, whether such variations occur in man,* although possibly if one particular kind of food is taken for a long time such an adaptation may be arrived at, and a 'digestive habit' for that form of diet established.

\section{Motility.}

1. Tonicity. - In the empty stomach there is normally a slight degree of tension present which keeps up a pressure within it, which has been estimated in man as equal to a manometric pressure of about 4 to 5 centimetres of water. $\dagger$ This is due in part to a slight tonic contraction of the muscular coat, and in part also, perhaps, to the contractile pressure exerted by the

* See Penzoldt, Deuts. Archiv f. Klin. Med., 1894, liii. 209, and Schüle, Zeit. f. Klin. Med., 1895, xxviii. 461, and 1896, xxix. 49.

+ See Dobrovici, Archiv f. Verdauungskrankh., 1907, xiii. 78; also Moritz, Ziit. f. Biologie, 1895, xxxii. 313. 
elastic tissue in the wall of the stomach, which forms two layers-one in the muscularis mucosæ, and the other and more definite layer between the submucous and muscular coats. In chief measure, however, the tension within the empty stomach is not the result of such factors as these, but is due simply to pressure exerted upon the stomach from without by the abdominal wall and by other viscera, especially the liver. Thus, the intragastric pressure is lowest when the individual is lying upon the right side, when the weight of the liver is taken off the stomach ; and it is worth noting that this is the position which it is best to adopt if vomiting be urgent, as in sea-sickness. It is of interest, too, to observe that, contrary to expectation, the intragastric tension is not increased in pregnancy, a fact which has important bearings upon some of the theories which have been advanced to explain the occurrence of vomiting in that condition.

After food enters the stomach the intragastric tension in the fundus rises to a pressure of 10 to 12 centimetres of water, and if enough food be taken to raise the pressure to 20 centimetres, the feeling of distension becomes painful. This, however, is nothing compared with the pressure which may be exerted upon the stomach by pressure from without, for it has been found that forced expiratory efforts with the diaphragm fixed and depressed may raise the pressure within the stomach to that of 330 centimetres of water, and such is the 'squeeze' brought to bear upon the organ in the act of vomiting.

The rise in intragastric tension after the taking of 
food is probably due to a slight active contraction of the wall, which is reflexly brought about and is designed to resist the mechanical pressure of the contents. Failure of this reflex contraction has been alleged to play a large part in the development of 'atonic dilatation' of the stomach, by allowing the fluid pressure of its contents to exert its distending effect unopposed.*

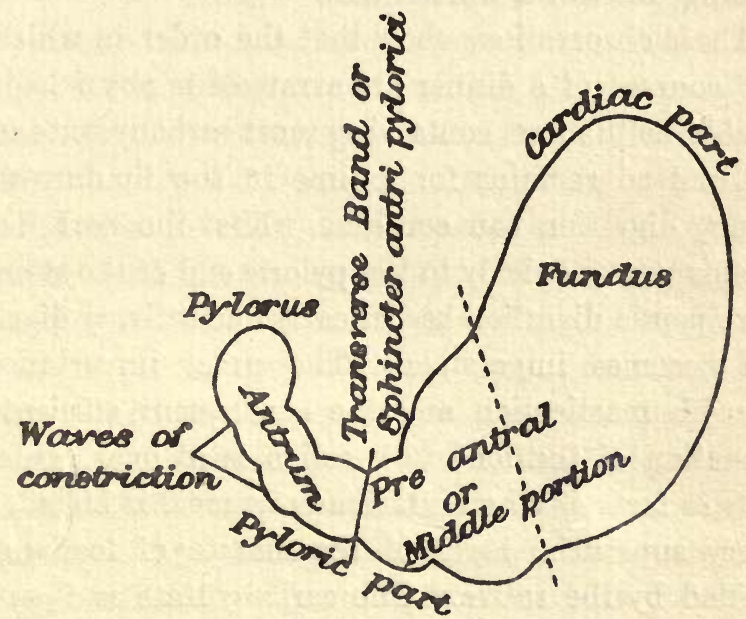

Fig. 16.-Fundtional Divisions of the Stomach.

2. Active Movements.-From the point of view of its active motility, the stomach may be divided into two distinct parts-(1) the fundus, (2) the antrum (Fig. 16). These are separated from each other by a muscular constriction-the transverse band-situated a little to the left of the pyloric orifice, and no mixing of the contents

* See a paper by Agéron, Archiv. f. Verdauungskrankh., 1905, xi. 460. 
of the two parts occurs. The fundus serves the function of a reservoir, in which the food is gradually mixed with the gastric juice and slowly squeezed on into the pyloric end. It is not the seat of any very active churning movements, and as each bolus of food is swallowed it is received into the centre of the accumulated mass, where the gastric juice only slowly reaches it, thus affording the saliva time to act.

' These observations show that the order in which the chief courses of a dinner are arranged is physiologically suitable, as the part containing most carbohydrate comes last, and so remains for a time in the fundus, where salivary digestion can continue, whilst the part rich in proteids passes quickly to the pyloric end of the stomach, where peptic digestion begins early and salivary digestion soon becomes impossible. The great importance of thorough mastication and the consequent efficient impregnation of the food with saliva is at once explained by these facts. When a farinaceous meal is bolted, only a very superficial layer of the masses of food can be digested by the saliva. The carbohydrate is then very liable to undergo bacterial fermentation with the production of flatulence and all its unpleasant results. This is prevented when salivary digestion can occur, as dextrin, the first product of the digestion of starch, is less easily decomposed by bacteria than starch, and maltose and dextrose, the final products of salivary digestion, are soluble and readily diffuse into the pyloric end of the stomach, where the presence of hydrochloric acid prevents the occurrence of bacterial decomposition' (Hertz).

The movements of the pyloric end of the stomach are 
much more forcible and active than those of the fundus ${ }^{\circ}$ It is here that the food is mixed with the gastric juice, rubbed down to a more or less fluid consistency, and gradually expelled into the duodenum. The mechanism by which this takes place is as follows (Cannon): Whilst food is present in the stomach constriction waves are seen continually coursing over the antrum towards the pylorus. The fundus meanwhile serves as an active reservoir for the food, and squeezes out its contents gradually into the pyloric portion. The stomach is emptied by the formation, between the fundus and antrum, of a tube ('pre-antral' or 'middle' portion, in Fig. 16), along which constrictions pass* at regular intervals of fifteen to twenty seconds. The contents of the fundus are pressed into the tube, and the tube and antrum slowly cleared of food by the waves of constriction. The food in the pyloric portion is first pushed forwards by the running wave, and then by pressure of the stomach wall is returned backwards through the ring of constriction, being thus thoroughly mixed with gastric juice. Finally, when the solid food has been thoroughly triturated by the constrictions, the pylorus opens and allows the contents of the antrum to escape.

It will be readily understood from this description that the stomach is much more likely to be affected by mechanical injuries at its pyloric end than at the fundus, and it is perhaps for this reason that this portion is most often the seat of an ulcer. Seeing, too, that the pressure is highest at this end of the organ, it is important in

* The waves of constriction can be seen very well, in cases of congenital pyloric stenosis, coursing from left to right. 
performing gastro-enterostomy that the opening should be made as near the natural pylorus as possible, so that the expulsive effect which results from the 'systolic' contraction of this part of the organ may be taken advantage of.

The movements of the stomach are apparently myogenic in origin, or, at least, dependent upon a purely local nerve mechanism, for they continue even when all its nerves are divided, but there is no doubt that the vagus can exert both a stimulating and an inhibitory influence upon them.* On the other hand, the sympathetic appears to be incapable of exerting any effect in either direction. It has been found experimentally that emotional states-such as rage, fear, or distress-inhibit the movements of the stomach, and in accordance with this is the well-recognized influence of such states in the production and maintenance of dyspepsia. It is stated by Moritz $\dagger$ that the movements of the stomach are not affected by electrical stimulation. On the other hand, it has been shown that they are considerably strengthened by massage. If these observations are correct, they have important bearings on the therapeutics of 'atonic' dyspepsia.

What is the stimulus to the movements of the stomach? To this question physiology is not able to furnish a clear reply. The presence of free $\mathrm{HCl}$ seems to increase the activity of the movements; but that it is not their sole cause is shown by the fact that they may

* See Page May, Brit. Med. Journ., 1902, ii. 779.

+ Zeit. f. Biologie, 1895, xxxii. 313. 
take place quite efficiently when no gastric juice is secreted at all, as in cases of achylia. Probably the mere presence of food is in itself an exciter of the movements. There is equal doubt as to the agent which unlocks the pylorus and allows the food to escape into the intestine. According to some, free $\mathrm{HCl}$ is also the active agent in this process. This, however, is unlikely for several reasons. In the first place, as has just been pointed out, the discharge of the stomach contents into the intestine may take place quite quickly when no free $\mathrm{HCl}$ is present at all. In the second place, observations on patients with gastric fistulæ show that free $\mathrm{HCl}$ tends to inhibit the opening of the pylorus rather than to favour it,* and there is some clinical evidence for the belief that the presence of an excess of acid may cause pyloric spasm. In the third place, there is no doubt that the presence of acid in the duodenum prevents the pylorus from opening until it has been neutralized. It would be very unlikely, surely, that the presence of acid on one side of the pylorus should open it, and on the other should cause it to close. On the whole it seems more probable that the pylorus opens when the waves of contraction in the stomach become strong enough, provided it be not reflexly inhibited by distension of the duodenum or the presence in the latter of an acid reaction or of fat. Warmth, internal or external, and the presence of alkalies in the stomach seem to unlock the pylorus; hence, probably, the usefulness of poultices, hot liquids, and alkalies in relieving gastric pain. On

* See v. Pfungen, Centralb. f. Physiol., 1887-88, i. 220, 277. 
the other hand, the presence of insoluble lumps of food in the stomach seems to excite a powerful contraction of the pylorus, which expresses itself as 'stomach-ache.' The result is that such undissolved lumps are retained in the stomach for more prolonged digestion and attrition. The presence of an ulcer or fissure in the near neighbourhood of the pylorus would seem to be capable of inhibiting the relaxation of the latter, which normally occurs when peristaltic waves reach it. In this way the outlet may be blocked and dilatation of the stomach result.

The rate at which different substances leave the stomach seems to depend upon many different circumstances, chief of which is the mechanical form and consistence of the substance in question. Fluids begin to pass out of the stomach almost at once, warm fluids sooner than cold. 'Slops' begin to pass out almost as soon, and even solids may begin to be discharged in less than half an hour. These observations show the importance of attending to the mechanical form of the food in cases in which the stomach has difficulty in emptying itself.

The chemical composition of the food, however, is not without influence upon the rate of its discharge. Some observations by Cannon* are of interest in this connection. As the result of experiments in the Harvard Physiological Laboratory, he states that 'it was proved that when carbohydrates, proteins, and fats of the same consistency are fed separately and in equal amounts, they do not leave the stomach at the same rate. Fats remain long in the stomach. Their discharge into the small * Amer. Journ. of Med. Sciences, 1906, exxxi. 563. 
intestine begins slowly, and continues at about the same rate as their absorption or their passage onward into the large intestine. Carbohydrates begin to leave the stomach soon after their ingestion (within ten minutes). They pass out with rapidity, and at the end of two hours reaeh a maximum amount in the small intestine, almost twice the maximum for proteins, and two and a half times the maximum for fats, both of which maxima are reached only at the end of four hours. Proteins frequently do not leave the stomach at all during the first half-hour, and, occasionally, not for an hour. The initial departure of proteins from the stomach, therefore, is much later than that of carbohydrates, and the rate of discharge slower than that of either carbohydrates or fats. The pylorus evidently permits the carbohydrates not digested by the gastric juice to pass quickly into the intestine, where they are digested, and retains the proteins, digested in the stomach, there to undergo digestion. When proteins are fed first, and carbohydrates later, the proteins occupy the pyloric end of the stomach, and the carbohydrates lie mainly in the cardiac end. Under these circumstances the presence of the proteins near the pylorus causes a characteristic slow discharge, which thereby checks the carbohydrate departure. If, on the other hand, the carbohydrate is fed first, it passes on at once to the small intestine for further digestion and absorption, and the protein remains to undergo the changes produced by the stomach. It would seem from these experiments that the American breakfast, in which the cereal precedes the meat, has a rational and physiologically economic arrangement; and 
the ancient English custom of eating the pudding before the meat is likewise more defensible than the modern order of the dinner menu.'

The cardiac orifice is normally in a state of tonic contraction,* which is aided by the fibres of the diaphragm, which embrace the end of the cesophagus, as well as by the oblique entry of the latter into the stomach. Division of the vagus causes relaxation of this tonic contraction. It is possible that such a diminution of vagus control during life may play a part in the regurgitation of food or the escape of gases into the œsophagus, which is the cause of some forms of flatulence.

The cardiac orifice, like the pyloric, is controlled by a special nerve centre situated in the medulla. Stimulation of this centre causes contraction of the longitudinal fibres which pass from the lower end of the œsophagus and spread out over the stomach. A horse is unable to vomit because the longitudinal fibres of its œsophagus wind round spirally in the neighbourhood of the cardia instead of running straight on to the stomach, as in most mammals.

\section{Absorption from the Stomach.}

The absorptive power of the stomach is surprisingly small, and in this fact one may see a provision for the protection of the body, for it allows of the neutralization or rejection of injurious substances before they have time to enter the blood. Alcohol is of all substances

* Sinnhuber, abst. in Archiv. f. Verdauungskrankh., 1904 x. 93. 
that which the stomach absorbs most readily, which explains to some extent the rapidity with which it exerts its effects. Peptone, sugar, and salts are also absorbed to some degree. On the other hand, water, curiously enough, is scarcely absorbed at all. Hence, in pyloric stenosis the tissues may suffer from water starvation unless water be administered by other routes-e.g., the rectum.

There is reason to believe that the process of absorption by the stomach partakes much more of the nature of a mere physical osmosis than is the case in the intestine, and it is accompanied by the pouring out of a good deal of secretion. It is in this way, perhaps, that a mixture of alcohol and sugar, such as is found in sweet wines and malt liquors, may cause 'acidity.'

\section{The Gases of the Stomach.}

The stomach usually contains a small amount of gas, which consists of a mixture of nitrogen and $\mathrm{CO}_{2}$, the latter being present in the same proportion as oxygen in atmospheric air, whilst the nitrogen is present in the same proportion as it is in air. It is believed that the nitrogen is derived from swallowed air, the oxygen of which has been absorbed by the bloodvessels of the gastric mucous membrane, whilst the nitrogen escapes absorption because the blood is saturated with it already. The $\mathrm{CO}_{2}$ is probably transfused from the blood. Evans* has brought forward evidence, derived from a study of the gas contained in the swim-bladder of fish, in favour

* Brit. Med. Journ., 1897, i. 649. 
of the view that some of the nitrogen may also be derived from the blood. This has important bearings on the subject of gastric flatulence.

\section{The Physiology of Vomiting.}

The act of vomiting is preceded by an abundant flow of saliva, which, along with air, is swallowed. There follows a series of spasmodic contractions of the diaphragm, during which the entrance to the larynx remains closed, so that the air is forced into the stomach. Thus the intra-abdominal pressure is raised, whilst that in the thorax is lowered. The cardiac orifice then opens, and the cosophagus is shortened by contraction of its longitudinal fibres.

Meanwhile, as observations with the X-rays have shown, the cavity of the stomach itself, after the development of a series of strong waves of peristalsis, becomes separated into two parts by a constriction at the entrance to the antrum (see Fig. 16), the cardiac portion relaxes, and the contents of the fundus are forced up by the pressure brought to bear upon them by the diaphragm and abdominal wall (see p. 242). Occasionally antiperistaltic waves occur from the pylorus towards the cardia.

The stomach, therefore, does not play an entirely passive rôle in the act of vomiting, and one can easily understand how, for example, sutures in its wall might be torn out in the course of the act. That it is able, even by its own contraction, to empty itself of its contents is shown, too, by the possibility of vomiting taking 
place even when all the abdominal muscles are paralyzed. That the pylorus does not remain tightly closed during the whole process is indicated by the clinical facts that bile, gall-stones, and intestinal worms may all be vomited.

The simultaneous contraction of the diaphragm and the abdominal muscles, which is peculiar to vomiting, raises enormously the intra-abdominal pressure, and forces blood up into the heart. The blood-pressure is thereby increased, and the feeling of faintness which precedes the act of vomiting is relieved. This explains the great relief which immediately follows vomiting in cases of sea-sickness; and, indeed, the tendency to vomiting which is exhibited in all cases of cerebral anæmia must really be regarded as a conservative measure vhich is calculated to increase cerebral blood-pressure.

The complicated mechanism by which vomiting is brought about is controlled by a special centre situated in the medulla in the neighbourhood of the calamus scriptorius, and close to the respiratory and vasomotor centres. Destruction of this centre renders vomiting impossible, whilst the application to it of a dilute solution of apomorphine excites the act in an extreme degree.

The proximity of the respiratory and vomiting centres explains how it is that irritation of the former, as in dyspnœa, often induces nausea or even actual vomiting as well. On the other hand, it has been found that the induction of apnœa-i.e., the temporary inhibition of the irritability of the respiratory centre-can arrest the act of vomiting for a time, a fact which is often acted upon 
unconsciously by patients who seek to stop vomiting by the taking of a series of deep breaths.

The vomiting centre can be excited either directly or reflexly. The former mode of excitation occurs in the vomiting of cerebral anæmia or hyperæmia, in intoxications-e.g., uræmia-in cases of intracranial disease, and in the vomiting of psychical origin. Reflex irritation of the centre can be brought about by stimuli reaching it from many peripheral sources.

\section{Duodenal Digestion.}

In the duodenum the chyme discharged from the stomach meets the bile and pancreatic juice. The mixture of the two latter forms a yellowish-green fluid of a specific gravity of 1010, and of a neutral or slightly alkaline reaction.* The addition of the acid chyme to this throws down a precipitate which consists of mucin, bile acids, and bile pigments, but which does not contain pepsin; and if there be sufficient chyme to give it a decidedly acid reaction, digestion goes on just as in the stomach, and this undoubtedly must happen to a considerable extent when the stomach produces an excess of acid. As a rule, however, beyond the first few inches of the duodenum, there is no free mineral acid present, and it may be for this reason that duodenal ulcers are only met with for a short distance beyond the pylorus.

Pure human pancreatic juice, as derived from a fistula, $\dagger$ is a clear fluid of specific gravity 1007, alkaline

* Boas, Zeit.f. Klin. Med., 1890, xvii. 155.

+ Glaessner, Zeit. f. Physiol. Chemie, 1903-4, xl. 465. 
in reaction, and containing 15 per cent. of protein (chiefly albumin) and 6 per cent. of ash. About 500 to 600 c.c. of it are produced in twenty-four hours.

It is not yet determined whether there is a psychical or 'appetite' production of pancreatic, as there is of gastric, juice, but the chief flow is reached about three hours after the taking of food, and is the result of a chemical stimulus exerted on the pancreas by the substance secretin, which is produced by the action of acids upon the cells lining the upper part of the intestine. That the presence of acids is not essential for the production of the stimulus, however, there can be no doubt, for the secretion may still go on in cases in which the production of hydrochloric acid by the stomach is entirely arrested, and Pawlow has shown that fats are also capable of calling out a flow of the juice.

The pancreatic juice contains a proteolytic ferment (trypsinogen), which is converted into trypsin by mixture with the enterokinase of the intestinal juice. Unless enterokinase be present, trypsinogen is inactive, which explains the fact that the pancreas does not digest itself. In addition to trypsinogen, the juice contains the fatsplitting ferment (lipase) and a diastasic ferment, which converts starch to maltose. Both of these are present in the fresh juice, though the action of the fat-splitting ferment is intensified by the presence of bile and intestinal juice.

Absence of pancreatic juice from the intestine interferes to some extent with the absorption of protein, but to a greater extent with that of fat, although the splitting up of fat seems still to go on to a considerable 
extent,* probably as the result of bacterial action. The presence of large quantities of fat in the stools should therefore suggest pancreatic disease or blocking of the duct.

From its action in digestion bile is entitled to rank as a secretion. Its properties as an excretion will be considered in another chapter (p. 282).

The chief use of bile in digestion consists in the power it possesses of increasing the breaking up and absorption of fat, which resides, as Starling says, $\uparrow$ ' in its power of serving as a vehicle for the suspension and solution of the interacting fats, fatty acids, and fat-splitting ferment.' This is due to the peculiar physical properties of the bile salts along with those of the lecithin and cholesterin which they hold in solution. Hence it is not surprising that when bile fails to enter the intestine the loss of fat in the fæces is greatly increased, $\downarrow$ and part of the pale colour of the stools in jaundice is due to this cause. In such cases fats should be withheld from the diet.

The antiseptic power of bile in the intestine has probably been exaggerated, but if free bile acids are present, as they are when acid gastric juice is entering the intestine freely, a certain degree of antiseptic power is exerted. On the other hand, the increased amount of intestinal putrefaction which undoubtedly occurs in

* Vaughan Harley, Journ. of Pathology, 1896, iii. 245 ; se also Krehl's 'Clinical Pathology,' English translation, p. 280.

† 'Recent Advances in the Physiology of Digestion' (Constable), 1906, p. 117.

† Mueller, Zeit. f. Klin. Med., 1887, xii. 45 . 
cases in which bile is prevented from escaping into the bowel is due to the unabsorbed fat favouring putrefaction.

The frequency with which biliary obstruction is associated with constipation has led to the belief that bile acts as a stimulant to peristalsis, but of this there is as yet no experimental proof.

The stimuli to the discharge of bile into the intestine are apparently the same as those of pancreatic secretion-acids and fats. Proteins also call out an increased secretion of bile, probably because they lead to a large production of acid in the stomach. Starches have very little influence; hence it may be that restriction of starchy foods and an increase of the amount of meat in the diet are useful in cases of 'biliousness' in which bile production is believed to be defective.

\section{Intestinal Digestion.}

The importance of the succus entericus as a digestive agent has been greatly enhanced in recent years since it became known that by means of enterokinase it 'activates' trypsinogen, and since the discovery in it of the ferment 'erepsin,' which, though not able to attack proteins (except, apparently, casein), has the power of splitting up proteoses and peptones with the formation of amines and diamines. It is believed that this part of its action is not exerted in the lumen of the intestine, but in the actual cells of the villi, and its importance in the picking to pieces of the protein molecules of the food and their reconstitution into body proteins has already been referred to (p. 30). 
In addition to these ferments, intestinal juice contains a series which invert the various sucroses (cane-sugar, lactose and maltose) into dextrose and lævulose, the existence of which has long been known, and by means of which it completes the work already begun by the saliva and the pancreatic juice.

The stimuli which lead to the production of normal intestinal juice have not yet been clearly made out, though here again secretin is believed to play a part. Mechanical stimuli lead to the production of a very watery secretion which has little or no digestive power, and the object of which, apparently, is to wash away the source of irritation. It is in this way, seemingly, that solid indigestible substances, as well as some purgatives, excite diarrhœea.

\section{Intestinal Movements.}

The intestine exhibits two forms of movement: (1) Movements of rhythmical segmentation (which occur at the rate of about seven per minute in man), the object of which is to ensure thorough mixing of the contents of the gut, but which have no translatory effect (Fig.17). These movements are most vigorous in hunger, the small amount of material left in the intestine being searched again and again for nutriment until it has all been absorbed, just (to quote a German writer) as one may peel an apple, eat it, and then nibble the peel. An exaggeration of these movements in nervous subjects is the cause of borborygmi, which, as is well known, are most troublesome when the stomach is empty. 
(2) Peristaltic movements which propel the contents of the gut downwards, every such movement consisting in a contraction of the gut above the point of stimulation and relaxation of it below that point (Starling's 'Law of the Intestines ').

The peristaltic contractions are the result of a local nerve mechanism (Auerbach's plexus), but they are also, apparently, under the influence of the central nervous system, especially through the medium of the splanchnics,
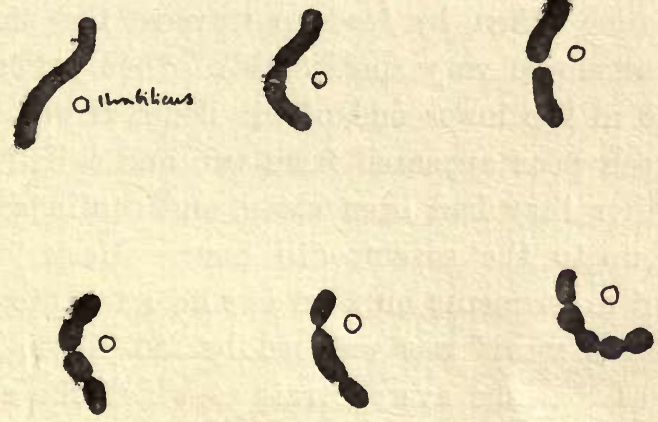

Fig. 17.-Diagram of Seggmentation in Human Small Intesstines occurring simultaneously with Peristalsis. (Hertz.)

which appear to exert a slight tonic inhibition of them. Thus paralysis of the solar plexus induces an exaggerated peristalsis with diarrhœa, and 'nervous diarrhœe' is probably brought about in this way. On the other hand, irritation of the splanchnics induces colic and constipation, as happens in lead-poisoning or in cases of intraabdominal inflammation.*

* See Largiel Lavastine, abst. in Archiv f. Verdauungskrankh., 1903, ix. 417. 
It must not be supposed that a peristaltic wave traverses the intestine steadily from one end to the other. On the contrary, as it has been graphically put,* the contents 'are moved in an irregularly pendulumlike fashion downwards, somewhat like a walker who always takes two steps on and one back, then several forwards, then stands still for some time, and then, as if he had forgotten something, runs back again, but finally, although naturally much later than one who walked right on, he arrives at his goal.'

The time taken by food to traverse the small intestine seems to vary considerably. In a patient with a fistula at the lower end of the ileum it was found + that green peas appeared from two and a half to five hours after they had been eaten, and continued to be passed up to the seventeenth hour. Hertz, $\ddagger$ as the result of experiments on men in whom the progress of a 'bismuth meal' was watched by aid of the X-rays, concludes that the average rate at which the contents of the small intestine travel is about 1 inch per minute. Progress through the large intestine is much slower (see Fig. 18).

Inco-ordination of peristalsis, by which relaxation in front fails to coincide with contraction behind, results in colic. Strong mechanical irritation results often in a local tetanic contraction (enterospasm) and in a peristaltic wave. Local inflammation of the gut (enteritis)

* Grützner, Archiv f. d. Ges. Physiol., 1898, Ixxi. 492.

$\dagger$ Neucki, MacFadyen, and Sieber, Archiv f. Exper. Path. und Pharmak., 1891, xxviii. 311.

† Guy's Hospital Reports, 1907, 1xi. 389. 
does not in itself lead to peristalsis, but exaggerates greatly the sensitiveness of the bowel to other stimuli.

Antiperistalsis has not been clearly proved to occur in the small intestine experimentally, although it has been observed to take place in a case of intestinal

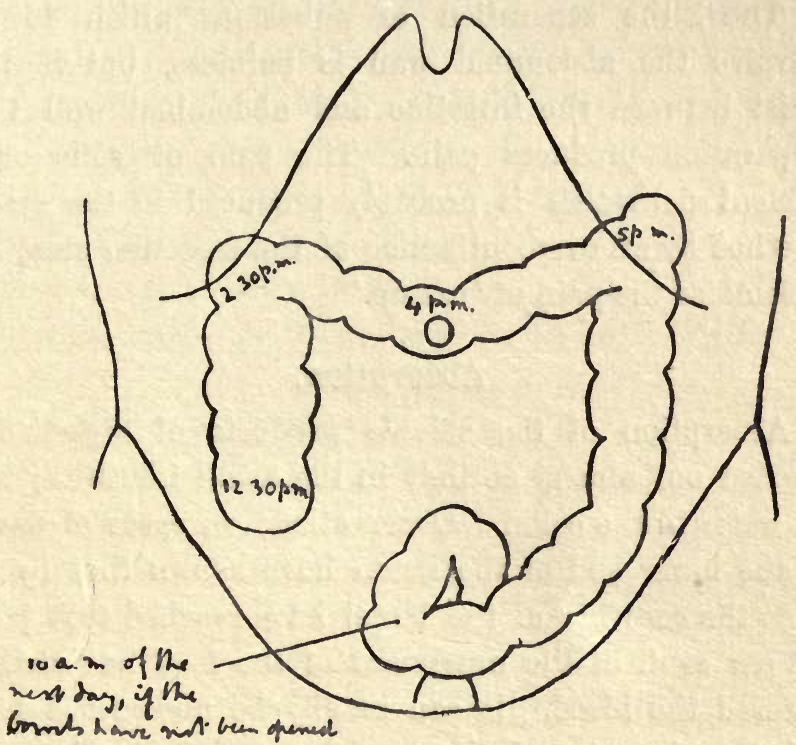

Fig. 18.-Average Time at which Various Potnts of the Colon arm reached afier a Bismuth Breakfast taken AT 8 A.M. (Hertz.)

fistula in man.* It may, perhaps, occur in pathological conditions.

\section{Sensibility of the Intestines.}

The intestine would appear to be insensitive to all ordinary stimuli. Intestinal pain arises either from * Busch, Virchow's Archiv, 1858, xiv. 110. 
(1) traction upon the nerves which run beneath the parietal peritoneum (the visceral peritoneum is insensitive), or (2) from violent contraction of the muscular coat, producing local anæmia, which stimulates the nerves of the bowel.

Thus, the separation of adhesions which do not involve the abdominal wall is painless, but if they exist between the intestine and abdominal wall their separation produces pain. The pain of colic or of violent peristalsis is probably produced in the second method by an overcontraction of the muscular coat, and resembles the pain of 'cramp.'

\section{Absorption.}

Absorption of the soluble products of digestion is carried out almost entirely in the small intestine; that of water in the colon. Observations on cases of fistula at the lower end of the ileum have shown that by the time the contents of the bowel have reached that point 87 per cent. of the nutriment of the food has already entered the blood. It can readily be understood from this that in cases of diarrhoea due entirely to disease of the colon a patient's nutrition does not appreciably suffer. Even when the passage of the food through the small bowel is accelerated, as in enteritis, absorption is not interfered with so much as one might expect, owing, apparently, to the enormous provision made for it by the great length of the ileum. It is only, indeed, in cases of severe disease of the intestinal mucous membrane, such as amyloid degeneration, or where the lymphatics leading from the bowel are blocked, as in 
tuberculosis of the mesenteric glands, that any great arrest of absorption seems to occur.

The importance of the colon in the absorption of water is very great. As the contents of the ileum pass into the cæcum they contain only from 5 to 10 per cent. of solid matter, and as they amount to something like $\frac{1}{2}$ to 1 pint in the twenty-four hours, the activity with which water is absorbed in order to convert them into solid fæces must be very considerable. It is not difficult to understand, therefore, how, in a case in which the contents of the bowel are discharged from an artificial anus without passing through the colon, the patient may easily come to suffer from a defective absorption of water.*

In addition to water, the colon absorbs some forms of sugar very readily-peptone to an appreciable degree, but fats very slightly. Those facts have an important bearing upon the question of rectal alimentation.

As the result of the combined action of the small and large intestines, it may be taken that the nutritive constituents of an ordinary mixed diet are absorbed to the following extent :

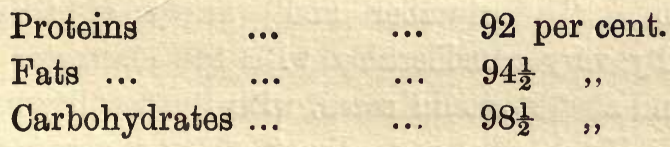

But the exact amount of absorption varies greatly with the composition of the diet.

The fate of the protein and carbohydrate absorbed

* See Monier-Williams, 'The Importance of the Colon,' Brit. Med. Journ., 1906, 787. 
from the intestine has already been described (pp. 30 and 37) ; the fat, after being reconstituted in the cells covering the intestinal villi, enters the lacteals, and thence passes to the thoracic duct, forming with the lymph the milky fluid termed 'chyle.' The composition of the chyle discharged from wounds of the thoracic duct in man varies considerably with the amount of fat in the diet, but as a rule it contains about 92.5 per cent. of water, 3 to 4 per cent. of protein, 0.5 per cent. of salts, and 2 to 3 per cent. of fat.*

It is a somewhat viscid fluid, and readily coagulates on standing. As much as 6 litres of it have been discharged from a wound of the duct in the course of a day, and it can readily be imagined how in such circumstances a patient emaciates rapidly and suffers severely from thirst.

\section{Bacteriology of the Bowel.}

Bacteria of all sorts are, of course, constantly being swallowed with the food. Of these a certain number are destroyed in the stomach, but a considerable quantity run the gauntlet of the gastric juice, and reach the intestine. The number and variety of these will naturally vary considerably with the character of the diet, and also, it would seem, with the locality in which the individual happens to live.t That their presence is not essential to normal digestion is shown by the fact that animals can be reared on sterile food, and also that

* Carlier, Brit. Med. Journ., 1902, ii. 175; and Veau, Gaz. des Hôp., October 30, 1906 (?), p. 1205.

† Bruini, Archiv f. Verdauungskrankh, 1905, xi. 162. 
the frees of many animals in Arctic regions are free from them. Nor is the number or character of the bacteria in the fæces very different in animal and vegetable feeders, ${ }^{*}$ or whether the diet be an ordinary mixed or a purely vegetarian one.

The characteristic organisms of the small intestine are those which produce acids from carbohydrates; that of the large intestine, the Bacillus coli. Putrefactive bacteria are not found to any extent in the ileum, and the contents of the latter, even at its lower end, contain no putrefactive products such as leucin, tyrosin, indol, or skatol. $\dagger$ Hence they are also devoid of fæcal odour.

In the ileum bacteria are present in greatest number at the lower end-the restraining power of the gastric juice being apparently still operative higher up $\downarrow$-and it is interesting to remember that it is just this part of the bowel which is most subject to infective disease.

The acids produced by the acid-forming bacteria tend constantly to be neutralized by the alkaline secretion of the pancreas and intestine, but in spite of that the activity of acid production is sufficient to give the contents of the ileum a slightly acid reaction, which tends to restrain putrefaction. Hence a diet which contains much carbohydrate is one on which little intestinal putrefaction can occur. $\S$

In the colon putrefactive organisms get the upper

* Levin, abstract in Archiv f. Verdauungskrankh, 1904, x. 530.

$\dagger$ Neucki, etc., loc. cit.

¥ Lorrain Smith and Tennant, Brit.Med. Journ., 1902, ii. 1941.

$\S$ Backman, Zeit.f. Klin. Med., 1902, sliv. 458. 
hand, and the contents of the bowel acquire a fæcal odour; and the more watery the contents, the greater is the degree of putrefaction. For this reason, if the contents of the ileum be hurried into the colon very rapidly and retained there, the stools may become very offensive. This takes place in cases in which there is catarrh limited to the small intestine.

The gases of the intestine consist chiefly of nitrogen, hydrogen, carbonic acid gas, sulphuretted hydrogen, and marsh gas. Of these, the last four are produced by bacterial action-carbonic acid by fermentation of carbohydrate in the small intestine; $\mathrm{H}_{2} \mathrm{~S}$ from proteins; and marsh gas and hydrogen from cellulose, and chiefly by bacteria present in the colon. $\mathrm{CO}_{2}$ is also produced by the action of acids on the pancreatic and intestinal juices. The possible source of nitrogen in the alimentary canal has already been discussed.

The gases of the intestine no doubt help to promote peristalsis by their mechanical pressure on the wall of the bowel, but sulphuretted hydrogen appears to act as a chemical stimulant also. Sulphur apparently owes its laxative properties to the production from it of $\mathrm{H}_{2} \mathrm{~S}$, whilst the constipating action of bismuth may be due in part to its power of fixing that gas. $\mathrm{CO}_{2}$ seems also to stimulate peristalsis when present in excess; hence, perhaps, the spontaneous action of the bowels which sometimes occurs in asphyxia.

\section{Movements of the Colon.}

When the intestinal contents enter the colon a strong general contraction takes place along the cæcum and 
ascending colon, forcing some of the food onwards; a moment later antiperistaltic waves begin, which drive the food back again into the cæcal pouch, thus churning the contents up and exposing them to the absorbing wall. It is here that the absorption of the remains of the nutritive constituents of the food takes place, as well as that of most of the water, for the contents of the transverse colon are usually nearly as solid as those of the sigmoid.

As material accumulates in the transverse colon, deep waves of constriction appear one after the other and carry the material into the descending colon, leaving the ascending and transverse portions free for the occurrence of antiperistalsis.

The occurrence of antiperistalsis as a normal process in the upper part of the colon makes clear the significance of the ileo-cæcal valve, which is competent for the amount and character of the material normally discharged from the ileum. It can be overcome, however, by large injections of fluid from below, which has been proved both experimentally* and by observations on patients with a fistula of the ileum, $\uparrow$ as well as by accumulated instances of the vomiting of enemata. $\neq$

Fig. 18 shows the average rate at which the colon is traversed by a bismuth meal according to the observation of Hertz. $\S$

* Grützner Pflüger's Archiv, 1898, Ixxi. 492.

$\dagger$ See Neucki, etc., loc. cit.

¥ See Mohroof, Indian Med. Gaz. 1902, xxxvii. 394.

$\S$ Loc. cit. 


\section{Defæcation.}

In evacuating the large intestine the material in the lower part of the descending colon is first expelled by the combined action of peristalsis and pressure by the abdominal muscles and diaphragm. The material higher up is then carried down into the cleared area and the process of evacuation repeated.

During the straining which normally accompanies the act of defæcation, the diaphragm descends to its lowest point, carrying with it the hepatic and splenic flexures of the colon. The hepatic flexure, indeed, may nearly reach the level of the umbilicus, so that the ascending colon is compressed to an almost globular form (Hertz). The transverse colon also descends from about an inch above to an inch below the umbilicus.

As fæces are forced into the rectum and anal canal, afferent impulses are set up which produce strong peristaltic contractions, involving the whole length of the colon.

In normal circumstances the stool passed to-day is probably derived in chief measure from the food of the day before yesterday.

The functions of the colon as an organ of excretion will be considered in another chapter (p. 287).

Reviewing the whole trend of recent work on the physiology of digestion, and considering its bearings upon practical medicine, one is struck by the great delicacy and complexity of the processes by which the digestion of the food is accomplished, and one ceases to 
wonder that a mechanism so constituted should easily become deranged. One is impressed, too, by the increasing importance attached by physiologists to the part played by the nervous system in the inception and coordination of the various muscular and chemical functions of the organs concerned, which amply justifies the view long held by physicians, that functional disorders of digestion are really manifestations of an affection of the nervous centres.

Experiment has made clear to us how it is that disorder of one section of the alimentary apparatus may throw out of gear the working of other sections, and how healthy intestinal digestion is dependent upon a normal state of the stomach, and that in its turn upon the efficient carrying out of the preliminary processes of digestion in the mouth; and it follows from this that, in trying to cure disturbances in one part of the alimentary canal, we must often direct our treatment to the part which lies above it. The cure of gastritis by attention to the teeth, and of some forms of chronic diarrhœa by the administration of hydrochloric acid, are instances in point. At the same time, one cannot help being im. pressed, from the physiological point of view, by the liberal provision made in the digestive tract for the supplementing of defective action of one part by a more vigorous exercise of function by others, and the lesson of this to the physician is one of hope and encouragement. 


\section{CHAPTER VIII}

\section{THE APPLIED PHYSIOLOGY OF EXCRETION}

Much discussion has taken place as to the difference between a secretion and an excretion, and as to whether certain organs are to be regarded as secretory or excretory in function. The simplest way of looking at the matter, for clinical purposes at least, is to define as an excretion any waste matter which is discharged from the body and is incapable of being further utilized, and to regard any organ which is responsible for getting rid of such matters as excretory in function, whether it merely picks them out of the blood or builds them up from simpler compounds before getting rid of them. From this point of view the excretory organs of the body, and the waste substances which they discharge, may be arranged as follows:

Organ.

Excretion.

\begin{tabular}{|c|c|c|c|}
\hline Kidney & ... & ... & $\begin{array}{l}\text { Waste products of nitrogenous metabolism, } \\
\text { soluble mineral matters, and water. }\end{array}$ \\
\hline Liver ... & & 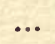 & Waste products of the red blood corpuscles. \\
\hline Cung . & & $\ldots$ & $\begin{array}{l}\text { Waste products of 'carbonaceous' meta- } \\
\text { bolism and water. }\end{array}$ \\
\hline atestine & & ... & $\begin{array}{l}\text { Unabsorbed residues of food and of the } \\
\text { digestive juices, and some less soluble } \\
\text { mineral matters-e.g., calcium and iron. } \\
270\end{array}$ \\
\hline
\end{tabular}


The skin is commonly spoken of as an organ of excretion, but, as we shall see later, it is very doubtful whether it is right to regard it as such in any but an accidental way.

\section{Excretion by the Kidney.}

It is admitted by physiologists that we are still very much in the dark as to the mechanism by which the kidney produces the urine, but we know it to be an organ of excretion in the strict physiological sense, for, with the exception of hippuric acid, all the ingredients of the urine are already present in the blood. Hence, in disease of the kidneys the urinary constituents may accumulate in the body.

Opinion has long been divided between the relative merits of the 'vital' theory of urine production propounded by Bowman and the so-called 'mechanical' theory of Ludwig, nor can the controversy be regarded as even yet finally closed. Perhaps the view which finds most favour at the present day is that which attributes to the glomeruli the function of separating out water and mineral constituents (except phosphates), and perhaps some foreign ingredients, such as sugar, whilst regarding the cells of the convoluted tubules as responsible for picking out of the blood the specific organic components of the urine, such as urea. Whether any reabsorption of water takes place during the passage of the urine along the tubules is still disputed. The strictly mechanical theory of filtration through the glomeruli, however, has been generally abandoned since evidence has accumulated to show that the cells covering the 
glomeruli are capable of some selective action. The proteins of the blood, for instance, are not excreted by a healthy kidney, whilst 'foreign' proteins, such as egg albumin and peptone, are. Good examples of such selective excretion of foreign proteins are also seen in human pathology in the excretion of hæmoglobin by the kidney in paroxysmal hæmoglobinuria, and of the socalled 'Bence Jones's albumose' in myelopathic albumosuria, and a study of the urine in these diseases is alone sufficient to disprove any purely mechanical filtration theory of urine production.

It cannot be said, however, that the clinician is acutely interested in the physiological theories of renal function, for when disease affects the kidney the organ usually suffers as a whole, and it is but rarely that the glomeruli or the tubules are either solely, or even preponderatingly, involved. In scarlatinal nephritis, it is true, the glomeruli are sometimes much more disorganized than the tubules, and such cases are characterized by the production of a scanty and concentrated urine, which is evidence, so far as it goes, in favour of the view that the glomeruli are chiefly concerned in the production of water. It is interesting to note that the epithelium which covers the glomerulus is more differentiated than that which lines Bowman's capsule, and, in harmony with this, it shows a different reaction in disease. Like all highly differentiated epithelia, it is very vulnerable, and its cells readily necrose, a process which can be well observed in a kidney which has been damaged by the excretion of the poisons of scarlatina or diphtheria. The epithelium which lines Bowman's capsule, on the other hand, par- 
takes more of the nature of ordinary endothelium, such as lines a lymph space, and, when irritated, responds like the latter by the production of connective tissue.

The volume of urine produced by the kidney depends upon the amount of blood passing through it in a given time, and the blood-pressure in the renal capillaries. Care must be taken to distinguish between a high general blood-pressure and a high renal pressure, for the latter may occur independently of the former. If, for example, the cutaneous vessels become contracted from exposure to cold, the vessels of the abdominal organs, including those of the kidney, become overfilled, and the renal pressure rises, with the result that more water is excreted in the urine; and yet this may happen without there being any rise of general blood-pressure. All that has taken place has been a redistribution of blood in the body (see p. 167). It is in this way that exposure to cold increases the volume of the urine, whilst warmth, hot-air baths, and a mild climate-all of which tend to ' determine' blood to the surface-lessen the pressure in the kidney, and are therefore useful in nephritis and renal congestion. If, again, the control exercised by the vasomotor nerves over the renal bloodvessels is relaxed, more blood goes to the kidney, the pressure in the glomeruli rises, and more water is excreted. This is the explanation of the polyuria of nervousness and hysteria. On the other hand, constriction of the renal vessels, with consequent diminution of the urine, occurs in asphyxia and in the convulsions of epilepsy and strychnine-poisoning.

In all these cases we are dealing simply with an altera- 
tion in the distribution of the blood, which results in the kidney getting more or less than its usual share.

On the other hand, the amount of urine is also influenced by alterations in the general blood-pressure, provided the kidney participates in them. If the general pressure falls, the amount of water excreted by the kidney is lessened, and if the fall in the renal capillaries be great enough (down to 40 millimetres), excretion stops altogether. In conditions of shock the urine may become very scanty from the fall of blood-pressure, which results from 'pooling' of the blood in the abdominal veins. The polyuria of chronic nephritis, on the other hand, is probably due, in part at least, to a marked rise of general blood-pressure. One must distinguish between the polyuria which results from alterations in the bloodsupply of the kidney, and which consists mainly in an increased excretion of water, and a true diuresis, in which the specific organic constituents of the urine are also voided more freely. The latter can only be brought about by an increased activity of the epithelial cells, but of the factors which determine such an increased activity we know little, except that one of them may be the presence in the blood of an unusual amount of waste material to be eliminated. Some diuretic drugs, however, such as caffeine, appear to possess the power of stimulating the renal cells, and it is in such a property that their chief virtue as medicines resides.

Important effects upon the renal circulation in certain circumstances are brought about by the fact that the capsule of the kidney is comparatively inelastic. When, therefore, the epithelium of the organ swells, as it does, 
for example, in acute inflammation, the capillaries become compressed, the organ is rendered comparatively anæmic, and the volume of urine falls. This effect is exactly comparable to the cerebral anæmia, and consequent paralysis of brain functions, which results from cerebral compression and increased intracranial pressure (see p. 175), and attempts have been made in some cases of acute nephritis to relieve the pressure by incision of the capsule, and so restore again the blood-flow through the organ, just as one relieves intracranial tension by trephining.

In viow of this 'renal anæmia,' it must be obvious that any attempt to 'wash out the renal tubules,' by causing the patient to drink large quantities of water, is not likely to be successful, even were the existence of such blocking probable in itself.

Physiologists have not succeeded in proving the existence of any secretory nerves for the kidney, and experimental variations in the volume of the urine can only be brought about through the vasomotor nerves (splanchnics) of the organ. The occurrence of what is known as 'reflex suppression,' however, is at least suggestive of the existence of secretory fibres. Whether or not the kidney produces an internal secretion is also still under dispute. Experimentally it is found that, if a sufficiently large amount of renal substance be excised, the volume of the urine is-for unknown reasons -permanently increased, and at the same time a widespread disturbance of metabolism, manifested by a great rise in urea production, sets in. It has been suggested that this is due to the withdrawal of an internal secretion. 
These experiments have a very direct bearing on some of the clinical phenomena of contracted kidney.

\section{The Normal Constituents of the Urine.}

Water.-The amount of water excreted in the urine varies greatly, for reasons already considered, and depends also upon the amount of water drunk. In health, however, the quantity in the urine is always greater than that taken in by the mouth. Even although the amount of solids and liquids in the diet be the same, the amount of water excreted varies greatly in the same individual in different circumstances and in different individuals in the same circumstances. This is due to the reciprocal action of the skin and kidneys; for the greater the amount of the insensible perspiration, the less the amount of water excreted by the kidney, and vice versâ. In other words, some individuals have active skins, and others active kidneys. The former excrete a more concentrated urine, and are more prone to suffer from gravel and stone; the latter, one which is more dilute, and are probably more subject to renal congestion and inflammation.

The rate at which water is excreted by the kidney probably varies in different persons, but as a rule, if a litre of it be swallowed, it has usually all reappeared in the urine before the lapse of three hours.

In health the volume of urine excreted by day is much greater than that produced during the night; but in cases of renal disease the quantity of day and night urine is more nearly equal. The reason for this 
is not understood, but it may be due in part to the kidney acting more slowly when diseased.

Solid substances excreted by the kidney tend to carry a certain amount of water with them. The polyuria of diabetes mellitus is a good example of the excretion of sugar causing such a flow of water. Some diuretics probably owe their power of increasing the volume of the urine to the same mechanism.

Acidity.-The acid reaction of the urine is due to the presence of acid phosphates and organic acids. Much discussion took place at one time as to how it is that the kidney can separate an acid urine from an alkaline fluid such as the blood. It must be remembered, however, that, although the blood is alkaline to litmus, its chief salts, acid phosphates, and bicarbonates, are technically acid. The former acid is eliminated by the kidney, the latter $\left(\mathrm{CO}_{2}\right)$ by the lung; hence the preponderance of acid in the renal excretion. The mineral constituents of an animal diet yield an acid, and those of a vegotable diet an alkaline ash, which is the reason why the urine of carnivora is highly acid, whilst that of herbivora is alkaline.

Advantage may be taken of this effect of diet in modifying the reaction of the urine in cases of disease.

The total amount of acid eliminated by the kidney is much greater during the day than during the night, but owing to the concentration of the night urine its percentage acidity is greater than that of the day. It is for this reason that uric acid is more apt to separate out in the urine secreted by night, a fact which must be borne in mind when one is treating cases of gravel. 
The percentage acidity of the day urine is also reduced by the 'alkaline tide' which follows meals, and which is due to the alkaline carbonates set free in the blood as the result of the elaboration of the gastric juice.

By estimating the total acidity of the urine and that part of it which is due to phosphoric acid separately, one can arrive at a measure of the amount of the acidity which is due to the presence of unoxidized organic acids, and which are often an index of some disorder of metabolism. A method of doing this has been devised by M. Joulie, and has been largely employed in clinical work in France.

\section{Nitrogenous Constituents.}

Of the total amount of nitrogen (about 16 grammes) excreted in the urine on an ordinary diet-

84 to 87 per cent. is in the form of urea ;

2 to 5 per cent. is in the form of ammonia compounds ;

1 to 3 per cent. is in the form of uric acid;

whilst the balance is contained in such substances as purin bases, hippuric acid, creatinin, and some undetermined compounds.

Urea. - The amount of urea present in the urine depends almost entirely upon the amount of protein in the food. It is therefore useless to estimate it for clinical purposes unless the composition of the diet is taken into consideration. Seeing that it is mainly formed in the liver from ammonia compounds, it is 
diminished in severe disease of that organ, such as acute yellow atrophy, its place being taken by salts of ammonia and amino-bodies. As it is merely picked out of the blood by the kidneys, it accumulates in the circulation in cases of severe impairment of renal function, and, being very soluble, may be found in any of the secretions-e.g., the sweat.

Uric Acid.-The origin of the uric acid in the urine has been considered in a previous chapter (p. 45), but it must again be emphasized here that its amount is very largely dependent upon the amount of purin bodies in the food, and that it bears no constant ratio to urea. The influence of diet is shown by the following figures (von Noorden):

Daily excretion of uric acid on a 'purinfree' diet $\quad \ldots \quad \ldots \quad \ldots \quad \ldots \quad 0.25$ to 0.6 gramme.

Daily excretion of uric acid on a mixed diet $\quad \ldots \quad \ldots \quad \ldots \quad \ldots \quad \ldots . \quad \ldots \quad 0.5$ to 1 gramme.

Daily excretion of uric acid on a largely meat diet ... $\quad \ldots \quad \ldots \quad \ldots$ 1 to $1 \frac{1}{2}$ or 2 grammes.

Ammonia.-The amount of ammonia excreted in the urine may be taken as an index of the amount of acid entering the circulation, for it is by the neutralization of acid by carbonate of ammonia that the body protects itself against 'acidification.' The amount is therefore greater on an animal than on a vegetable diet, whilst in some pathological states, such as in the later stages of diabetes, and in some of the toxæmias of pregnancy, when organic acids are entering the blood in large quantities, the excretion of ammonia may rise enormously. Of the remaining nitrogenous constituents, ereatinin 
is derived partly from meat in the food and partly from the muscles of the body. On a diet free from meat the amount of it excreted is very constant for any given individual under the same conditions. Creatinin is of little clinical importance, but it is interesting to note that, as might be expected, the amount of it excreted is greatly diminished in cases in which there is extensive muscular atrophy.

Of the inorganic constituents of the urine, the sulphates are derived chiefly from the decomposition of proteins in the body, and the quantity of them eliminated therefore runs closely parallel to the elimination of nitrogen. Sulphur is met with in the urine in three forms-(1) as inorganic sulphates; (2) as organic or ethereal sulphates; (3) as neutral or unoxidized sulphur. The inorganic sulphates are derived almost entirely from the 'exogenous' metabolism of foodprotein, and their amount is therefore dependent upon the nature of the diet. The organic sulphates are produced partly metabolically and partly as the result of the union of aromatic substances produced by intestinal putrefaction (phenol, indoxyl, skatoxyl) with sulphuric acid. They are therefore only to some degree an index of the extent of such putrefaction, and not an absolute gauge of it, as has sometimes been assumed clinically. The neutral sulphur is derived entirely from the endogenous metabolism of body-protein, and is a measure of its intensity.

Of the other inorganic constituents, common salt is derived entirely from the food, and provided its amount in the latter be constant, the excretion of it is also con- 
stant. It is retained in the body whenever water is being retained (e.g., in dropsy), and also, although for unknown reasons, in some febrile conditions. The phosphates of the urine are derived mainly from the food, but also to some extent from the decomposition of phosphorus compounds-e.g., nuclein, in metabolism. The condition termed 'phosphaturia' is really in most cases not an indication of an excessive excretion of phosphorus, but of a diminished acidity of the urine, which causes the earthy phosphates to be thrown out. In some instances it appears to be the result of an excessive excretion of calcium by the urine, so that the normal mono-di-calcium phosphates are replaced by the much less soluble tri-calcium salt. It would appear, too, that the amount of phosphates in the urine is determined to some extent by the amount of calcium in the food. When this is high, as in herbivora, phosphorus is excreted by the bowel as calcium phosphate.

Oxalic acid is present in the urine to a small extent, chiefly combined with calcium. It is derived partly from vegetable foods, of which some, such as rhubarb and spinach, are specially rich in it, and is partly produced in the body in some unknown way as the result of metabolic processes. It cannot, therefore, be made to disappear entirely from the urine even if the diet be free from it. The presence of magnesium salts in the urine helps to keep it in solution, and poverty of these is one cause of 'oxaluria.' Of the origin of normal urine pigment (urochrome) we know nothing, although it is probably derived somehow from hæmoglobin, and it is therefore of little clinical interest. Urobilin is present 
in traces in normal urine, and is often greatly increased in disease. It is identical with the so-called stercobilin of the fæces, and is derived by absorption from the intestine. It is therefore apt to appear in the urine in augmented quantity whenever blood destruction, and therefore bile-pigment formation, is excessive-e.g., in extensive extravasations and in pernicious anæmia. Conversely, it disappears from the urine when bilepigment formation is defective, as in cirrhosis of the liver, or when bile is unable to enter the intestine, as in occlusion of the common duct.

\section{Excretion by the Liver.}

The liver differs from the kidney as an excretory organ in that it actually forms the waste matters which it excretes, instead of merely picking them out of the blood. This has led to some dispute as to whether bile is to be regarded as an excretion or a secretion, and in the domain of pathology as to whether jaundice may be hæmatogenous as well as hepatogenous in origin. Since it has been established by physiologists, however, that the constituents of bile are formed by the liver and do not pre-exist in the blood, it has come to be recognized that all forms of jaundice are in the last resort hepatogenous, or, in other words, that without the liver jaundice would be impossible.

The chief waste matter which the liver excretes is the pigment derived from the destruction of red blood corpuscles in the portal system. Under the action of the liver cells hæmoglobin is converted into hæmatin, 
then into hæmochromogen, and finally into bilirubin, which is the cause of the golden-yellow colour of normal fresh bile. If the destruction of blood corpuscles be excessive, so much bile pigment may be formed that the bile capillaries get choked, and some of the bile is reabsorbed-hence the so-called ' hæmatogenous' jaundice; whilst, if the destruction be greater still, some hæmoglobin may escape into the bile unconverted, or even into the general circulation, and reach the urine.

In the intestine bilirubin is reduced under the action of micro-organisms to urobilin; but if diarrhœe be present there is no time for this to take place, and the stools may then contain bile pigment. Owing to the absence of micro-organisms from the intestine of the newly-born child, the meconium contains no urobilin.

Bile pigment seems to act like a weak acid, and forms salts with alkalies or earth : a combination of bilirubin with calcium, for instance, is a common ingredient of gall-stones.

The ultimate source of the bile acids is unknown, but they may fairly be regarded as excretory products, for from 30 to 40 per cent. of them appears in the fæces, and traces also in the urine. The remaining 50 to 60 per cent., however, is reabsorbed from the intestine, and returned to the liver, to be again excreted. This circulation of the larger part of the bile acids between the intestine and liver is rather peculiar, and it is difficult to see the reason for it. It is true that the bile salts incidentally aid in keeping the cholesterin of the bile in solution, and by this circulatory arrangement a small amount of bile salts is enabled to go a long way, 
but this is hardly likely to be the sole reason for its occurrence. If the bile escapes by a fistula the reabsorption of bile salts is, of course, arrested; hence fistula bile is always poorer in that ingredient than natural bile, and the results of analysis of the former cannot be taken as representing the true composition of the natural secretion.

The bile salts have a distinctly toxic action in the body, causing destruction of red blood corpuscles, a slowing of the heart by direct action upon its muscle and the cardiac ganglia, and a paralyzing action on the higher cerebral centres, which results in coma and death. To these effects some of the clinical symptoms of jaundice have been attributed.

The cholesterin of the bile is now generally admitted to be derived from the cells lining the biliary passages and gall-bladder. In catarrh of these the amount of cholesterin produced may be increased beyond the power of the bile salts to keep it in solution, and the formation of cholesterin gall-stones is favoured. Attempts have been made, but without much success, to dissolve such stones by administering bile salts by the mouth.

It used to be believed that the cholesterin of bile was a waste product derived from the nervous system, and one theory of cholæmia was based upon the assumption that the symptoms of that condition were due to an insufficient removal of waste products from the brain and nervous system. Since the true source of cholesterin has been discovered, however, this theory has been abandoned.

The chief mineral constituent of the bile is calcium, 
which, as has already been mentioned, is often found in gall-stones in combination with bile pigment; whether or not an increased consumption of calcium salts in the food is followed by an augmented excretion of them in the bile is still disputed. The question is one of interest in relation to the dietetic treatment of cholelithiasis.

The total volume of bile produced daily seems to vary between 500 and 1,100 c.c. Its amount probably depends upon the activity of the general metabolism, but it is almost impossible to increase it by artificial means. Diet has no appreciable influence upon it, nor has the amount of water drunk. The effect of drugs is very uncertain, and, as far as most experiments go, negative; but any agent which causes an increased destruction of red corpuscles will, of course, increase the excretion of bile pigments. Administration of bile acids or dried bile by the mouth has been said to stimulate the liver to form more bile, but this statement is apparently based upon a misinterpretation of the results of experiments upon animals or patients with biliary fistulæ. The greater richness of the bile observed in such cases when dried bile is given by the mouth is not due to the liver forming more natural bile, but merely to its excreting that portion of the artificially administered bile which has been absorbed from the intestine. We are still, therefore, without a true cholagogue or hepatic stimulant.

Bile is produced at a very low pressure-not more than 16 to 24 millimetres of mercury. One consequence of this is that a comparatively slight obstruction in the bile passages is sufficient to retard its escape, and may 
cause jaundice. By squeezing the liver between the diaphragm and the abdominal muscles the pressure is raised, and the escape of bile favoured. This is believed to explain the beneficial effect of horseback exercise in some cases. During the act of vomiting the liver is forcibly squeezed in this way, and the older school of physicians used often to induce an artificial vomit at the outset of an acute fever, in the belief that by this means poisonous materials could be voided from the liver.

The discharge of bile into the intestine reaches its maximum about three hours after a meal, and is apparently brought about by contraction of the muscular coat of the gall-bladder, the motor nerve for which is the vagus, whilst the sympathetic supplies it with relaxing fibres. If the gall-bladder contains biliary calculi its contraction causes pain, and the occurrence of this at a definite period after the taking of food is apt to suggest that the pain is of gastric origin, and to lead to errors of diagnosis.

In addition to the well-recognized biliary constituents, it is probable that the liver excretes or destroys other toxic materials, some of which may be derived from the bowel, and inefficiency in performing this function has been advanced as an explanation of biliousness. The liver, in fact, may be regarded as a filter placed between the portal system and the general circulation, the purpose of which is to prevent the escape of poisonous materials from the former into the latter. Seeing, too, that the liver is concerned in the final stages of the formation of urea, and in the destruction of uric acid, it must be regarded as in every respect one of the most 
important organs for dealing with the waste products of the body, and it is not surprising that extensive disease of it is often associated with pronounced toxic symptoms. Its reserve power, however, is so great that probably only about one-fifth of its actual substance is essential for life, which explains how it is that the organ may be the seat of the most extensive cirrhosis without health being greatly affected.

\section{Excretion by the Intestine.}

The intestine excretes (1) the residue of the intestinal juices; (2) the unabsorbed remains of the food; (3) certain mineral salts, such as calcium and iron.

On an ordinary mixed diet the amount of fæces excreted is from 120 to 150 grammes, containing 30 to 37 grammes of solid matter. Their composition is very uniform. They are to be regarded as chiefly made up of the residue of the digestive juices; they also contain, however, some starch granules, vegetable débris, and a few muscle fibres derived from the food. In reaction the normal fæces are neutral or slightly alkaline. The alkalinity is the result of putrefaction, and is therefore more pronounced if there is much protein in the diet.

The normal colour of the stools is due in part to stercobilin, but it is greatly influenced by the nature of the food. Thus, if there be much meat in the diet, the fæces are very dark, and if more fat be taken than can be completely absorbed, they assume a clay colour. Normal bile pigment (bilirubin) is never present in the stools in ordinary circumstances except in early infancy, but it may appear if diarrhœa be present. If the stools 
be acid, the bilirubin may be converted into biliverdin, and they then become green. The usual amount of water in the fæces is about 75 per cent., but if there be any delay in the large intestine, the stools may become much drier, as is often seen in constipation. The bulkiness of the stools on a vegetable diet is largely due to the presence of an excess of moisture.

As will be seen from what has been said, the influence of the food upon the physical and chemical character of the stools is so great that it is necessary, when one wishes to investigate the digestive processes in the intestine clinically, to put the patient upon a standard or 'test diet,' the character of the fæces that result from which in health is known.

The intestine is also responsible for the excretion of the greater part of the calcium which is absorbed from the food, and crystals of calcium phosphate are often found even in normal fæces, and make up a large part of the 'intestinal sand' sometimes excreted in cases of disease.

In some pathological conditions the intestine seems to be unable to excrete calcium, which then appears in the urine in abnormal quantity, producing one variety of so-called 'phosphaturia' (see p. 281).

Iron is also mainly excreted by the intestine, and so probably is copper. The recovery of these metals from the stools is therefore no proof that they have not been absorbed and passed through the body, although the artificial colouring of vegetables with sulphate of copper has sometimes been excused on the ground that most of the metal can be recovered from the stools, and has therefore not been absorbed. 
It will be observed from a study of the excretory functions of the intestine that they are so entirely different from those of the kidney that it is unlikely that the bowel can be made to replace the kidney to any extent as a channel of excretion in cases of renal disease.

The excretory functions of the lungs have been considered in another chapter (Chap. VI.), and, as regards the skin, it need only be said that the sweat is essentially a secretion which is of use in regulating the body temperature, and is not properly an excretion at all. Incidentally it may contain any soluble substance which is present in excess in the blood-such, for example, as urea; but, like the intestine, it can never be made to take the place of the kidney to any appreciable degree, and the value of maintaining a free action of the skin in cases of renal disease is probably to be ascribed to effects other than the promotion of excretion. 



\section{N D E X}

ABDOMINAL respiration, 195

Absorption, gastric, 251 intestinal, 262

Accelerator nerves to heart, 122

Achylia, 247

Addison's disease, 26

Adenin, 46

Adenoid tissue, 83

Adipose tissue, 16

Adrenalin, 26

Air, complemental, 199

residual, 198

supplemental, 199 tidal, 199

Air passages, 177

Alanin as source of sugar, 41

Albumose, Bence Jones's, 272

Alimentary glycosuria, 39 lævulosuria, 40

Alkaline tide, 278

Alveoli, pulmonary, 182

Amido-acids, 30, 34

Amino-purins, 46

Ammonia of urine, 279

Anæmia, cerebral, 175 renal, 275

Antiperistalsis, 267

Apex-beat, 109

Apnœa, 253

Appetite, 238

Arterial circulation, 142 pulse, 144

Arteries, 142

Asphyxia, 213

Auerbach's plexus, 259

Augmentor nerves to heart, 122

Bacteria, intestinal, 264

Balfour on the heart, 128
Banting treatment, 17, 36

Barr on the pleura, 185, 191

Basophile cells, 85, 87

Beard on the thymus, 102

Beat, cardiac, 105, 132

Bence Jones's albumose, 272

Beri-beri and protein diet, 6

Bier's treatment of dropsy, 155

Bile, 80, 282

acids, 283

antiseptic properties of, 256

in digestion, 256

discharge, 286

excretion or secretion, 282

pigment, 79, 282

pressure, 285

a secretion, 256

volume of, 285

Bilirubin, 283, 287

Biliverdin, 288

Blood, 71-104

cellular constituents, 73

corpuscles, red, 73

white, 81

distribution in body, 167

plasma, 91

platelets, 90

Buckmaster on, 90

-pressture, 159

arterial, 159

capillary, 155

diastolic and systolic, 160

intracranial, 174

regulation of, 166

variations in, 163

reaction, 92

sugar in, 94

Bodily energy, 2 et seq. 
Body heat, 49-70

chemical regulation of, 60

Clifford Allbutt on, 61

Davy on, 61

Hobday on, 61

internal regulation, 68

Jurgensen on, 61

nervous mechanism of, 64

physical regulation of, 53

Rubner on, 61

sources of, 64

Borborygmi, 258

Bouchard on metabolism, 28

Bowman, vital theory of urine production, 271

Bradycardia, 134

Broadbent on the pulse, 152

Brodie on circulation, 169

on pulmonary bloodvessels, 183

Bronchi, 180

Buckmaster on blood platelets, 90 on coagulation, 97

Bunge on proteins, 91

Caisson disease, 218

Calcium salts in bile, 283-4 and coagulation, 97

Calorimetric experiments, 8

Campbell, H., on pulmonary circulation, 184

Cannon on digestion, 245, 248

Capillary circulation, 153 pressure, 155

Carbohydrate assimilation, 40

conversion to fat, 40

diet as source of energy, 13

metabolism, 37

and pancreas, 42

Cardiac beat, 105

irregularity, 132 et seq. conductivity, 106, 119

contractility, 118

excitability, 131

innervation, 121

physiological properties of, 118

rhythmicity, 131

tonicity, 119

muscle, 105

rhythm, 106, 130 et seq.
Castration, effects of, 26

Cerebral circulation, 174 metabolism, 20 pressure, 174

Chemistry of respiration, 209

Cheyne on diet, 46

Cheyne-Stokes respiration, 205, 223

Chittenden's standard dietary, 4, 14

Chlorosis, 96

Cholesterin of bile, 284

Chyle, 264

Circulation, 141-176

arterial, 142

cerebral, 175

and respiration, 173

venous, 157

Claude Bernard on glycosuria, 43

Clifford Allbutt on body heat, 61

Clothes and body heat, 56

Coagulation, 96 et seq.

Cohnheim on metabolism, 28

Cold, clinical effects of, 65

Colon, bacteriology of, 265

functions of, 262

movements of, 268

Compressed-air baths, 219

Conduction, in the body, 54

Count Rumford on, 57

Conductivity of cardiac muscle, 106, 119

Conservation of bodily energy, 8

of tissue substance, 2

Contractility of cardiac muscle, 118

Convection, 55

Convoluted tubules of kidney, functions, 271

Costal respiration, 195

Coughing, 203, 221

Count Rumford on conduction, 57

Creatinin of urine, 31, 279

Crile on peripheral resistance, 161-2

Davy on body heat, 61

Defæcation, 268

Deglutition, 229

Denitrification, 31 et seq.

Depressor nerves, 126 
Diabetes, $14,28,36,38,42$ and heat production, 62 phloridzin, 43

Diabetic coma, 215 Pembrey on, 215

Diaphragm, action of, 193

Diastasic ferment of pancreatic juice, 255

Diet, standard, 3 et seq. and growth, 6

Digestion, 225-269 duodenal, 254 intestinal, 257 rate of gastric, 248

Dropsy, causes of, 157

Duodenal digestion, 254

Dyspnca, 207

Elasticity, arterial, 142

Emphysema, 185, 194, 199, 219

Energy, conservation of bodily, 8 expenditure of bodily, $8 \mathrm{et} \mathrm{seq.}$ in exertion, 19

income of, 12

physiological expenditure, 8 , 19

protein, 31

repair of bodily, 31

sources of, 12,20

surplus storage of, 15

Enterokinase, 255, 257

Eosinophil cells, 86

Epithelium, physiological functions of living, 211

Lorrain Smith on, 211

Erasmus Wilson on evaporation, 55

Erepsin, 257

Erythromelalgia, 170

Evans on gases of stomach, 251

Evaporation, 55

Erasmus Wilson on, 55

Excitability, cardiac, 131

Excretion, 270-289

cutaneous, 289

hepatic, 282

intestinal, 287

pulmonary, 209

renal, 271

versus secretion, 24

Fæces, 268, 287
Fats, assimilation of, 34

in the body, 16

in diet, 13

derived from protein, 36

as source of energy, 13, 35

storage in tissues, 15

Fatty tissues, 16

Ferments, enterokinase, 255, 257

erepsin, 257

fibrin, 86,97

gastric, 235

leucocytic, 86

lipase, 255

pancreatic, 42, 255257

pepsin, 241

plasmase, 97

ptyalin, 226

salivary, 226

thrombin, 96

trypsinogen, 255

Fever, 68

and protein diet, 32

temperatures, 220

Fibrin ferment, 97

Food, heating power of, 64

Freudberg on reaction of blood, 93

Gases of intestine, 266

of stomach, 251

Gaskell on conductivity of heart, 137

on vagus control, 122

Gastric absorption, 250

digestion, 231

flatulence, 252

innervation, 246

juice, 232 et seq.

movements, 243

pressure, 241

regulation of food temperature, 233

secretion, 235

tension, 241

tonicity, 241

Gastric juice, antiseptic action, 232

composition, 239

secretion, 235

Gelatin and coagulation, 98

as a food, 13

Glénard's disease, 193.4 
Globin, 78

Glomeruli, functions of, 271

Glycosuria, alimentary, 39 puncture, 43

Gossage on the heart, 131

Graves' disease, 26

Gravity, influence on circulation, 170

Growth and diet, 6 et seq.

Guanin, 46

Hæmatin, 78, 282

Hæmatogenous jaundice, 81, 283

Hæmatoidin, 79

Hæmatology, 72

Hæmatoporphyrin, 79

Hæmin, 79

Hæmochromogen, 283

Hæmodynamic pressure, 170

Hæmoglobin, 78, 282

Hæmolysins, 75

Hæmopoietic organs, 71-104

Hæmostatic pressure, 170

Haig on diet, 46

Haldane on respiration, 213, 217

Harris tweed, 59

$\mathrm{HCl}$ in gastric juice, 232, 239-40, 247

Heart, 105-140

beat, 105, 132

conductivity, 119

contractility, 118

innervation, 121

nervous control of, 121

rhythm, 130

sounds, 113, 135

tonicity, 119

valvular mechanism, 112

work done by, 8,115

Heat production, 9, 51 action of alcohol, 67 centre for, 66

chemical regulation of, 60

internal regulation, 68 and myxœdema, 62 nerve mechanism of, 64 physical regulation, 53

Heating power of food, 64

Heidenhain's vital theory of secretory cells, 156

Hepatic excretion, 282
Hepatogenous jaundice, 282

Hertz on indigestion, 230 on peristalsis, 260,267

Hibernation, 51

Hiccough, 222

High altitudes, effect of, 75

Hill on capillary pressure, 155 on cerebral pressure, 176 on splanchnic system, 169

Hobday on body heat, 61

Hueppe on work, 11

Hutchinson on vital capacity, 201

Hydrothorax, 185, 190

Hyperpyrexia, 69

Ileum, bacteriology of, 265 reaction, 265

Internal secretion, 23 of kidney, 275

Intestinal absorption, 262 bacteriology, 264 digestion, 257 excretion, 287 movements, 258

Intragastric tension, 242

Intrathoracic pressure, 190

Iodothyrin, 24

Islands of Langerhans, 42

Janeway on arterial pressure, 160 Jaundice, 282

hæmatogenous, 81, 283

hepatogenous, 282

Jones on ventilation, 216

Joulie's method of estimating acidity, 278

Jurgensen on heat production, 61

Keith on the heart, 113 on the lung, 189, 192

Kidney, excretion by, 271 innervation, 275 internal secretion, 275

Lævulosuria, 40

Langhing and crying, 223

Leucocytes, 81 et seq.

functions, 85

number, 87

vitality, 89

Leukæmia, 83-4 
Lewes on body heat, 62

Lipase, 255

Liver, excretion by, 282

functions of, 286

Locke on clothing, 59

Lorrain Smith on epithelium, 211

Ludwig, mechanical theory of capillary interchanges, 156 mechanical theory of urine production, 271

Luxus consumption, 4

Lymphatic gland, functions, 103

Lymphatics, pulmonary, 185

Lymphocytes, 83

functions, 86

Lymphoid cells, 84

MacAlister on the heart, 112

Machine, the human, 2, 11

Mackenzie on the pulse, 133-4, 148

Massage and metabolism, 20

Mast cells, 85

Mechanics of respiration, 188

Menopause, the, 26

Menstruation, 26

Mental work and metabolism, 20

Metabolic balance-sheet, 15-17

Metabolism, 1.48

re age and sex, 17

anabolic, 2

and body temperature, 52

carbohydrate, 37,42

cerebral, 20

fat, 34

katabolic, 2

and massage, 20

and mental work, 20

and muscular tone, 22

and nervous system, 21

protein, 29

qualitative, 29

quantitative, 2

and reproductive glands, 26

and stature, 17

and suprarenals, 26

Metchnikoff on phagocytosis, 85

Methæmoglobin, 79

Milk as standard diet, 4

Muir on white blood corpuscles, 88
Müller on expenditure of energy, 19

Muscular tone, 22

work, 8, 10 et seq. and tissue waste, 7

Muskens on vagus control, 122

Myogenic versus neurogenic theory of cardiac action, 105, 131

Myxœdema, 25

and heat production, 62

Negative pressure of pleural cavity, 190

of thorax, 173

Nervous control of heart, 121

diarrhœa, 259

mechanism of respiration, 201 of temperature regulation, 64

system and metabolism, 21

Nitrogenous constituents of urine, 278

equilibrium, 3

Obesity, metabolism of, 28 treatment of, 36

Oliver on blood-pressure, 165

Ovarian extract in ovariotomy, 27

Oxalic acid of urine, 281

Oxygen inhalation, 213

Pancreas and carbohydrate metabolism, 42

ferments of, 42

Pancreatic juice, 254, 257 ferments of, 255,257

Parry on body heat, 67

Pavy on sugar production, 37

Pawlow on digestion, 225, 236-7, 241,255

Pembrey on diabetic coma, 215

on Cheyne-Stokes respiration, 224

on heat regulation, 67

Pentosuria, 39

Penzoldt on gastric digestion, 240

Pericardium, 111

Peristaltic movements, 259 anti-, 267 
Phagocytosis, 85

Metchnikoff on, 85

Phloridzin diabetes, 43

Phosphates of urine, 281

Phosphaturia, 281

Phosphoric acid as brain food, 20

elimination of, 20

Physiological personality, 27

Pigments, bile, 282 et seq.

blood, 78

urinary, 281

Plasma, 91

Plasmase, 97

Pleural effusion, 185

pressure, 190

Pneumothorax, 190-1

Traube on, 203

Poikilocytosis, 74

Polycythæmia, 76

Polyuria, 273

Precipitin, 99

Pressure, in bilc-ducts, 285

capillary, 155

cerebral, 174

gastric, 241

intrathoracic, 190

pleural, 190

Priestley on respiration, 219

Protein, denitrification of, 31 diet, 2, 29

and beri-beri, 6 and tuberculosis, 6

energy, 31

equation, 3 et seq.

metabolism, 2 et seq., 29

repair, 31

serum, 30

source of energy, 4 et seq. fat, 36 sugar, 41

-sparers, 32

tissue, 30

in tissue waste, 2

Ptyalin, 226

Pulmonary circulation, 183 innervation, 183, 201 respiration, 209

Pulse, arterial, 144

Pulsus paradoxus, 174

Puncture, glyçosuric, 43

Claude Bernard on, 43
Purin bodies, 45

Qualitative metabolism, 29

Quantitative metabolism, 2

Radiation, 54

Raynaud's disease, 75, 170

Red blood corpuscles, 73

Red marrow, 73, 77, 83

Reflex inhibition of heart, 129

Renal anæmia, 275

Repair protein, 31

Reproductive glands and metabolism, 26

Residual air, 198

Respiration, 170-224

abdominal, 195

at high altitudes, 218

centre for, 201

chemistry of, 209

and circulation, 173

costal, 195

nervous mechanism of, 201

pulmonary, 209

Respiratory centre, 201

exchanges, 209

Rhythmicity of heart, 131

Rickets, 14

Rubner on body heat, 61

Saliva, constituents of, 226 ferments, 226

Salivary glands, excretory functions of, 228

secretion, 225

Salt in urine, 280

Schmaltz on volume of plasma, 95

Secretion and excretion, 24 internal, 23

Secretory nerves, 227

to kidney, 275

Seidelin on gastric digestion, 240

Sensibility of heart, 126

of intestine, 261

of stomach, 234

Serum, 98 proteins, 30

Sibson on the lungs, 199

Sighing, 222

Skodaic resonance, 189

Sneezing, 203, 221 
Sobbing, 222

Sounds of heart, 113, 135

Specific heat of body, 69

Sphygmogram, 147

Splanchnic system, 168

Spleen, 99

Hill on the, 169

Standard dietaries, 3 et seq.

Starling on bile, 256

Starling's law of the intestines, 259

Stercobilin, 282, 287

Stolnikow on liver, 169

Stenosis, aortic, 117 mitral, 116

Stomach, 231 et seq.

functional divisions of, 243

innervation, 246

pressure in, 241, 245

uses of, 231

Succus entericus, 254257

Sugar, assimilation of, 40

conversion into fat, 40

fermentable, 39

into glycogen, 37

protein source of, 41

Sulphates of urine, 280

Supplemental air, 199

Suprarenals in metabolism, 26

Sweat, 289

Sympathetic nerves to heart, 123-4

Tachycardia, 123, 134

Temperament, 27-29

Temperature, body, 49 chemical regulation of, 65 nervous mechanism of, 64 physical, 53

Thrombin, 96

Thymus, 102

Thyroid secretion, 24

Tidal air, 199

Tissue proteins, 30

repair, 2

respiration, 219

substance, conservation, 2

tension, 161

waste, 2 et seq.

Tonicity, cardiac, 119

gastric, 241

Trachea, 180
Traube on respiration, 203

Trophic nerves, 22

Trypsinogen, 255, 257

Uræmia, 211

Urea, 278

Uric acid, 44, 279 endogenous, 46 exogenous, 45 metabolism, 44 synthesis of, 47

Urinary pigments, 281

Urine, constituents of, 276 et seq.

ammonia, 279

creatinin, 31,279

oxalic acid, 281

phosphates, 281

salts, 280

sulphates, 280

urea, 278

uric acid, 279

water, 276

reaction of, 277

production, vital and mechanical theories $r e, 271$

volume of, 273,276

Urobilin, 281, 283

Vagus control of heart, 122

in respiration, 202

Valves of heart, 112

Vegetarian diet, 3

Venous circulation, 157

Ventilation, 215

Virchow on the blood, 81

Vital capacity, 200

Voit's standard dietary, 3

Vomiting, 252 centre for, 253

Von Noorden, balance-sheet of energy, 14

on glycogen, 38

on uric acid, 279

on work, 19

Warm-blooded animals, 50

Weather and metabolism, 21

Wenckebach on cardiac contractility, 118 
White corpuscles, 81 classification, 82 enumeration, 87

Work, digestive, 8,9 internal, 8 muscular, 8, 10 et seq.
Xanthin, 46

Yawning, 222

Zuntz on expenditure of energy 19 



THIS BOOK IS DUE ON THE LAST DATE STAMPED BELOW

AN INITIAL FINE OF 25 CENTS WILL BE ASSESSED FOR FAILURE TO RETURN THIS BOOK ON THE DATE DUE. THE PENALTY WILL INCREASE TO 50 CENTS ON THE FOURTH DAY AND TO \$1.00 ON THE SEVENTH DAY OVERDUE.

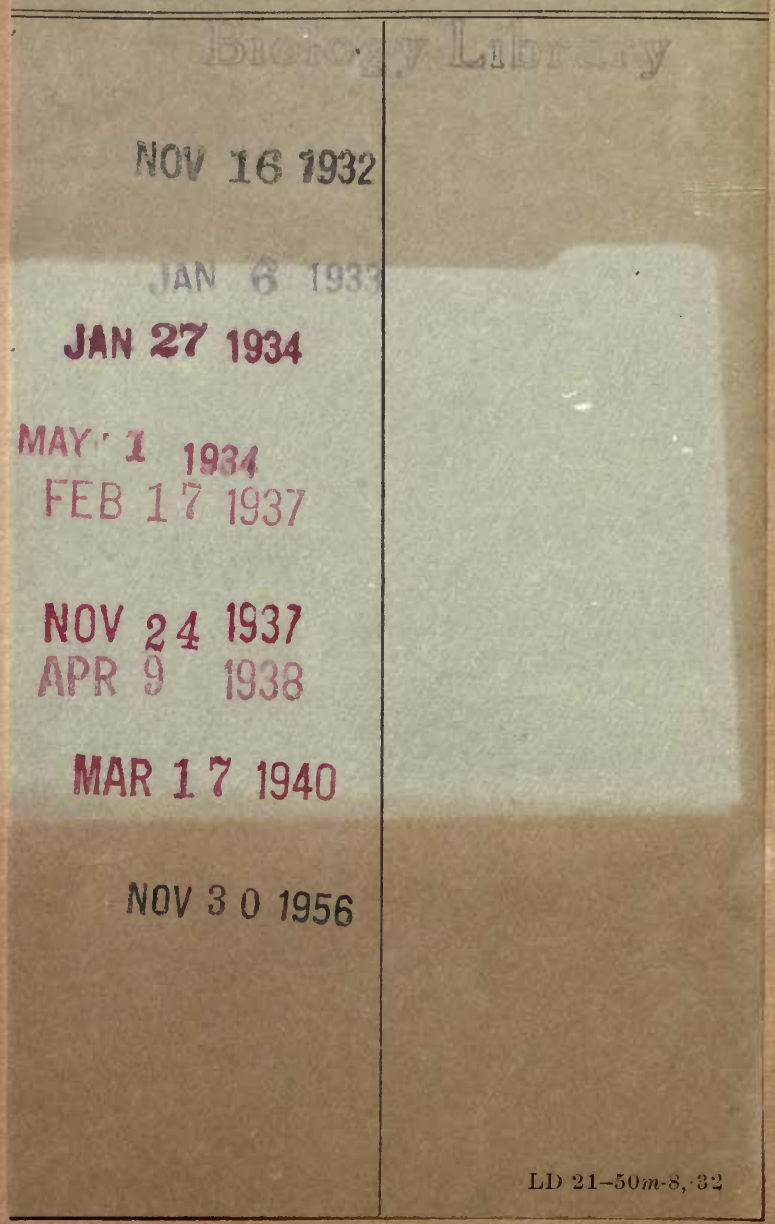




\section{YB 79518}

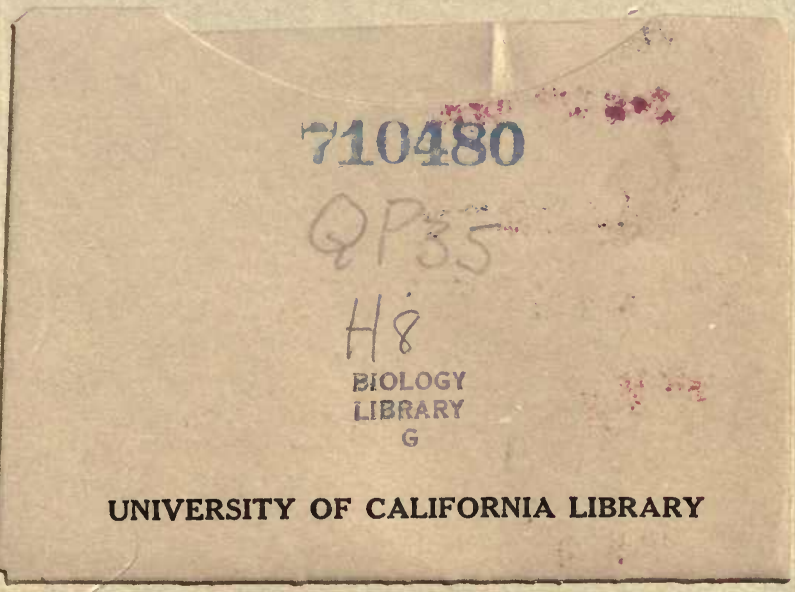


